\title{
Developing Operating Procedures for a Low-Level Radioactive Waste Disposal Facility
}

\author{
A. A. Sutherland \\ G. L. Miner \\ K. F. Grahn \\ C. G. Pollard \\ Published October 1993 \\ Rogers \& Associates Engineering Corporation \\ P. O. Box 330 \\ Salt Lake City, Utah 84110-0330
}

Prepared for EG\&G Idaho, Inc.

Under Subcontract No. C93-170227

and for the

U.S. Department of Energy

Assistant Secretary for Environmental Restoration and Waste Management Under DOE Idaho Operations Office

Contract DE-AC07-76ID01570 


\section{DISCLAIMER}

Portions of this document may be illegible in electronic image products. Images are produced from the best available original document. 


\section{ABSTRACT}

This document is intended to assist persons who are developing operating and emergency procedures for a low-level radioactive waste disposal facility. It provides 25 procedures that are considered to be relatively independent of the characteristics of a disposal facility site, the facility design, and operations at the facility. These generic procedures should form a good starting point for final procedures on their subjects for the disposal facility. In addition, this document provides 55 annotated outlines of other procedures that are common to disposal facilities. The annotated outlines are meant as checklists to assist the developer of new procedures.

\section{DISCLAIMER}

This report was prepared as an account of work sponsored by an agency of the United States Government. Neither the United States Government nor any agency thereof, nor any of their employees, makes any warranty, express or implied, or assumes any legal liability or responsibility for the accuracy, completeness, or usefulness of any information, apparatus, product, or process disclosed, or represents that its use would not infringe privately owned rights. Reference herein to any specific commercial product, process, or service by trade name, trademark, manufacturer, or otherwise does not necessarily constitute or imply its endorsement, recommendation, or favoring by the United States Government or any agency thereof. The views and opinions of authors expressed herein do not necessarily state or reflect those of the United States Government or any agency thereof. 


\section{EXECUTIVE SUMMARY}

Many new low-level radioactive waste disposal facilities are being developed by states and compacts in the United States. A key element in the safe and efficient operation of these new facilities will be procedures that describe in great detail how operations will be carried out and what activities will take place in the event of emergencies. This document was prepared to assist the developers of those procedures by providing basic information about the probable content of procedures and examples of how procedures can be developed. Twenty-five "generic" procedures-procedures that are relatively independent of the characteristics of the disposal facility site, facility operations, and facility design-are provided as a starting point for a complete set of operating and emergency procedures. In addition, 55 annotated outlines are provided for other procedures that will probably be necessary at most low-level radioactive waste disposal facilities. The use of the annotated outlines to develop a full procedure is illustrated. While considerable effort must be exerted to develop a complete set of procedures for any specific new low-level radioactive waste disposal facility, it is felt that the information provided in this document will make that job considerably easier. 


\section{CONTENTS}

ABSTRACT $\ldots \ldots \ldots \ldots \ldots \ldots \ldots \ldots \ldots \ldots \ldots \ldots \ldots \ldots \ldots \ldots \ldots \ldots \ldots$

EXECUTIVE SUMMARY $\ldots \ldots \ldots \ldots \ldots \ldots \ldots \ldots \ldots \ldots \ldots \ldots \ldots$

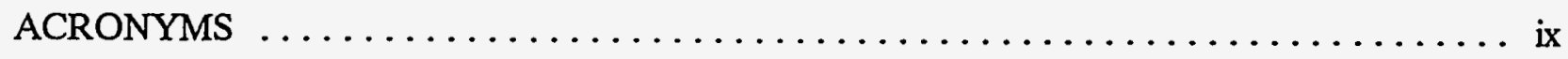

1. INTRODUCTION $\ldots \ldots \ldots \ldots \ldots \ldots \ldots \ldots \ldots \ldots \ldots \ldots \ldots \ldots \ldots \ldots \ldots$

1.1 Background $\ldots \ldots \ldots \ldots \ldots \ldots \ldots \ldots \ldots \ldots \ldots \ldots \ldots \ldots \ldots \ldots \ldots \ldots \ldots$

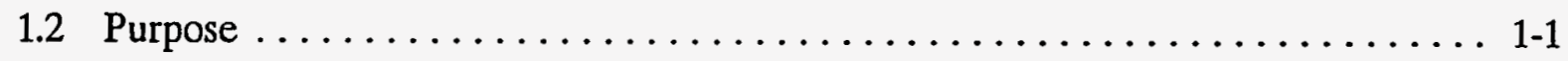

1.3 Organization of the Report $\ldots \ldots \ldots \ldots \ldots \ldots \ldots \ldots \ldots \ldots \ldots \ldots \ldots$

2. GENERAL ASSUMPTIONS $\ldots \ldots \ldots \ldots \ldots \ldots \ldots \ldots \ldots \ldots \ldots \ldots \ldots \ldots \ldots$

3. SITE AND FACILITY DESCRIPTION $\ldots \ldots \ldots \ldots \ldots \ldots \ldots \ldots \ldots \ldots \ldots$

4. GENERIC PROCEDURES $\ldots \ldots \ldots \ldots \ldots \ldots \ldots \ldots \ldots \ldots \ldots \ldots \ldots \ldots \ldots$

5. ANNOTATED PROCEDURES $\ldots \ldots \ldots \ldots \ldots \ldots \ldots \ldots \ldots \ldots \ldots \ldots \ldots \ldots$

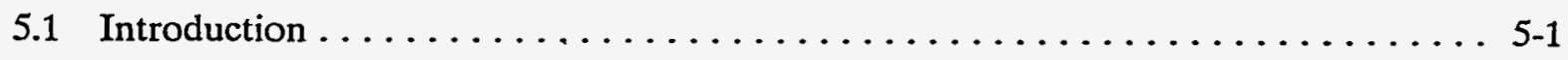

5.2 Annotated Outline for Common Sections of the Operating Procedures $\ldots . \ldots .5-1$

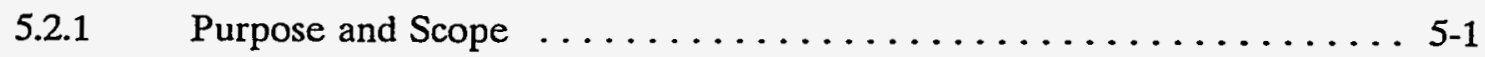

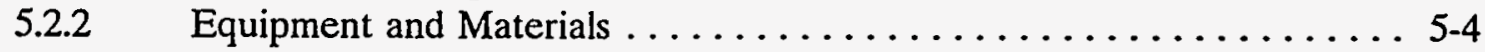

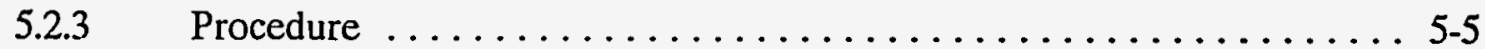

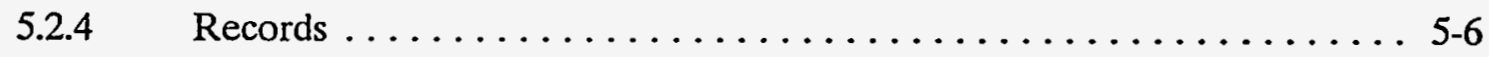

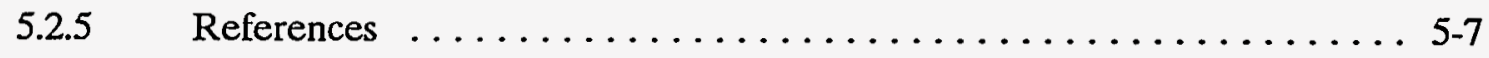

5.3 Annotated Outlines for the Instructions Section of Specific Procedures $\ldots \ldots \ldots 5-7$

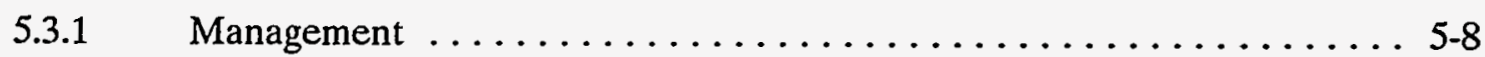

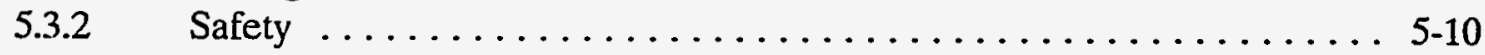

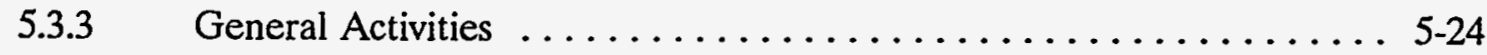

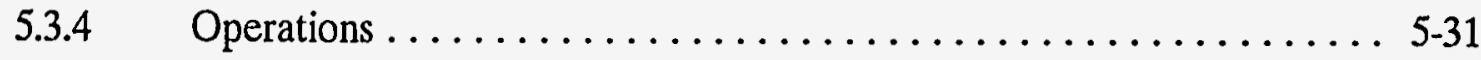

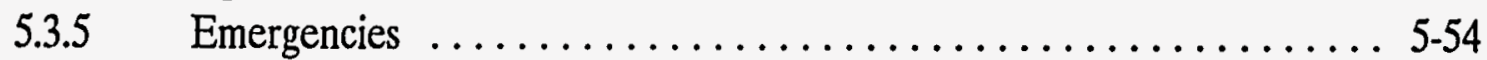

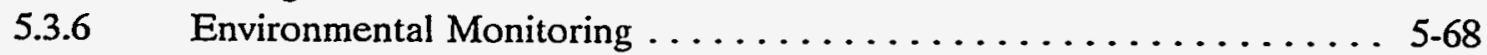

5.3.7 Regulatory Compliance $\ldots \ldots \ldots \ldots \ldots \ldots \ldots \ldots \ldots \ldots \ldots \ldots$

5.4 Use of the Annotated Procedures $\ldots \ldots \ldots \ldots \ldots \ldots \ldots \ldots \ldots \ldots$ 


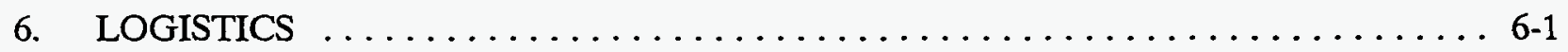

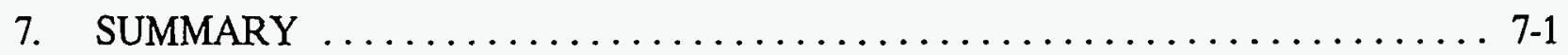

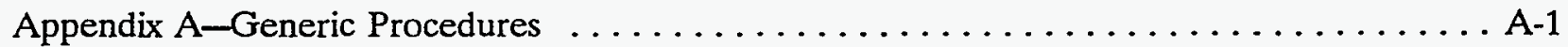

\section{FIGURES}

3-1. Assumed disposal facility operator's organization

\section{TABLES}

4-1. Generic procedures provided in Appendix A

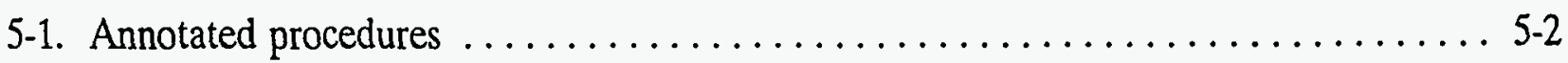

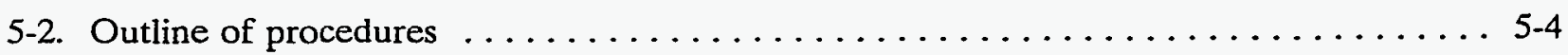




\section{ACRONYMS}

Most of the abbreviations and acronyms that appear here are used in the generic procedures in Appendix A. When they are so used, they are also defined when first used in each procedure.

$\begin{array}{ll}\text { ALARA } & \text { As low as reasonably achievable } \\ \text { APR } & \text { Air purifying respirator } \\ \text { CFR } & \text { Code of Federal Regulations } \\ \text { CPM } & \text { Counts per minute } \\ \text { CPR } & \text { Cardiopulmonary resuscitation } \\ \text { DPM } & \text { Disintegrations per minute } \\ \text { DOT } & \text { U.S. Department of Transportation } \\ \text { DRD } & \text { Direct reading dosimeter } \\ \text { FAX } & \text { Facsimile } \\ \text { HPS } & \text { Health Physics Supervisor } \\ \text { I.D. } & \text { Identification } \\ \text { LLW } & \text { Low-level radioactive waste } \\ \text { LSA } & \text { Liquid scintillation analyzer } \\ \text { MCA } & \text { Multichannel analyzer } \\ \text { MDA } & \text { Minimum detectable activity } \\ \text { NCR } & \text { Nonconformance report } \\ \text { NIOSH } & \text { National Institute of Occupational Safety and Health } \\ \text { No. } & \text { Number } \\ \text { NVLAP } & \text { National Voluntary Laboratory Accreditation Program } \\ \text { OSHA } & \text { Occupational Safety and Health Administration } \\ \text { QA } & \text { Quality assurance } \\ \text { ROI } & \text { Region of interest } \\ \text { SAT } & \text { Satisfactory } \\ \text { SCBA } & \text { Self-contained breathing apparatus } \\ \text { SSN } & \text { Social Security number } \\ \text { TLD } & \text { Thermoluminescent dosimeter } \\ \text { U.S. } & \text { United States } \\ \text { UNSAT } & \text { Unsatisfactory } \\ & \end{array}$




\section{INTRODUCTION}

\subsection{Background}

The operation of a low-level radioactive waste (LLW) disposal facility is a complex activity. Furthermore, improper execution of the activities at the facility can cause serious hazards to workers and the public.

It is important that most activities at an LLW disposal facility be carefully thought out and documented. The documentation will be used

- For training

- To ensure uniformity when conducting activities

- For auditing to ensure activities are being executed correctly

- For step-by-step instructions when seldom-executed activities are conducted. facility.

But, most importantly, compliance with the documentation will ensure safe operation of the

The documentation of how activities will be carried out at an LLW disposal facility takes the form of procedures. This report specifically addresses procedures for the operation of the facility and dealing with emergencies. The process of developing procedures is iterative and depends, for most activities, on the disposal facility site and design and how the facility will be operated. Procedure development contributes directly to the efficient and safe operation of a disposal facility because it imposes a thought discipline that requires careful consideration of the interactions between all elements of the disposal system and the safety aspects of activities at the facility.

\subsection{Purpose}

The purpose of this document is to give developers of operating and emergency procedures for new LLW disposal facilities a head start. It provides 25 generic procedures that are relatively independent of the disposal facility, design, and operating characteristics and can be adapted quickly to most near-surface disposal facilities. It also provides annotated outlines of 55 additional procedures that tend to depend more on specifics of the disposal facility and therefore must be developed separately for each facility. An example of how an annotated outline can be used to develop a full procedure for a specific facility design is also given.

\subsection{Organization of the Report}

The procedures, even the generic and annotated ones, depend to a small degree on broad assumptions of the disposal facility. These assumptions are given in Section 2, which provides the general assumptions; and Section 3, which gives assumptions about the site and the facility. 
Section 4 describes the purpose of the 25 generic procedures given in Appendix $A$ and provides a list of those procedures. Section 5 provides annotated outlines for 55 additional procedures. The annotated outlines serve as checklists of information that should go into such procedures. An example of how an annotated outline is converted to a full procedure is also given in Section 5.

Section 6 discusses the logistics of using information in this report to develop a full set of procedures for a specific disposal facility. Section 7 summarizes the document. Appendix A contains 25 generic procedures. 


\section{GENERAL ASSUMPTIONS}

This section presents some of the general assumptions regarding the disposal facility for which the procedures in this report apply. Some additional assumptions are presented in the site and facility description in Section 3.

It is assumed that the disposal facility only receives Class $A, B$, and $C$ low-level radioactive wastes. These are the wastes that are considered the responsibility of the State by the Low-Level Radioactive Waste Policy Amendments Act of 1985. It is further assumed that there is no mixed radioactive waste disposed at the facility; therefore, hazardous waste regulations do not apply. Regulations promulgated by the U.S. Nuclear Regulatory Commission in 10 CFR 61 or State versions of those same regulations developed by Agreement States do apply. It is assumed that waste acceptance criteria have been developed for the facility and that these criteria are at least as restrictive on the characteristics of acceptable waste as those in 10 CFR 61.

The waste is assumed to arrive by truck. Any large additional containers that may be part of the disposal method, that can be transported to the site, such as concrete canisters are assumed to be constructed offsite and inspected upon arrival. There is a limited onsite capability to repair damaged waste containers and the facility owners are assumed to have little desire to do so themselves. They may require waste generators whose containers arrive damaged or contaminated to contract with third parties for repairs or decontamination at the facility. Under no circumstances will a damaged or contaminated waste container be allowed to leave the facility. 


\section{SITE AND FACILITY DESCRIPTION}

This section provides a broad outline of the facility and the site in which it is located. The disposal facility for which these procedures apply is assumed to be a near-surface facility (i.e., the waste is disposed in the top 30 meters of the earth's surface according to the NRC definition of nearsurface). In other words, this facility is not a mine for the disposal of LLW. However, these procedures would also apply to abovegrade, earth-covered facilities.

The waste is assumed to be disposed in separate disposal units. The waste may be segregated according to waste class and disposed in separate units by waste class. However, if Class $A$ waste is properly stabilized, it can be commingled in the same disposal units as Class B and C wastes.

The disposal units and most other activities involving the waste are assumed to be in a controlled access area. Within the controlled area personnel are required to wear dosimeters, and equipment and vehicles are either dedicated to use in that controlled area or are checked for contamination when they leave. Storage for limited volumes of LLW is assumed to be available at the disposal facility. The storage may be in more than one location on the facility, depending on the radiation exposure rate of the waste packages. For high radiation exposure waste, a separate storage area may exist to provide adequate shielding. The primary purpose of the storage is to store waste that cannot be disposed immediately. This may include waste packages that are damaged or contaminated or for which the paperwork is not complete. Another major purpose of waste storage on the facility is the accumulation of LLW that is generated onsite before a sufficient volume is reached for its disposal.

Frequent reference is made in the generic procedures in Appendix $A$ to titles of individuals who are assigned responsibility for specific activities at the disposal facility. Figure 3-1 is an assumed organization chart for the agency that operates the disposal facility. This chart shows the relative positions of individuals mentioned in the generic procedures and some positions that are not

mentioned. It also shows which individuals are normally located at the disposal facility and which individuals are not.

No significant assumptions are made about the hydrogeology or climate at the site. It is assumed that concrete pouring or curing will not take place when temperatures are so low that the final properties of the concrete will be affected. The disposal units are assumed to be above the saturated zone. The facility is assumed to be subject to the full range of climate and other natural disruptions, such as floods, earthquakes, tornadoes, lightning storms, and blizzards.

While hydrogeologic conditions can influence the characteristics of the disposal facilities in actual sites-the procedures described here do not depend on such characteristics for the disposal units. They are broad enough to encompass all anticipated designs. 


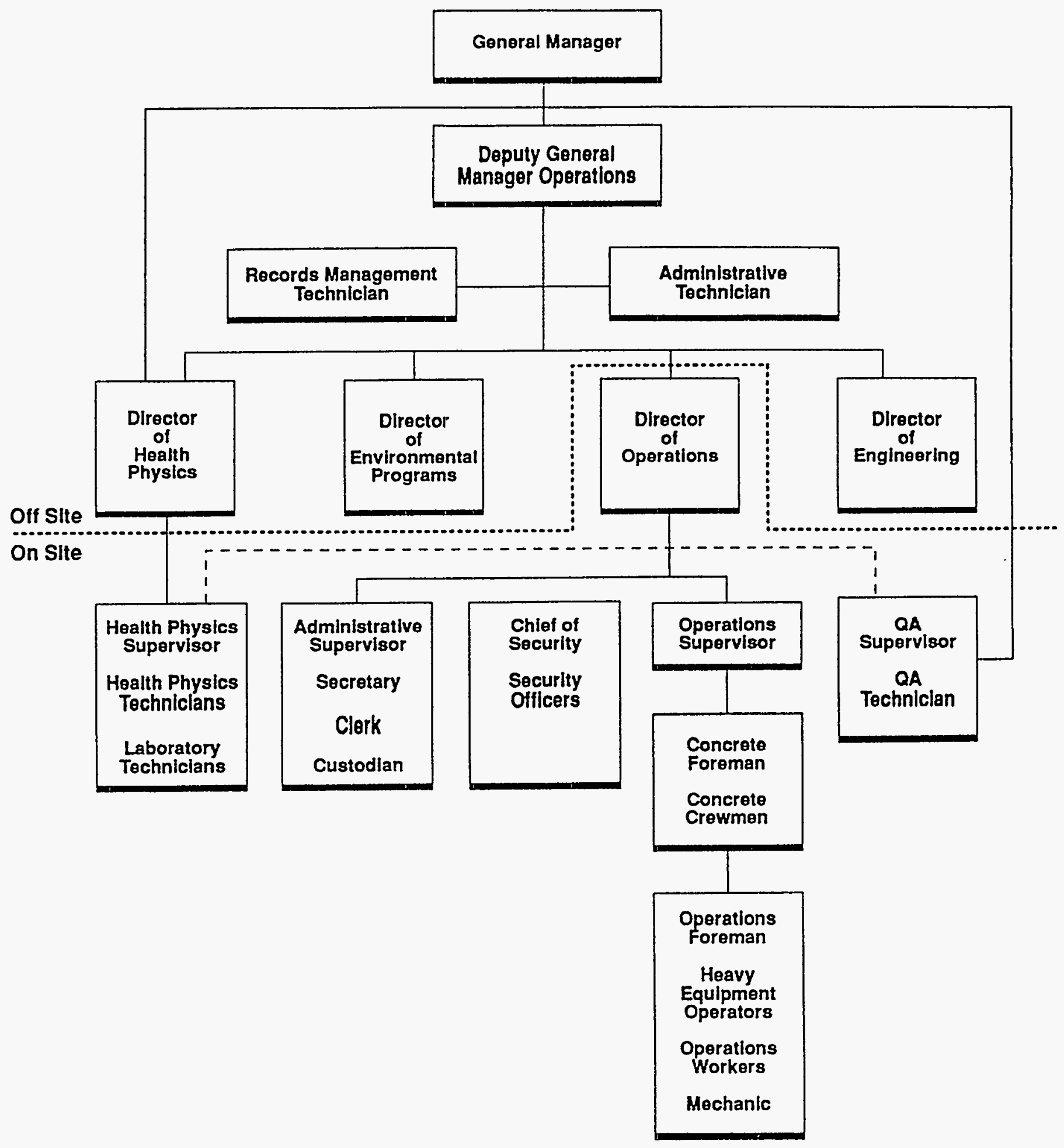

RAE - 104949

Figure 3-1. Assumed disposal facility operator's organization. 


\section{GENERIC PROCEDURES}

Twenty-five generic procedures for an LLW disposal facility are provided in Appendix A. Table 4-1 lists those procedures. The generic procedures describe activities common enough to all LLW disposal facilities that the activities are relatively independent of the characteristics of the disposal site and of the facility design and operation. Many of these procedures come from a set of operating procedures being developed for a projected facility in Texas. The twenty-five generic procedures are included to illustrate how complete procedures look and to provide a convenient and relatively complete starting point for new sets of procedures that must be developed by operators of new LLW disposal facilities.

These generic procedures address radiation and general safety activities that should be similar for most near-surface disposal facilities. Of course, no procedure can be truly generic, so the procedures must be carefully reviewed before being adapted for use at any particular site. For example, acceptable contamination and radiation exposure levels may depend on State regulations and measuring equipment used. Even if these quantities are specified in the generic procedures, they can vary from facility to facility. More specifically, the size of the security force assumed in the Facility Security procedure may have to be adjusted upward for a larger facility.

To use these generic procedures, individuals familiar with the specific facility must carefully read them and make any changes that are necessary. The generic procedures in Appendix A should, however, make a useful core for the set of procedures that must be developed for each new facility. 
Table 4-1. Generic procedures provided in Appendix A.

Safety Management

Management/Radiation Safety Annual Reviews

Site Safety Review Committee

Annual Radiation Safety Audit

On-Site Safety Training

Survey Review and Evaluation

Employee Safety Feedback

\section{Radiation Safety}

Dosimeter Issuance

Internal Radiation Monitoring

Personnel Decontamination

Respiratory Protection Equipment Issuance

Respirator Maintenance and Cleaning

Respiratory Protection Fit Testing

\section{Security}

Facility Security

Transport Vehicle Security

\section{Radiation Instrumentation}

Liquid Scintillation Counter Operation

Multi-Channel Analyzer Operation

Scaler Operation

Portable Instrumentation Operation

Portable Instrumentation Response and Source Checks Calibration

\section{Other Activities}

Shipment Document Review

Radioactive Waste Classification Verification

Truck Wash Facility

Equipment Operation and Maintenance

Environmental Monitoring Data Review and Evaluation

Vendor Audits 


\section{ANNOTATED PROCEDURES}

\subsection{Introduction}

This section presents 55 annotated procedures; Table 5-1 lists the titles of those procedures and the numbers of the pages where they begin. Annotation constitutes a description of the kind of information that should be included in each procedure without giving specific details. The latter will depend on the design of the disposal units, the layout of the disposal facility and details of the facility operation, and, to some extent, the nature of the site.

The outline of the procedures is the same as the generic procedures in Appendix $A$. The elements of that outline are given in Table 5-2. Most elements of the annotated procedures are common to all 55 procedures. For example, the kind of information that goes in the Safety Equipment section will be the same; of course the specific equipment listed in a particular procedure will depend on the procedure, the facility design and operation, and perhaps the facility site. Section 5.2 describes the information that goes in all sections of the procedure except the one giving instructions, Procedure Section 3.4.

Section 5.3 provides 55 separate descriptions of the contents of the instructions sections of the procedures listed in Table 5-1. Unlike the common parts discussed in Section 5.2, the content of the instructions section is very different for each procedure. As noted in Section 5.4, new procedures can be developed for the 55 titles given in Table 5-1 by using the descriptions of the important elements of procedure contents provided in Sections 5.2 and 5.3.

\subsection{Annotated Outline for Common Sections of the Operating Procedures}

It was determined that the descriptions of the contents that constitute the annotated outline of the 55 procedures discussed in this section are identical for all parts of the procedure outline in Table 5-2 except the procedure section on instructions. Therefore, it was possible to prepare the annotated outline for the common parts of the procedure and present it only once. This section provides the annotated outline for the common parts. Section 5.3 presents 55 annotated outlines for the procedure sections on instructions for the 55 annotated procedures.

This section is organized according to the outline of procedures given in Table 5-2. A brief description of the general contents of the procedure section on instructions follows.

\subsubsection{Purpose and Scope}

The purpose and scope section should convey the reasons why the procedure is performed, the goals to be accomplished, and an outline of activities that should be included. In some cases, to avoid misunderstanding, it may be necessary to state specific activities that are not part of the procedure at hand. Reference other procedures that address activities that are related to but not a part of the procedure at hand. 
Table 5-1. Annotated procedures.

\begin{tabular}{|c|c|}
\hline Title & $\begin{array}{c}\text { Page } \\
\text { number }\end{array}$ \\
\hline Management & $5-8$ \\
\hline Weekly Inspections & 5.8 \\
\hline Operator Qualifications Requirements & $5-9$ \\
\hline Safety & $5-10$ \\
\hline Basic Radiation Protection Training & $5-10$ \\
\hline Radiation Worker Training & $5-11$ \\
\hline Occupational Safety & $5-12$ \\
\hline Fire Safety & $5-15$ \\
\hline Equipment Testing and Certification & $5-16$ \\
\hline Incoming Vehicle Surveys & $5-17$ \\
\hline Transport Vehicle Release Surveys & $5-18$ \\
\hline Routine Surveys and Reviews & $5-20$ \\
\hline Cask Surveys & $5-21$ \\
\hline Closed Disposal Unit Surveys & $5-23$ \\
\hline General Activities & $5-24$ \\
\hline$\overline{\text { Waste Verification Testing }}$ & $5-24$ \\
\hline Decontamination of Operational Equipment and Transport Vehicles & $5-26$ \\
\hline Decontamination of Casks and Shipping Containers & $5-27$ \\
\hline Waste Containers Not Acceptable Upon Arrival & $5-28$ \\
\hline Handling Damaged Waste Containers & $5-29$ \\
\hline Repairing Damaged Waste Containers & $5-30$ \\
\hline Operations & $5-31$ \\
\hline Pre-Shipment Approval & $5-31$ \\
\hline Arriving Vehicle Safety Inspection & $5-32$ \\
\hline Waste Shipment Acceptance & $5-33$ \\
\hline Disposal Unit Construction & $5-34$ \\
\hline Canister Inspection & $5-36$ \\
\hline Transport Vehicle Movement to Disposal Unit & $5-37$ \\
\hline Canister Emplacement & $5-38$ \\
\hline Waste Shipment Off-Loading & $5-39$ \\
\hline Placement of Waste in Canisters & $5-40$ \\
\hline Grouting & $5-41$ \\
\hline Sand and Gravel Fill & $5-43$ \\
\hline Temporary Cover Placement & $5-44$ \\
\hline Disposal Unit Closure & $5-45$ \\
\hline Onsite Generated Waste Disposal & $5-47$ \\
\hline Temporary Storage of Low Radiation Exposure Rate Waste & $5-48$ \\
\hline Temporary Storage of High Radiation Exposure Rate Waste & $5-49$ \\
\hline Temporarily Stored Waste Disposal & $5-51$ \\
\hline Non-Routine Operations & $5-52$ \\
\hline Emergencies & $5-54$ \\
\hline Emergency Response Team & $5-54$ \\
\hline
\end{tabular}


Table 5-1. (continued).

\begin{tabular}{lc}
\hline \multicolumn{1}{c}{ Title } & $\begin{array}{c}\text { Page } \\
\text { number }\end{array}$ \\
\hline Emergency Response Training and Drills & $5-57$ \\
Radioactive Materials Releases & $5-59$ \\
Fires & $5-60$ \\
Personal Contamination or Injuries & $5-62$ \\
Weather-Related Incidents & $5-64$ \\
Security Incidents & $5-67$ \\
Environmental Monitoring & $5-68$ \\
Air Monitoring & $5-68$ \\
Vegetation Monitoring & $5-70$ \\
Soil and Sediment Monitoring & $5-71$ \\
Surface Water Monitoring & $5-72$ \\
Groundwater Monitoring & $5-73$ \\
Environmental TLD Monitoring & $5-75$ \\
Regulatory Compliance & $5-76$ \\
Notification of Regulatory Agencies & $5-76$ \\
Radiation Exposure Records & $5-78$ \\
Visitor Exposure Reports & $5-80$ \\
Exposure Data Review and Reporting & $5-80$ \\
Source Control and Inventory & $5-81$ \\
Acknowledgement of Waste Received and Recording of Disposal Data & $5-83$ \\
\hline
\end{tabular}


Table 5-2. Outline of procedures.

1 Purpose and Scope

2 Equipment and Materials

2.1 Operating Equipment

2.2 Safety Equipment

2.3 Radiological Equipment

2.4 Special Equipment

3 Procedure

3.1 Prerequisites

3.2 Training

3.3 Special Precautions

3.4 Instructions

4 Records

4.1 Required Forms

4.2 Completion and Approval Requirements

4.3 Processing and Archival Requirements

5 References

\subsubsection{Equipment and Materials}

The equipment and materials section can be divided into subsections as shown below. This section should list all items of equipment and material needed to perform the procedure. Details about the listed equipment and materials should include sizes, model numbers, and required capabilities, as applicable.

5.2.2.1 Operating Equipment. Operating equipment is heavy machinery such as bulldozers and cranes or equipment with a broad range of application such as hand tools.

5.2.2.2 Safety Equipment. Safety equipment is anything that functions primarily to protect personnel from bodily injury or ill health, such as hard hats, coveralls, safety glasses, and steel-toed shoes. It should be stated if certain items are not mandatory for persons executing the particular procedure. The person who decides when such items will be used should be indicated.

5.2.2.3 Radiological Equipment. Radiological equipment is any equipment used to measure radiation exposure or radionuclide contents. These typically include field instruments such as survey meters, thermoluminescent dosimeters, ionization chambers, etc. If a laboratory procedure is 
involved, it may include such devices as liquid scintillation counters and multi-channel analyzers. Radiological equipment could also include special shielding devices.

5.2.2.4 Special Equipment. Special equipment is considered to be equipment with a narrow range of application pertinent to the procedure at hand, such as geotextile seaming tools, specially designed ladders, remotely operated crane-hook releases, and disposal canister inserts.

\subsubsection{Procedure}

5.2.3.1 Prerequisites. The prerequisites section should list activities or considerations that should be realized prior to commencing the sequence of instructions in Section 3.4. Sometimes it is difficult to distinguish between prerequisites and preliminary instructions. An item is a prerequisite if it does not always fall in the normal sequence of instructions in a timely manner, or can and should be performed before the start of the procedure itself. For example, the following is a prerequisite in all of the procedures that involve working within the disposal unit: "When assigning personnel to work within the disposal unit, a radiation survey and review of personnel radiation exposure will be performed for exposure control considerations prior to commencing the work." This message is necessary, but the activity described is not in the normal sequence of instructions for procedures involving specific activities in the disposal unit. It also can be performed sometime before commencing those procedures.

5.2.3.2 Training. The training section should state the specific training or certification required for personnel performing the procedure at hand and the necessary updating frequency of this training or certification. General statements about training that apply to all procedures are appropriate in this section also. If an onsite training procedure exists, it should be referenced in this section.

5.2.3.3 Special Precautions. The special precautions section should list warnings or actions that should be taken while performing the procedure to prevent bodily injury or ill health to personnel, damage to equipment, or failure of the procedure. For example, while cleaning respirators, "Water temperatures shall not exceed $120^{\circ} \mathrm{F}$. Temperatures above this level can distort or damage respirator face pieces."

5.2.3.4 Instructions. The instructions section is very specific to the procedure. It should be written in a sequential format. Exercise care to exclude items from this section that should be in the prerequisites section. Avoid aggregating several significant activities in one step. Instructions that direct the reader to skip steps based on a condition [e.g., logic ("if"), branching, or "go to" instructions] are acceptable; however, instructions that cause the reader to jump around or revert to previous steps should be avoided.

Some procedures include steps for inspections and testing. The results from these inspections should be documented on standard forms for the procedure. Ideas about designing forms are described in Section 4.1. Specific points in the procedure as to when forms should be filled out should be indicated. Do not include instructions on how to fill out the forms-those instructions should be on a separate page next to the form they describe. A discussion about writing instructions for forms is found in Section 4.2. 
Take advantage of opportunities to use tables, flow charts, and figures when writing instructions. Tables are useful in summarizing data and relating one parameter to another. Ensure the tables, flow charts, and figures have titles and numbers to which the text can refer. The numbers should fit logically into the numbering scheme of the procedure.

Flow charts are particularly useful in graphically representing a sequence of events, points of decision, and the course of action based on a decision. They should not, however, be used as substitutes for text describing what must be done; they are a useful supplement to the text. Use standard flow chart symbols. Common symbols and what they represent are: rectangles (process steps), hexagons (preparatory steps), and equilateral diamonds (decision points). When flow lines cross, ensure that it is clear which path to take. Also make sure that a final step is reached regardless of the decisions made in the flow chart.

The headings in tables should be sufficiently descriptive to avoid misunderstanding. If necessary, provide coded notes below tables to define abbreviations or explain assumptions. If numerical values are given or are to be placed in tables, indicate the units associated with those values.

Use figures when describing specific parts or the orientation of objects, such as people or vehicles. For example, simple sketches would be useful to a technician performing radiation surveys.

\subsubsection{Records}

5.2.4.1 Required Forms. The required forms section should list all forms that are completed during the performance of the procedure. All forms should have titles and numbers to which the text can refer. The numbers should fit logically into the numbering scheme of the procedure. Forms should be developed so that the spaces for data entry correspond to the order in which the data is received and are an appropriate size for the entries required. Make the format of forms as simple as possible by eliminating all but necessary lines and information.

Each form should have at least one place for the dated signature of the person responsible for ensuring that the information in the form is correct. Similar spaces for reviewers or verifiers may also belong on some forms.

5.2.4.2 Completion and Approval Requirements. The completion and approval requirements section should state the titles of the forms listed in Section 4.1, followed by the titles of the individuals responsible for completing the forms. The titles of the individuals responsible for reviewing and signing the completed forms should be included also, if such functions are required.

All forms should be accompanied by a set of instructions. The instructions should address all blanks on the forms where data entry is required. Make no assumptions about the form user's ability to understand what entry should be made without some instruction. The instructions should state the title of the individuals required to fill out the forms. Instructions for data entry should correspond to the order in which the data is received and entered on the form. Ensure the names of blanks and headings correspond exactly to those on the form. Example entries for each item described in the instructions are useful. 
5.2.4.3 Processing and Archival Requirements. This section should state the nature of the documents supporting the procedure, e.g., "safety" or "quality assurance," so they are filed in the appropriate records package. This section should direct the individuals completing the forms to submit them to the appropriate custodian. Reference should be made to the Administrative Procedures to ensure the records are retained in accordance with them.

\subsubsection{References}

List all sources of information and guidance that can be referenced, including federal and State regulations and design standards.

\subsection{Annotated Outlines for the Instructions Section of Specific Procedures}

This section provides annotated outlines of the content of the procedure section on instructions, Section 3.4, for the 55 procedures listed in Table 5-1. Each of these is very specific to the procedure at hand. Furthermore, when an actual procedure is developed, the details of that procedure will depend on specifics about the facility design, operation, and site.

The instructions section should be written in a sequential format. Care should be exercised to omit items from this section that should be in the prerequisites section. Several significant activities should not be combined in one step. Instructions that direct the reader to skip steps based on a condition [e.g., logic ("if"), branching, or "go to" instructions] are acceptable; however, instructions that cause the reader to jump around or revert to previous steps should be avoided.

The instructions section of some procedures will include steps for inspections and testing. The results from these inspections should be documented on standard forms for the procedure. Ideas about designing forms are described in Section 5.2.4.1 of this document. Specific points in the procedure where forms need to be filled out should be indicated. Do not include instructions on how to fill out the forms in the body of the procedure-those instructions should be on separate pages next to the form they describe. A discussion about writing instructions for forms is found in Section 5.2.4.2 of this document.

When writing instructions, take advantage of opportunities to use tables, flow charts, and figures. Tables are useful in summarizing data and relating one parameter to another. Ensure the tables, flow charts, and figures have titles and numbers to which the text can refer. The numbers should fit logically into the numbering scheme of the procedure.

Flow charts are particularly useful in graphically representing a sequence of events, points of decision, and the course of action based on a decision. They should not, however, be used as substitutes for text describing what must be done; they are a useful supplement to the text. As noted above, flow charts should serve as a supplement to text, not replace it. Also, not all procedures can be sensibly flow-charted. Use standard flow chart symbols. Common symbols and what they represent are: rectangles (process steps), hexagons (preparatory steps), and diamonds (decision points). Ensure that it is clear which path to take when flow lines cross. Also make sure that a final 
step is reached regardless of the decisions made in the flow chart. An example of a flow chart is given at the end of the procedure titled "Personnel Decontamination" in Section A-2 of Appendix A.

The headings in tables should be sufficiently descriptive to avoid misunderstanding. If necessary, provide coded notes below tables to define abbreviations or explain assumptions. If numerical values are given or are to be placed in tables, indicate the units associated with those values. Most of the generic procedures in Appendix A contain tables.

Use figures when describing specific parts or the orientation of objects, such as people or vehicles. For example, simple sketches would be useful to show where measurements should be or were taken while performing radiation surveys. An example of a figure is given on the second page of Form Number OP 2.2.3-1 in the procedure titled "Personnel Decontamination" in Section A-2 of Appendix A.

\subsubsection{Management}

5.3.1.1 Weekly Inspections. The purpose of this procedure is to describe methods for weekly inspection of the waste disposal facility. This procedure could describe methods for performing weekly inspections of buildings, disposal unit markers, disposal units, monitoring wells, closed disposal units, monitoring stations, berms, and drainage ditches, as well as verifying that radiation surveys were conducted at the controlled area, fenceline, and active disposal units.

The following steps should be followed and elements included in the instructions for the procedure:

1. State the titles of the individuals at the facility who will perform this procedure.

2. State all features or types of features that will be inspected.

3. Checklists that list each of the features that will be inspected. For example, if the feature is a building then some of the details to be inspected could be:

- Windows

- Locks

- Utilities

- $\quad$ Fire extinguishers

- General housekeeping

- Safety hazards

- Safety equipment. 
If checklists are used, include separate steps for completing the checklists. The steps should include the titles of the checklists and the titles of the individuals completing them.

4. Describe what actions should be taken if a deficiency is noted during an inspection, including the titles of the individuals who should be notified and additional required documentation.

5. Ensure that a mechanism is included in the procedure to follow up and correct any noted deficiencies.

5.3.1.2 Operator Qualifications Requirements. The purpose of this procedure is to ensure that health physics and operations personnel are properly trained to perform their assignments in a safe and efficient manner and that they maintain high levels of operational proficiency through additional training, retraining, and requalification. This procedure applies to all operators of heavy equipment and machinery, specialized equipment (e.g., health physics instruments, industrial hygiene instruments), vehicles, and industrial equipment at the disposal facility.

The following steps should be followed and elements included in the instructions for the procedure:

1. State the job titles of individuals at the facility to whom this procedure applies, including, if appropriate, subcontractor personnel and visitors.

2. State the titles of individuals at the facility who are responsible for operator qualifications.

3. State how the necessity for training will be determined. For example, new equipment, new facilities, and changing needs usually prompt new training requirements. The success of training programs can be determined by observation of employee response to operating, written, and oral evaluations.

4. Reference regulations and procedures that apply to specific training programs.

5. Include separate sections for each type of required training (training program), such as:

- Onsite safety

- $\quad$ Radiation worker

- Respirator use

- Heavy equipment operation (e.g., cranes, bulldozers, backhoes)

- Industrial equipment operation (e.g., jackhammers, forklifts, steam cleaners)

- $\quad$ Specialized equipment operation (e.g., health physics instruments)

- Vehicle operation (e.g., automobiles, vans, tractor-trailers). 
6. Identify the goals and objectives of each training program.

7. State the requirements for each training program. Requirements can be determined from the extent of training needed to safely perform the tasks associated with a job position.

8. State the minimum criteria necessary to pass each training program, such as a minimum score on a written examination and demonstrated ability to safely operate the equipment.

9. State the minimum requalification frequency for each training program.

10. Describe the mechanism used to record and keep updated the qualification status of each person required to have specific training under this procedure.

11. Include separate steps for completing any forms. Those steps should include the titles of the forms and the titles of individuals completing them.

\subsubsection{Safety}

\subsubsection{Radiation Safety.}

5.3.2.1.1 Basic Radiation Protection Training-This procedure provides guidance on content and format of the basic radiation protection training that will be provided to all facility employees and contractors.

The following steps should be followed and elements included in the instructions for the procedure:

1. State the frequency at which this training will be conducted.

2. List the materials that each trainee should receive, such as textbooks, handouts, and pamphlets.

3. State who will conduct the training courses and the approximate lengths of the courses.

4. Include a list of subjects to be covered. The list will include, for example:

- Radioactive materials and radiation

- Hazards from radiation

- Background radiation

- Sources of radiation specific to the facility

- Radiation exposure control

- Individual responsibilities. 
5. Include an instruction to have the trainees tested with a written examination covering the course material. State a minimum allowable passing score.

6. Require discussion of incorrect answers with the trainees and retesting of the trainees.

7. Include separate steps for completing any forms, such as attendance rolls and lesson plans. Those steps should include the titles of the forms and the titles of the individuals completing them.

5.3.2.1.2 Radiation Worker Training-This procedure provides guidance on content and format for Radiation Worker Training. This training is required for all permanent employees working inside radiation controlled areas and contract or temporary workers that could be exposed to radiation or handle contaminated equipment.

The following steps should be followed and elements included in the instructions for the procedure:

1. State the frequency at which this training will be conducted.

2. List the materials that each trainee should receive, such as textbooks, handouts, and pamphlets.

3. State who will conduct the training courses and appropriate lengths of the courses.

4. Include a list of subjects to be covered. The list could include, for example:

- Radioactive materials and radiation

- Biological effects of ionizing radiation

- Radiation dosimetry and exposure control

- Contamination and contamination control

- Control of radiation work (e.g., work plans, and access and egress control)

- Posting

- Emergencies

- Rights and responsibilities.

5. Include a list of additional topics for training supervisors. The list could include, for example:

- Expected radiation levels 
- Standards, limits, and the ALARA philosophy

- Importance of training workers

- $\quad$ Planning and procedure review

- Methods of controlling contamination

- Dose control methods

- Personnel and area decontamination

- Control and use of sealed sources.

6. Include an instruction to have the trainees tested with a written examination covering the course material. State a minimum allowable passing score.

7. Require discussion of incorrect answers with the trainees and retesting of the trainees.

8. Include instructions for testing trainees' practical knowledge by demonstrating their ability to perform such functions as donning and removing personal protective equipment.

9. Include separate steps for completing any forms, such as attendance rolls and lesson plans. Those steps should include the titles of the forms and the titles of the individuals completing them.

\subsubsection{Industrial Safety.}

5.3.2.2.1 Occupational Safety-This procedure will contain instructions on the occupational safety program. It is intended to ensure the personal safety of each employee on the facility. It covers Authority and Occupational Safety and Health Administration (OSHA) occupational safety requirements at the facility.

The following steps should be followed and elements included in the instructions for the procedure:

1. Preliminary instructions

a. Reference all applicable provisions of state and federal laws and regulations relating to job safety and indicate that all employees must understand and comply with these laws and regulations.

b. State the title of the individual who is responsible for onsite safety.

c. Include an instruction for unannounced inspections of all work activities to understand actual working conditions. State the frequency of these inspections and the title of the individual who will conduct them. 
d. Instruct the individual who is responsible for onsite safety to prepare periodic occupational safety reports. State the frequency of this reporting and the titles of the individuals to whom the reports will be sent.

e. Include an instruction for all employees to revicw this procedure periodically. State the frequency of the review and include a form to document the fact that the review occurred.

f. Include separate steps for completing forms. Those steps should state the title of the form and the individual completing it.

2. Safety hazards.

It is logical to divide this procedure into sections according to safety hazard. The sections could address safety rules regarding general safety, personal protection, hazardous materials, and electrical safety.

a. General safety

1. Inform the employees that safety is ultimately their responsibility, even though the facility and its procedures are designed for safety. It is appropriate, therefore, to include a system for tracking employees who violate safety rules and procedures. This system should include a standard for notifying employees of safety violations, and a follow-up mechanism through the individual who is responsible for onsite safety, to ensure that violations are corrected.

2. Include an instruction to report all accidents and injuries to the individual who is responsible for onsite safety. State that the accident or injury should be reported the same day it occurs.

3. Include a statement to the employees about their being subject to personal searches of themselves and their belongings. Explain the consequences of refusing to submit to a search. State the titles of the individuals who are authorized to conduct such searches.

4. List the items forbidden on the facility, such as illegal drugs, alcoholic beverages, and weapons. Explain the consequences of possession of forbidden items at the disposal facility. Being found under the influence of prohibited substances should also be considered a violation.

5. Include an instruction that addresses prescription drugs employees are taking. Provide a system for employees to report these drugs to determine any possible impacts on their performance related to health and safety. State the title of the individual to whom prescription drug use will be reported. Projected periods of use would also be good information. Emphasize that the purpose of this system is not to discourage prescription drug use, since that could be harmful to the workers' health. 
6. Include an instruction to implement a fire prevention program. This program could, for example, prescribe specific containers for flammable or combustible liquids, appropriate warning signs, and fire extinguisher locations. Fire risk activities such as welding should also be addressed. Refer to applicable regulations such as OSHA and NFPA.

7. Include an instruction to prohibit inappropriate activities such as gambling, fighting, or horseplay.

8. State the types of areas where first-aid kits should be located. Provide direction on how to maintain the kits, including kit inspections and inventories and the frequency thereof, and shelf life of kit components. Also state the types of areas where other safety equipment should be located, such as emergency showers, goggles, and safely blankets.

9. Establish a speed limit for the facility.

10. Define the standards a vehicle must meet before being allowed on the site and state whose vehicles are allowed on the site. Some facilities allow only their own vehicles onsite.

11. Include instructions that address: good housekeeping; physical hazards (excavations, floor openings, open-sided floors, etc.); use of ladders and scaffolding; tools; and appropriate lighting, temperature levels, and ventilation of buildings.

b. Personal protection safety rules

1. Include instructions that address the use of hard hats, eye and face protection, full body clothing, foot protection, and hearing protection. These instructions should provide direction on the proper uses of this equipment and caution against common improper uses of this equipment. A separate list of personal protection equipment that must be worn on the facility at all times should be provided.

c. Dangerous materials safety

1. Include an instruction that describes how potentially harmful materials are accounted for.

2. Include instructions to utilize a "Hazard Communication" and worker "Right to Know" program. These instructions should mandate training for employees about Material Safety Data Sheets and other aspects of the program.

3. Describe how compressed gas cylinders should be handled in terms of markings, color coding, transporting, appropriate pressure regulators, and storage (e.g., compatibility of multiple gases). 


\section{d. Electrical safety}

1. Include instructions that address electrical safety in terms of: the type of wiring and extension cords that are acceptable, connector adapters, use of personal electrical equipment, condition of electrical equipment, qualifications of those working with or repairing electrical machinery or circuits, shock prevention, and standards for all electrical tools (OSHA and National Electrical Code Standards).

5.3.2.2.2 Fire Safety-The purpose of this procedure is to detail fire safety measures that exist within the disposal facility and what action facility personnel should take in the event of a fire. There are sections on fire prevention, actions in case of a fire, and drills.

The following elements should be included in the instructions for the procedure:

1. Fire prevention

a. A fire prevention checklist should be provided with the procedure to facilitate inspections and inform employees. The fire prevention checklist can be arranged in sections according to activities such as welding and cutting, or hazard categories such as electrical equipment and friction. The checklist would probably best be placed in an appendix. State where checklists will be posted.

b. Include an instruction to have emergency information available at designated areas. Emergency information could be onsite and offsite emergency telephone numbers and authorized evacuation routes.

c. Include an instruction that smoking will be allowed only in designated areas.

d. Provide direction on controls over open flames at the facility.

e. Include an instruction addressing good housekeeping of escape routes and proper functioning of fire doors. For example, escape routes are not to be constricted and fire doors are not to be propped open.

f. Include an instruction about proper marking and lighting of emergency routes, and fire emergency equipment.

g. Include an instruction addressing the dangers, proper storage, and use of flammable and hazardous materials, including combustible gases and oxygen.

h. Describe how the status of fire extinguishers will be known. State the title of the individual responsible for checking the status of fire extinguishers and what that individual will check for (e.g., proper tagging and inspection dates). 
2. Actions in case of a fire

a. Include a list of instructions to follow for all fire emergencies. Note that there is a separate fire emergency procedure giving detailed instructions to specific individuals at the facility.

b. Include other instructions stating who is authorized to use certain fire-fighting equipment, and suggestions for containing the fire, such as closing doors and windows.

c. Include an instruction about orderly evacuation and state the title of the individual responsible for accounting for personnel.

3. Drills

a. State the frequency required for fire safety drills and the title of the individual responsible for conducting them.

b. List information the responsible individual should check to know the fire preparedness of the facility employees. The types of information should include: location of emergency phone numbers, sounds and meanings of alarms, designated evacuation routes, meeting locations, who to report to, and other actions in case of a fire.

c. State what actions will be taken after a drill if the individual responsible for conducting the drill is not satisfied with the outcome.

5.3.2.2.3 Equipment Testing and Certification-The purpose of this procedure is to prevent industrial accidents caused by equipment failure. It describes the testing and certification required for heavy equipment and any related safety devices. The activities covered do not include normal maintenance of the equipment, such as lubrication.

The following steps should be followed and elements included in the instructions for the procedure:

1. State the titles of individuals at the facility who will perform the procedure.

2. State the types of equipment covered by the procedure, such as cranes and forklifts. Also state the type of tests to be performed on the equipment.

3. State the frequency of testing for each type of test and equipment.

4. Describe how the specific tests should be carried out. For example, if the test was a static load test, some multiple of the design load will be applied in such a manner to create the maximum tensile, compression, shear, and bending stresses in the equipment. Include separate tests, if necessary, to achieve the various maximum stresses. 
5. Include instructions to inspect safety-related devices such as back-up alarms and hydraulic systems. Describe how tests will be conducted on these types of devices.

6. Provide a method for accounting for the testing and certification program. For example, durable tags could be affixed to the tested equipment. Forms should be used to document the inspections and tests.

7. Include separate steps for completing forms. These steps should include the title of the form and the titles of the individuals completing it.

8. Include general warnings to take safety devices and equipment out of service immediately if evidence of deterioration is present.

\subsubsection{Radiation Surveys.}

5.3.2.3.1 Incoming Vehicle Surveys-The purpose of this procedure is to provide instructions to be followed when performing radiation and contamination surveys of incoming low-level waste transport vehicles before acceptance of the waste for disposal. These surveys are required to ensure that U.S. Department of Transportation regulations for exclusive use vehicles are being met when the waste arrives at the facility for disposal.

The following steps should be followed and elements included in the instructions for the procedure:

1. Radiation level surveys

a. Radiation level surveys measure the radiation exposure rates at varying distances from the vehicle.

1. State the titles of individuals responsible for conducting radiation level surveys.

2. Provide directions on how to conduct radiation level surveys including the type of instruments to be used. These directions should include the locations of the vehicles that should be surveyed, distances probes should be held away from those locations, and the maximum speed at which the probes can be moved while doing the survey.

3. Provide maximum allowable radiation levels for specific locations on the vehicles and distances from vehicle surfaces. Describe actions to be taken if that level is exceeded at any time.

4. Provide forms on which the results from the surveys may be recorded, and state the titles of individuals responsible for completing the forms. 


\section{Contamination surveys}

a. Contamination surveys measure levels of radionuclide contamination on the surfaces of the vehicle, with emphasis on removable contamination that can wipe off onto personnel and their clothing.

1. State the titles of the individuals responsible for conducting contamination surveys.

2. Provide directions on how to conduct contamination surveys using a smear sample. State the type of material to be used for taking smears and the area over which the smear must be wiped and reference the DOT regulations that require it. State the number of smears to be taken and the locations on the vehicle where they should be taken. State whether smears should also be taken on the vehicle's cargo (e.g., waste containers). These numbers and locations will vary, so specify the numbers and locations corresponding to the type of vehicle (such as flat-bed trailers or vans).

3. State the number of smears to be taken on the waste packages.

4. State the appropriate laboratory equipment for counting the smears. One appropriate device is the liquid scintillation counter.

5. Provide a maximum allowable radiation level corresponding to the DOT limits and actions to be taken if that level is exceeded at any time.

6. Provide forms on which the results from the surveys may be recorded and state the titles of the individuals responsible for completing the forms.

3. Radiation level or contamination in excess of DOT limits.

a. State the titles of the individuals who should be notified if DOT limits are exceeded.

b. When decontamination is required, reference the appropriate procedures and state who will supervise such activities.

5.3.2.3.2 Transport Vehicle Release Surveys-The purpose of this procedure is to prescribe the manner in which waste transport vehicles leaving the controlled area will be surveyed for radioactive contamination of external surfaces.

This procedure applies to any waste transport vehicle that is being released from the controlled area for unrestricted use or, for cask-carrying vehicles, for return to a generator/broker. It may not apply to the survey of onsite equipment that is being released from the controlled area for maintenance or other restricted use.

The following steps should be followed and elements included in the instructions for the procedure: 
1. State the titles of the individuals who will conduct the various actions described in this procedure.

2. State where the vehicle will be taken to be surveyed and who will drive the vehicle to that location. (For example, must an employee of the disposal facility drive the vehicle or can the vehicle owner or operator's driver move it?)

3. Include an instruction addressing items that are authorized for return to a generator/broker for general unrestricted use. This instruction ensures that potentially contaminated items such as pallets used during shipment of waste drums remain at the facility. All these items should be removed before starting the survey.

4. Include instructions to ensure that all areas of the vehicle are readily accessible by leaving doors, etc. unlocked during the survey.

5. Include an instruction that personnel should be prepared to provide operating equipment, such as ladders, cherry pickers, etc., to reach difficult locations of the vehicle.

6. Include an instruction to the individual responsible for operations to notify the individuals conducting the surveys if there is any reason to suspect there are unacceptable levels of contamination on the vehicle (from spills, etc.) and where that contamination would be found. This will encourage closer scrutiny of suspect areas.

7. Include an instruction to determine if decontamination or air sampling at the survey location is needed during the survey.

8. Describe specifically, step by step, how the survey should be conducted, as follows.

a. Surveying instruments

1. State the types of instruments to be used, the distance the probe should be held from the surveyed surface, the maximum speed at which it can be moved, a maximum acceptable number of counts above background, and actions that should be taken if readings exceed that maximum number. State the maximum numbers for beta-gamma and alpha contamination separately.

b. Smear samples.

1. State the type of material to be used and the area over which the smear must be wiped and reference the DOT regulations that state the required area. State the number of smears to be taken and the locations on the vehicle where they should be taken. These numbers and locations will depend on the type of vehicle being surveyed. State the appropriate laboratory equipment for counting the smears. Provide a maximum allowable radiation level corresponding to the DOT limits and actions to be taken if that level is exceeded at any time. 
Because the nature of the measurements, the action levels, and the actions based on those levels are different, it may be helpful to provide a table that summarizes these details.

9. Provide forms on which the results from the surveys may be recorded and state the titles of the individuals responsible for completing the forms. Detailed instructions for the forms should be included.

10. State where the vehicle will be taken after the survey and who will drive the vehicle to that location.

11. Because this procedure involves decisions and different actions based on those decisions, a flow chart may be useful as a supplement to the text.

5.3.2.3.3 Routine Surveys and Reviews-The purpose of this procedure is to provide general instructions for performing routine radiation and contamination surveys. This procedure also describes the methodology to be used for regular review of these surveys by appropriate management personnel.

Under normal circumstances, most disposal facilities will operate under non-contaminated conditions. Routine surveys are used to look for any radioactive contamination and monitor levels of such contamination. The surveys will be conducted to characterize workplace conditions and to identify areas requiring cleanup, posting, or other protective measures to prevent inadvertent radiation exposure to personnel. These surveys will also be used to note any unsafe or unusual condition observed.

This procedure tends to be relatively independent of the disposal facility site and design. There are specific procedures for surveys of waste containers, vehicles, and waste disposal units.

The following steps should be followed and elements included in the instructions for the procedure:

1. State the titles of the individuals responsible for conducting routine surveys.

2. State the areas that will be subject to routine surveys, such as radiologically controlled and non-controlled areas, buildings, vehicles, etc.; air in radiologically controlled areas; and work areas where radioactive material is involved. State the frequency of these routine surveys.

3. State the title of the individual responsible for reviewing the results of the periodic surveys and the frequency of those reviews.

4. Include detailed instructions to perform contamination surveys using smear samples and survey instruments. A survey form or map may also be helpful to the technician conducting the survey. 
a. Smear samples

1. State the type of material to be used to take smear samples and the area over which the material must be wiped to obtain a representative sample.

2. State specifically the surfaces from which smears will be taken, such as walls, ladders, handrails, horizontal surfaces, and potential points of leakage like flanges and valves. Include a reminder to include non-uniform objects or surfaces such as small objects and odd shapes.

3. Include instructions to deal with contaminated materials that may be found. These instructions may include placing the objects in plastic bags or labeling unmovable objects.

b. Survey instruments

1. Indicate that the purpose of using survey instruments is to determine "fixed" and removable levels of contamination.

2. Include an instruction requiring a background count and describing how to determine this background count.

3. State the types of instruments to be used, the distance the probe should be held from the surveyed surface, and the maximum speed at which it can be moved.

4. Provide limits for all types of radiation to which the measured values may be compared. These limits lend themselves well to a tabular format. Include a criterion that dictates when the measured values should be recorded on a form. For example, such a criterion could be when the measured values exceed half of the limits.

5. Provide forms on which information (such as measured values), building and room numbers, date and time, a sketch or description of the area or object surveyed, etc., may be recorded and state the titles of the individuals responsible for completing the forms.

5.3.2.3.4 Cask Surveys-This procedure provides instructions for inspecting shipping casks received at the facility before they are released from the facility and returned to the waste generators. The surveys are performed to detect physical or radiological conditions that could create a hazard during their return travel or in subsequent use.

The following steps should be followed and elements included in the instructions for the procedure:

1. State the titles of the individuals performing the procedure.

2. This procedure lends itself well to the use of checklists and reporting forms. A comprehensive checklist could be developed to assist the inspector during the inspection. 
Forms will be necessary to document the radiation surveys and to track the casks through the process.

3. Describe how the cask should be inspected. This inspection should include the cask's interior and exterior and other features of the cask.

a. Interior radiation surveys

1. Include an instruction to perform a radiation level survey over the interior of the canister. State the type of survey instrument to be used.

2. Include an instruction to perform a survey of removable contamination using smears. State the number of smears required and the area over which these smears should be wiped. Also state the locations of these smears (e.g., floor, hottest spot, etc.).

3. Provide maximum contamination limits and describe actions to be taken if the casks received exceed those limits, such as additional wipes to determine extent of contamination and decontamination.

4. Refer to the appropriate decontamination procedure to be used if the limits are exceeded.

b. Exterior radiation surveys

1. Include an instruction to perform a radiation level survey and a removable contamination survey of the exterior of the cask. These exterior surveys are similar to the interior surveys; however, maximum contamination limits may be different. This survey activity may be covered as part of another procedure, such as one for transport vehicle release surveys.

c. Physical damage

1. The interior walls of the cask should be inspected for damage that could affect the integrity of the cask, e.g., holes or large dents. If the interior surface of the cask is rough, pitted, or badly scraped, this condition could trap fixed or removable contamination. In that case, the cask owner should be advised to have the cask repaired to correct this condition.

2. The exterior of the cask should be visually inspected for damage that could affect the integrity of the cask.

3. Other features of the cask should be visually inspected for damage, weathering, warpage, etc. A list of example features that could be checked follows.

a. Seal and gasket: There should be no rust spots or corrosion in the seal area or channel. The seal and gasket should be free of crimps or tears. 
b. Studs and nuts: Check for thread damage and cracking. Replacements should meet cask certification requirements.

c. Dowels: The lid alignment dowel should be inspected for damage that would prevent proper alignment of the lid.

d. Name plate: Check that it is in place and legible.

e. Lid: Check for warpage.

f. Lifting lugs: The lifting lugs should be checked for signs of weakening, such as cracking or bending.

g. Drain plug (do not remove): Check for excessive rust or accumulation of particulate matter.

h. Tiedown system: Inspect components such as lugs, shackles, tiedown ratchets and cables for damage.

i. Ratchet binders: The retaining pins and locking pins should be inspected for cracks and wear which would affect their strength.

4. Describe what actions should be taken if a problem is found during the inspection. For example, a supervisor should be notified who should contact the cask shipper or owner, relate the extent of the problems, and request further instructions. Describe the conditions under which a cask with a problem may be released for shipment or be held pending corrective action. State who will provide such corrective action (most likely the cask owner).

5. State what forms will be completed and how those forms are used to follow up on problems identified during the inspection.

5.3.2.3.5 Closed Disposal Unit Surveys-This procedure provides instructions for performing and documenting direct gamma radiation surveys of covered disposal units, including closed disposal units and disposal units with temporary covers. Such surveys help ensure that direct radiation levels in the controlled area of the disposal facility remain as low as reasonably achievable (ALARA) and they support the monitoring program for the long-term performance of the closed disposal units. The elements of the procedure that are presented below are appropriate for disposal units with earthen covers. This procedure may not be necessary for disposal units without covers, such as bare concrete vaults.

The following steps should be followed and elements included in the instructions for the procedure:

1. State the titles of the individuals who will perform this procedure.

2. Indicate how frequently the surveys will be conducted. 
3. Describe the method to be used for documenting the location of each disposal unit surveyed. This documentation is often accomplished using a scale map attached to a survey form. The survey form would contain information about the disposal unit being surveyed, such as its designation, the type of waste it contains, the status of the cover, and baseline radiation levels. It could also contain information about the survey instrument used, such as its type, serial number, last calibration date, and source check.

4. Describe ways to provide reference points along the perimeters of the disposal cells as visual aids for performing the surveys. Describe what will be used for reference points, such as posts.

5. Make the person conducting the survey aware of the importance of following any prescribed paths when conducting the surveys.

6. State where instrument readings should be recorded with respect to reference points on the disposal unit (e.g., at the edge, a certain distance from the edge, distance intervals thereafter). Average instrument readings for each square in a prescribed grid may be desired.

7. Explain what actions should be taken if unusually high radiation levels are indicated while surveying. Explain these actions in terms of a more thorough survey of the area of potentially high radiation exposures, and notification of the appropriate individuals as soon as practicable.

8. Include an instruction to have the recorded surveys reviewed. State the title of the individual who will review the recorded survey.

9. Establish generally acceptable radiation levels for the covered disposal units. State the titles of the individuals who will determine these values.

10. Describe the actions that should be taken, including the titles of the individuals who will be notified, if instrument readings are greater than the generally acceptable values (within instrument errors).

\subsubsection{General Activities}

\subsubsection{Routine General Activities.}

5.3.3.1.1 Waste Verification Testing-This procedure describes the methods used to verify form and content of the radioactive waste received at the disposal facility. It should probably be used only if one of the following criteria are met: there is reason to suspect a possible compliance violation, there is sufficient evidence to indicate a discrepancy between the waste received and the shipping manifest, or the generator has previously notified the disposal facility of an unusual hazard associated with the waste.

The following steps should be followed and elements included in the instructions for the procedure: 
1. State the titles of individuals at the facility who will perform the procedure.

2. State waste characteristic requirements, deviations from which will prompt an investigation by visual verification of the waste content or sampling and analyzing the waste. These requirements are typically derived from 10 CFR 61 and may include:
a. Waste solidification or packaging in a sufficient amount of absorbent material.
b. Prohibition of wastes that generate toxic fumes or are spontaneously flammable or explosive.

c. Packaging for gaseous wastes at a pressure that does not exceed a certain pressure. Also include a maximum allowable activity per container.

d. Maximum allowable amount of free-standing liquid.

3. If a more thorough inspection of the waste form is determined to be necessary, state the steps in conducting such an inspection. These could include:

a. Developing a waste verification plan: The complexity and level of detail of the plan should vary to accommodate the specific inspection verification needs. For example, the plan may require simple visual inspection of the waste package contents, puncturing the container to locate voids or liquids, or taking samples for laboratory analysis.

b. Transporting the waste package to a designated inspection location.

c. Spill containment: Include an instruction to provide spill containment, such as a liquid containment pan, especially when checking for free liquids.

d. The inspection enclosure: Describe the inspection enclosure and any filtered ventilation system. State a minimum air flow for the ventilation system to achieve the proper capture velocity.

e. Air sampling: State the locations (inside and outside the enclosure) and the frequency of air sampling.

f. Waste sampling: Describe how the waste is to be sampled to obtain a representative sample, depending on the medium and analytes.

g. Resealing the waste container: Describe how the waste container should be resealed.

4. Include an instruction to conduct a contamination survey and analyze air samples and any smears that may have been taken. The inspected container should not be removed and normal access to the inspection enclosure should not be restored until contamination levels are below a specified maximum allowable level. 
5. Include an instruction to conduct personnel monitoring, such as collecting and analyzing bioassays and conducting thyroid scans.

6. State the actions to be taken, such as contacting the waste generator, if the visual verification or sampling of the waste indicate significant deviations from the values listed on the manifest.

7. Include an instruction to report violations of any state, local, or federal regulations as required.

8. Include separate steps for completing any forms, such as nonconformance reports. Those steps should include the titles of the forms and the titles of the individuals completing them.

5.3.3.1.2 Decontamination of Operational Equipment and Transport Vehicles-The purpose of this procedure is to describe activities for decontamination of operating equipment and transport vehicles. Surveys will be conducted of equipment and vehicles in accordance with other procedures, and this procedure will be followed if contamination levels are unacceptable.

The following steps should be followed and elements included in the instructions for the procedure:

1. State the titles of the individuals at the facility who will perform decontamination and who will decide where and how it will be conducted.

2. State the location where decontamination activities will take place.

3. Describe how the method for decontamination will be chosen, depending on how firmly the contamination is thought to be attached to the surface of the equipment or vehicle. Methods may range from mild procedures such as tape pressing to harsh procedures such as abrasion.

4. Include instructions about radiation monitoring requirements (e.g., dosimetry, air monitoring), personal protective requirements (e.g., respiratory protection, gloves, coveralls), and safety requirements (e.g., fall protection, face shielding), depending on the decontamination area conditions and the method used.

5. Include an instruction about using engineering controls to prevent the spread of contamination to the environment.

6. Include an instruction to minimize the generation of waste from the decontamination process.

7. State maximum internal and external contamination levels under which equipment and vehicles may be placed back in service. 
8. Describe the actions taken if the internal or external contamination levels exceed the maximum allowable levels. The actions taken will most likely be to repeat the decontamination procedure.

9. Describe the actions taken if it is determined that persistent decontamination efforts are unsuccessful. For example, the equipment could be classified for restricted use and be labeled as such.

10. Describe disposal of any waste created during the decontamination process.

11. Include separate steps for completing any necessary forms. The instructions could occur at several points in the procedure and should include the titles of the forms and the titles of individuals completing them.

5.3.3.1.3 Decontamination of Casks and Shipping Containers-The purpose of this procedure is to describe the activities for decontamination of casks and shipping containers. Surveys will be conducted on casks and shipping containers in accordance with other procedures. If contamination levels are unacceptable, this procedure will be followed.

The following steps should be followed and elements included in the instructions for the procedure:

1. State the titles of the individuals at the facility who will perform decontamination and who will decide where and how it will be conducted.

2. State the location where decontamination activities will take place.

3. Describe how the method for decontamination will be chosen, depending on how firmly the contamination is thought to be attached to the surface of the cask or container. Methods may range from mild procedures such as tape pressing to harsh procedures such as abrasion.

4. Include instructions about radiation monitoring requirements (e.g., dosimetry, air monitoring), personal protective requirements (e.g., respiratory protection, gloves, coveralls), and safety requirements (e.g., fall protection, face shielding), depending on the decontamination area conditions and the method used.

5. Include an instruction about using engineering controls to prevent the spread of contamination to the environment.

6. Include an instruction to minimize the generation of waste from the decontamination process.

7. State maximum internal and external contamination levels under which shipping containers or casks may be placed back in service. 
8. Describe the actions taken if the internal or external contamination levels continue to exceed the maximum allowable levels for release. The actions taken will most likely be to repeat the decontamination procedure.

9. Describe the actions taken if it is determined that persistent decontamination efforts are unsuccessful. For example, the container or cask could be shipped as "Radioactive Empty" per 49 CFR 173.427, or the owner could be consulted for further instructions. Another option is to ship the container back to the owner as a "Radioactive Shipment" subject to U.S. Department of Transportation regulations.

10. Describe disposal of any waste created during the decontamination process.

11. Include instructions for completing any necessary forms. These instructions could take place at several points in the procedure and should include the titles of the forms and the titles of individuals completing them.

\subsubsection{Non-Routine General Activities.}

5.3.3.2.1 Waste Containers Not Acceptable Upon Arrival-The purpose of this procedure is to describe the actions to be followed when waste containers are not acceptable upon arrival. Waste containers may not be accepted for at least four basic reasons: exceeding contamination limits, exceeding radiation exposure limits, damaged containers, and improper container types. Surveys of casks and shipping containers will be conducted in accordance with other procedures. This procedure will be followed if contamination levels are unacceptable.

The following steps should be followed and elements included in the instructions for the procedure:

1. State the titles of individuals at the facility performing this procedure.

2. Provide contamination and radiation exposure limits as defined in U.S. Department of Transportation regulations or as defined by the facility license.

3. Describe measures to be taken if it is determined that radiation exposure limits have been exceeded, such as:

a. Notification of responsible individuals at the facility: State the titles of individuals to be notified. Reference the procedure for notification of regulatory agencies.

b. Measures to be put into effect to minimize personnel radiation exposure from the waste container.

c. Preparing nonconformance reports: This will start the process to determine and document appropriate corrective action.

4. Describe measures to be taken if it is determined that contamination limits have been exceeded, such as: 
a. Notification of responsible individuals at the facility: State the titles of the individuals to be notified. Reference the procedure for notification of regulatory agencies.

b. Measures to be put into effect to minimize the spread of contamination from the canisters: Reference procedures for decontamination of casks and shipping containers.

c. Preparing nonconformance reports: This will start the process to determine and document the appropriate corrective action.

5. Describe measures to be taken if it is determined that the waste container does not meet the waste acceptance criteria, such as:

a. Notification of the waste generator/broker for coordination and instructions regarding repackaging or requesting a waiver: Reference the procedure for notification of regulatory agencies.

b. Preparing nonconformance reports: This will start the process to determine and document the appropriate corrective action.

6. Describe measures to be taken if it is determined that the waste container is damaged, such as:

a. Immediate actions, as necessary, to control and minimize the spread of contamination: Reference the procedure for handling damaged waste containers.

b. Notification of responsible individuals at the facility: State the titles of individuals who will be notified. Reference the procedure for notification of regulatory agencies.

c. Preparing nonconformance reports: This will start the process to determine and document the appropriate corrective action.

7. Include separate steps for completing any forms such as nonconformance reports. Those steps should include the titles of the forms and the titles of individuals completing them.

5.3.3.2.2 Handling Damaged Waste Containers-The purpose of this procedure is to describe the activities involved in handling damaged waste containers at the disposal facility. This procedure applies to all waste containers that are either known to be damaged or are of questionable structural integrity.

The following steps should be followed and elements included in the instructions for the procedure:

1. State the titles of individuals at the facility who will perform this procedure. 
2. Include an instruction to verify that radiation and contamination surveys were conducted prior to handling damaged waste containers.

3. State contamination levels above which decontamination procedures must be invoked.

4. Include an instruction to visually inspect the container to determine that proper handling techniques can be applied. If the container can't be safely removed to the appropriate repair area using normal container handling procedures, a special procedure may need to be developed.

5. Include a list of instructions describing how to handle damaged waste containers considering:

- Protection of workers and the environment: Include necessary precautions. For example, plastic sheeting and catch basins may be needed to protect workers and the environment when moving damaged containers.

- Changing conditions such as containers that become pressurized or start leaking.

- Keeping an adequate supply of absorbent packing material nearby.

- Capability of the lifting equipment to handle the anticipated loads.

- Potential for handling the containers remotely, using front-end loaders, cranes, drum grapplers, etc.

- The driver's visibility: Depending on the equipment and the facility, workers may have to guide the driver's motion.

- Actions to contain any contamination released during handling. This may require invoking another procedure.

6. Include separate steps for completing any forms. Those steps should include the titles of the forms and the titles of the individuals completing them.

5.3.3.2.3 Repairing Damaged Waste Containers-The purpose of this procedure is to describe activities during repair of damaged waste containers at the disposal facility. Repair, in this case, includes placing containers in overpacks.

The following steps should be followed and elements included in the instructions for the procedure:

1. State the titles of individuals at the facility who will perform the procedure.

2. State the location where repair of damaged waste containers will be performed. Include instructions on managing situations when it is not possible to safely transport the damaged waste containers to the designated repair area. 
3. Include an instruction to ensure that external radiation and contamination surveys are conducted on damaged containers prior to repairing them.

4. Include a list of instructions addressing contamination control for situations when radioactive material can be easily released and dispersed from a container. For example, materials such as tape, plastic sheeting, and catch basins can be used to minimize the spread of contamination.

5. Describe how damaged containers are overpacked (e.g., a 55-gallon drum could be placed inside an 85-gallon drum). Indicate if and how the void spaces between the inner and outer containers will be filled.

6. State acceptable methods of container repair and where those methods are applicable. For example, small cracks or openings may be sealed with silicone sealant. Other methods could be fiberglass epoxy, alumaweld epoxy, etc.

7. Include instructions addressing the possibility of radioactive materials releases that might occur during repair activities. State the actions to be performed in the event of a release during container repair or overpacking. For example, reference may be made to the radioactive materials releases emergency procedure.

8. Include separate steps for completing any forms. These steps should include the titles of the forms and the titles of the individuals completing them.

9. Describe, probably by reference to other procedures, what will be done with the repaired containers.

\subsubsection{Operations}

\subsubsection{Routine Operations Activities.}

\subsection{Preemplacement-}

5.3.4.1.1.1 Preshipment Approval-The purpose of this procedure is to document the administration and communication process for approval of waste receipt from a generator or broker (called the shipper here) that takes place before shipment of the waste. This procedure applies to all requests for shipment of low-level radioactive waste to the facility. It provides criteria to be met by the shipper to gain authorization for waste shipment to the facility.

The following steps should be followed and elements included in the instructions for the procedure:

1. State the titles of the individuals at the disposal facility who will perform this procedure.

2. Describe the acceptable methods of communication from the shipper concerning requests for disposal of waste at the facility. For example, it may be acceptable for the shipper to FAX the form requesting approval to send the waste, but an original signature copy may 
be required to be at the disposal facility before the waste will be accepted. State the acceptable timing of receiving the form and the waste shipment. A common method is to FAX the form to start the shipment process and then follow the FAX with the signed original by mail.

3. Describe the actions to be taken if the information provided by the shipper is inadequate. For example, the shipper should be informed of the inadequacies and should submit a new form including the required information.

4. Include an instruction to determine the facility's ability to accept the waste at a given time, considering such factors as weather conditions, workload at the facility, waste and container type, generator need, availability of off-loading equipment, and other similar factors that could significantly impact waste management operations at the facility.

5. Include an instruction to notify the shipper of the approval or denial of the request to ship waste. State the maximum amount of time that should pass between receiving a request and contacting the shipper with the determination. State the method of communication that should be followed to notify the shipper of the determination. For example, the shipper could be contacted by telephone, followed by written notice. The written notice could be a copy of the form the shipper submitted with a portion of that form completed by the disposal facility staff documenting the approval.

6. State the maximum amount of time that may pass between approving the shipment and scheduling its delivery to the facility, at a time agreeable to both the shipper and the disposal facility.

7. State the amount of time before the scheduled delivery that the disposal facility will contact the shipper to confirm or reschedule the delivery. State the title of the individual who should contact the shipper for this confirmation.

5.3.4.1.1.2 Arriving Vehicle Safety Inspection-The purpose of this procedure is to describe the method for performing inspections on vehicles arriving at the facility. This procedure applies to all waste shipment vehicles arriving at the facility. It provides a checklist to ensure that the vehicle has been properly inspected and surveyed for radiation and contamination and that the vehicle meets the vehicle safety criteria as specified in 49 CFR parts 390-397.

The following steps should be followed and elements included in the instructions for the procedure:

1. State the titles of the individuals who will conduct this procedure.

2. This procedure lends itself well to the use of a checklist that can facilitate inspections and documentation. A form can be developed for that purpose. It may include, for example:

- Verify that radiation surveys have been conducted

- Verily that the waste manilest and shipper's certification are in proper order 
- Verify that security seals are intact

- Verify proper vehicle placarding

- Inspect safety-related items such as brakes, tires, the trailer hitch, etc. A list of required inspection items is given in 40 CFR 393

3. State how the inspector will note satisfactory or unsatisfactory items. A form that also serves as the checklist could be provided for the inspector to record these determinations. If an item is unsatisfactory, state the title of the individual to whom the inspector will report that fact.

a. Unsatisfactory items will either be immediately correctable or not.

For items that are immediately correctable, indicate who will make the necessary corrections. Provide a mechanism for documentation and follow-up of this inspection and correction process.

For items that are not immediately correctable, include an instruction to make a safety determination based on the potential endangerment of facility workers, the public, or the environment. The safety determination will affect whether the vehicle can continue to be used on site, or if the waste should be transferred to a compliant vehicle. A determination must also be made about whether the vehicle will be allowed to leave the facility without the unsatisfactory items being corrected. UNDER NO CIRCUMSTANCES WILLA VEHICLE WITHUNSATISFACTORY INSPECTION ITEMS BE ALLOWED TO LEAVE THE FACILITY WITH WASTE ON BOARD OR WITHOUT UNDERGOING A RELEASE SURVEY. State the title of the individual responsible for making the safety determination and what documentation will be involved.

5.3.4.1.1.3 Waste Shipment Acceptance-The purpose of this procedure is to document methods for receipt and inspection of incoming vehicles and waste packages. The inspections are performed to ensure that waste shipments meet facility waste acceptance criteria and are in compliance with applicable regulations and license criteria. This procedure applies to all low-level radioactive waste received by the facility for disposal. The activities prescribed ensure that each shipment has been properly inspected and surveyed for contamination, that the manifest is reviewed, and waste classification verified before acceptance for disposal.

The following steps should be followed and elements included in the instructions for the procedure:

1. State the titles of individuals responsible for performing this procedure.

2. Include an instruction to ensure that the prerequisite procedures, covering such subjects as pre-shipment approval, arriving vehicle safety inspection, and waste classification verification, have been performed. State the title of the individual responsible for making this verification. 
3. Include an instruction to visually inspect the waste shipment to ensure that it complies with facility and license requirements and that proper handling techniques can be applied. The following are examples of the types of details that should be visually inspected:

- Container integrity

- $\quad$ Proper labeling

- The quantity and type of waste agrees with manifest

- Ability of onsite equipment to safely handle the waste containers.

4. Provide a mechanism, typically a form or forms, to document any deficiencies identified during the inspection, determine and document appropriate corrective action, and follow up to ensure the corrective action was performed. Indicate who fills out the form or forms and who else, such as the waste shipper or state officials, should be notified of deficiencies.

5. If any waste containers have lost their integrity, include instructions on actions that should be taken to avoid the spread of contamination or exposure to facility workers. State the titles of the individuals who will be responsible for determining the degree of the potential resultant hazard, and who should be notified. List the procedures to be invoked to remedy the loss of container integrity.

6. Indicate which disposal facility personnel may decide that additional verification of the content of the waste shipment is needed. If additional verification is needed indicate what actions should be taken, such as waste storage or moving the transport vehicle to another location.

5.3.4.1.1.4 Disposal Unit Construction-The purpose of this procedure is to describe the construction of disposal units before waste emplacement. There can generally be two major components to disposal units: earthworks and man-made structures. Construction of earthworks includes activities involving the placement or excavation of soils. Man-made structures are the components, other than earthworks, incorporated into the disposal unit design; these are typically concrete bunkers. Because the procedure for constructing a disposal unit is very specific to its design, this annotated procedure is very general.

The following elements should be included in the instructions for the procedure:

1. State the titles of individuals who will perform the procedure. Separate statements may be needed as different portions of the construction are described.

2. State the equipment that should be used at the start of each instruction that involves equipment.

3. The following ideas will be helpful in developing instructions for earthworks: 
a. Describe, in a series of instructions, the processes used to place or remove soil at the disposal unit and any soil stockpiles.

1. Construction of earthworks will probably be accomplished using one or a combination of dump trucks, front-end loaders, bulldozers, and cranes with dump buckets. Include design-specific details about thickness of lifts of the earthen materials that will be emplaced and differences in material from one location to another in the disposal unit. Also include instructions on how to use special devices. For example, if geomembranes are used, how their seams will be made should be described, at least in terms of the use of special seaming tools.

b. Describe how earthen materials should be compacted, if compaction is necessary. Generally, the more granular the material, the less compaction is required. Refer to the specifications that state the required compaction for the subject material. Refer to a compaction procedure if one exists.

1. State how inspection of the compacted areas will be accomplished. The sand cone test and the nuclear density gauge are two compaction testing options.

2. Documentation may be required for testing of compaction; in those cases, include separate steps for completing forms verifying that the desired compaction and other in-place material properties have been achieved. These steps should state the title of the form and the individual completing it.

c. Indicate where specifications for dimensions, slopes, etc. are found; who inspects these parameters; and how the satisfactory inspection is recorded.

4. The most common materials used for man-made structures are pre-cast concrete and steelreinforced cast-in-place concrete. The following ideas will be helpful in developing instructions for the construction of man-made structures.

a. Whenever an activity involves dimensions or adherence to specifications, reference the pertinent drawings or specifications.

b. Try to divide the procedure into one activity per step. The construction activities, therefore, should be divided at logical breaking points.

c. Ensure that the construction steps follow a logical sequential order.

d. For precast concrete components, include a series of instructions to get the component in place. These instructions would include descriptions of how the component is lifted, how it is lowered into place, how it is attached to other components, and how it is oriented.

e. For steel-reinforced cast-in-place concrete components, include instructions for determining and inspecting the proper configuration of the re-bar and the proper 
concrete mix, and methods for conveying the concrete, vibrating the concrete to eliminate void spaces, finishing the concrete, and caring for the concrete until it is cured.

f. Include instructions for the placement and inspection of waterstops in concrete joints and any sealants or other outer coating put on the concrete.

5.3.4.1.1.5 Canister Inspection-The purpose of this procedure is to describe methods for inspection of canisters that may be used in the disposal unit as additional containers for low-level radioactive waste packages. The inspections will help ensure that the canisters are strong, tight, and suitable for waste disposal. This procedure applies to all such canisters received by the facility. It ensures that canisters have been properly inspected and surveyed for radioactive contamination and that they have been approved for disposal of low-level radioactive waste according to the specifications in the facility license.

The following steps should be followed and elements included in the instructions for the procedure:

1. State the titles of individuals who will perform this procedure.

2. Include an instruction to remove the lid from the canister. State the equipment that will be used to remove the lid and where it will be placed during the inspection.

3. A checklist is recommended that would assist the inspector in identifying specific items to be inspected. Examples of inspection items would be:

- Completeness of canister documentation

- Verification that a survey was made of the canister for radioactive contamination

- Dimensions of the canister at key places

- A general visual inspection of key safety features, such as lifting lugs, and of the physical condition of the canister interior and exterior.

4. Provide a mechanism for documenting and following up on inspection results. Typically this can be a form that serves as both a checklist and record of inspection.

5. Describe the activities to be performed if an item does not pass inspection. The following activities could be included:

- Notification of appropriate individuals regarding the extent of the discrepancy. State the titles of the individuals to be notified.

- Description of the actions of those individuals, such as documentation of the discrepancy (perhaps in a nonconformance report) and communication with the canister manufacturer. 
- Canister repair if any. State under what conditions canister repair can take place.

6. Describe the disposition of the canisters after the inspection.

a. State where accepted canisters will be placed.

b. State where rejected canisters will be placed, describe marks to be made on them to ensure they won't be used, and indicate how they will be disposed of.

5.3.4.1.1.6 Transport Vehicle Movement to Disposal Unit-The purpose of this procedure is to describe the actions required for moving loaded waste transport vehicles from the receiving area to the appropriate active disposal unit. This procedure applies to all shipments of radioactive waste coming into the radiologically controlled area.

The following steps should be followed and elements included in the instructions for the procedure:

1. Include an instruction that references any procedures necessary to gain access to radiologically controlled areas.

2. State what equipment will be used to transport the waste into the radiologically controlled area.

a. For tractor trailer vehicles, state whether tractors other than facility tractors are allowed inside the controlled area. If not, state what the over-the-road driver is to do with his tractor and himself while waiting for the return of his trailer.

b. For single unit vehicles (e.g., cargo vans), state who is allowed to drive the vehicle into the controlled area. If only facility personnel are allowed to drive the vehicle into the controlled area, state what the driver is to do while waiting for his vehicle to return.

3. Include an instruction describing how the driver is informed of the disposal unit the vehicle is to be moved to, the route to be taken to that disposal unit, vehicle positioning, and other necessary information.

4. Include an instruction to the driver to proceed expeditiously by the safest and most direct route, following the instructions given. Remind the driver to observe all site speed limits and road signs. If applicable, entrance to the disposal unit itself may be controlled, in which case, state the title of the individual who can grant access into the disposal unit.

5. Include an instruction to off-load the waste according to the appropriate shipment off-loading procedure.

6. State the location to which the driver will take the vehicle after the waste is off-loaded and the route to that location. 
7. The transport vehicle release survey procedure can be referenced at the end of this procedure, as it is the next logical procedure in the process.

\subsection{Disposal Unit Operations-}

5.3.4.1.2.1 Canister Emplacement-The purpose of this procedure is to describe the steps by which empty concrete canisters are placed in the disposal units prior to being loaded with waste. This procedure is limited to the placement of the canisters in a disposal facility that uses canisters and does not put waste in them until they have been placed at their permanent location.

The following elements should be included in the instructions for the procedure:

1. State the titles of individuals at the facility who will perform this procedure.

2. Include an instruction to ensure that the disposal unit is configured to accept the next concrete canister prior to off-loading it from the truck.

3. A form might be provided to document the fact that the canister was inspected prior to emplacement and the placement location of the canister.

4. Describe in a series of instructions how the canisters should be placed in the disposal unit, considering:

a. Positioning the crane so it can easily reach the intended location of the canister.

b. Positioning the canister shipment truck where the crane can reach the canister on the truck.

c. Inspecting the hydraulic and structural integrity and documenting the inspection.

d. Labeling the canister: One method is to assign a unique number to the canister and paint that number on the canister so it is visible regardless of its orientation.

e. Achieving the desired spacing between canisters: One method is to provide some type of spacer wrapped around each canister. The spacer would have to be removable so it would not interfere with backfilling between the canisters.

f. Visually inspecting cables, hooks, and lifting loops for damage.

g. Attaching the crane rigging to the canister: If it is attached manually, describe how the worker accesses the attachment devices. For example, a customized ladder could be provided for climbing the sides of large cylindrical canisters.

h. Cautioning personnel to maintain a safe distance from suspended canisters. 
i. Placing the canisters: The crane operator should be directed to lift the canisters only as high as necessary. Also, a worker may be needed to approach the suspended canister (when it is not swinging and nearly in place) to help position it.

j. Removing the crane rigging attachments from the canister.

5. Describe in a series of instructions how lids, if any, are placed on the canisters. The process will be very similar to that used to put the canisters in place. At this point, lids may only be temporary devices to keep precipitation and debris out of empty canisters; lids that will be placed on the canisters permanently after they are filled might also be used as temporary lids.

5.3.4.1.2.2 Waste Shipment Off-Loading-The purpose of this procedure is to describe the steps for off-loading waste packages at the disposal facility. Depending on the design of the disposal facility and the nature of the transporting vehicle, a crane or a forklift will probably be used to lift the waste packages.

It is possible, depending on the facility procedure, that waste inspections could occur prior to arrival of the package at the disposal unit where it will finally rest. However, this annotated procedure assumes that waste inspection occurs for the first time in the disposal unit, after completion of the unloading procedure.

The following steps should be followed and elements included in the instructions for the procedure:

1. State the titles of the individuals at the facility who will perform this procedure.

2. Include a series of instructions on preparation for waste shipment off-loading, considering:

a. Positioning the lifting equipment: The crane or forklift should be positioned in the disposal unit where it can reach the disposal location where the waste will be placed. This positioning is not so important for a forklift because of its mobility; however, it is critical for a crane because a crane should avoid extending its boom to a nearly horizontal angle.

b. Contamination release prevention: For example, a high density polyethylene membrane could be placed at the point where the waste will be inspected to prevent releases from the waste packages from contaminating that location. Include instructions on maintaining the contamination release prevention measures, if applicable. (A plastic membrane would require periodic replacement and would have to be replaced if it were punctured or contaminated.)

c. Positioning the waste shipment truck: The truck should be positioned to facilitate off-loading and be within the reach of the crane.

d. Determining the type of waste: It is important to know if the waste has a high radiation exposure rate, since its handling during off-loading may depend on the 
exposure rate. This can be determined from shipping information so the proper equipment can be assembled.

3. Include a series of instructions for off-loading all types of waste packages that may come to the disposal facility. For example, waste packages may be shipped bare or in casks and classified as high or low radiation exposure rate.

a. Off-loading pallets of drums or boxes shipped bare: Describe how the forklift should access the truck, remove the pallet of waste, and set it down.

b. Off-loading from casks (low radiation exposure rate waste): Include instructions to remove the lid bolts from the cask, attach the crane hoisting cables to the cask lid, inspect the lifting apparatus for damage (if damage is found, work should stop until repairs are made), remove the lid, set the lid down, attach the cables to the waste package, remove the waste package, and set it down.

c. Off-loading from casks (high radiation exposure rate waste): When off-loading high radiation exposure rate waste, if a shielding bell is used there will be additional steps to the process for off-loading the waste. Additional instructions will be needed to describe the use of the shielding bell. These instructions should describe how the bell is attached to the crane and how the waste package is drawn up into and lowered from the bell. Instructions should be included to ensure that unnecessary personnel keep far from the operation, especially when the bell containing waste is raised above the ground.

4. When the package is removed and set down, refer to the waste shipment acceptance procedure and the placement of waste in canisters procedure. State what actions should be taken if the waste package is unacceptable per the waste shipment acceptance procedure, such as referencing the waste containers not acceptable upon arrival procedure.

5.3.4.1.2.3 Placement of Waste in Canisters-The purpose of this procedure is to describe the steps by which waste is placed in disposal canisters. The canisters are viewed as oversized packages that can receive drums, liners, boxes, etc. and may, by themselves, provide structural stability. Whether such canisters will be used at a specific facility will depend on the design of the facility.

The following steps should be followed and elements included in the instructions for the procedure:

1. State the titles of the personnel at the facility who will perform this procedure.

2. This procedure lends itself well to using a form that documents the origin and destination of the waste. For example, the form could contain information such as the transport container I.D. number, waste generator, disposal unit, final canister location in a disposal unit, date of emplacement, and appropriate signatures. 
3. This procedure typically involves lifting heavy objects using a crane and associated lifting apparatus. Include instructions to inspect the lifting apparatus for damage anytime a step requires lifting. State that work should stop if damage is discovered and should not resume until it is repaired.

4. Include instructions for positioning the crane, canister, and waste package before attaching the crane to the waste package.

5. Include a series of instructions for the emplacement of low radiation exposure rate waste considering:

a. Attaching the crane cables to the lid of the canister, if a lid is in place before the waste is to be put in the canister.

b. Removing the lid from the canister and setting it down out of the way.

c. Attaching the crane hoisting cables to the waste package.

d. Raising the waste package and positioning it over the canister.

e. Cautions for handling and positioning the waste packages. For example, waste packages should not be allowed to drop or jam in the canisters.

f. Disconnecting the hoisting cable from the waste package. To minimize personal exposure, this step may require special attention, as it may not be desirable to climb atop the packages and remove the cables manually.

6. Include a series of instructions for the emplacement of high radiation exposure rate waste in the disposal canisters. When emplacing high radiation exposure rate waste, a shielding bell may be used to protect personnel from radiation. Incorporate additional instructions that describe the use of the shielding bell. These instructions should describe how the package with the shielding bell over it is raised and handled around the canisters to prevent damaging them. It should also specify that all non-essential personnel stay as far away from the waste as possible, even when it is covered by the shielding bell, and especially when the waste and bell are raised off the ground.

7. Include separate steps for completing any forms. Those steps should include the titles of the forms and the titles of individuals completing them.

8. State that the canisters should be filled with grout, if this is part of the design, as soon as possible after they are full. Refer to a grouting procedure. If the canisters have separate lids, note that the lids should be put in place as soon as possible while awaiting grouting.

5.3.4.1.2.4 Grouting-The purpose of this procedure is to describe the steps for pouring grout into the spaces between waste and a canister that may be used to overpack the waste. After the grouting, pre-cast lids may be placed on the canisters, or cast-in-place lids may be constructed. 
The latter may be considered as extensions of the grouting operation and activities for their construction are also described here.

The following steps should be followed and elements included in the instructions for the procedure:

1. State the titles of individuals at the facility who will perform this procedure.

2. Include a series of instructions for placing the grout in the canister around the waste, considering:

a. Inspection of the grout to ensure it meets specifications.

b. The method for conveying the grout to the inside of the canister. For example, is the grout pumped through a tremie pipe or dumped from a crane dump bucket?

c. The amount of space to be left to accommodate a lid. Refer to the design dimensions of the disposal canister and then specify the amount of space to be left.

d. Vibrating the grout as it is being poured so that all void spaces around the waste package are filled.

e. Finishing the top of the grout surface.

f. Covering the canister to prevent rain and debris from entering as the grout hardens.

g. The amount of time required for the grout to cure sufficiently to receive a cast-in-place roof, if one is to be used.

h. Verification that the grout is cured sufficiently.

3. In designing the grouting procedure, care must be taken to minimize radiation doses to workers.

4. If a pre-cast concrete lid is to be placed on the canister after grouting, include a series of instructions for placement. These instructions would include descriptions of how the lid is lifted, how it is lowered in place, and how it is sealed and attached to the canister.

5. Some designs may use a cast-in-place concrete cover constructed after grouting. If this is the case, include a series of instructions for constructing the cover, considering:
a. Inspection of any steel re-bar that may be used for possible damage
b. Proper placement of any re-bar
c. Inspecting the concrete mix to ensure it meets the design specifications 
d. The amount of concrete to be placed

e. Finishing the top of the concrete cover

f. Covering the wet concrete to prevent rain and debris from harming the finished surface while it is curing.

5.3.4.1.2.5 Sand and Gravel Fill-The purpose of this procedure is to describe the steps by which the voids around the waste containers that have been placed in a disposal unit are filled.

The following steps should be followed and elements included in the instructions for the procedure:

1. State the titles of individuals at the facility who will perform this procedure.

2. Describe how the equipment will access the area of the disposal unit where fill activities will take place. In some cases, multi-phased operations may be required. For example, the equipment specified to conduct normal fill operations may not be usable at all stages of filling the disposal units. Therefore, other equipment and different backfill processes may be required at times. Consequently, a series of subprocedures may be specified.

3. Describe, in a series of instructions, the process used to get the sand or gravel in place in the disposal unit, starting with its removal from stockpiles.

a. Sand and gravel emplacement will probably be accomplished using one or a combination of dump trucks, front-end loaders, bulldozers, and cranes with dump buckets. Include design-specific details about how thick each lift of material is placed before it is compacted and differences in material from one location to another in the disposal unit. For example, the material between the disposal containers may be different from that placed on top of the containers. Also include instructions on how to use special devices. For example, an extension pipe could be used on a crane dump bucket to better direct the material to its desired location between canisters that are close to each other.

4. If needed, describe how compaction of sand and gravel will be accomplished. Generally, the larger the grains of material, the less compaction required. Refer to the facility design specifications for the required compaction for the subject material. Refer to a compaction procedure if one exists.

5. State how inspection of the compacted areas will be accomplished. The sand cone test and the nuclear density gauge are two possible compaction inspection methods.

6. Documentation is commonly required for testing of compaction; in those cases, include separate steps for completing forms verifying that the desired compaction and other in-placed material properties have been achieved. These steps should state the title of the form and the individual completing it. 
7. Describe how the surface of the sand and gravel fill will be finished. This process will depend on the design of the facility. For example, where large concrete canisters are emplaced in layers, fill placed on top of the lower layers of canisters will probably require to have a firm, level surface to support the upper layers of canisters.

8. Include warnings stating restrictions on equipment allowed on top of different material layers, to prevent damage to the in-place material or the disposal containers below.

5.3.4.1.2.6 Temporary Cover Placement-The purpose of this procedure is to describe the steps by which temporary covers will be placed over the filled and closed canisters in the disposal units.

The temporary cover will be placed after a certain amount of progress has been made in the disposal unit. Progress will depend on the design. Some designs use a working face with on-going waste emplacement and covering. Other designs place the cover system after waste emplacement is finished. The temporary cover will serve two purposes: preventing water infiltration and providing a radiation barrier.

The following steps should be followed and elements included in the instructions for the procedure:

1. State the titles of individuals at the facility who will perform this procedure.

2. Some designs use a geomembrane material in the cover system to prevent precipitation from infiltrating into the disposal unit. If a geomembrane is included in the design, the following items should be addressed:

- The surface on which the geomembrane is placed: The surface should be smooth and compacted to prevent puncturing of the geomembrane from materials beneath, and to prevent tearing due to differential settlement.

- Anchoring: State how the geomembrane will be anchored at the sides of the disposal unit. Geosynthetic materials are usually secured in anchoring trenches that are sized according to the tensile strength of the material. Include specific dimensions of the anchoring trench and how it will be excavated.

- How the geomembrane will be rolled out: There may be an advantage to roll out the material in a certain direction depending on the design of the disposal unit.

- Seaming methods: Various methods exists for seaming geomembrane (e.g., fillet extrusion, hot air, ultrasonic). State the acceptable methods and reference manufacturer's recommendations.

- Securing the geomembrane from wind: For example, bales of straw or sand bags can be placed intermittently over the area of the geomembrane. 
- Runoff control: Because the geomembrane will prevent infiltration, it is necessary to provide a means to deal with the runoff the geomembrane creates.

3. Include a series of instructions describing how the various layers of soil in the cover system will be placed, considering:

a. The method used to distribute the soil. For example, a bulldozer may distribute the soil by pushing it, or a dump truck may distribute the soil by dumping while moving.

b. Layer and lift thicknesses: Reference the design drawings and specifications with instructions to maintain layer and lift thicknesses.

c. Compaction: Describe how compaction should be accomplished. Depending on the material, state whether compaction is necessary. The more granular the soil, the less compaction required. Refer to the specifications that state the required compaction for the subject soil. Refer to a compaction procedure if one exists.

1. State how inspection of the compacted areas will be accomplished. The sand cone test and the nuclear density gauge are two testing options.

2. Documentation is commonly required for compaction activities; therefore, include separate steps for completing forms. These steps should state the title of the form and the individual completing it.

d. Shape of the layer surfaces: A slope is usually specified for the surfaces of the soil layers. The slope is critical, especially for low permeability soils such as clay. Reference the drawings and specifications that detail such slopes. State how the sloping will be accomplished. For example, stakes may be driven to the specified elevations and used as guides for a grader operator.

1. An inspection may be necessary, using surveying instruments to ensure that the slopes were achieved within a specified tolerance.

e. Include warnings stating what types of equipment are allowed on specific layers in order to avoid damaging already placed layers.

\subsection{Other Routine Operations-}

5.3.4.1.3.1 Disposal Unit Closure-The purpose of this procedure is to describe the steps by which disposal units will be permanently closed using a multi-layer cap, engineered to prevent percolating water from reaching the waste. If concrete vaults are used for disposal, closure activities for them, such as putting a permanent roof on a vault, would be similar to the construction of the vault and may be covered in another, separate closure procedure.

The following steps should be followed and elements included in the instructions for the procedure: 
1. State the titles of individuals at the facility who will perform this procedure.

2. Include an instruction to remove any objects, such as bales of straw or sand bags, that may have been part of a temporary cover but will not be part of the permanent cover.

3. Include a series of instructions describing how to place the various layers of materials in the cover system. A separate series of instructions may be needed for each layer. These instructions should consider:

a. The method used to place the cover materials. For example, they may be distributed by a bulldozer pushing them from a pile, or by dumping them from a truck.

b. Layer and lift thicknesses: Reference the design drawings and specifications with instructions to maintain layer and lift thicknesses. (A lift is the amount of soil placed between compaction events.) Lift thicknesses should be specified to maintain the desired compaction.

c. Compaction: If necessary, describe how compaction of natural materials should be accomplished. Generally, the more granular the material, the less compaction required. Refer to the specifications that state the required compaction for the subject material. Refer to a compaction procedure if one exists.

State how inspection of the compacted areas will be accomplished. Two compaction testing options are the sand cone test and the nuclear density gauge.

Documentation is commonly required for testing of compaction; in those cases include separate steps for completing forms verifying that the desired compaction and other in-place material properties have been achieved. These steps should state the title of the form and the individual completing it.

d. Shape of the layer surfaces: A slope is usually specified for the surfaces of the layers. The slope is critical, especially for low permeability materials such as clay. Reference the drawings and specifications that detail such slopes. State how the sloping will be accomplished. For example, stakes may be driven to the specified elevations of the top of the layer and used as guides for a grader operator.

An inspection may be necessary, using surveying instruments to ensure that the slopes were achieved within a specified tolerance.

e. Include warnings stating restrictions on equipment allowed on the top of different layers in order to prevent damage to the in-place material in each layer.

4. Some designs may use a geomembrane (impermeable) material in the cover system to prevent precipitation from infiltrating into the disposal unit, or geofabric (permeable) material to prevent infiltration of fine materials into coarse materials. If either is included in the design, the following items should be addressed: 
a. The surface on which the geomembrane or geofabric is placed: The surface should be smooth and compacted to prevent puncturing of the geomembrane or geofabric by materials beneath and to prevent tearing due to differential settlement.

b. Anchoring: State how the geomembrane or geofabric will be anchored at the sides of the disposal unit. Synthetic materials are usually secured in anchoring trenches that are sized according to the tensile strength of the material. Proper sizing ensures that the material will remain properly stretched without allowing it to tear. Include specific dimensions of the anchoring trench and how it will be excavated and closed.

c. How the geomembrane will be rolled out: It may be advantageous to roll out the material in a certain direction, in order to have the seams running in that direction, depending on the design of the disposal unit.

d. Seaming methods: Various methods exist for seaming geomembrane and geofabric (e.g., fillet extrusion, hot air, ultrasonic). State the acceptable methods and reference manufacturer's recommendations.

e. Securing the geomembrane or geofabric from wind if it is to be uncovered for a while: For example, bales of straw or sand bags can be placed intermittently over the area of the geomembrane.

f. Runoff control: Because a geomembrane will prevent infiltration, it is necessary to provide a means to deal with runoff from it.

5.3.4.1.3.2 Onsite Generated Waste Disposal-The purpose of this procedure is to describe the steps by which any low-level radioactive waste generated during normal operations at the disposal facility is classified, packaged, and disposed of. Low-level waste that results from accidents may not be covered by this procedure. It is assumed for the purpose of this procedure that the onsite generated waste does not present a high radiation exposure hazard.

The following elements should be included in the instructions for the procedure:

1. State the titles of individuals at the facility who will perform this procedure.

2. Include a series of instructions that describe how the onsite generated waste is collected, considering:

- Containers in which waste will be placed and how those containers will be marked.

- A policy for keeping the containers closed. For example, if the containers are fifty-five gallon drums filled ones should have lids securely fastened, and partially filled drums should have lids in place and weighted down.

- Handling emergency cleanup or contaminated shipment wastes that may be appropriate for this procedure. Any differences in ways these wastes are handled from the way typical onsite generated wastes are handled should be mentioned. For 
example, how will partially filled drums of cleanup waste be filled before they are closed?

- A designated waste classification area: An area should be provided where the waste can be classified.

3. Include a series of instructions that describe how the waste is prepared for proper onsite disposal, considering:

a. Waste classification: Describe how the waste will be classified. Reference a classification procedure if one exists.

b. Documentation: The classification that was determined in the previous step should be documented. Include separate steps for completing forms for tracking onsite generated waste. These steps should state the title of the form and the individual completing it.

c. Waste stabilization: Depending on the classification determined earlier, it may be necessary to stabilize the waste. Describe how this will be done or reference a separate procedure on waste stabilization.

d. Waste storage: If the waste will not be placed in a disposal unit promptly, refer to a procedure on temporary waste storage.

5.3.4.1.3.3 Temporary Storage of Low Radiation Exposure Rate Waste-The purpose of this procedure is to describe the steps by which low radiation exposure rate waste is temporarily stored. Storage may be necessitated by some minor discrepancy identified in the process of receiving the waste, one that is expected to be easily resolved and doesn't involve external contamination on the waste packages. Onsite generated waste may also be stored until a sufficient number of waste packages is collected for disposal.

The following elements should be included in the instructions for the procedure:

1. State the titles of individuals at the facility who will perform this procedure.

2. Include a list of instructions that describe how the waste will be assigned to a storage area, considering:

a. Radiation exposure rates: State a maximum allowable exposure rate level, measured at stated distances from the waste package surface, that determines whether waste can be stored in the temporary storage area for low radiation exposure rate waste. If the radiation exposure rate is greater than the maximum allowable level, refer to a procedure for storing high radiation exposure rate waste.

For waste shipped in casks, whether the waste is "low radiation exposure rate" waste should be determined from the shipment manifest. Relying on the manifest will 
prevent unnecessary worker exposure that might occur if direct measurements were conducted.

b. Waste class. All Class B and C waste may be stored with high exposure rate wastes regardless of the radiation exposure rate.

c. Operational safety.

3. Include a list of instructions that describe how the waste will be removed from the transport vehicle and placed in its storage location, including:

a. Positioning the waste shipment truck: Describe how the truck should be positioned depending on the design of the storage area. For example, the truck may have to be positioned at a dock where a forklift could access it.

b. Removing the waste from the truck: For example, if the equipment used to remove the waste is a forklift, a description would be included of how the forklift would remove the waste from the truck.

c. Inspection: Include an instruction to inspect the waste package to ensure that it is acceptable for storage. Reference the applicable inspection procedures and state the location where the inspection will be performed, such as the loading dock.

d. Location of storage: State how the location within the storage area where the waste will be stored will be determined. Indicate who will designate that location.

e. Documentation: Include separate steps for completing forms verifying the location of storage and other information characterizing the waste. These steps should state the title of the form and the individuals completing it.

f. Radiation levels: Depending on the waste and the storage location, waste in temporary storage may elevate radiation levels at the facility boundary. Include instructions describing how often the storage area boundary and the facility boundary should be surveyed. For example, the storage area boundary could be surveyed for gamma radiation every time waste is added to storage, and the facility boundary could be surveyed at stated intervals. State maximum allowable radiation levels for these boundaries.

5.3.4.1.3.4 Temporary Storage of High Radiation Exposure Rate Waste-The purpose of this procedure is to describe the steps by which high radiation exposure rate waste is temporarily stored. Storage of this kind of waste may take place at a relatively remote location on the disposal facility. Storage may be necessitated by some minor discrepancy identified in the process of receiving the waste, one that is expected to be easily resolved and doesn't involve external contamination on the waste packages.

The following steps should be followed and elements included in the instructions for the procedure: 
1. State the titles of individuals at the facility who will perform this procedure.

2. Include a list of instructions that describe how the waste will be assigned to a storage area, considering:

a. Radiation exposure rates: State a maximum allowable exposure rate level, measured at stated distances from the waste package surface, that determines whether waste can be stored in the temporary storage area for low radiation exposure rate waste. If the radiation exposure rate is greater than the maximum allowable level, then it must be stored in the location designated for storing high radiation exposure rate waste.

For waste shipped in casks, whether the waste is "low radiation exposure rate" waste should be determined from the shipment manifest. Relying on the manifest will prevent unnecessary worker exposure that might occur if direct measurements were conducted instead.

b. Waste class. All Class B and C waste may be stored with high exposure rate wastes regardless of the radiation exposure rate.

c. Operational safety.

3. Include a list of instructions that describe how high radiation rate waste will be off-loaded in the storage area, considering:

a. Positioning the lifting equipment: The crane that will lift the waste should be positioned in the storage area where it can reach the location where the waste will be stored. This positioning is critical because a crane should avoid extending its boom to a nearly horizontal angle.

b. Contamination release prevention: Waste packages may be inspected after removal from a transport vehicle and before storage or disposal. If the facility requires inspection, some type of contamination release prevention practice should be in place. For example, a high density polyethylene membrane could be placed at the point where the waste would be inspected to prevent releases from the waste packages from contaminating that location.

c. Positioning the waste shipment truck: The truck should be positioned to facilitate off-loading and be within the easy reach of the crane.

d. Accommodations for retrieval of stored waste: Because the waste must be retrieved in the future, it is not advisable to stack waste packages in the high radiation rate waste storage area. If special devices are required, such as adjustable stands used to facilitate retrieval of the waste packages, describe them and how they are to be placed and used. 
e. Shielding: When off-loading high radiation exposure rate waste employing a shielding bell, additional steps will be needed to describe shielding bell use. These instructions should describe how the bell is attached to the crane and how the waste package is drawn up into and lowered from the bell. Instructions should be included to ensure that unnecessary personnel keep far from the operation, especially when the bell containing waste is raised above the ground.

4. Include a list of instructions that describe how high radiation rate waste will be emplaced, considering:

a. Accessing the storage location: Describe how to access the specific storage location, depending on the design of the storage area.

b. Handling and positioning the waste packages: Describe how the waste packages should be handled and positioned depending on the design of the storage area. Include cautions about minimizing personnel exposure and preventing damage to the waste package or storage area.

5. Include separate steps for completing any forms. These steps should include the titles of the forms and the titles of the individuals completing them.

5.3.4.1.3.5 Temporarily-Stored Waste Disposal-The purpose of this procedure is to describe the steps for the disposal of waste into the active disposal unit from both the low and high radiation rate waste storage areas.

The following steps should be followed and elements included in the instructions for the procedure:

1. State the titles of individuals at the facility who will perform this procedure.

2. Include a series of instructions describing how waste will be removed from the low radiation rate waste storage area, considering:

a. The criteria for when waste should be removed from this area: This criteria will probably depend on the design of the disposal containers. For example, if the disposal containers were designed to hold pallets of a certain number of drums, then a logical criterion would be the accumulation of that number of drums.

b. Positioning the waste transfer vehicle: Describe how the vehicle that will take the stored waste to the disposal unit should be positioned depending on the design of the storage area. For example, the vehicle may have to be positioned at a dock where a forklift could access it directly.

c. Loading the waste onto the transfer vehicle: For example, if the equipment used to load the waste is a forklift, include a description of how the forklift will load the waste onto the vehicle. 
d. At the end of this series of instructions, refer to procedures for waste inspection, if necessary, and placement of waste in the disposal unit.

3. Include a list of instructions describing how waste will be removed from the high radiation rate waste storage area, considering:

a. Positioning the lifting equipment: The crane used to remove the waste should be positioned where it can reach the storage location where the waste was placed. This positioning is critical because a crane should avoid extending its boom to a nearly horizontal angle.

b. Positioning the waste transfer vehicle: The vehicle should be positioned to facilitate loading and be within easy reach of the crane.

c. Loading from remote storage: When loading high radiation rate waste employing a shielding bell, additional steps to the process will be needed to describe shielding bell use. These instructions should describe how the bell is attached to the crane and how the waste package is drawn up into and lowered from the bell. Instructions to ensure that unnecessary personnel keep far from the operation, especially when the bell containing waste is raised above the ground, should be included.

d. At the end of this series of instructions, refer to procedures for waste inspection, if inspection is necessary, and placement of waste in the disposal unit.

4. Postretrieval inspection of the high radiation rate waste storage area, considering:

a. Describe inspection of any devices used in the high radiation rate waste storage area, such as adjustable stands or spacers used to facilitate retrieval of the waste packages. Include instructions to ensure that these devices are in place for future use of the high radiation rate waste storage area.

b. Include instructions to ensure that the high radiation rate waste storage area is free of contamination in preparation for using it again.

5. Include separate steps for completing forms documenting the removal from storage. These steps should state the titles of the forms and the individuals completing them.

5.3.4.2 Nonroutine Operations. The purpose of this procedure is to describe a process for preparing new, special procedures that ensure the health and safety of workers and the general public. New procedures may be needed, for example, if a waste generator has an unusual package of waste that needs disposal. An unusual package of waste may be one that has weight, shape, size, or radiation exposure rate that is different from those anticipated in normal handling procedures.

The following steps should be followed and elements included in the instructions for the procedure:

1. State the titles of individuals at the lacility who will perform this procedure. 
2. Include a list of instructions about gathering data needed to develop a new procedure. These instructions should state the types of data necessary, such as:

a. Information about the anticipated new operations: This data could come from surveys, shipping documents, interviews with experienced personnel, or review of safety analysis reports.

b. Important characteristics of the waste package such as weight, shape, etc: Particular emphasis should be placed on extraordinary radiation risks.

c. How the waste package will fit in a disposal container: For example, special inserts or other devices that may be necessary.

d. How the waste shipment will be removed from the shipping vehicle: Special attachment points or rigging may be required.

e. Additional shielding or remote handling equipment needed if extraordinary radiation risks exist.

3. Include a list of instructions describing how to develop a new operating procedure, considering:

- Discussing the sequence of activities with the operations crew before writing the procedure, then having them review it to ensure its feasibility and practicality.

- Identification of personnel who will be responsible for performing the procedure.

- $\quad$ Special equipment required.

- Occupational and radiological safety precautions.

- Applicable regulations, standards, design requirements, or specifications.

4. A rehearsal, using non-radioactive materials, of any new procedure may be desired. The procedure could be rehearsed to determine exposure rates, safety concerns, or difficulties that could be encountered. For example, a mockup could be created of the part of the disposal unit where the procedure would be executed. All personnel involved in implementing the procedure could be briefed before the rehearsal. The rehearsal could be observed to improve safety and performance in case the procedure is used again. All personnel could be debriefed to discuss lessons learned for inclusion in the draft procedure.

5. Include a list of instructions describing how the draft procedure would be reviewed, considering:

a. Analyzing each step for methods to maintain radiation doses as low as reasonably achievable for the operation. 
b. The maximum exposure the operation could cause under normal conditions (e.g., barring an accident).

c. Refining the sequence of steps and precautions.

6. Describe how the reviewed procedure would be approved. State the titles of all individuals from whom written approval should be obtained.

7. Describe how to follow up on execution of the procedure. This could include specific plans to observe the procedure and even take special measurements of key parameters such as dose rates. If the execution of the operation proved to be satisfactory and generated no unexpected radiation exposure, the operation could be designated "routine" and the new procedure placed on file in case the same situation arises again.

\subsubsection{Emergencies}

\subsubsection{Organization for Emergencies.}

5.3.5.1.1 Emergency Response Team-This procedure describes overall emergency planning and the organization of the Emergency Response Team that will respond to any emergency at the waste disposal facility. It applies to all emergency situations at the disposal facility, including those involving radioactive material releases, fires, personal contamination and injuries, weather-related incidents, and security incidents. This procedure delineates responsibilities of the Emergency Response Team for the spectrum of potential emergency situations at the facility. The Emergency Response Team may be comprised of several specialty teams that could include a Radioactive Materials Incident Response Team, a First Aid Response Team, a Security Response Team, and a Fire Response Team. Individual procedures are typically provided for incidents that would be addressed by each of the specialized teams. In addition, a separate procedure may address training and drills.

The following steps should be followed and elements included in the instructions for the procedure:

1. State the titles of the individuals at the facility performing the various functions in the response teams. Describe the succession of authority so each specialty team leadership position will have an alternative person and a backup person for the alternative who is prepared to take over leadership responsibility.

2. Describe actions to be taken by, and the responsibilities of, the first person on the scene of an emergency. This could include assessing the situation, providing lifesaving first aid, requesting additional support, and evaluating and securing the immediate area.

3. State the titles of individuals who should be notified in case of an emergency in addition to the Emergency Response Team and state acceptable modes of communication (e.g., radio, voice, telephone, or alarm). 
4. Define the responsibilities of the first Emergency Response Team member to arrive at the scene. Typically, this will involve quickly assessing the incident to determine the scope of the emergency, including, for example:

a. Determining if there is a fire. If so, determining the type of fire.

b. Identifying other apparent hazards such as radiation, chemicals, flammables, etc.

c. Determining if there are victims. If so, the types of injuries are also important.

d. Providing as much accurate information concerning the incident scene as possible, to allow a preliminary assessment of the emergency scene before the response team arrives.

e. Responding to the emergency using available resources.

5. Define the responsibilities of the Emergency Response Team Leader, including, for example:

a. Assessing the emergency

b. Determining the need to shelter personnel in place (closing windows and doors) or evacuate the site

c. Determining the need for additional help, such as offsite resources

d. Establishing a command post and staging areas for incoming equipment

e. Rescuing personnel

f. Developing an action plan

g. Determining what materials are involved

h. Assessing potential utility hazards

i. Notifying appropriate onsite and offsite management personnel about the incident

j. Developing a recovery plan

k. Directing incident followup (e.g., investigation, remediation, and environmental monitoring)

1. Directing all requests for information about the incident to the proper individuals. 
6. Define the responsibilities of the Facility Emergency Director, including, for example:
a. Determining if site closure is necessary
b. Requesting aid from offsite sources
c. Notifying regulatory agencies.

7. Define the responsibilities of the Chief of Security, including, for example:

- Serving as leader of the First Aid Response Team

- Assuring that all security officers are properly trained in emergency medical techniques and cardiopulmonary resuscitation

- Providing general orders and direction to security officers and site personnel during security emergencies

- $\quad$ Providing security expertise.

8. Define the responsibilities of the security officers, including for example:

- Safeguarding personnel

- $\quad$ Directing evacuations

- $\quad$ Acting as liaison between the emergency scene and facility authorities.

9. Define the responsibilities of the First Aid Response Team members, including, for example, administering basic first aid and cardiopulmonary resuscitation. All personnel working in remote areas of the facility should be trained as First Aid Response Team members.

10. Define the responsibilities of the Health Physics Supervisor, including, for example:

a. Directing the activities of the Radioactive Materials Incident Response Team

b. Acting as a liaison between the radioactive materials spill scene and facility authorities

c. Clearing and physically securing the spill area

d. Establishing a controlled area around any contaminated area

e. Recording the names of personnel entering and leaving the controlled area and radiation doses received during emergency operations 
f. Setting up monitoring and decontamination stations.

11. Define the responsibilities of the Radioactive Materials Incident Response Team, including, for example:

a. Containing any spill or release

b. Separating injured, contaminated, and exposed personnel for immediate treatment

c. Obtaining and supervising the use of radiation survey instrumentation, personal protective equipment, and respiratory protection

d. Setting up air samplers

e. Interviewing witnesses to determine radiation sources involved and, if possible, obtaining manifests for the wastes involved.

12. Include separate steps for completing any forms. Those steps should include the titles of the forms and the titles of the individuals completing them.

5.3.5.1.2 Emergency Response Training and Drills-The purpose of this procedure is to outline the training program required for the disposal facility's Emergency Response Team and the methods for planning and conducting drills and exercises. This procedure applies to all facility personnel who are members of the Emergency Response Team or who may be involved in drills or exercises.

The following steps should be followed and elements included in the instructions for the procedure:

1. State the titles of individuals at the facility who will perform this procedure and their responsibilities, such as implementing training, conducting drills, delegating authority, and planning and evaluating drills and exercises.

2. Describe in a series of instructions how the Emergency Response Team training will be conducted, considering:

a. Training effectiveness evaluation: State the minimum acceptable percentage on test scores for passing. Describe a method for retesting.

b. Hands on activities: Note that the training should include opportunities to use fire-fighting, spill cleanup, and first-aid equipment.

c. Basic training: Include the basic 40-hour Hazardous Waste Operation and Emergency Response Training, special firefighting and first aid/CPR courses, and all other courses required.

d. Annual refresher courses: Describe refresher courses for all training. 
3. Describe in a series of instructions how drill and exercise planning will be conducted, considering:

- Orientation drills: Include an instruction to conduct orientation drills to familiarize the staff with facility procedures, such as building evacuation drills.

- Tabletop exercises and walk-throughs: Tabletop exercises and walk-throughs are invaluable in providing properly learned responses to actual casualty situations. Include instructions for all participants to meet and discuss what they would do in a real emergency and to conduct a physical walk-through of the drill at a planned location.

- Functional drills and exercises: Describe how a drill or exercise will test a specific function. For example, a fire drill could be used to test the Fire Response Team's function and the success of a building evacuation.

- Full scale exercises: Describe how full scale exercises will be used to cover complicated scenarios where multiple response teams are needed to deal with fire, injuries, contamination, or other issues. The full scale exercises are usually preceded by tabletop exercises and walk-throughs and are usually a combination of functional exercises with multiple teams.

- Drill and exercise schedule: State the frequency of drills and exercises. State the scenarios that should be represented in these drills.

- State that drills combining scenarios should be encouraged.

4. Describe how the drills and exercises will be evaluated. Drills and exercises should be evaluated by personnel who are familiar with the activity and have a knowledge of the type of drill, objectives, and scenario. They should evaluate the thoroughness of the drill and whether the objectives were satisfactorily met. Other observations, both positive and negative, should be provided as lessons learned.

5. Describe how drills and exercises should be critiqued, considering:

a. Timing of the critique: It should be conducted as soon as possible with all participating personnel in attendance.

b. Scope of the critique: The entire drill should be discussed, from problem areas and proper actions to comments for improvement and lessons learned.

c. Documentation of the critique: The critique should be documented. The documentation should include items such as a list of personnel attending the exercise, lessons learned, problem areas, and areas that worked well.

6. Include separate steps for completing forms and other documentation. These steps should include the titles of the forms and the titles of the individuals completing them. 


\subsubsection{Major Emergencies.}

5.3.5.2.1 Radioactive Materials Releases-The purpose of this procedure is to describe steps to follow in the event of a release of radioactive materials at the disposal facility. These steps are intended to minimize the radiologic impacts of such a release, to restore the environment, and to return the facility to normal operation as expeditiously as possible. Response to releases that occur offsite or during transport are not covered in this procedure.

The following steps should be followed and elements included in the instructions for the procedure:

1. State titles of individuals at the facility who will perform this procedure.

2. State the responsibilities of any individuals who would be involved in responding to a radioactive materials release. Examples of facility personnel titles are used below.

a. Those who discover the release: State the title of the individual to whom their findings should be reported.

b. The incident commander: Identify this person and the titles of individuals to whom he or she should report. State other responsibilities, such as directing the activities of the radioactive materials incident response team, evacuating and securing the area, establishing and operating a contamination control point and boundary, and setting up a $\log$ book for personnel entering and leaving the scene.

c. The facility emergency director: Identify this person and the titles of the individuals to whom he or she should report. State other responsibilities, such as notifying all facility personnel, suspending normal operations, evacuating personnel, accounting for all personnel, notifying appropriate offsite authorities, and directing the appropriate individuals to screen traffic entering the facility.

d. The radioactive materials incident response team: Identify the team members by name or by job title. Describe the actions the team should perform, such as containing the release; separating injured, contaminated, or exposed personnel; obtaining and using radiation survey instruments and personal protective equipment; locating gross hazards; setting up samplers; and interviewing witnesses.

e. The health physics supervisor: Describe the actions he or she should perform, such as determining the nature and extent of the incident, the location, the radionuclides involved, the potential for escalation of the release, the quantity of materials involved, the wind direction and speed, potential exposures, the intensity or potential for fire, the proper method for firefighting (if needed), and the need for additional assistance.

f. Other senior managers: Describe the actions other senior managers should perform, such as providing necessary operating equipment and clean clothing, invoking appropriate decontaminating procedures, and determining when emergency remedial 
activities are completed and when normal operations will resume. Each activity should be linked to a specific manager.

3. State the responsibilities of various facility personnel for actions after the critical portion of the emergency release has passed, such as:

- Collecting and containerizing all recovered released material

- Ensuring that all equipment used in the emergency is decontaminated and fit for normal use

- Collecting and containerizing all personal protective equipment (e.g., gloves and protective clothing)

- Cleaning respiratory protection equipment

- Collecting, decontaminating, and inspecting all respiratory protection equipment

- Inspecting fire extinguishers before placing them back in service.

4. Additional, more detailed instructions may be included for specific activities, such as containing releases to surface water.

5. Include separate steps for completing any forms. Those steps should include the titles of the forms and the titles of the individuals completing them.

5.3.5.2.2 Fires-This procedure describes actions to be taken in the event of a fire. It describes the responsibilities of facility employees and the Fire Response Team and fire response procedures.

The following elements should be included in the instructions for the procedure:

1. State the titles of individuals at the facility who will perform this procedure.

2. Describe the actions that should be taken by all employees who discover fires, considering:

a. Notification of the proper authorities: State the titles of the individuals to notify if a fire is discovered, and the proper modes of communication.

b. Pertinent information: List the types of information the employee should give to the authorities, such as his or her name, the nature of the fire, the location of the incident, information about the materials involved, and the degree of hazard to life, property, and the environment.

c. The location of assembly areas for employees in case of fire: Also state precautions to take when proceeding to the assembly arcas, such as traveling via a route that is generally upwind of the fire. 
3. Describe the actions to be taken by those who serve on the Fire Response Team, considering:

a. Assembly location: State the location where the team members should assemble. For example, the team members should assemble at the location of the fire, or at another designated location for those team members who cannot proceed directly to the fire expeditiously.

b. Getting the fire truck to the scene: State the title of the individual who is responsible for driving the fire truck with other necessary equipment to the scene.

c. The responsibilities of the first team member to the scene: State the responsibilities of the first team member to the scene, such as determining the type of fire, apparent hazards present, and any injuries, and reporting that information to the team leader.

d. Fighting the fire: Include any warnings in addition to instructions for fighting a fire, such as minimizing the volume of water used when radioactive materials are involved.

4. Describe the actions to be taken by the leader of the Fire Response Team, considering:

a. Assessment of the situation to determine if additional onsite or offsite resources are needed

b. Activation of other emergency response teams, such as those for first aid or radioactive materials release

c. Control of the fire scene and evacuating the immediate areas, or determining the need for shelter rather than evacuation

d. Establishing of a command post and staging areas

e. Oversight of rescue efforts

f. Firefighting and the control of potential radioactive material entrainment in the plume

g. Assessment of hazards from or to utilities

h. Verification of materials involved in the fire using sampling, records, labels, placards, or other information

i. Formulation of a recovery plan in order to expedite resumption of normal operations.

5. Describe the actions to be taken by the security officers considering:

a. Immediate actions to protect or safeguard personnel 

b. Execution of evacuations
c. Regulation of traffic
d. Assistance by other response teams.

6. Describe the actions to be taken by the first aid response team, including treatment of injuries to facility personnel and firefighters.

7. Describe the actions to be taken by the facility emergency director, considering:
a. Informing facility personnel of actions required as a result of the emergency
b. Notification to regulatory agencies
c. Public relations
d. Site closure.

8. Describe the actions to be taken by other facility personnel, including:

a. Maintenance of the facility fire truck

b. Daily inspection of the fire truck to ensure it is fully equipped and functional.

9. Include separate steps for completing any forms. These steps should include the titles of the forms and the titles of the individuals completing them.

10. While such warnings may be a part of the prerequisites section, it is important to include warnings to be especially cautious about fighting fires where radioactive material may be involved.

\subsubsection{Other Accidents and Incidents.}

5.3.5.3.1 Personal Contamination or Injuries-This procedure describes the activities involved in assisting individuals at the disposal facility who are contaminated, injured, or ill. This procedure applies. to all personnel at the disposal facility who may become ill, contaminated, or injured, as well as their caregivers.

The following steps should be followed and elements included in the instructions for the procedure:

1. State the titles of individuals at the facility who will perform this procedure.

2. State the responsibilities of the individual who will serve as the leader of the First Aid Response Team, such as ensuring that all team members are properly trained in first aid, $\mathrm{CPR}$, and performing triage. 
3. State the responsibilities of the First Aid Response Team regarding personal contamination or injuries, such as rendering initial medical assistance and summoning ambulance service.

4. Describe the immediate actions that should be taken by appropriate facility personnel in the event of personal contamination or injuries that take place outside the radiologically controlled area, such as:

a. Notifying the proper authorities with pertinent information concerning the condition of the victim, known injuries, and potential rescue difficulties.

b. Administering first aid. Remind the givers of first aid that injured persons should not be moved until professional medical assistance is available unless an imminent hazard to the victim exists.

c. Determining if outside assistance is necessary.

d. Alerting an offsite medical transportation service.

e. Checking the injured person for contamination if time allows. Describe the actions to be taken if the victim is contaminated, such as performing decontamination or wrapping the contaminated areas to prevent the spread of contamination.

5. Provide general first aid guidelines for situations when victims:

a. Are unconscious.

b. Are not breathing.

c. Have a weak or slow pulse.

d. Have cuts and massive bleeding. Note: Regulations exist for Occupational Exposure to Bloodborne Pathogens (CFR 1910-1030) that will be of value in this case.

e. Are in shock.

f. Have fractured bones.

6. Describe the immediate actions that should be taken for individuals who are injured or contaminated inside a radiologically controlled area, such as:

a. Notifying proper authorities, including a health physics technician. Provide pertinent information concerning the condition of the victim, known injuries, and potential rescue difficulties. 
b. Determining the severity of the injury: State the title of the person on the First Aid Response Team who will determine the severity of the injury. Include a warning to not scrub wounds that may be radiologically contaminated.

c. Treating the injury: Include a suggestion to take special care to minimize the use of fluids and treat all flushing solutions as though they are contaminated and must be properly disposed of. Include instructions to check the wound, clothing, and victim for contamination, remove all contaminated clothing, and decontaminate the victim if practicable.

d. Preventing the spread of contamination: Include an instruction to wrap the victim in a blanket or something similar if they require immediate medical attention and cannot be decontaminated before treatment. If evacuation is necessary, cover the stretcher with a disposable cover, if practicable, and send a health physics technician to the hospital with the victim to alert medical personnel to the contamination.

e. Notifying the hospital with information about the individual who is enroute, such as their name, their employer, the nature of the injury, the estimated time of arrival, and the extent of radioactive contamination.

7. Include separate steps for completing any forms. Those steps should include the titles of the forms and the titles of the individuals completing them.

5.3.5.3.2 Weather-Related Incidents-This procedure deals with potential emergencies resulting from extreme natural phenomena that could affect the disposal facility, including conditions caused by floods, thunderstorms, winter storms, or other natural occurrences such as earthquakes. It outlines the actions to be taken by employees to protect themselves, their co-workers, the public, and the environment. This procedure describes hazards and provides protective action guidelines for use during weather-related emergencies.

The following elements should be included and steps followed in the instructions for the procedure:

1. State the titles of individuals at the facility who will perform this procedure, and the responsibilities they must undertake, including:

- All employees informing the security officer of their location when they are on site at times other than their regularly scheduled shift hours

- Gathering information to decide when facility closure is necessary due to adverse weather conditions

- Informing employees of their status as essential employees during temporary facility closure due to severe weather

- Notifying all shippers to discontinue shipments until further notice 
- Monitoring communications from all sources of information concerning sevcre weather

- Informing all facility personnel of recommended shelters and determining those areas at the facility that offer the greatest protection

- Establishing a command post and staging area for incoming emergency equipment

- Rescuing personnel

- Incident follow-up: Incident investigation, repair estimates, and environmental monitoring.

2. When considering tornadoes and wind storms, include instructions that address the following items:

a. Hazards: List the potential hazards of tornadoes and wind storms, such as high winds, falling objects, broken glass, electrical shock and power outages, and fire.

b. Preparation: List actions that should be taken in preparation for the storm, such as knowing the appropriate alert signal, securing waste containers, shutting equipment off, and lowering crane booms.

c. Tornado watches: List actions that should be taken during tornado watches, such as notification of the appropriate facility authorities, a general announcement starting the period of time for which the watch is in effect, and appropriate warnings, such as looking for dark funnel-shaped clouds.

d. Tornado warnings or actual tornado: List actions that should be taken during tornado warnings or actual tornadoes, such as a general announcement stating that a tornado has been sighted and appropriate instructions (such as ceasing outdoor operations and securing waste containers) notifying personnel in remote locations by telephone, proceeding immediately to safe shelter.

e. Recovery: List actions that should be taken following a tornado, such as preventing any contaminants that may have been released from contacting water supplies, a general announcement stating that the tornado or threat of a tornado has passed, accounting for all facility personnel and visitors, alerting emergency response teams to respond to emergencies, reporting all injuries or damages, assessing damages, initiating recovery plans and corrective measures, implementing emergency plans, prioritizing personnel needs and equipment repairs, and conducting radiation surveys.

3. When considering flooding, include instructions that address the following items:

a. Hazards: List the potential hazards of flooding, such as vehicle accidents, drownings, and erosion. 
b. Preparation: List actions that should be taken in preparation for flooding, such as staying out of low-lying areas and drainage areas.

c. Recovery: List actions that should be taken following a flood, such as assessing damage to the facility, roadways, or equipment and repairing such damage before resuming operations.

4. When considering lightning and thunderstorms, include instructions that address the following items:

a. Hazards: List the potential hazards of lightning and thunderstorms, such as electrical shock and power outages.

b. Preparation: List actions that should be taken in preparation for lightning and thunderstorms, such as grounding essential electrical functions, providing uninterruptable power supplies to computers, and personal protective measures.

c. Thunderstorms: List actions that should be taken during a thunderstorm, such as ceasing all outdoor activities, including crane operations and lowering the crane boom to its lowest position, taking cover (preferably in large metal-framed buildings), and not touching such conductors in the building as plumbing fixtures, telephones, and television sets.

d. Recovery: List actions that should be taken, such as assessing damage to the facility or equipment and repairing such damage before resuming operations.

5. When considering winter storms, include instructions that address the following items:

a. Hazards: List the potential hazards of winter storms, such as low temperatures, ice on roads and equipment, and reduced visibility.

b. Preparation: List actions that should be taken in preparation for winter storms, such as monitoring weather communications.

c. List actions that should be taken during winter storms, such as keeping outside operations to a minimum, ceasing vehicle unloading operations, keeping emergency exits clear, and sending non-essential personnel home with precautions for travelling through unpopulated areas during winter storms.

d. Recovery: List actions that should be taken following a winter storm, such as all personnel checking their work areas for hazards and reporting them to their supervisor.

6. When considering earthquakes, include instructions that address the following items: 
a. Hazards: List the potential hazards of earthquakes, such as panic, falling objects, splintering glass, toppling furniture, fallen power lines, ruptured gas lines, releases of harmful materials, and loss of stability for cranes.

b. Preparation: List actions that should be taken in preparation for earthquakes, such as moving large or heavy objects to lower shelves and bracing or anchoring top-heavy objects.

c. List actions that should be taken indoors during an earthquake, such as avoiding areas where objects may fall, staying away from windows, taking cover under a table, desk, or in a corner or doorway: List actions that should be taken if outside during an earthquake, such as avoiding tall walls, power poles, storage tanks, and areas where objects may fall.

d. Recovery: List actions that should be taken following an earthquake, such as exiting buildings as soon as possible, meeting in an assembly area, accounting for all persons, assembling the emergency response team, avoiding wind-blown dust, checking for fires, forbidding open flame or sparks, conducting physical and radiological surveys of all waste storage areas, isolating any damaged waste containers, and repairing damage before resumption of operations.

7. Include separate steps for completing any forms. These steps should include the titles of the forms and the titles of the individuals completing them.

5.3.5.3.3 Security Incidents-This procedure contains instructions on how to respond to security incidents such as trespassing, theft, bomb threats, and assault, as well as access disruptions caused by demonstrations, protests, strikes, or other blockage of the facility entrance. It also includes information on requirements for contacting the local law enforcement authorities. This procedure outlines the immediate steps for facility employees and security personnel to use when responding to and initiating coordination with local law enforcement authorities in the event of a security incident. It only addresses the violations of facility rules and state and local laws that disrupt the routine operation of the facility or jeopardize the health and safety of personnel.

The following steps should be followed and elements included in the instructions for the procedure:

1. State the titles of individuals at the facility who will respond to security incidents. If there is a designated Security Response Team, indicate who serves on and who leads that team. Also include the responsibilities of these individuals, such as:

- Providing general oversight by giving orders and direction to security officers and personnel

- $\quad$ Providing security expertise 
- Notifying offsite agencies to request immediate assistance: for example, contacting the telephone company to trace bomb threats, contacting the local law enforcement authorities, and investigating onsite traffic accidents

- Safeguarding personnel

- Conducting evacuations

f. Public relations.

2. Describe appropriate actions to be taken in response to security incidents, such as:

a. Bomb threats: Employees should be trained to receive bomb threats. Some type of prepared material, such as a checklist located by the phone, would help employees to remain calm and obtain critical information if possible. Include an instruction for all employees to be aware of suspicious objects in their normal work areas and to report suspicious objects or threatening calls to the proper authorities. Other actions may include the restriction of employee movement, evacuation of all or part of the facility, and forming search teams.

b. Theft or vandalism: Employees should report suspected theft or vandalism and cooperate with investigations. Documentation often is helpful in resolving theft incidences. Most such incidents will ultimately be handled by local law enforcement authorities.

c. Other disruptive activities, such as civil demonstrations, protests, intruders, and trespassers: Describe actions, such as notifying the proper authorities, closing the main gate, and observing the activity from a distance. State the circumstances under which force should be used and who, if anyone, is authorized to use force. Most such incidents will ultimately be handled by appropriate offsite authorities.

3. Include separate steps for completing any forms. These steps should include the titles of the forms and the titles of the individuals completing them.

\subsubsection{Environmental Monitoring}

5.3.6.1 Air Monitoring. The purpose of this procedure is to provide instructions for monitoring levels of radioactive particulates in the air at and around the disposal facility.

The following steps should be followed and elements included in the instructions for the procedure:

1. State the titles of individuals at the facility who will perform this procedure.

2. Include a list of instructions addressing air sampling at monitoring stations, considering: 
a. The minimum air flow capacities for air samplers and the types of particulate filters to be used.

b. The frequency at which the collection devices, such as particulate filters and silica gel columns, should be changed. Give permissible ranges of allowable times between changes (e.g., not less than five days nor more than nine days).

c. How any tritium cartridges will be installed in the monitoring stations. For example, a common arrangement consists of three silica gel columns in series.

d. What parameters the air samples will be analyzed for; or refer to a document where those parameters are given.

e. The frequency of calibration of the air monitoring equipment.

3. Include a list of instructions addressing daily operational checks of the air sampling equipment, including:

a. The items to check, such as up-to-date calibration, elapsed time, and flow rate for particulate and tritium samplers.

b. Describe how to adjust particulate sampler flow rates. Specify a target flow rate.

c. Describe how to adjust tritium sampler flow rates with, for example, a flow control meter. Specify the target flow rate. Often the calibrated flow is marked on the flow meter and can be verified with a graph.

d. Recording information gathered during the checks.

4. Include a list of instructions addressing periodic change-out of tritium columns, considering:

a. The frequency at which the tritium columns will be changed: If possible, this change-out will be performed in conjunction with periodic particulate filter changes.

b. Installing the flow calibration meter: State clearly where the meter goes.

c. Verifying the flow rate through the tritium section: Include instructions on actions to take if the flow rate is unacceptable.

d. Calculating the volume of tritium sample: Include instructions on how to calculate this volume and what data to record.

e. Sending the sample for analysis: Include instructions on sample handling and shipment, or refer to a procedure that discusses these topics.

5. Include a list of instructions addressing grab air samples, considering: 
a. Situations when grab samples are necessary, such as offloading waste, opening waste containers, while performing decontamination, and while personnel are using respiratory equipment.

b. Minimum volumes for the samples and any filtering that should be done as the sample is collected.

c. How the grab sample is to be taken.

d. Accounting for the physical and chemical state of the contaminants, sampling location, and wind direction in relation to the work area.

6. Include a list of instructions addressing particulate air sample analysis, considering:

a. Field counting of air particulate sample filters. For example, samples should be counted as soon as practical after removal from the sampler to determine if an immediate problem exists. State the trigger level of counts per minute above background. Include instructions on actions to take if the count is greater than the trigger level.

b. Quantitative analysis of air particulate sample filters: Include the necessary equations and algorithms to determine, for example, the number of curies in the air per unit volume, the radioactivity half-life if radon or radon-daughters are suspected, and minimum detectable counts for the instrument to be used.

7. Include separate steps for completing any forms, such as chain of custody forms. Those steps should include the titles of the forms and the titles of the individuals completing them.

5.3.6.2 Vegetation Monitoring. The purpose of this procedure is to provide instructions for the periodic vegetation monitoring program at the disposal facility. Vegetation monitoring should normally be performed in conjunction with soil monitoring.

The following steps should be followed and elements included in the instructions for the procedure:

1. State the titles of individuals at the facility who will perform this procedure.

2. State that all foliage must come from live plants.

3. State the schedule for collection of vegetation samples. The schedule should be determined by local growth cycles.

4. State the locations from which vegetation samples will be taken. A sample collection map would be helpful to the sampling technician in determining the correct sampling locations. Provide sampling location numbers for use in designating sample numbers. Instruct the sampler to record the locations of any non-routine samples. 
5. State the areas from which vegetation samples will be taken. All samples should be taken from designated areas. Provide sampling location numbers for use in designating sample numbers. Instruct the sampler to record the locations of any non-routine samples.

6. Specify the minimum allowable amount (e.g., weight) of vegetation needed to obtain a representative sample. Indicate whether a sample will be required if the minimum amount cannot be collected in a particular monitoring area.

7. Include an instruction to note the type and quantity of foliage in each sample.

8. Include an instruction to seal the sample in a container with the date, time, and sample location written on the container.

9. Include instructions on sample handling and shipment, or refer to a procedure that discusses these topics.

10. Include separate steps for completing any forms such as chain of custody forms. Those steps should include the titles of the forms and the titles of the individuals completing them.

5.3.6.3 Soil and Sediment Monitoring. The purpose of this procedure is to provide instructions for the periodic soil and sediment monitoring program at the disposal facility. Soil and sediment monitoring should be performed in conjunction with vegetation monitoring.

The following steps should be followed and elements included in the instructions for the procedure:

1. State the titles of individuals at the facility who will perform this procedure.

2. State the frequency for conducting soil and sediment monitoring. Alternatively, refer to the facility monitoring plan for this information.

3. State the locations from which soil and sediment samples will be taken. A sample collection map would be helpful to the sampling technician in determining the correct sampling locations. Provide sampling location numbers for use in designating sample numbers. Instruct the sampler to record the locations of any non-routine samples.

4. State the number of samples required and their purpose, such as duplicates, composites, and archive samples.

5. Describe the sampling protocol, considering:

a. Sampling from undisturbed areas.

b. The area from which the total amount of the sample should be taken; for example, 12 inches by 12 inches by 1 inch. 

c. Specify the maximum depth of sampling.
d. Sifting the sample: Specify a screen size to remove undesired larger debris.

6. Specify the minimum allowable amount (weight or volume) of soil or sediment needed to obtain a representative sample.

7. Include instructions to seal the sample in a container with the date, time, and sample location written on the container.

8. Include instructions to decontaminate the sampling tools in order to prevent cross contamination from one location to another.

9. Include instructions on sample handling and shipment, or refer to a procedure that discusses these topics.

10. Include separate steps for completing any such forms as chain of custody forms. Those steps should include the titles of the forms and the titles of the individuals completing them.

5.3.6.4 Surface Water Monitoring. The purpose of this procedure is to provide instructions for the periodic surface water monitoring program at the disposal facility.

The following steps should be followed and elements included in the instructions for the procedure:

1. State the titles of individuals at the facility who will perform this procedure.

2. State the frequency for conducting surface water monitoring. Alternatively, refer to the facility monitoring plan for this information.

3. State the locations from which surface water samples will be taken. A sample collection map would be helpful to the sampling technician in determining the correct sampling locations. Provide sampling location numbers for use in designating sample numbers. Instruct the sampler to record the locations of any non-routine samples.

4. Include instructions describing how to calibrate the field measurement instruments, considering:

a. The temperature of the standard solutions for $\mathrm{pH}$ meters and conductivity meters: Depending on the sophistication of the sampling equipment, it may be possible to bathe the standard solution containers in the surface water. Regardless of the methods, the $\mathrm{pH}$ and conductivity meters should be calibrated at the temperature of the sample water because the parameters they measure are temperature-dependent. 
b. Other equipment-specific calibration techniques: If field measurements other than $\mathrm{pH}$ and conductivity are desired (e.g., turbidity and dissolved oxygen), include instructions describing how to calibrate those instruments.

5. Include a list of instructions describing how to use the instruments to take field water quality measurements. This section would include a list of the desired parameters, such as temperature, $\mathrm{pH}$, conductivity, and turbidity and instructions describing how to operate each piece of equipment designed to measure each parameter.

6. Include a list of instructions describing the sampling protocol to obtain surface water samples, considering the desired analytes. The following items are dependent upon the desired analytes:
a. Type of container, such as plastic or glass, and amber or clear
b. Type of sample preservative, such as acid or base, and cooling to $4^{\circ} \mathrm{C}$
c. Holding time: The elapsed time between collecting the sample and analyzing it
d. Volume of sample
e. Method of sampling and containerizing, such as exercising care to not disturb sediment.

7. Include instructions to seal the sample in a container with the date, time, and sample location written on the container.

8. Include instructions to decontaminate the sampling tools in order to prevent cross contamination from one location to another.

9. Include instructions on sample handling and shipment, or refer to a procedure that discusses these topics.

10. Include separate steps for completing any forms such as chain of custody forms. Those steps should include the titles of the forms and the titles of the individuals completing them.

5.3.6.5 Groundwater Monitoring. The purpose of this procedure is to provide instructions for the periodic groundwater monitoring program at the disposal facility.

The following steps should be followed and elements included in the instructions for the procedure:

1. State the titles of individuals at the facility who will perform this procedure.

2. State the frequency for conducting groundwater monitoring. Alternatively, refer to the facility monitoring plan for this information. 
3. Include an instruction to inspect the monitoring wells before starting to purge them. The inspection could include the well cap and standpipe to ensure that the well has not been tampered with or damaged.

4. Include an instruction to take a water level measurement before starting to purge. Describe the point from which the measurement should be taken and specify the desired precision; for example, to the nearest 0.1 inch.

5. The purpose for purging a well is to remove stagnant water from the well and obtain a water sample from the aquifer. Describe how the well should be purged, considering:

a. The disposition of the purged water: State the criteria for disposing of the purged water.

b. Amount of purging: Generally a sample should be taken only after $\mathrm{pH}$, conductivity, and temperature have stabilized. However, this procedure cannot be followed in low permeability formations because the well will go dry and may take hours or months to recover. Include directions for wells that go dry during purging. For example, a common protocol is to wait until the static water level is fully recovered, or up to 48 hours, before sampling.

c. The pumping rate: The pumping rate provides an indirect indication of the recharge rate of the well, which is good information to note.

6. Include instructions describing how to calibrate the field measurement instruments, considering:

a. The temperature of the standard solutions for $\mathrm{pH}$ meters and conductivity meters: Depending on the sophistication of the sampling equipment, it may be possible to bathe the standard solution containers in the purge water during purging. Regardless of the methods, the $\mathrm{pH}$ and conductivity meters should be calibrated at the temperature of the sample water because the parameters they measure are temperature-dependent.

b. Other equipment-specific calibration techniques: If field measurements other than $\mathrm{pH}$ and conductivity are desired (e.g., turbidity and dissolved oxygen), include instructions describing how to calibrate those instruments.

7. Include a list of instructions describing how to use the instruments to take field water quality measurements. This section would include a list of the desired parameters, such as temperature, $\mathrm{pH}$, conductivity, and turbidity and instructions describing how to operate each piece of equipment designed to measure each parameter.

8. Include a list of instructions describing the sampling protocol to obtain groundwater samples from monitoring wells, considering the desired analytes. The following items are dependent upon the desired analytes: 

a. Type of container, such as plastic or glass, and amber or clear
b. Type of preservative, such as acid or base, and cooling to $4^{\circ} \mathrm{C}$
c. Holding time: The elapsed time between collecting the sample and analyzing it
d. Volume of sample
e. Method of sampling and containerizing, such as minimizing agitation and eliminating headspace.

9. Include instructions to seal the sample in a container with the date, time, and sample location written on the container.

10. Include instructions to decontaminate the sampling tools in order to prevent cross contamination from one location to another.

11. Include instructions on sample handling and shipment, or refer to a procedure that discusses those topics.

12. Include separate steps for completing any forms such as chain of custody forms. Those steps should include the titles of the forms and the titles of the individuals completing them.

5.3.6.6 Environmental TLD Monitoring. The purpose of this procedure is to provide instructions for the periodic changing of thermoluminescent dosimeters (TLDs) used for monitoring radiation doses at fixed locations at and near the disposal facility.

The following steps should be followed and elements included in the instructions for the procedure:

1. State the titles of individuals at the facility who will perform this procedure.

2. State the frequency for changing TLDs.

3. State the locations where the TLDs will be placed. The location designation will usually include a height above the ground. A location map would be helpful to the person placing the TLDs in finding the TLD locations. Provide sampling location numbers for use in designating sampling numbers.

4. Include instructions describing how to place and secure the TLDs to avoid damaging them during placement. For example, tiewraps or TLD cages could be used to secure the TLD from shifting or falling. Instruct the individual placing the dosimeters to ensure that they are not shielded.

5. Include instructions describing how to record the numbers and locations of the new TLDs put in place. 
6. Describe how the mail control TLDs for the dosimeters being removed and those being installed are handled. For example, indicate that the control dosimeter for the newly-installed TLDs should be placed in a shielding device.

7. Include separate steps for completing any forms, such as chain of custody forms. Those steps should include the titles of the forms and the titles of the individuals completing them.

\subsubsection{Regulatory Compliance}

5.3.7.1 Notification of Regulatory Agencies. The purpose of this procedure is to describe the activities for notifying various regulatory agencies during an emergency or incident at the disposal facility. The scope of this procedure encompasses any and all emergencies or incidents as well as reporting requirements for the disposal facility. It does not include requirements for reporting of environmental monitoring results, routine disposal activities, or periodic health and safety reports.

The following steps should be followed and elements included in the instructions for the procedure:

1. State the titles of individuals at the facility who will perform this procedure.

2. State the acceptable modes of communication (e.g., fax or telephone) between regulatory agencies and the facility, depending on the nature of the incident.

3. Depending on the nature of the incident, notification is necessary either immediately or within 24 hours. State criteria used to determine the necessity for notifying regulatory agencies, both immediately or within 24 hours, considering such items as:

a. Personnel exposure to radiation: State maximum allowable exposure limits for the whole body, skin, and extremities (e.g., feet, ankles, hands, or forearms)

b. Release of radioactive material: State the maximum allowable amount that may be released to air or water

c. Loss of operation time at the disposal facility: State the maximum allowable amount of time the facility may be out of operation

d. Property damage: State the maximum allowable dollar value that can be lost due to damage.

4. After the initial notification, a written report to authorities will generally be required. State the maximum amount of time that can elapse between the initial and written reports. Also state what elements must be included in the report, such as:

a. The nature of the incident and cause of exposure.

b. Each exposure of individuals to radiation. 
c. Concentrations of radioactive material at some location (such as an unrestricted area).

d. The levels of radiation or concentrations of radioactive material involved.

e. Corrective actions taken or planned to ensure against recurrence.

f. Information about exposed individuals, such as their name, social security number, date of birth, and an estimate of the individual's exposure.

5. State who should be notified, and how, if the security of the facility is threatened, such as the local sheriff or other law enforcement agency.

6. State who should be notified, and how, in the event of a major fire. Those notified could include any local fire department and any other state or federal resources (e.g., the National Guard or the Forestry Service).

7. State who should be notified, and how, in the event of a radioactive or hazardous material spill requiring outside assistance. Those notified could include the state department of health, the U.S. Department of Energy, specialized spill response contractors, the National Response Center, and the Poison Control Center. Include instructions indicating the agency providing assistance and the location for response, and conveying specific information such as the type of material spilled, the quantity of material, and the primary contaminants.

8. State who should be notified, and how, in the event of an industrial safety accident. Those notified could include the state Department of Health, the Occupational Safety and Health Administration, or the National Institute of Occupational Safety and Health. Include instructions to indicate the type of industrial accident and specific information such as personnel involved and personnel injuries.

9. State who should be notified, and how, in the event of shipping violations or notifications relating to the transportation of radioactive materials. Those notified could include the state Department of Health and the U.S. Department of Transportation. Conditions requiring notification are, for example, improper placarding, improper shipping containers, excessive radiation levels, and excessive contamination levels.

10. State who should be notified, and how, in the event of an environmental release to the groundwater or air. Those notified could include the state Department of Health or the U.S. Environmental Protection Agency.

11. Include steps for completing any forms. Those steps should include the titles of the forms and the titles of individuals completing them. 


\subsubsection{Recordkeeping.}

5.3.7.2.1 Radiation Exposure Records-The purpose of this procedure is to provide instructions for completing and maintaining radiation exposure records for occupationally exposed personnel. This procedure describes how to compile the exposure data from procedures that address personnel monitoring.

The following steps should be followed and elements in the instructions for the procedure:

1. State the titles of individuals at the facility who will perform this procedure.

2. Include an instruction describing how individual dosimetry files are used to hold in one file all dosimetry records for a given employee. The records contained in the individual dosimetry files may include:

- A radiation exposure questionnaire: The form would inquire about previous occupational radiation exposure.

- A radiation exposure history: This information would be requested from previous employers depending on the employee's responses to the questionnaire.

- Current occupational external radiation exposure: This information would be collected starting at the time of initial hiring. It would usually be summarized annually using measured dose data.

- Internal monitoring records: This information would consist of internal monitoring reports from past employers, current urine sampling results, and other current internal monitoring reports.

- Training records: This information could include all training, qualifications, and requalifications regarding subjects related to radiation safety, documented in chronological order.

- Fit test records: This information would include respirator fit test and physical examination records.

3. Include an instruction describing the radiation exposure records that are maintained to ensure that individual dosimetry files contain the most current radiation exposure information for each employee. The records will document the following activities:

a. Dosimeter issuance: Each individual's dosimetry file would contain a copy of his or her radiation exposure/dose data. State the frequency for exchanging and reading dosimeters (usually every month).

b. Lost or damaged dosimeter: Describe the actions to be taken if an individual loses or damages their dosimeter. For example, the person could provide a summary of where the dosimeter was lost or damaged, the job being performed, and names of 
individuals performing the same work during the time of issuance. Based on the information from the other workers, an estimate of the exposure could be made.

c. TLD vendor reporting: Describe how information on TLD vendor reports is used.

d. Authorizing exposure extensions: Describe the actions to be taken if operating conditions require an exposure extension or if an employee has exceeded the facility's administrative control exposure limits for occupationally exposed employees.

e. Planned special exposures: State the conditions under which special exposures are allowed. Special exposures should be allowed only in exceptional situations when alternatives that might avoid the higher exposure are unavailable or impractical.

State the title of the individual who will authorize the special exposure. This person should ascertain prior doses during the lifetime of each individual involved and estimate the dose resulting from the planned special exposure.

State the information that each individual involved should receive before the operation, such as: the purpose of the operation, estimated doses and specific radiation levels, potential risks, and measures to be taken to keep doses ALARA.

f. Exposure reporting: Describe what periodic exposure reports contain, how often they are published, and how the information is obtained. For example, it could be a compilation of each individual's radiation exposure from dosimeter readings. This report would provide a ready reference of whole body exposures received to date. State the locations where this information would be posted (e.g., office, laboratory, operations building). Include an instruction to investigate cases where individuals received exposures higher than those of other personnel performing the same tasks.

g. Doses to embryos/fetuses: Include an instruction to pregnant women to declare their pregnancy, including estimated date of conception. State how the dose to an embryo/fetus will be calculated. State that the dose to the embryo/fetus due to occupational exposure must not exceed an established limit.

h. Exposure at termination of employment: Describe the actions that will be taken when an employee terminates. For example, the facility could mail a report to the employee regarding the employee's exposure.

i. Former employee exposure requests: State the maximum time that may elapse between a former employee's request for a report on radiation dose and response by the facility. State the information that should be included in the report.

4. Describe how administrative control levels are established as part of the ALARA program for the facility. 
5. This procedure involves numerous forms. Include separate steps for completing any forms. Those steps should include the titles of the forms and the titles of the individuals completing them.

5.3.7.2.2 Visitor Exposure Reports-The purpose of this procedure is to provide instructions for reporting radiation doses received by visitors to the waste disposal facility.

The following steps should be followed and elements included in the instructions for the procedure:

1. State the titles of individuals at the facility who will perform this procedure.

2. Describe the actions to be taken when a visitor has been in the radiologically controlled area (thereby requiring dosimetry). Such actions will probably include a report furnished to the visitor of any dose received. The report will include information, such as the dates of exposure, the dose equivalent to the individual, and, if available, the total organ dose equivalent to the maximally exposed organ.

3. State the amount of time that can elapse between the exposure to the visitor and his or her receipt of the dose report.

4. Include separate steps for completing any forms. Those steps should include the titles of the forms and the titles of individuals completing them.

5.3.7.2.3 Exposure Data Review and Reporting-The purpose of this procedure is to detail the requirements for estimating and evaluating radiation doses. The records generated by this procedure are used to ensure that worker doses are maintained as low as reasonably achievable (ALARA).

The following steps should be followed and elements included in the instructions for the procedure:

1. State the titles of individuals at the facility who will perform this procedure.

2. Include instructions for a radiation safety committee to establish priorities and goals to minimize worker doses and to review radiation dose data and evaluations to ensure doses are ALARA. The committee should consider, for example:

a. Projected and historical time and manpower allocations

b. The results of personnel dosimetry

c. Site environmental monitoring data

d. Priority reviews for employecs recciving the greatest doses or having the most significant risk of radiation dose 
e. Goals for dose based on estimates of operational parameters furnished by the health physics staff

f. Periodic review of the goals to minimize occupational doses and make any changes determined necessary.

3. Include an instruction to review and evaluate personnel dose data at specified frequencies. Guidelines and goals formulated by the radiation safety committee could be used to evaluate this data.

4. Include an instruction describing actions to be taken in the event the dose data indicate the ALARA goals have not been met or may not be met. For example, an explanation could be prepared by the health physics supervisor including any changes affecting the assumptions upon which the radiation safety committee based its goals, which could account for the goals having not been met. The explanation could also include options that could lead to reduction of occupational doses.

5. Include an instruction to estimate and evaluate radiation doses received as a result of non-routine operations. This evaluation can be broken into three phases:

a. Before the operation: Radiation exposure rates and contamination levels should be considered. Determinations could be made considering who will perform the work, the time required for every major step of the operation, the dose expected to be received, risk of internal doses, and spread of contamination.

b. During the operation: If possible, actual doses could be tracked for major steps. These doses could be compared to the estimated doses. Describe actions to be taken if it is determined that exposure conditions have been significantly underestimated. For example, the remaining steps in the operation could be reevaluated to try to reduce radiation exposures.

c. After the operation: Actual doses could be compared to estimated doses. Include an instruction to indicate why any doses differed by greater than some specified percentage from estimates and how doses could be reduced during similar future operations.

6. Include separate steps for completing any forms. Those steps should include the titles of the forms and the titles of the individuals completing them.

7. Describe how administrative exposure goals are established as part of the ALARA program for the facility.

5.3.7.2.4 Source Control and Inventory-The purpose of this procedure is to provide guidance for the control of radioactive instrument check sources and to ensure that they are handled in accordance with regulations. 
The following steps should be followed and elements included in the instructions for the procedure:

1. State the titles of individuals at the facility who will perform this procedure.

2. Include a list of instructions describing how the inventory of source materials will be maintained, considering:

a. A source file: This file could include the procurement and disposition history of each source, copies of other source-related forms, leak test data, and any other correspondence related to the sources.

b. A physical inventory: Describe how the stock of sources should be inventoried periodically and how additions to or deletions from the stock should be accounted for.

c. Missing sources: State the actions that should take place if it is discovered that a source is missing. For example, an immediate search could be conducted and written reports could be required if the source cannot be found.

d. Limiting access: Describe how access to sources could be limited. For example, the sources could be stored in a locker and keys could be issued only to authorized individuals. Sign-out sheets could be effective in addition to the limited access.

3. Include a list of instructions describing how leak tests will be performed in the event a source is suspected of having a loss of encapsulation or other possible leakage, considering:

a. A visual inspection of the source for physical damage

b. Dry wipe and wet wipe tests: Describe how these tests are performed

c. Disposition of sources found leaking: State how the results of leak tests will be reported and who determines whether the source will be repaired or disposed of.

4. Describe how the sources are to be stored, considering:

a. Labeling of the storage locker: Include an instruction to clearly label the storage locker with a Radioactive Materials label.

b. Include an instruction to perform radiation surveys of the storage locker periodically and immediately after additional check sources are received.

c. Radiation levels: State the maximum acceptable radiation level at the exterior surface of the storage locker. Describe the actions to take if radiation levels exceed the acceptable limit. 
5. Include separate steps for completing forms. Those steps should include the titles of the forms and the titles of the individuals completing them.

5.3.7.3 Acknowledgement of Waste Received and Recording of Disposal Data. This procedure details the steps in acknowledging waste received and recording data about when and where the waste is disposed of.

It describes the recording of disposal data and any discrepancies between materials listed in the manifest and materials received that are discovered during the waste receipt, inspection, and acceptance process. It also describes the preparation of a formal acknowledgement of receipt and disposal of waste for the waste generator.

The following steps should be followed and elements included in the instructions for the procedure:

1. State the titles of individuals at the facility who will perform this procedure.

2. State how the receipt of waste will be acknowledged, considering:

a. The maximum amount of time that may elapse between receipt of the waste, acknowledgement of its receipt on appropriate forms, and notification of the shipper (licensee who last possessed the waste) of its receipt.

b. The nature of the communications with the shipper. For example, the waste facility could send a copy of the manifest signed by a responsible individual, an acknowledgement form, and notes of any discrepancies between the materials listed on the manifest and the materials received.

3. State that disposal data will be recorded on the appropriate form. For example, the disposal data could include the waste disposal unit number, the canister I.D. number (if a canister is used), the disposal location (i.e., row, position, layer), and the date of disposal.

4. Include separate steps for completing any forms. These steps should include the titles of the forms and the titles of the individuals completing them.

\subsection{Use of the Annotated Procedures}

When it becomes time to develop procedures for a new LLW disposal facility, the annotated procedures in this chapter should be very useful. Their principal role will be to serve as checklists for what information needs to go into each procedure. The following paragraphs illustrate how this process will work by reviewing selected parts of Sections 5.2 and 5.3 and then demonstrating how an annotated procedure is developed into a particular section of a full procedure.

The procedure to be developed is the one titled "Placement of Waste in Canisters." The annotated instructions for this procedure are contained in Section 5.3.4.1.2.3 of this chapter. It is assumed that the procedure is being written for a disposal facility whose disposal units are large 
trenches cut into the ground in an arid region. Within these trenches the waste is placed in large concrete canisters and then grouted in place in the canisters. It is assumed that the trenches are so large that, for practical purposes, empty concrete canisters are first put in place in the trench and provided with covers to keep out rain and debris. The waste trucks are then driven into the trenches and the waste is removed from the trucks, placed on impermeable membranes for acceptance inspection, and then placed in the canisters. The procedure covers activities following successful inspection of the waste.

Section 5.2.1 describes the elements of the Purpose and Scope portion of the procedures. For this procedure that portion could read as follows:

\subsection{PURPOSE AND SCOPE}

The purpose of this procedure is to describe the steps by which waste is taken from the impermeable membrane inspection pad and placed in the disposal canisters.

This procedure does not address permanent closure of the canisters. Permanent closure of the canisters is described in Procedure , Grouting.

Sections 5.2.2.1 and 5.2.2.2 describe the elements of the Operating Equipment and Safety Equipment portions of the Equipment and Materials portion of the procedures. It is judged that no radiological or special equipment peculiar to this procedure are needed. For this procedure, the Equipment and Materials portion could read as follows:

\subsection{EQUTPMENT AND MATERIALS}

\subsection{OPERATING EQUIPMENT}

1. Crane

2. Cables and hooks for lifting canister covers, waste packages, and the shielding bell

3. Forklift

4. Rigging necessary to lift pallets of waste with the crane

5. Radiation shielding bell

6. Concrete canister temporary caps

7. Special purpose device for remote disconnection of the crane cables that hold the waste packages.

\subsection{SAFETY EQUTPMENT}

1. Hard hats 


\section{Safety shoes}

3. Safety glasses

4. Coveralls

5. Other equipment that may be specified by the Operations Supervisor or the Health Physics Supervisor.

Section 5.2.3.1 of this document describes the Prerequisites portion of the procedures. For this procedure, that portion could include the following:

\subsection{PREREQUISITES}

1. To meet the requirements of minimizing radiation exposure, all workers must remain as far from the waste packages as possible and still be able to perform their duties.

2. When assigning personnel to work within the disposal unit, a radiation survey and a review of personnel radiation exposure will be performed for exposure control considerations before commencing work.

3. Waste placement in canisters will not be conducted without the required air samplers operating.

4. All lifting cables and hooks must have been properly inspected in accordance with Procedure Number , Equipment Testing and Certification.

Section 5.2.3.2 describes information that belongs in the Training portion of the procedures. That portion of this procedure could look like the following:

\subsection{TRAINING}

Safety training will be according to Procedure Number , Onsite Safety Training.

Personnel operating equipment and vehicles on the disposal facility must have valid certification by the site manager, or his or her authorized representative, that they are current in all operations and safety training for the types of vehicles they are operating.

Section 5.2.3.3 describes the kind of information that can go in the Special Precautions portion of the procedures. For the procedure on placement of waste in canisters, that portion could include the following:

\subsection{SPECIAL PRECAUTIONS}

1. No one is allowed under any suspended objects such as waste pallets, waste packages, and the shielding bell. These objects can be very heavy and can cause grave injury if they swing or drop. 
Section 5.2.3.4 summarizes the kind of information that belongs in the Instructions portion of the procedures. Fifty-five individual annotated outlines of this portion of the procedure are provided in Section 5.3. As noted above, the annotated procedure covering placement of waste in canisters is numbered 5.3.4.1.2.3. Following that annotated procedure, an Instructions portion for the Placement of Waste in Canisters procedure could look like the following, taking into account the specifics of disposal facility design and operation described above:

\subsection{INSTRUCTIONS}

The following activities will be performed by operations personnel.

1. Emplacement of low radiation exposure rate waste.

a. Attach the crane hoisting cables to the loops on the lid of the canister in which the next waste package will be placed. The operations worker will visually inspect the crane cables and hooks, and the canister lid lifting loops for damage. If there is any question about the integrity of these items, the QA Supervisor will be notified and work will stop until the QA Supervisor inspects the cables and hooks and approves their use.

b. Raise the lid vertically to remove it from the canister.

c. Place the lid on the floor of the disposal unit, out of the way.

d. Detach the hoisting cable from loops on the lid.

e. Attach the crane hoisting cables to the lifting rings on the waste package. The operations worker will visually inspect the crane cables and hooks and the lifting apparatus for the waste package for damage. If there is any question about the integrity of these items, the QA Supervisor will be notified, and work will stop until the QA Supervisor inspects the cables and hooks and approves their use.

f. Raise the waste package, and move it to the appropriate canister.

g. Position the waste package over the canister and lower it until it rests in the bottom of the canister such that it is centered with space between the container and the canister wall. At least six inches of space should be allowed for the canister top. Waste packages will not be dropped or allowed to jam in the concrete canister. If the canister is already partially full, the new waste package will rest on the old one.

h. Using the special disconnection device, detach the hoisting cable from the waste package.

i. The Operations Supervisor will complete the Waste Origin and Destination Form, Number 
j. Using the crane hoisting cables, retrieve the canister lid from the floor of the disposal unit and place it temporarily on the canister until permanent closure. The operations worker will visually inspect the crane cables and hooks and the attachment rings on the shielding bell for damage before attaching the hooks to the rings. If there is any question about the integrity of these items, the QA Supervisor will be notified and work will stop until the QA Supervisor inspects the cables and hooks and approves their use. For permanent closure of the canisters, refer to Procedure Number Grouting.

\section{Emplacement of high radiation exposure rate waste.}

All high radiation exposure rate waste will be placed in the lower layer of the disposal unit. The lid on the canister where the high radiation exposure rate waste will be placed will have been removed before the waste package is removed from the truck cask. This sequence of activities begins after the waste package has been inspected and accepted, and the waste package is located on the membrane with the shielding bell over it. The crane cables and hooks are still attached to the waste package and shielding bell as described in Procedure Number , Waste Shipment Off-Loading.

a. Before lifting the waste package, all personnel will move as far away from the package as possible. Nonessential personnel will move away from the immediate area or stand behind adjacent equipment which acts as shielding.

b. Lift the waste package, with the shielding bell over it, and move it to the canister in which it will be placed. Keep the shielding bell as close to the ground as possible to minimize radiation exposure from the open bottom of the bell.

c. Position the shielding bell so the bottom of the bell is about one foot above the top of the canister in which the waste will be placed. Exercise caution to not hit any canister with the shielding bell.

d. Lower the waste package slightly, and position the exposed lower part of the waste package in the center of the canister.

e. When the lower part of the waste package is centered in the canister, lower it entirely out of the shielding bell, down into the canister.

f. The Operations Supervisor will complete the Waste Origin and Destination, Form Number

g. The concrete canister will be immediately filled with grout. For permanent closure of the canisters, refer to Procedure Number , Grouting.

Tables and flow charts described in Section 5.3.3.4 of this report are illustrated at the end of this section, where a complete procedure for Emplacement of Waste in Canisters is given. 
Section 5.2.4 describes the Records portions of the procedures. For this procedure the portion could look as follows:

\subsection{RECORDS}

\subsection{REQUIRED FORMS}

Waste Origin and Destination, Form Number

\subsection{COMPLETION AND APPROVAL REQUTREMENTS}

The Waste Origin and Destination form will be completed by the Operations Supervisor.

\subsection{PROCESSING AND ARCHIVAL REQUIREMENTS}

1. Documents required or created in support of this procedure are quality assurance records. The Waste Origin and Destination form will be included in the quality assurance records package.

2. The records shall be submitted to the Records Management Technician who, as custodian, will ensure each document is complete, legible, and adequately identifiable. The quality assurance records resulting from this procedure shall be retained in accordance with (Administrative Procedure AP ) by the records custodian.

Section 5.2.5 describes information that belongs in the References portion of the procedures. For this procedure that portion could look like the following:

\subsection{REFERENCES}

1. 10 CFR 61.

2. Procedure Number ___ Onsite Safety Training.

3. Procedure Number , Grouting.

When all of the portions of the Placement of Waste in Canisters procedure given above are assembled and a flow chart and the form titled Waste Origin and Destination are added, the full procedure for this important activity results. This procedure is provided in its assembled form on the following pages. 


\section{PLACEMENT OF WASTE IN CANISTERS}

Date:

Revision No.: $\underline{0}$

Supersedes:

Page 1 of 7

Approval:

Concurrence:

Title

Date

Title

Date

\section{$1.0^{\circ}$ PURPOSE AND SCOPE}

The purpose of this procedure is to describe the steps by which waste is taken from the impermeable membrane inspection pad and placed in the disposal canisters.

This procedure does not address permanent closure of the canisters. Permanent closure of the canisters is described in Procedure Number , Grouting.

\subsection{EQUIPMENT AND MATERIALS}

\subsection{OPERATING EQUIPMENT}

1. Crane

2. Cables and hooks for lifting canister covers, waste packages, and the shielding bell

3. Forklift

4. Rigging necessary to lift pallets of waste with the crane

5. Radiation shielding bell

6. Concrete canister temporary caps

7. Special purpose device for remote disconnection of the crane cables that hold the waste packages. 


\subsection{SAFETY EQUIPMENT}

1. Hard hats

2. Safety shoes

3. Safety glasses

4. Coveralls

5. Other equipment that may be specified by the Operations Supervisor or the Health Physics Supervisor.

\subsection{PROCEDURE}

\subsection{PREREQUISITES}

1. To meet the requirements of minimizing radiation exposure, all workers must remain as far from the waste packages as possible and still be able to perform their duties.

2. When assigning personnel to work within the disposal unit, a radiation survey and a review of personnel radiation exposure will be performed for exposure control considerations before commencing work.

3. Waste placement in canisters will not be conducted without the required air samplers operating.

4. All lifting cables and hooks must have been properly inspected in accordance with Procedure Number , Equipment Testing and Certification.

\subsection{IRAINING}

Safety training will be according to Procedure Number , Onsite Safety Training.

Personnel operating equipment and vehicles on the disposal facility must have valid certification by the site manager or his or her authorized representative that they are current in all operations and safety training for the types of vehicles they are operating.

\subsection{SPECIAL PRECAUTIONS}

1. No one is allowed under any suspended objects such as waste pallets, waste packages, and the shielding bell. These objects can be very heavy and can cause grave injury if they swing or drop. 


\subsection{INSTRUCTIONS}

The following activities will be performed by operations personnel.

1. Emplacement of low radiation exposure rate waste.

a. Attach the crane hoisting cables to the loops on the lid of the canister in which the next waste package will be placed. The operations worker will visually inspect the crane cables and hooks, and the canister lid lifting loops for damage. If there is any question about the integrity of these items, the QA Supervisor will be notified and work will stop until the QA Supervisor inspects the cables and hooks and approves their use.

b. Raise the lid vertically to remove it from the canister.

c. Place the lid on the floor of the disposal unit, out of the way.

d. Detach the hoisting cable from loops on the lid.

e. Attach the crane hoisting cables to the lifting rings on the waste package. The operations worker will visually inspect the crane cables and hooks and the lifting apparatus for the waste package for damage. If there is any question about the integrity of these items, the QA Supervisor will be notified and work will stop until the QA Supervisor inspects the cables and hooks and approves their use.

f. Raise the waste package, and move it to the appropriate canister.

g. Position the waste package over the canister and lower it until it rests in the bottom of the canister such that it is centered with space between the container and the canister wall. At least six inches of space should be allowed for the canister top. Waste packages will not be dropped or allowed to jam in the concrete canister. If the canister is already partially full, the new waste package will rest on the old one.

h. Using the special disconnection device, detach the hoisting cable from the waste package.

i. The Operations Supervisor will complete the Waste Origin and Destination Form, Number

j. Using the crane hoisting cables, retrieve the canister lid from the floor of the disposal unit and place it temporarily on the canister until permanent closure. The operations worker will visually inspect the crane cables and hooks and the attachment rings on the shielding bell for damage before 


$$
\text { Page } \frac{4}{\text { Revision }} \frac{7}{0}
$$

attaching the hooks to the rings. If there is any question about the integrity of these items, the QA Supervisor will be notified and work will stop until the QA Supervisor inspects the cables and hooks and approves their use. For permanent closure of the canisters, refer to Procedure Number Grouting.

2. Emplacement of high radiation exposure rate waste.

All high radiation exposure rate waste will be placed in the lower layer of the disposal unit. The lid on the canister where the high radiation exposure rate waste will be placed will have been removed before the waste package is removed from the truck cask. This sequence of activities begins after the waste package has been inspected and accepted, and the waste package is located on the membrane with the shielding bell over it. The crane cables and hooks are still attached to the waste package and shielding bell as described in Procedure Number , Waste Shipment Off-Loading.

a. Before lifting the waste package, all personnel will move as far away from the package as possible. Nonessential personnel will move away from the immediate area or stand behind adjacent equipment which acts as shielding.

b. Lift the waste package, with the shielding bell over it, and move it to the canister in which it will be placed. Keep the shielding bell as close to the ground as possible to minimize radiation exposure from the open bottom of the bell.

c. Position the shielding bell so the bottom of the bell is about one foot above the top of the canister in which the waste will be placed. Exercise caution to not hit any canister with the shielding bell.

d. Lower the waste package slightly, and position the exposed lower part of the waste package in the center of the canister.

e. When the lower part of the waste package is centered in the canister, lower it entirely out of the shielding bell, down into the canister.

f. The Operations Supervisor will complete the Waste Origin and Destination, Form Number

g. The concrete canister will be immediately filled with grout. For permanent closure of the canisters, refer to Procedure Number , Grouting. 


\subsection{RECORDS}

\subsection{REQUIRED FORMS}

Waste Origin and Destination, Form Number

\subsection{COMPLETION AND APPROVAL REQUIREMENTS}

The Waste Origin and Destination form will be completed by the Operations Supervisor.

\subsection{PROCESSING AND ARCHIVAL REQUIREMENTS}

1. Documents required or created in support of this procedure are quality assurance records. The Waste Origin and Destination form will be included in the quality assurance records package.

2. The records shall be submitted to the Records Management Technician who, as custodian, will ensure each document is complete, legible, and adequately identifiable. The quality assurance records resulting from this procedure shall be retained in accordance with (Administrative Procedure AP custodian. by the records

\subsection{REFERENCES}

\section{10 CFR 61 .}

2. Procedure Number , Onsite Safety Training.

3. Procedure Number , Grouting. 


\section{INSTRUCTIONS FOR USING THE WASTE ORIGIN AND DESTINATION FORM NUMBER}

1. Enter the Operations Supervisor's name in the "Operation Supervisor's Name" column.

2. Enter the transport container's description and identification number in the "Transport Container Description and I.D. Number" column.

3. Enter the name of the entity that generated the waste in the "Waste Generator" column.

4. Enter the disposal unit description, the numbers corresponding to the canister's identification and the location where the waste was placed in the "I.D. Number," "Row," "Position," and "Layer" columns, and the date of waste placement.

5. The Operations Supervisor will sign in the "Operations Supervisor's Signature" column. 
WASTE ORIGIN AND DESTINATION

FORM NUMBER

\begin{tabular}{|c|c|c|c|c|c|c|c|c|c|}
\hline \multirow{2}{*}{$\begin{array}{l}\text { Transport } \\
\text { Cortaner } \\
\text { Description } \\
\text { and L.D. } \\
\text { Number }\end{array}$} & \multirow{2}{*}{$\begin{array}{l}\text { Waste } \\
\text { Generator }\end{array}$} & \multirow{2}{*}{$\begin{array}{c}\text { Disposal } \\
\text { Unit } \\
\text { Designation }\end{array}$} & \multicolumn{4}{|c|}{ Disposal Canister Location } & \multirow{2}{*}{$\begin{array}{c}\text { Date of } \\
\text { Waste } \\
\text { Placemenent }\end{array}$} & \multirow{2}{*}{$\begin{array}{l}\text { Operations Supervisor's } \\
\text { Name }\end{array}$} & \multirow{2}{*}{$\begin{array}{l}\text { Operations Supenisor's } \\
\text { Signature }\end{array}$} \\
\hline & & & $\begin{array}{c}\text { L.D. } \\
\text { Number }\end{array}$ & Row & Position & Layer & & & \\
\hline & & & & & & & & & \\
\hline & & & & & & & & & \\
\hline & & & & & & & & & \\
\hline & & & & & & & & & \\
\hline & & & & & & & & & \\
\hline & & & & & & & & & \\
\hline & & & & & & & & & \\
\hline & & & & & & & & & \\
\hline & & & & & & & & & \\
\hline & & & & & & & & & \\
\hline & & & & & & & & & \\
\hline & & & & & & & & & \\
\hline & & & & & & & & & \\
\hline & & & & & & & & & \\
\hline & & & & & & & & & \\
\hline & & & & & & & & & \\
\hline
\end{tabular}




\section{LOGISTICS}

The annotated and generic procedures provided in this report are meant to give the developer of a set of procedures for a specific low-level radioactive waste disposal facility an advanced starting - point. This chapter describes in broad terms how the generic and annotated procedures can be adapted and developed to provide a complete set of procedures for a disposal facility.

Twenty-five generic procedures are provided in Appendix A. As noted earlier, these procedures are provided in their full form because they are felt to be relatively independent of the facility site, facility design, and operations. Even so, these generic procedures will require careful review and modification to make them appropriate for a specific disposal facility. Reasons for changes in the generic procedures could include, for example:

- Use of other designs for the disposal facility. For example, concrete canisters may not be used.

- $\quad$ Changes in names of titles of individuals and portions of the facility, such as buildings, etc.

- Changes in the scale of the facility. The procedures may need to be changed if two-shift operations are conducted or if the staff is generally larger than was anticipated in the preparation of the generic procedures.

- Changes in operations. Despite their general nature, the generic procedures given in Appendix A may require changes if the operations at the particular disposal facility differ from the ones anticipated in their development.

Specific reasons why generic procedures may have to be changed include, for example, when the disposal facility under consideration requires wearing respirators as part of the normal routine in some parts of the facility. In that case, it may be necessary to enhance the Respiratory Protection Equipment Issuance generic procedure to account for that fact. Also, a larger site security force may be employed at a facility that is larger than the one described in the generic procedures here. The generic procedure on facility security in Appendix $A$ is based on the assumption that the security force will consist of a chief of security and three security officers. With a larger staff it may not be necessary, for example, to leave the guard house at the entrance unmanned while conducting a patrol around the site. For that matter, the guard house may be called something else and its function may be fulfilled by another building. All of these are examples of why the generic procedures must be carefully reviewed and adapted to the specific disposal facility under consideration.

Generally, more work is needed to transform the annotated procedures to full procedures than to adapt the generic procedures. The transformation will depend on the site characteristics, facility design, facility operations, and possibly specific regulations for the state in which the facility is located. An example of such a transformation is given in Section 5.4. The evolution of the procedure on Emplacement of Waste in Canisters described there could be different for different circumstances. For example, waste could be placed in the canisters outside of the disposal unit, a different crane 
design than the one assumed could be used, or the procedure could even be unnecessary because canisters are not used. All of these conditions would influence the final product.

The material provided in this report, especially the 25 generic procedures, gives sufficient examples for procedure writers to assist them in developing full procedures from the annotated outlines in Chapter 5. The annotated procedures, especially those for the Instructions portions in Section 5.3, should be used as checklists and reminders. Certainly not all ideas that should be contained in every procedure are found in Chapter 5. The 55 procedures for which annotated outlines of the Instructions portions are provided in Section 5.3 and the 25 generic procedures in Appendix A do not necessarily constitute a complete set of operating and emergency procedures for a low-level radioactive waste disposal facility. They represent a core set of procedures to which others may be added and from which some may be subtracted. When the design and operation of a specific disposal facility are worked out, any additional or unnecessary procedures should become evident. There are also administrative and quality assurance procedures that need to be developed for a low-level radioactive waste disposal facility; these are not addressed in this report. 


\section{SUMMARY}

This document presents information that should be of value to persons preparing operating and emergency procedures for specific low-level radioactive waste disposal facilities. Twenty-five generic procedures are presented. These are considered independent enough of the details of the disposal facility site, design, and operations, to be given as full procedures that can be used, with some modifications, by almost all near-surface LLW disposal facilities.

In addition to the generic procedures, annotated outlines are given for 55 other procedures. The specifics of those procedures are more dependent on the site, design, and operations at a disposal facility, and therefore they must be developed for each specific facility. An example of how the annotated outlines can be used to develop a full procedure is also provided.

This document is intended to assist persons responsible for developing LLW disposal facility operating and emergency procedures. The set of procedures discussed is extensive but is not meant to be all-inclusive. However, it is felt that the information provided will materially assist the preparers of sets of procedures for new LLW disposal facilities. 


\section{Appendix A}

Generic Procedures 


\section{CONTENTS FOR APPENDIX A}

A-1 SAFETY MANAGEMENT PROCEDURES $\ldots \ldots \ldots \ldots \ldots \ldots \ldots \ldots \ldots \ldots$

Management/Radiation Safety Annual Reviews $\ldots \ldots \ldots \ldots \ldots \ldots \ldots \ldots \ldots$. . . . . .

Site Safety Review Committee . . . . . . . . . . . . . . . . . . . A 26

Annual Radiation Safety Audit $\ldots \ldots \ldots \ldots \ldots \ldots \ldots \ldots \ldots \ldots \ldots \ldots \ldots \ldots \ldots$

On-Site Safety Training . . . . . . . . . . . . . . . . . . . A-36

Survey Review and Evaluation $\ldots \ldots \ldots \ldots \ldots \ldots \ldots \ldots \ldots \ldots \ldots \ldots \ldots$

Employee Safety Feedback . . . . . . . . . . . . . . . . . . . A-55

A-2 RADIATION SAFETY PROCEDURES . . . . . . . . . . . . . A-65

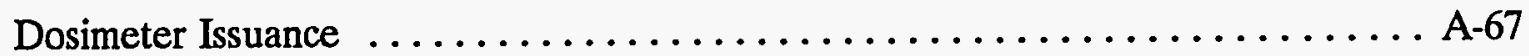

Internal Radiation Monitoring $\ldots \ldots \ldots \ldots \ldots \ldots \ldots \ldots \ldots \ldots \ldots \ldots \ldots \ldots$

Personnel Decontamination . . . . . . . . . . . . . . . . . . . . . . . A-92

Respiratory Protection Equipment Issuance $\ldots \ldots \ldots \ldots \ldots \ldots \ldots \ldots \ldots \ldots \ldots$ A $\ldots \ldots$.105

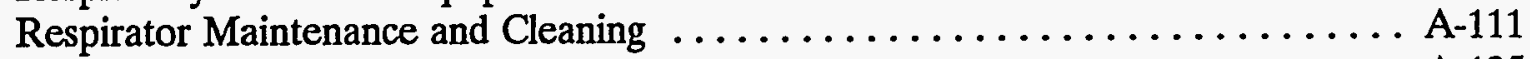

Respiratory Protection Fit Testing $\ldots \ldots \ldots \ldots \ldots \ldots \ldots \ldots \ldots \ldots \ldots \ldots \ldots \ldots \ldots$

A-3 SECURITY PROCEDURES $\ldots \ldots \ldots \ldots \ldots \ldots \ldots \ldots \ldots \ldots \ldots \ldots \ldots$

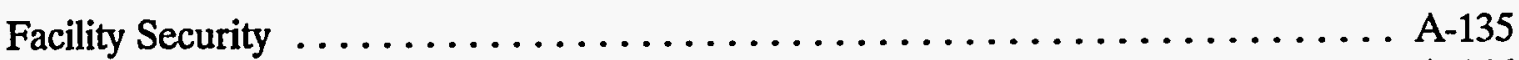

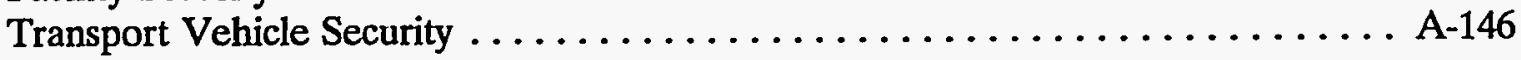

A-4 RADIATION INSTRUMENTATION PROCEDURES . . . . . . . . . . . . A-149

Liquid Scintillation Counter Operation . . . . . . . . . . . . . . . A-151

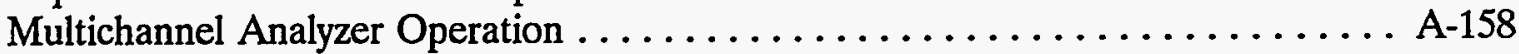

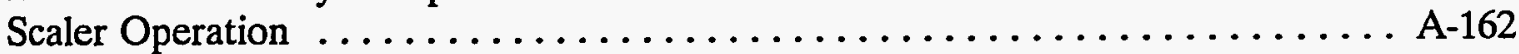

Portable Instrumentation Operation . . . . . . . . . . . . . . . . . A-173

Portable Instrumentation Response and Source Checks Calibration ......... A-177

A-5 PROCEDURES FOR OTHER ACTIVITIES $\ldots \ldots \ldots \ldots \ldots \ldots \ldots \ldots \ldots \ldots$

Shipment Document Review $\ldots \ldots \ldots \ldots \ldots \ldots \ldots \ldots \ldots \ldots \ldots \ldots \ldots$ A $\ldots \ldots \ldots$

Radioactive Waste Classification Verification . . . . . . . . . . . . . . . . A A-198

Truck Wash Facility . . . . . . . . . . . . . . . . . . . . . A-210

Equipment Operation and Maintenance . . . . . . . . . . . . . . A A-213

Environmental Monitoring Data Review and Evaluation ............. A-217

Vendor Audits ................................ A-233 


\section{Appendix A}

\section{Generic Procedures}

This appendix provides 25 example generic procedures. The procedures are designated as generic because they tend to be independent of the specifics of the design, operation, or site of the disposal facility. Therefore the full example procedures provided here may be readily adaptable, with a minimum of changes, for use at many near-surface LLW disposal facilities. The user of these procedures is cautioned, however, to review them carefully for details that may have to be changed for use at a particular facility.

Many of the procedures in this appendix are adapted from procedures being prepared for the LLW disposal facility being developed by the Texas Low-Level Radioactive Waste Disposal Authority and the cooperation of that agency is appreciated. To avoid unnecessary editing, the numbers on the forms at the backs of these procedures were not changed from the numbers used in Texas. This should not cause confusion in their adaptation to other disposal facilities. Where reference is given to other procedures a space is left for the user to fill in the procedure number at a later time. 


\section{A-1. SAFETY MANAGEMENT PROCEDURES}




\section{OPERATING PROCEDURE}

\section{MANAGEMENT/RADIATION SAFETY ANNUAL REVIEW}

\section{Date:}

Supersedes:

Revision No.: 0

Approval:

Concurrence:

Page 1 of $\frac{0}{19}$

Concurrence:

\begin{tabular}{|c|c|c|c|}
\hline Title & Date & Title & Date \\
\hline
\end{tabular}

\subsection{PURPOSE AND SCOPE}

\subsection{PURPOSE}

The purpose of this procedure is to describe the protocol for conducting the annual radiation safety program review. The review will be performed by the General Manager, the Deputy General Manager for Operations, and the Director of Health Physics.

\subsection{SCOPE}

The scope of the annual review is to:

1. Verify that activities are performed in conformance with policies and rules, approved operating procedures, license provisions, and regulatory requirements.

2. Review significant proposed facility changes, tests, and procedures.

3. Verify that important events, such as those that must be reported to the other agencies, are being promptly investigated and corrected in a manner that reduces potential impacts from the event and the probability of their occurrence.

4. Detect trends that might not be apparent to a day-to-day observer. 
5. Verify corrective actions taken in response to findings from previous reviews.

6. Review administrative procedures normally incident to any business.

\subsection{EQUIPMENT AND MATERIALS}

None.

3.0 PROCEDURE

\subsection{PREREQUISITES}

None.

\subsection{TRAINING}

The reviewers will be qualified by training and experience to review the disposal facility management's adherence to the Radiation Safety Program, the license, and the Facility Operating Procedures for assuring protection of health and minimizing danger to life or property. The Deputy General Manager for Operations and the Director of Health Physics will have successfully completed the Radiation Worker Training Course. The General Manager, the Deputy General Manager for Operations, and the Director of Health Physics will receive Quality Assurance training prior to conducting the review described herein.

\subsection{SPECIAL PRECAUTIONS}

None.

\section{$3.4 \quad$ INSTRUCTIONS}

1. All organizations involved in the review will be notified of the review by the General Manager or his designee at least two weeks prior to the date of the review. The notification will include the scheduled date of the review, the time and place of the pre-review meeting, the personnel that should attend the meeting, the scope of the review, and the names of the review team members.

2. In preparing for the review, the individuals conducting it will examine the Management/Radiation Annual Review, Form Number OP 2.1.1-1, plus the license, documents incorporated by reference into the license, applicable operating procedures, and prior Management/Radiation Safety Annual Review reports and responses. Each component of the checklist will be covered during the review to assure adequate depth and continuity. However, the checklist will not restrict the extent or depth of the review when evidence raises additional concerns not specifically included in the checklist. 
3. Upon arrival at the facility, the reviewers will first hold a pre-review meeting with the Director of Operations and other personnel participating in the review to explain the purpose and objectives of the review, discuss the review checklist and sequence, examine previous annual review results, arrange an exit interview, and request assistance, as needed.

4. Each component of the checklist, Form Number OP 2.1.1-1, will be evaluated during the review, either by direct observation of activities or conditions or by review of records in the administrative files at the site. The General Manager will assign specific questions on the checklist to each reviewer. The reviewers will record on the checklist an " $X$ " in the "yes" or "no" box beside each question and any comments, findings, or observations related to that question, or the reviewer will note if the review item is not applicable. Any finding or observation that may indicate a threat to safety, health, the general public, or the environment will be reported immediately to the supervisor of the activity being reviewed, the Director of Operations, and the Quality Assurance Supervisor. Facility personnel will immediately take actions to correct the situation.

The review activities will be performed in the following sequence:

a. During the first portion of the review, administrative files will be examined to determine that appropriate records are being maintained in accordance with procedures and are in compliance with applicable regulations and license conditions.

b. After files and records have been reviewed, observations will be made of the facility operations to determine if they are being performed in accordance with procedures and are in compliance with applicable regulations and license conditions.

5. Any findings will be described in the "Comments" column of the checklist along with the initials of the reviewer identifying the finding. All reviewers will sign the last page of the checklist at the completion of the review.

6. Reviewers will adhere to the following policies in conducting the review:

a. Interference with operations will be minimized.

b. All findings will be recorded and will be objective, factual, and verifiable.

c. If findings involve a specific procedure or person, the procedure will be identified by number or the name or title of the individual will be indicated.

d. Actions taken at the time of the reviews to correct deficiencies identified during the review will be described on the checklist. 


$$
\text { Page } \frac{4}{\text { Revision } \frac{19}{0}}
$$

e. All deficiencies observed will be listed and communicated to the appropriate supervisor, regardless of the pertinence to the review being conducted.

7. Upon completion of the review and prior to leaving the facility, the reviewers will conduct an exit interview with the Director of Operations to examine the review findings. The exit interview attendees will also include members of the organization that can verify the validity of the findings and observations and management personnel who can correct any problems identified during the review. The objectives of the exit interview will be to discuss review findings, determine and resolve any errors or misunderstandings regarding the findings, obtain concurrence on each finding or observation and reach agreement as to when a written response will be returned, discuss corrective action and possible solutions, recommend improvements based on observations, and establish a schedule and completion dates for implementing corrective action.

8. At the end of the review the Director of Health Physics, the Deputy General Manager for Operations, and the General Manager will sign Form Number OP 2.1.1-1, Management/Radiation Safety Review Checklist.

9. Within five working days of completion of the review, the reviewers will prepare a written Management/Radiation Safety Annual Review Report and will forward it to the Director of Operations with copies to the Quality Assurance Supervisor and all members of the Site Safety Review Committee (see the next procedure in this appendix) for information. The report will include any observations or problems noted during the review and will include a statement of conclusions regarding the radiation safety program effectiveness. Any findings will be listed either in a separate report or in a separate section of the review report.

10. Within ten working days of receipt of the review report, the Director of Operations will respond in writing to the report indicating actions scheduled, or already taken, to correct any deficiencies. All action items will include dates for completion or implementation. The Director of Operations will be responsible for ensuring that corrective action is completed as planned.

11. The General Manager will inform the Director of Operations and the Quality Assurance Supervisor in writing of any unsatisfactory response, indicating why the reply is considered unsatisfactory and specifying a reply due date.

12. The reviewers will verify final acceptance of corrective actions by means of a written report submitted to the Director of Operations, Quality Assurance Supervisor, and the Site Safety Review Committee. 


$$
\text { Page } \frac{5}{\text { Revision } \frac{19}{0}}
$$

\subsection{RECORDS}

\subsection{REQUIRED FORMS}

Management/Radiation Safety Annual Review Checklist, Form Number OP 2.1.1-1.

\subsection{COMPLETION AND APPROVAL REQUIREMENTS}

1. Within five working days of the review, the reviewers will prepare a written report on the review. The report will include a discussion of findings for each item on the checklist, Form Number OP 2.1.1-1, as well as other observations and deficiencies found during the review. This report and the form will be signed by the Director of Health Physics, the Deputy General Manager for Operations, and the General Manager. This report will be forwarded directly to the Director of Operations with copies to the Quality Assurance Supervisor and.. all members of the Site Safety Review Committee for information.

2. The Director of Operations will provide a written response to the report within ten working days of receipt of the review report indicating actions scheduled, or already taken, to correct any deficiencies. All action items will include dates for completion and implementation.

3. The General Manager will inform the Director of Operations and the Quality Assurance Supervisor in writing of any unsatisfactory responses and why the response is considered unsatisfactory. A reply due date will also be specified.

4. Final acceptance of corrective actions will be verified by means of a written report signed by each of the reviewers.

\subsection{PROCESSING AND ARCHIVAL REQUIREMENTS}

1. Documents required or created in support of this procedure are quality assurance records and will be included in the quality assurance records package. The Management/Radiation Safety Annual Review Checklist, annual review report, written responses with proposed corrective actions, and final acceptance of corrective actions will be included in the quality assurance records package.

2. The records will be submitted to the Records Management Technician, who, as custodian, will ensure that each document is complete, legible, and adequately identifiable. The quality assurance records resulting from this procedure will be retained in accordance with Administrative Procedure AP by the records custodian.

3. Copies of the annual review report, written response with proposed corrective actions, and final acceptance of corrective actions will be 
Page $\frac{6}{\text { Revision }} \frac{19}{0}$

maintained and posted at the facility by the Director of Operations and remain posted until receipt of the next annual review.

\subsection{REFERENCES}

None. 
Page $\frac{7}{\text { Revision } \underline{19}}$

\section{INSTRUCTIONS FOR MANAGEMENT/RADIATION SAFETY ANNUAL REVIEW CHECKLIST FORM NUMBER 2.1.1-1}

1. The annual review checklist, Form OP 2.1.1-1, will cover at least the following areas:

a. Health physics authority and responsibility

b. Operating procedures involving the receipt, handling, and disposal of radioactive materials, and any procedure revisions

c. Personnel radiation monitoring program, including employee exposure records and bioassay procedures and records

d. Radiation safety training program records

e. Respiratory protection program

f. Records of daily inspections of log entries and summary reports of monthly reviews

g. Records and results of a representative sample of the required radiological surveys, sampling, tests for removable contamination, inspections and environmental monitoring

h. Facility and equipment design, including ventilation rates within buildings at the facility where radioactive material is used, fire control, and radioactive material storage and disposal locations

i. Control of airborne radioactive materials

j. Compliance with applicable regulations and conditions of the license

k. Safety meeting minutes.

2. Each reviewer will be responsible for evaluating the items on the checklist assigned to him/her prior to the review by the General Manager. The reviewer will first examine administrative files to determine that records are being maintained in accordance with procedures and are in compliance with applicable regulations and license conditions. The following records will be reviewed:

a. Position descriptions for the health physics staff required by the license will be reviewed. Organization charts and personnel records will be reviewed to ensure that these positions are filled with staff having at least the minimum qualifications listed in the position description.

b. The health physics staff members will be interviewed to ascertain that their understanding of their authorities and responsibilities is consistent with those established in the position descriptions. 
c. Personnel training records will be reviewed and compared with a current employee list to verify that all personnel are trained in the use of safety equipment and procedures.

d. Radiation safety training program records will be reviewed to determine if they are current and being maintained in accordance with procedures.

e. Radiation safety training records will be reviewed to determine if the training program has been conducted in accordance with procedures.

f. Safety meeting minutes will be reviewed to determine if regular meetings are being conducted and documented.

g. Employee exposure and bioassay records will be examined to determine if they are current and being maintained in accordance with procedures.

h. Employee exposure and bioassay records will be reviewed to determine if personnel exposure monitoring and bioassaying activities have been conducted in accordance with procedures.

i. Respiratory protection program records will be reviewed to determine if they are current and are being maintained in accordance with procedures.

j. Waste shipment records will be reviewed to verify that all waste shipments were accompanied by properly executed shipment records.

k. Waste shipment records will be reviewed to determine that proper notifications were made regarding any damaged packages.

1. Records of surveys of incoming vehicles will be reviewed to determine if surveys are being conducted as required.

m. Records of surveys of outgoing vehicles will be reviewed to determine if surveys are being conducted as required.

n. Records of off-loading and handling operations will be reviewed to determine that radiation surveys are being conducted to assess radiation and contamination levels and to identify problem situations.

o. Records of waste receipts will be reviewed to verify that survey results have been properly documented.

p. Records of personnel surveys will be reviewed to determine if these have been conducted as required.

q. Records will be reviewed to determine how well permanent records are being maintained on the boundaries of each disposal unit. 
r. Records will be reviewed to determine how well records are maintained on waste placement, both storage and disposal, and contents.

s. Records of ventilation rates within buildings where radioactive material is used will be reviewed to determine if they are within acceptable standards.

t. Records on the prevention of airborne radioactive material releases will be reviewed to determine if these materials are being controlled in accordance with procedures.

u. Environmental monitoring records will be reviewed to determine if environmental monitoring is being conducted as required.

v. Environmental monitoring records will be reviewed to determine that notifications were made of any exceeded action levels.

w. Records on passive monitoring devices will be reviewed to determine if these devices have been replaced and analyzed as required.

x. Environmental monitoring records will be reviewed to verify that monitoring results have been recorded in accordance with procedures.

y. Records of audits, inspections, and surveys conducted since the last management review will be reviewed to determine if they were conducted at appropriate intervals.

z. Records of audits, inspections, and surveys will be reviewed to determine if identified problems were corrected in a satisfactory and timely manner.

aa. Previous management reviews will be reviewed to determine if there are any outstanding items.

bb. Daily inspections of log entries will be reviewed to determine if they are current and are being maintained in accordance with procedures.

cc. Reports of Site Safety Review Committee reviews will be reviewed to determine if they are have been conducted and documented in accordance with procedures.

dd. Closed disposal unit survey records (see Procedure Closed Disposal Unit Surveys) will be reviewed to determine if this activity has been completed and documented.

3. After files and records have been reviewed, observations will be made of facility operations to determine if they are being performed in accordance with procedures and are in compliance with applicable regulations and license conditions. The following items and activities will be observed and evaluated during the review: 


$$
\text { Page } \frac{10}{\text { Revision } \frac{19}{0}}
$$

a. Is an emergency response plan for potentially dangerous situations posted on the bulletin board?

b. Is facility safety equipment inspected and readily available, including fire control equipment?

c. Is any waste shipment receipt that is occurring during the review activity accompanied by properly executed shipment records?

d. Are radiation surveys conducted of incoming vehicles and vehicles before release?

e. Are radiation surveys conducted during off-loading and handling operations to assess radiation and contamination levels and to identify problem areas?

f. Is all monitoring equipment properly used at the entrance to the disposal area?

g. Are proper surveys being conducted of facility equipment and personnel leaving the controlled area?

h. Are procedures for having damaged or leaking packages repaired for disposal being properly employed?

i. Are proper notifications made if any waste packages are damaged?

j. Is waste off-loaded and placed in disposal units in accordance with procedures?

k. Is proper personnel and radiation detection equipment available during receipt, handling, packaging, repackaging, and disposal operations?

I. Is proper protective clothing being worn by personnel during disposal operations?

m. Are personnel exposure monitoring activities conducted during the review conducted in accordance with procedures?

n. Are procedures for the respiratory protection program being properly applied when necessary?

o. Are airborne radioactive materials being prevented in accordance with applicable procedures?

p. Is a monument with prescribed information in place on each covered disposal unit? 
q. Is there any erosion, shrinkage, or settlement noted in disposal unit covers?

r. Are water diversion berms in place around the perimeter of the disposal units?

s. Is all waste stored above ground in accordance with the license?

t. Are environmental monitoring and personnel surveys being conducted as required?

u. Are passive monitoring devices in place?

v. Is the security fence in good repair?

w. Is the maintenance area orderly and free of safety hazards?

x. Are ventilation rates within buildings where radioactive material is used within acceptable standards?

y. Are keys to the controlled area properly controlled?

z. Are there any violations of good safety practices?

aa. Are daily inspections of log entries conducted according to procedures?

4. Yes-lf the checklist question can be answered "yes", place an " $X$ " in the "Yes" box.

5. No-If the checklist question is answered by "no", place an " $\mathrm{N}$ " in the "No" box.

6. Not Applicable - If the checklist question is not applicable to the current review, place an " $X$ " in the "Not Applicable" box.

7. Comments, with Initials of Reviewer-Record any comments, findings, or observations made relative to the checklist question. If more exhaustive comments are needed than can fit on the checklist form, attach additional sheets to the form. Record the reviewers' initials adjacent to the comment or finding description. Report any finding or observation that may create a threat to safety, health, the general public, or the environment immediately to the supervisor of the reviewed activity, the Director of Operations, and the Quality Assurance Supervisor.

8. Signature of Reviewers and Dates-The Director of Health Physics, the Deputy General Manager for Operations, and the General Manager will sign and date the form to indicate that they have completed this form. 
MANAGEMENT/RADIATION SAFETY ANNUAL REVIEW CHECKLIST FORM NUMBER 2.1.1-1

\begin{tabular}{|c|c|c|c|c|c|}
\hline \multicolumn{2}{|r|}{ Hem Reviewed } & \multirow[t]{2}{*}{ Yes } & \multirow[t]{2}{*}{ No } & \multirow{2}{*}{$\begin{array}{c}\text { Not } \\
\text { Applicablo }\end{array}$} & \multirow{2}{*}{$\begin{array}{l}\text { Comments, with Initials of Reviewer } \\
\text { (Attach additional sheets to this form if } \\
\text { more extensive comments are required) }\end{array}$} \\
\hline & Reviow & & & & \\
\hline 1. & $\begin{array}{l}\text { Do health physics staff have the } \\
\text { minimum qualifications listed in } \\
\text { their position description? }\end{array}$ & & & & \\
\hline 2. & $\begin{array}{l}\text { Do heaith physics staff have an } \\
\text { accurate knowledge of their } \\
\text { authorities and responsibilities? }\end{array}$ & & & & \\
\hline 3. & $\begin{array}{l}\text { Are all personnel trained in the } \\
\text { use of safety equipment and } \\
\text { procedures? }\end{array}$ & & & & \\
\hline 4. & $\begin{array}{l}\text { Are radiation safety training } \\
\text { program records maintained } \\
\text { according to procedures and are } \\
\text { records current? }\end{array}$ & & & & \\
\hline 5. & $\begin{array}{l}\text { Has the radiation safety training } \\
\text { program been conducted in } \\
\text { accordance with procedures? }\end{array}$ & & & & \\
\hline 6. & $\begin{array}{l}\text { Are site safety meetings } \\
\text { conducted and documented? }\end{array}$ & & & & \\
\hline 7. & $\begin{array}{l}\text { Are employee exposure records } \\
\text { and bioassay records maintained } \\
\text { according to procedures and are } \\
\text { records current? }\end{array}$ & & & & \\
\hline 8. & $\begin{array}{l}\text { Have personnel exposure } \\
\text { monitoring and bioassaying } \\
\text { activities been conducted in } \\
\text { accordance with procedures? }\end{array}$ & & & & \\
\hline
\end{tabular}


Page 13 of 19 Revision $\frac{19}{0}$

\section{MANAGEMENT/RADIATION SAFETY ANNUAL REVIEW CHECKLIST \\ FORM NUMBER 2.1.1-1 \\ (Continued)}

\begin{tabular}{|c|c|c|c|c|c|}
\hline \multicolumn{2}{|r|}{ Hem Reviewed } & \multirow[t]{2}{*}{ Yes } & \multirow[t]{2}{*}{ No } & \multirow{2}{*}{$\begin{array}{c}\text { Not } \\
\text { Applicable }\end{array}$} & \multirow{2}{*}{$\begin{array}{l}\text { Comments, with Initials of Reviewer } \\
\text { (Attach additional sheets to this form if } \\
\text { more extensive comments are required) }\end{array}$} \\
\hline 9. & $\begin{array}{l}\text { Are respiratory protection program } \\
\text { records maintained according to } \\
\text { procedures and are records } \\
\text { current? }\end{array}$ & & & & \\
\hline 10. & $\begin{array}{l}\text { Were all waste shipments } \\
\text { accompanied by properly } \\
\text { executed shipment records? }\end{array}$ & & & & \\
\hline 11. & $\begin{array}{l}\text { Were proper notifications made } \\
\text { regarding damaged packages? }\end{array}$ & & & & \\
\hline 12. & $\begin{array}{l}\text { Were surveys of incoming vehicles } \\
\text { conducted? }\end{array}$ & & & & \\
\hline 13. & $\begin{array}{l}\text { Were surveys conducted of } \\
\text { vehicles before release? }\end{array}$ & & & & \\
\hline 14. & $\begin{array}{l}\text { Were radiation surveys conducted } \\
\text { during off-loading and handling } \\
\text { operations to assess radiation and } \\
\text { contamination levels and to } \\
\text { identify problem situations? }\end{array}$ & & & & \\
\hline 15. & $\begin{array}{l}\text { Were waste receipt survey results } \\
\text { documented? }\end{array}$ & & & & \\
\hline 16. & $\begin{array}{l}\text { Have personnel surveys been } \\
\text { conducted as required? }\end{array}$ & & & & \\
\hline 17. & $\begin{array}{l}\text { Is a permanent record of each } \\
\text { disposal unit or other waste } \\
\text { disposal area boundaries } \\
\text { maintained? }\end{array}$ & & & & \\
\hline
\end{tabular}


Page $\frac{14}{\text { Revision } \frac{19}{0}}$

\section{MANAGEMENT/RADIATION SAFETY ANNUAL REVIEW CHECKLIST FORM NUMBER 2.1.1-1 \\ (Continued)}

\begin{tabular}{|c|c|c|c|c|c|}
\hline & Item Reviewed & Yes & No & Not & Comments, with Initials of Reviowor \\
\hline 18. & $\begin{array}{l}\text { Is a permanent record of waste } \\
\text { placement and contents } \\
\text { maintained? }\end{array}$ & & & & \\
\hline 19. & $\begin{array}{l}\text { Have ventilation rates within } \\
\text { buildings where radioactive } \\
\text { material is used been within } \\
\text { acceptable standards? }\end{array}$ & & & & \\
\hline 20. & $\begin{array}{l}\text { Have airborne radioactive material } \\
\text { releases been prevented in } \\
\text { accordance with applicable } \\
\text { procedures? }\end{array}$ & & & & \\
\hline 21. & $\begin{array}{l}\text { Has environmental monitoring } \\
\text { been conducted as required? }\end{array}$ & & & & \\
\hline 22. & $\begin{array}{l}\text { In the event action levels were } \\
\text { exceeded, have the proper } \\
\text { notifications been made? }\end{array}$ & & & & \\
\hline 23. & $\begin{array}{l}\text { Have passive monitoring devices } \\
\text { been replaced and analyzed as } \\
\text { required? }\end{array}$ & & & & \\
\hline 24. & $\begin{array}{l}\text { Have monitoring results been } \\
\text { recorded in accordance with } \\
\text { procedures? }\end{array}$ & & & & \\
\hline 25. & $\begin{array}{l}\text { Were audits, inspections, and } \\
\text { surveys conducted at appropriate } \\
\text { intervals? }\end{array}$ & & & & \\
\hline 26. & $\begin{array}{l}\text { Were identified problems } \\
\text { corrected in a satisfactory and ti- } \\
\text { mely manner? }\end{array}$ & & & & \\
\hline
\end{tabular}




\begin{tabular}{|c|c|c|c|c|c|}
\hline \multicolumn{2}{|r|}{ Item Reviewed } & \multirow[t]{2}{*}{ Yes } & \multirow[t]{2}{*}{ No } & \multirow{2}{*}{$\begin{array}{c}\text { Not } \\
\text { Applicable }\end{array}$} & \multirow{2}{*}{$\begin{array}{l}\text { Comments, with Initials of Reviewer } \\
\text { (Attach additional sheets to this form if } \\
\text { more extensive comments are required) }\end{array}$} \\
\hline 27. & $\begin{array}{l}\text { Have provious management } \\
\text { reviews been reviewed for } \\
\text { outstanding items? }\end{array}$ & & & & \\
\hline 28. & $\begin{array}{l}\text { Are records of daily inspections of } \\
\text { log entries maintained according } \\
\text { to procedures and are they } \\
\text { current? }\end{array}$ & & & & \\
\hline 29. & $\begin{array}{l}\text { Are regular Site } \\
\text { Safety Review Committee reviews } \\
\text { conducted and documented? }\end{array}$ & & & & \\
\hline 30. & $\begin{array}{l}\text { Have the closed disposal unit } \\
\text { survey records been completed } \\
\text { and documented? }\end{array}$ & & & & \\
\hline \multicolumn{6}{|c|}{ Observations of Facility Operations } \\
\hline 31. & $\begin{array}{l}\text { Is an emergency response plan for } \\
\text { potentially dangerous situations } \\
\text { posted on the bulletin board? }\end{array}$ & & & & \\
\hline 32. & $\begin{array}{l}\text { Is facility safety equipment } \\
\text { inspected and readily available, } \\
\text { including fire control equipment? }\end{array}$ & & & & \\
\hline 33. & $\begin{array}{l}\text { Is waste shipment receipt } \\
\text { occurring during this review } \\
\text { accompanied by properly } \\
\text { executed shipment records? }\end{array}$ & & & & \\
\hline 34. & $\begin{array}{l}\text { Are surveys conducted of } \\
\text { incoming vehicles and vehicles } \\
\text { before release? }\end{array}$ & & & & \\
\hline
\end{tabular}




\section{MANAGEMENT/RADIATION SAFETY ANNUAL REVIEW CHECKLIST FORM NUMBER 2.1.1-1 \\ (Continued)}

\begin{tabular}{|c|c|c|c|c|c|}
\hline \multicolumn{2}{|r|}{ Item Reviewed } & \multirow[t]{2}{*}{ Yes } & \multirow[t]{2}{*}{ No } & \multirow{2}{*}{$\begin{array}{c}\text { Not } \\
\text { Applicable }\end{array}$} & \multirow{2}{*}{$\begin{array}{l}\text { Comments, with Initials of Roviewer } \\
\text { (Attach additional sheets to this form if } \\
\text { more extensive comments are required) }\end{array}$} \\
\hline 35. & $\begin{array}{l}\text { Are radiation surveys conducted } \\
\text { during off-loading and handling } \\
\text { operations to assess radiation and } \\
\text { contamination levels and to } \\
\text { identity problem situations? }\end{array}$ & & & & \\
\hline 36. & $\begin{array}{l}\text { Is all monitoring equipment } \\
\text { properly used at the entrance to } \\
\text { the disposal area? }\end{array}$ & & & & \\
\hline 37. & $\begin{array}{l}\text { Are proper surveys conducted of } \\
\text { facility equipment and personnel } \\
\text { leaving the controlled area? }\end{array}$ & & & & \\
\hline 38. & $\begin{array}{l}\text { Are procedures being properly } \\
\text { employed for having damaged or } \\
\text { leaking packages repaired for } \\
\text { disposal? }\end{array}$ & & & & \\
\hline 39. & $\begin{array}{l}\text { Are proper notifications made } \\
\text { regarding damaged packages? }\end{array}$ & & & & \\
\hline 40. & $\begin{array}{l}\text { Is waste off-loaded and placed in } \\
\text { disposal units in accordance with } \\
\text { procedures? }\end{array}$ & & & & \\
\hline 41. & $\begin{array}{l}\text { Is proper personnel and radiation } \\
\text { detection equipment available } \\
\text { during receipt, handling, } \\
\text { packaging, repackaging, and } \\
\text { disposal operations? }\end{array}$ & & & & \\
\hline 42. & $\begin{array}{l}\text { Is proper protective clothing worn } \\
\text { by personnel during disposal } \\
\text { operations? }\end{array}$ & & & & \\
\hline 43. & $\begin{array}{l}\text { Are personnel exposure } \\
\text { monitoring activities conducted } \\
\text { during the review in accordance } \\
\text { with procedures? }\end{array}$ & & & & \\
\hline
\end{tabular}




\section{MANAGEMENT/RADIATION SAFETY ANNUAL REVIEW CHECKLIST \\ FORM NUMBER 2.1.1-1 \\ (Continued)}

\begin{tabular}{|c|c|c|c|c|c|}
\hline \multicolumn{2}{|r|}{ Hem Reviewed } & \multirow[t]{2}{*}{ Yes } & \multirow[t]{2}{*}{ No } & \multirow{2}{*}{$\begin{array}{l}\text { Not } \\
\text { Applicable }\end{array}$} & \multirow{2}{*}{$\begin{array}{l}\text { Comments, with lnitials of Reviewer } \\
\text { (Attach additional sheets to this form if } \\
\text { more extensive comments are required) }\end{array}$} \\
\hline 44. & $\begin{array}{l}\text { Are procedures for following the } \\
\text { respiratory protection program } \\
\text { being properly applied when } \\
\text { necessary? }\end{array}$ & & & & \\
\hline 45. & $\begin{array}{l}\text { Are airborne radioactive material } \\
\text { releases being prevented in } \\
\text { accordance with applicable } \\
\text { procedures? }\end{array}$ & & & & \\
\hline 46. & $\begin{array}{l}\text { Is a monument with prescribed } \\
\text { information in place on each } \\
\text { covered disposal unit? }\end{array}$ & & & & \\
\hline 47. & $\begin{array}{l}\text { Is any erosion, shrinkage, or } \\
\text { settlement noted in covers over } \\
\text { disposal units? }\end{array}$ & & & & \\
\hline 48. & $\begin{array}{l}\text { Are water diversion berms in place } \\
\text { around the perimeter of disposal } \\
\text { units? }\end{array}$ & & & & \\
\hline 49. & $\begin{array}{l}\text { Is all waste stored above ground } \\
\text { in accordance with the license? }\end{array}$ & & & & \\
\hline 50. & $\begin{array}{l}\text { Are environmental monitoring and } \\
\text { personnel surveys being } \\
\text { conducted as required? }\end{array}$ & & & & \\
\hline 51. & $\begin{array}{l}\text { Are passive monitoring devices in } \\
\text { place? }\end{array}$ & & & & \\
\hline 52. & $\begin{array}{l}\text { Is the security fence in good } \\
\text { repair? }\end{array}$ & & & & \\
\hline
\end{tabular}


Page 18 of 19 Revision 0

MANAGEMENT/RADIATION SAFETY ANNUAL REVIEW CHECKLIST

FORM NUMBER 2.1.1-1

(Continued)

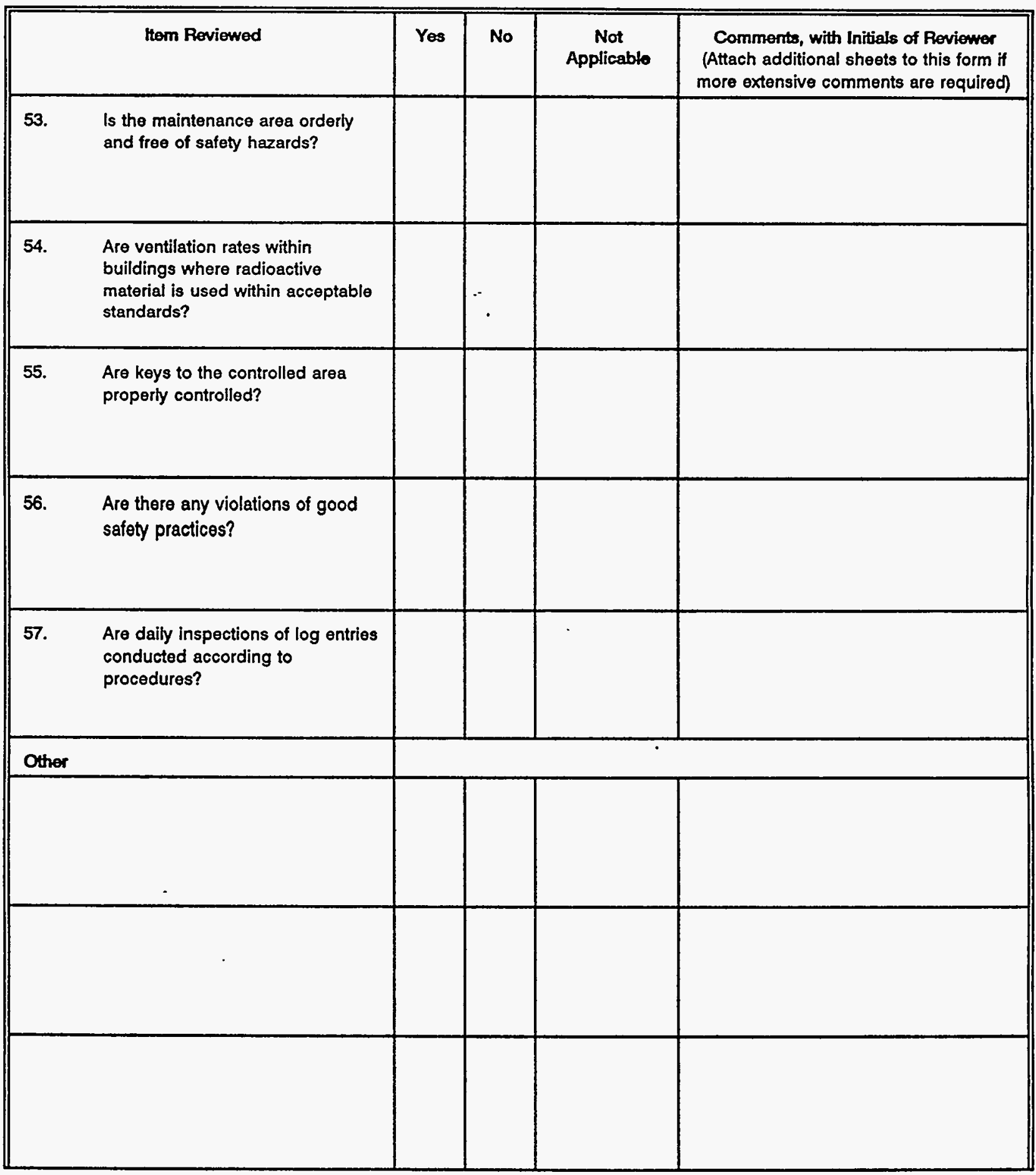


Page $\frac{19}{\text { Revision }}$ of $\frac{19}{0}$

\section{MANAGEMENT/RADIATION SAFETY ANNUAL REVIEW CHECKLIST}

FORM NUMBER 2.1.1-1

(Continued)

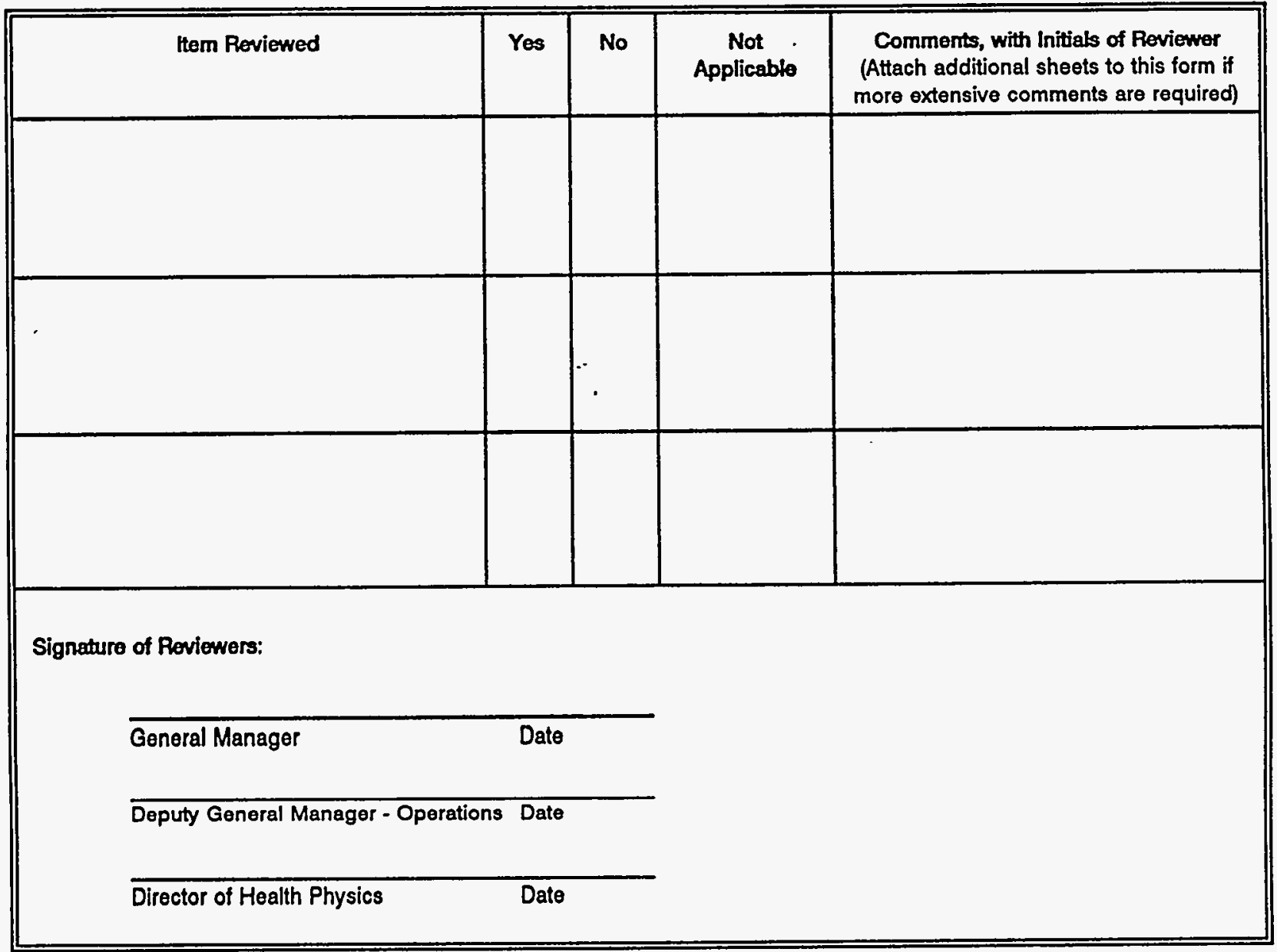




\section{OPERATING PROCEDURE}

\section{SITE SAFETY REVIEW COMMITTEE}

Date:

Revision No.: $\underline{0}$

Supersedes:

Page 1 of 4

Approval:

Concurrence:

\section{Title}

Date

Title

Date

\subsection{PURPOSE AND SCOPE}

\subsection{PURPOSE}

The purpose of this procedure is to describe the composition and function of the Site Safety Review Committee and the protocol for conducting site safety reviews.

\subsection{SCOPE}

The scope of the site safety reviev: will be to perform periodic inspections of site operations to verify that activities are being performed in conformance with site safety procedures. The reviews will cover both conventional and radiological safety issues.

\subsection{EQUIPMENT AND MATERIALS}

None

\subsection{PROCEDURE}

\subsection{PREREQUISITES}

1. Site Safety Review Committee reviews will be performed at least monthly in accordance with this procedure.

2. The Site Safety Review Committee will consist of six facility employees that are selected by the Director of Operations and the Operations Supervisor. Members will be selected from personnel representing varied disciplines and all aspects of site operations, including electricians, maintenance personnel, mechanics, health physics and quality assurance personnel, equipment operators, clerical staff, offloaders, and others. Membership on the Site Safety Review Committee will 
change at least every six months to ensure that all disciplines and site operations are represented on the Committee during the course of one year.

3. The Operations Supervisor will chair the Site Safety Review Committee. The Director of Operations will attend Committee meetings but will serve only as an observer.

\subsection{TRAINING}

All members of the Site Safety Review Committee will be qualified by training and experience to review their particular site working discipline. All Committee members will also receive quality assurance training appropriate to the implementation of this operating procedure.

\subsection{SPECIAL PRECAUTIONS}

None.

\section{$3.4 \quad$ INSTRUCTIONS}

1. The Site Safety Review Committee will meet at least monthly to investigate the selected buildings or locations to verify compliance with the facility site safety procedures. The facility buildings or locations to be reviewed will have been selected by the Committee Chairman in advance of the meeting. The Committee Chairman will ensure that every major building and location on the facility will be reviewed at least once during the course of a year.

2. No advance notice will be provided to the personnel working at the buildings or locations that will be inspected.

3. At the beginning of each Committee meeting, Committee members will review applicable safety requirements relevant to the buildings or locations being reviewed, including the site safety program, radiation safety and worker safety procedures, relevant results of the Management/Radiation Safety Annual Review, corrective actions on past items, and OSHA requirements. Relevant facility safety procedures that may be reviewed will include the following:

$\begin{array}{ll}\text { - } & \text { Employee Safety Feedback } \\ \text { - } & \text { Dosimeter Issuance } \\ \text { - } & \text { Persornal Radiation Monitoring } \\ \text { - } & \text { Respiratory Protection Equipment Issuance } \\ \text { - } & \text { Respirator Maintenance and Cleaning } \\ \text { - } & \text { Occupational Safety } \\ \text { - } \quad \text { Fire Safety } \\ \text { Equipment Testing and Certification. }\end{array}$

Based on this review of applicable safety requirements, the Committee will prepare a checklist of items to be reviewed for the specific buildings or locations to be evaluated. 
4. After review of applicable requirements and development of the checklist, the Committee will spend at least an hour or two conducting a physical inspection of the site buildings or locations being reviewed, completing the checklist as they proceed through the area. The types of items that will be reviewed by direct observation will include all aspects of the site safety program and OSHA requirements relevant to the particular building or location being reviewed, such as unsafe working practices, damaged electrical outlets or extension cords, frayed cables on power tools or other equipment, messy work sites, tripping hazards, overhead hazards, potential for falling items, wet areas that could cause potential electrical hazards, poor drainage, health hazards in areas such as showers and food areas, evidence of air leaks, availability and working condition of fire extinguishers, and other safety concerns identified by the Committee and noted on the checklist.

5. Only qualified team members will perform inspection activities that involve specialized expertise, such as the opening of electrical panels or equipment operating covers.

6. Any observation that may create a threat to safety, health, the general public, or the environment will be reported immediately to the supervisor of the reviewed activity, the Director of Operations, and the Quality Assurance Supervisor. Facility personnel will immediately take actions to correct the situation.

7. Within three working days after the inspection, the results of the review will be presented in a written report prepared by the Operations Supervisor. The report will include any observations or problems noted during the review. This report will be signed by Committee members. It will then be submitted to the responsible supervisor of the building or operation under review with copies to the Director of Operations and the Quality Assurance Supervisor.

8. Within ten working days of the review, the responsible supervisor for the building or operation that was reviewed will respond in writing to the Committee report indicating the corrective actions taken to comply with the review findings.

9. The Operations Supervisor will ensure that all items are corrected. The Operations Supervisor will inform the responsible supervisor and the Quality Assurance Supervisor in writing of any unsatisfactory corrective actions and will specify a deadline for compliance.

10. The Operations Supervisor will verify that corrective actions have been completed and will prepare a written report on the status of the corrective actions. The Operations Supervisor will indicate acceptance of the corrective actions by his/her signature on this report. The final report will be submitted to the responsible supervisor, members of the Site Safety Review Committee involved in the review, the Director of Operations, and the Quality Assurance Supervisor.

\subsection{RECORDS}

\subsection{REQUIRED FORMS}

None. 


\subsection{COMPLETION AND APPROVAL REQUIREMENTS}

1. The Operations Supervisor will prepare, within three days after the end of the review, a written report on the review, which will be signed by each reviewer. The report will include a discussion of the observations as well as any deficiencies found during the review. This report will be forwarded directly to the responsible supervisor of the operation under review, with copies provided to the Director of Operations and the Quality Assurance Supervisor.

2. The responsible supervisor will provide a written response to the report within ten working days of receipt of the Committee report, indicating the corrective actions taken to address with the review findings.

3. The Operations Supervisor will inform the responsible supervisor and the Quality Assurance Supervisor in writing of any unsatisfactory responses, the reasons the response is considered unsatisfactory, and a deadline for compliance.

4. Final acceptance of corrective actions will be verified by means of a written report prepared and signed by the Operations Supervisor. The final report will be submitted to the responsible supervisor, members of the Site Safety Review Committee involved in the review, the Director of Operations, and the Quality Assurance Supervisor.

\subsection{PROCESSING AND ARCHIVAL REQUIREMENTS}

1. Documents required or created in support of this procedure are quality assurance records and will be included in the quality assurance records package. The Site Safety Review Committee checklist and report, the written response with corrective actions, and the final report accepting corrective actions will be included in the quality assurance records package.

2. The records will be submitted to the Records Management Technician, who, as custodian, will ensure that each document is complete, legible, and adequately identifiable. The quality assurance records resulting from this procedure will be retained in accordance with Administrative Procedure AP — by the records custodian.

3. Copies of the Site Safety Review Committee checklists and review report, the written responses with proposed corrective actions, and final acceptance of corrective actions will be maintained at the facility by the Director of Operations and will also be posted in the building or location of the review by the responsible supervisor until the next review.

\subsection{REFERENCES}

None. 


\section{OPERATING PROCEDURE}

\section{ANNUAL RADIATION SAFETY AUDIT}

Date:

Supersedes:

Revision No.: 0

Approval:

Page 1 of 6

Concurrence:

Title

Date

Title

Date

\subsection{PURPOSE AND SCOPE}

This procedure describes the annual internal radiation safety audit program that will be conducted at the disposal facility. Annual radiation safety audits shall be conducted by the Health Physics Supervisor and shall consist of an examination of selected aspects of license conditions, operating activities, and regulatory requirements that directly affect radiation safety and the control of radioactive materials. Audits shall be performed on at least an annual basis and shall be unannounced.

Annual radiation safety audits will be the primary responsibility of the Health Physics Supervisor. The audits will include personnel requirements, instructions, and record keeping.

\subsection{EQUIPMENT AND MATERIALS}

Measuring and testing devices as deemed appropriate and necessary.

\subsection{PROCEDURE}

\subsection{PREREQUISITES}

Radiation survey instruments used shall have a current calibration and be checked with an appropriate check source of radiation prior to use to determine that the instrument is functioning properly. 


\subsection{TRAINING}

1. Safety training shall be according to Procedure Training. , On-Site Safety

2. Personnel operating equipment and vehicles on the disposal facility must have valid certification by the site manager that they are current in all operations and safety training for the types of equipment and vehicles they are operating.

\subsection{SPECIAL PRECAUTIONS}

1. Audits shall be conducted by appropriately trained and qualified personnel not having direct responsibility in the area being audited.

2. Audits shall be conducted in a manner that minimizes interference with operations in the areas being audited.

3. Auditors shall comply with all safety requirements applicable to the areas they are auditing.

\section{$3.4 \quad$ INSTRUCTIONS}

1. The Radiation Safety Audit Checklist, Form Number OP 2.1.3-1, shall be used as the basis of the audit. The audit will be conducted by the Health Physics Supervisor as lead auditor, assisted by any individuals he or she designates.

The audit shall consist of a comprehensive review and inspection of activities that have occurred since the last audit.

2. The audit shall consist of items specified on the checklist and shall include:
a. A review of all records pertinent to radiation safety and control of radioactive materials
b. Observation of operations with respect to radiation safety as prescribed by license conditions and government regulations
c. A review of corrective actions implemented since the last audit
d. Interviews with operations personnel, security officers, and quality assurance technicians with knowledge about the activities and areas being audited.

3. When problems or deficiencies are encountered, the scope of the audit may be expanded under the guidance of the Health Physics Supervisor to fully evaluate the problems or deficiencies. The expansion may be in 
addition to, but not in place of the items on the checklist, Form Number OP 2.1.3-1. Deficiencies will be reported on a Nonconformance Report per Quality Assurance Plan Section prepared by the Director of Health Physics.

4. Upon completion, the lead auditor shall prepare a written report of the audit findings. The findings of the audit shall be recorded and be objective, factual, and verifiable, with copies of nonconforming documents made when possible.

5. The audit report shall contain at a minimum:

a. Title page with the facility name, date of audit, auditor's name(s) and signature(s) and the signature of the Director of Health Physics

b. An introduction listing the general categories included in the audit

c. A findings section which addresses the following areas:

1. Trends in personal exposures for identifiable categories of workers and types of operating activities

2. Comments on whether equipment for radiation exposure control is properly used, maintained, and inspected

3. Deviations from safety controls and operating procedures.

d. A recommendations section on ways to reduce exposures

e. A summary of the following, as a minimum:

1. Employee exposure records

2. Bioassay results

3. Inspection log entries and summaries of inspections

4. Documented training activities

5. Radiation safety meeting reports

6. Radiological survey and sampling data

7. Overexposure reports, if any

8. Operating Procedures reviewed during the audit.

6. Copies of the audit report shall be forwarded to the Director of Health Physics, the Director of Environmental Programs, the Director of 
Operations, the Director of Engineering, and the Deputy General Manager for Operations.

7. The Deputy General Manager for Operations shall prepare a formal response to each audit finding and recommendation within 10 working days of receipt of the audit report. The response shall include the following:

- $\quad$ Dates by which corrective actions were or will be initiated

- Corrective actions to be taken in response to the findings or the recommendations

- Dates when the corrective actions were or will be completed.

\subsection{RECORDS}

\subsection{REQUIRED FORMS}

Radiation Safety Audit Checklist, Form Number OP 2.1.3-1.

\subsection{COMPLETION AND APPROVAL REQUIREMENTS}

The Radiation Safety Audit Checklist and Audit Report will be completed by the Health Physics Supervisor.

\subsection{PROCESSING AND ARCHIVAL REQUIREMENTS}

1. Documents required or created in support of this procedure are quality assurance records. The Radiation Safety Audit Checklist and the Audit Report will be included in the quality assurance records package.

2. The records shall be submitted to the Records Management Technician who, as custodian, will ensure each document is complete, legible, and adequately identifiable. The quality assurance records resulting from the procedure shall be retained in accordance with (Administrative Procedure AP $\checkmark$ by the records custodian.

\subsection{REFERENCES}

1. NUREG-1199.

2. NUREG-1200. 


\section{INSTRUCTIONS FOR USING THE RADIATION SAFETY AUDIT CHECKLIST FORM NUMBER OP 2.1.3-1}

1. Enter the date on which the audit is conducted on the "Date Audited" line.

2. Enter the date on which the last audit was conducted on the "Date of Last Audit" line.

3. Complete the checklist by initialing in the appropriate column as instructed on the form.

4. Additional comments may be entered in the "Other Comments" block.

5. The Health Physics Supervisor will sign on the "Health Physics Supervisor" line and enter the date of that signature. 


\section{RADIATION SAFETY AUDIT CHECKLIST FORM NUMBER OP 2.1.3-1}

\begin{tabular}{|c|c|c|c|}
\hline \multicolumn{2}{|l|}{ Date Audited: } & \multicolumn{2}{|c|}{ Date of Last Audit: } \\
\hline \multicolumn{4}{|c|}{$\begin{array}{l}\text { The audit shall be performed with respect to those areas that directly affect radiation safety and the control of } \\
\text { radioactive materials. }\end{array}$} \\
\hline \multicolumn{4}{|c|}{$\begin{array}{l}\text { Directions: Write initials in the SAT (Satisfactory) or UNSAT (Unsatisfactory) column. If an item does not apply, } \\
\text { write "NA" and initials in the REMARKS column. (Identify any changes since the last audit under REMARKS). } \\
\text { Attach additional sheets with remarks, if necessary. }\end{array}$} \\
\hline ITEM & SAT & UNSAT & REMARKS \\
\hline \multicolumn{4}{|l|}{ 1. Waste Receipt } \\
\hline \multicolumn{4}{|l|}{ Recelpt of Waste } \\
\hline \multicolumn{4}{|l|}{ Inspection of Waste } \\
\hline \multicolumn{4}{|l|}{ Waste Acceptance } \\
\hline \multicolumn{4}{|l|}{ 2. Waste Storage } \\
\hline \multicolumn{4}{|l|}{ Inspection of Waste } \\
\hline \multicolumn{4}{|l|}{ Waste Placement } \\
\hline \multicolumn{4}{|l|}{ Waste Removal } \\
\hline \multicolumn{4}{|l|}{ 3. Disposal Operations } \\
\hline \multicolumn{4}{|l|}{ Waste Emplacement } \\
\hline \multicolumn{4}{|l|}{$\begin{array}{l}\text { Worker Exposure Records } \\
\text { (TLD reports) }\end{array}$} \\
\hline \multicolumn{4}{|l|}{ Void Space Filling } \\
\hline \multicolumn{4}{|l|}{ Cover Placement } \\
\hline \multicolumn{4}{|l|}{ 4. Environmental Monitoring } \\
\hline \multicolumn{4}{|l|}{ Leachate Sampling } \\
\hline \multicolumn{4}{|l|}{ Air Sampling } \\
\hline \multicolumn{4}{|l|}{ Monitoring Well Sampling } \\
\hline \multicolumn{4}{|l|}{ Surface Water Sampling } \\
\hline \multicolumn{4}{|c|}{ Direct Gamma Measurements } \\
\hline 5. Accidental Release Data & & & \\
\hline
\end{tabular}

6. Other Comments: 


\section{OPERATING PROCEDURE}

\section{ON-SITE SAFETY TRAINING}

Date:

Revision No.: 0

Supersedes:

Page 1 of 14

Approval:

Concurrence:

Title

Date

Title

Date

\subsection{PURPOSE AND SCOPE}

The purpose of this procedure is to describe the steps necessary to conduct on-site safety training. Safety training courses and instructions will be provided to ensure that operations at the disposal facility are carried out in a safe efficient manner. Safety training will be conducted by the Health Physics Supervisor or a responsible person under his or her supervision. The Director of Operations and Director of Engineering may also arrange through the Health Physics Supervisor, acting as the On-Site Safety Officer, to conduct safety training.

\subsection{EQUIPMENT AND MATERIALS}

\subsection{SAFETY TRAINING EQUIPMENT}

1. Classroom area, large enough for all attendees

2. Overhead Projector

3. Slide Projector

4. Record or Log Book to record meeting minutes

5. Other equipment as necessary to demonstrate safety activities. 


\subsection{PROCEDURE}

\subsection{PREREQUISITES}

1. Safety training for all employees shall be given on safety-related subjects as they apply to the disposal facility. This training will be required of all new employees. The concepts presented in these safety courses will be reinforced for all employees in monthly safety refresher courses.

2. Monthly safety refresher courses will be held on the first Monday of every month.

3. On-site safety training generally involves four activities: safety training courses, safety refresher courses, safety-related problem solving meetings, and safety requirements meetings.

\subsection{TRAINING}

1. Safety-related training courses at the facility will include the following courses:
a. Basic radiation protection training
b. Radiation worker training
c. Low-level radioactive waste training
d. Facility operations training
e. Emergency procedures training
f. Qualification and requalification
g. Confined spaces training
h. First aid
i. Fire extinguisher use
j. Hazardous materials training
k. Right to know training
I. Small spills training.

Other courses may be added as deemed necessary by the Health Physics Supervisor. The Health Physics Supervisor will determine which courses are needed by which personnel as a function of their duties, and will 
maintain a record of the courses needed by each position on the facility roster.

2. The Health Physics Supervisor will be responsible for all safety material presented in the courses. He or she shall keep on file lesson plans and other written materials for all safety training lectures and demonstrations.

3. The Health Safety Physics Supervisor will schedule all safety training.

4. The appropriate section of this procedure $(3.4 .1,3.4 .2,3.4 .3$, or 3.4 .4$)$ will be used to plan and conduct the safety training.

\subsection{SPECIAL PRECAUTIONS}

None.

\subsection{INSTRUCTIONS}

1. Conducting a Safety Training Course.

Safety Training Courses will consist of prepared course materials. They will cover specific topics and will be presented by the Health Physics Supervisor or a responsible person under his/her supervision. These courses will be given to all new employees before their work at the disposal facility commences.

Each course will typically consist of lectures, demonstrations, and, where appropriate, application of the material taught. A question and answer period will follow each of these phases.

The following steps will be followed in conducting a Safety Training Course:

a. The Health Physics Supervisor will set a safety training course place and time.

b. The Health Physics Supervisor will appoint a responsible person to conduct the safety training course. This person will prepare the lesson plan and test to be given at the end of the course, assemble the necessary equipment, and complete Form Number OP 2.1.4-2, Meeting Agenda Form for Presenters.

c. The Health Physics Supervisor will approve the lesson plan and the test for the course. The tests will be kept in a secure location accessible only to the Health Physics Supervisor.

d. The Health Physics Supervisor will notify by internal memo all expected attendees at least two weeks prior to the course specifying the course time, place, and a contact person. 
e. Two days prior to the course, the Health Physics Supervisor will send out applicable advance course materials to all expected attendees for their review.

f. At the start of the course, the person in charge of the safety training course will pass out the roll sheet, Form Number OP 2.1.4-1, Safety Attendance Report Form, and its instruction sheet.

g. The person in charge of the safety training course will present the material prepared for the course using the outline attached to Form Number OP 2.1.4-2, Meeting Agenda Form for Presenters.

h. Questions will be taken by the person in charge of the safety training course from all present. Answers will be provided for all reasonable questions pertinent to the material presented.

i. The person in charge of the safety training course will administer a test to all employees attending the course.

j. The tests will be collected for grading and the Health Physics Supervisor or the person in charge of the safety training course will grade them. The completed tests will be kept for one year and then destroyed.

k. Employees receiving scores higher than 80 percent on their tests will be considered to have passed. Employees who did not pass the safety training course will be required to take the course again the next time it is given.

1. Employees who pass will affirm by their signature that, in addition to having passed the test, they feel that their understanding of the material is complete and they have no further questions. This will be done by completing Form Number 2.1.4-3, Completion of Safety Training.

2. Conducting a Safety Training Refresher Course.

A Safety Training Refresher Course will be conducted to reacquaint employees with current disposal facility safety procedures and practices. These courses will be required of all employees on a monthly basis.

The following steps will be followed in conducting Safety Training Refresher Courses:

a. The Health Physics Supervisor will reserve a time and place to conduct a safety training refresher course for all employees of the disposal facility the first Monday of every month. 


$$
\text { Page } \frac{5}{\text { Revision } \frac{14}{0}}
$$

b. The Health Physics Supervisor will appoint a responsible person to conduct the course. This person will prepare the lesson plan and the test that will be given at the conclusion of the course, assemble the necessary equipment, and complete Form Number OP 2.1.4-2 Meeting Agenda Form for Presenters.

c. The Health Physics Supervisor will approve the lesson plan and the test for the course. The tests will be kept in a secure location accessible only to the Health Physics Supervisor.

d. At the start of the course, the person in charge of the safety training refresher course will pass out the roll sheet, Form Number OP 2.1.4-1, Safety Attendance Report Form, and its instructions.

e. The person in charge will present the material prepared for the course, using the outline attached to Form Number OP 2.1.4-2, Meeting Agenda Form for Presenters.

f. Questions will be taken by the person in charge of the safety training refresher course from all present. Answers will be provided to all reasonable questions pertinent to the material presented.

g. The person in charge of the course will administer a test to all employees attending the course.

h. The tests will be collected and graded by the Health Physics Supervisor or his or her designee. The completed tests will be kept for one year and then destroyed.

i. Employees receiving scores higher than 80 percent on their tests will be considered to have passed. Employees who did not pass the safety training refresher course will be required to take the course again the next time it is given. Failure of the test will be reported to the employee's supervisor within one working day of grading of the test.

j. Employees who pass will affirm by their signature that, in addition to having passed the test, their understanding of the material is complete. This will be done by completing Form Number 2.1.4-3, Completion of Safety Training.

3. Conducting a Safety-Related Problem Solving Meeting.

Safety-Related Problem Solving Meetings are meetings called by and prepared by the Health Physics Supervisor, acting as the On-Site Safety Officer, to resolve a safety-related problem in disposal facility operations.

Safety problems will require prompt action by the Health Physics Supervisor. This meeting format is designed to bring the problem to light 
and get a corrective action quickly. This meeting procedure will be initiated whenever a facility safety problem is reported, and such a meeting is deemed necessary by the Health Physics Supervisor.

The following steps will be followed in conducting a Safety-Related Problem Solving Meeting:

a. All employees will report suspected safety-related problems immediately to Health Physics Supervisor or to their immediate supervisor. This will be done in accordance with Employee Safety Feedback, Procedure - If immediate action is deemed necessary to protect health and safety, the Health Physics Supervisor will implement that action upon being informed of the problem.

b. The Health Physics Supervisor will determine the time and place for the meeting.

c. The Health Physics Supervisor will be responsible for conducting the meeting.

d. The Health Physics Supervisor will send out a meeting notice specifying the problem and the time and place of the meeting to all employees affected by the safety-related problem. This notice will also be posted on all company bulletin boards, employee locker rooms, lounges, and lunchrooms, so that every effort is made to inform all employees of the problem and the meeting.

e. At the start of the meeting the Health Physics Supervisor will pass out the roll sheet, Form OP 2.1.4-1, Safety Attendance Report Form, and its instructions.

f. The Health Physics Supervisor will appoint a meeting secretary to record meeting minutes and important comments in the Meeting Log Book.

g. The Health Physics Supervisor will describe the safety-related problem and possible solutions to resolve the problem.

h. The problem will be brainstormed by all invited attendees. Attendees will be expected to participate in defining the problem, generating possible solutions to the problem, and specifying the steps that need to be taken in order to implement a solution that will eliminate the problem. These proceedings and subsequent solutions will be recorded by the meeting secretary.

i. The designated meeting secretary will submit the minutes to the Health Physics Supervisor at the conclusion of the meeting. 
j. Within one working day after the meeting adjourns, the Health Physics Supervisor will issue a written declaration of actions to be taken.

k. Additional employee training will be scheduled by the Health Physics Supervisor if the problem resolution warrants it.

\section{Conducting a Safety Requirements Meeting.}

A Safety Requirements Meeting will be convened by the Health Physics Supervisor anytime disposal facility safety policies or procedures are updated. Attendance at safety requirements meetings will be required of all employees.

The following steps will be followed in conducting a Safety Requirements Meeting:

a. The Health Physics Supervisor will determine the time and place for the meeting.

b. The Health Physics Supervisor will conduct the meeting.

c. The Health Physics Supervisor will send out a meeting notice to all employees at the disposal facility at least one week prior to the meeting specifying meeting time and place.

d. Two days prior to the meeting time set, the Health Physics Supervisor will send out a memorandum on the new safety requirements or regulations to be discussed with all employees.

e. At the start of the meeting the Health Physics Supervisor will pass out the roll sheet, Form Number OP 2.1.4-1, Safety Attendance Report Form, and its instruction sheet.

f. The Health Physics Supervisor will appoint a meeting secretary to record meeting minutes and important comments in the Meeting Log Book.

g. The Health Physics Supervisor will present the material prepared for the safety requirements meeting.

h. Questions will be taken by the Health Physics Supervisor from all present. Answers will be provided for all reasonable questions pertinent to the material presented.

i. The designated meeting secretary will submit the minutes to the Health Physics Supervisor at the conclusion of this process. 


\subsection{RECORDS}

\subsection{REQUIRED FORMS}

Safety Attendance Report Form, Form Number 2.1.4-1.

Meeting Agenda Form, Form Number 2.1.4-2.

Completion of Safety Training, Form Number 2.1.4-3.

Meeting Log Book.

\subsection{COMPLETION AND APPROVAL REQUIREMENTS}

The Safety Attendance Report Form will be prepared by course or meeting attendees. The Meeting Agenda Form for Presenters will be filled out by the person responsible for presenting the course or conducting the meeting. The Completion of Safety Training Form will be filled out by each employee who successfully completes a course. Copies of these forms will be placed in the employee's permanent record and the safety records package.

\subsection{PROCESSING AND ARCHIVAL REOUIREMENTS}

1. Documents required or created in support of this procedure are safety records. These documents shall be included in the Safety Records package. In addition, copies of records documenting employee participation shall be placed in the employee's permanent record file.

2. The records shall be submitted to the Records Management Technician who, as custodian, will ensure each document is complete, legible, and adequately identifiable. The safety records resulting from this procedure shall be retained in accordance with Administrative Procedure AP by the records custodian.

\subsection{REFERENCES}

29 CFR 1910.

29 CFR 1518.

American National Standards Institute (ANSI) Standards.

National Safety Council - Safe Practices Pamphlets. 


$$
\text { Page } \frac{9}{\text { Revision }} \text { of } \frac{14}{0}
$$

\section{INSTRUCTIONS FOR \\ SAFETY ATTENDANCE REPORT FORM \\ FORM NUMBER 2.1.4-1}

1. The Health Physics Supervisor or the responsible person in charge will complete instructions 2 and 3.

2. Enter the safety training topic presented.

3. Enter the date and place of presentation.

4. Enter the date.

5. Print your full name.

6. Enter your Social Security number. ..

7. Sign your name. Your signature verifies you were in attendance at the meeting.

NOTE: $\quad$ Employees found to have filled out this form for someone else or have filled it out for themselves at a time or place different from when the meeting or course took place will be subject to immediate dismissal. 
Safety Training Topic:

Date and Place:

\begin{tabular}{|c|c|c|c|}
\hline Date & Name (Printed) & $\begin{array}{l}\text { Social Security } \\
\text { Number }\end{array}$ & Signature \\
\hline & & & \\
\hline & & & \\
\hline & & & \\
\hline & & & \\
\hline & & & \\
\hline & & & \\
\hline & & & \\
\hline & & & \\
\hline & & & \\
\hline & & & \\
\hline & & & \\
\hline & & & \\
\hline & & & \\
\hline & & & \\
\hline & & & \\
\hline & & & \\
\hline & & & \\
\hline & . & & \\
\hline & & & \\
\hline & & & \\
\hline & & & \\
\hline & & & \\
\hline
\end{tabular}




$$
\text { Page } \frac{11}{\text { Revision } \frac{14}{0}}
$$

\section{INSTRUCTIONS FOR \\ MEETING AGENDA FORM FOR PRESENTERS \\ FORM NUMBER 2.1.4-2}

1. Enter the date or dates of the meeting or course.

2. Enter the location of the meeting or course.

3. Enter the names of the people presenting the material.

4. Enter the name of the person designated by the Health Physics Supervisor as being responsible for preparing and conducting the meeting or course.

5. Enter the topic of the meeting.

6. Enter the type of meeting being conducted.

7. Enter the primary objectives of the meeting or course.

8. Attach an outline of the materials presented. 


\section{MEETING AGENDA FORM FOR PRESENTERS}

FORM NUMBER OP 2.1.4-2

Date

Location

Meeting Presenters

Person Responsible for the meeting

Topic

Type of Meeting

Objectives 


\section{INSTRUCTIONS FOR \\ COMPLETION OF SAFETY TRAINING \\ FORM NUMBER 2.1.4-3}

1. Enter the date.

2. Enter the employee's name and social security number.

3. Enter the Safety Training Completed.

4. The employee will read and sign declaration of safety training completed. 


\section{COMPLETION OF SAFETY TRAINING}

FORM NUMBER OP 2.4.1-3

Date

Employee's Name

Employee's SSN

Safety Training Completed

I have completed the above safety training and feel that my understanding of the materials presented is complete. I feel I am able to perform job functions requiring this safety training without reservation.

Signed

Date: 


\section{OPERATING PROCEDURE}

\section{SURVEY REVIEW AND EVALUATION}

Date:

Supersedes:

Revision No.: 0

Page 1 of $\frac{0}{5}$

Approval:

Concurrence:

Title

Date

Title

Date

\subsection{PURPOSE AND SCOPE}

This procedure provides instructions necessary for reviewing and evaluating data from radiation surveys of equipment and installations at the disposal facility. Reviews of radiation exposures of personnel will be conducted separately under Procedure Exposure Data Review and Reporting. Radiation survey data will be reviewed quarterly to determine that all requirements for surveys have been met, to check for problem areas, to note and report any trends, and to compare with applicable background limits.

A final survey review and evaluation report will be the responsibility of the Health Physics Supervisor.

\subsection{EQUIPMENT AND MATERIALS}

None.

\subsection{PROCEDURE}

\subsection{PREREQUISITES}

All reports created from radiation surveys required by the facility operating procedures will be obtained. Routine radiation surveys are performed as outlined in Procedures titled Incoming Vehicle Surveys, Transport Vehicle Release Surveys, Routine Surveys and Reviews, Cask Surveys, and Closed Disposal Unit Surveys.

\subsection{TRAINING}

None. 


\subsection{SPECIAL PRECAUTIONS}

None.

\section{$3.4 \quad$ INSTRUCTIONS}

The Health Physics Supervisor will:

a. Assemble all of the survey records and reports for the appropriate quarter. This will include entry and exit surveys (personnel and equipment), survey maps, survey logbooks, etc.

b. Log all survey material collected into the Survey Review and Evaluation Form, Form Number 2.1.5-1.

c. Review all survey records and reports documenting trends in survey information.

d. Identify trends in personnel survey information. For example, one employee may consistently be contaminated or one may be prone to contamination on a specific body part. Information of this type will be reported so retraining can be implemented.

e. Identify and record irregular items regarding dose and dosimetry issue, usage, loss, misreading, etc.

f. Identify and record irregular items regarding instrumentation function, reports of instrumentation malfunction, and general instrumentation performance. Frequent reports of instrumentation error may indicate lack of familiarity with a particular instrument. Retraining or training may be required.

g. All findings from this review will be incorporated in a report delivered to the Director of Health Physics and the Deputy General Manager.

\subsection{RECORDS}

\subsection{REQUIRED FORMS}

Survey Review and Evaluation Form (Form Number 2.1.5-1)

\subsection{COMPLETION AND APPROVAL REQUIREMENTS}

The Survey Review and Evaluation Form (Form Number 2.1.5-1) will be completed by the Health Physics Supervisor. The Survey and Review Evaluation Form will be included as an Appendix to the report on Survey Review and Evaluation submitted to the Director of Health Physics and the Deputy General Manager on a quarterly basis. 


\subsection{PROCESSING AND APPROVAL REQUIREMENTS}

1. Documents required or created in support of this Procedure are quality assurance records. The Survey Review and Evaluation Report will be included in the quality assurance records package.

2. The record of this survey review and evaluation report shall be submitted to the Records Management Technician who, as custodian, will ensure that the document is complete, legible, and adequately identifiable. The quality assurance records resulting from this procedure shall be retained in accordance with Administrative Procedure AP custodian. by the records

\subsection{REFERENCES}

None. 
Page 4 of 5

Revision $\frac{5}{0}$

\section{SURVEY REVIEW AND EVALUATION FORM}

FORM NUMBER 2.1.5-1

Date:

Survey Records and Documents reviewed covered the period from

to

List of Survey Records and Documents reviewed:

1.

2.

3.

4.

5.

6.

7.

8.

9.

10.

Signature of Health Physics Supervisor: 


\section{INSTRUCTIONS FOR THE SURVEY REVIEW AND EVALUATION FORM} FORM NUMBER 2.1.5-1

1. Enter the date the review was completed.

2. Enter the dates of the review quarter.

3. Enter the names and numbers of all documents reviewed.

4. Signature of the Health Physics Supervisor. 


\section{OPERATING PROCEDURE}

\section{EMPLOYEE SAFETY FEEDBACK}

Date:

Revision No.: $\underline{0}$

Supersedes:

Page 1 of 10

\section{Approval:}

Concurrence:

Title

Date

Title

Date

\subsection{PURPOSE AND SCOPE}

The purpose of this operating procedure is to prescribe the manner in which feedback regarding safety issues is received from personnel and directed toward management so that concerns and potential safety problems can be assessed, documented, and remedied when necessary.

This procedure applies to any safety concerns that any employee may deem threatening to health, life, and well being. The process is intended to be interactive between all employees and management without prejudice or bias to the employee. The process will initiate investigation into any health and safety issue that is observed in the course of facility operations and will provide a mechanism for the evaluation, control, documentation, and follow-through of the resolution of such problems.

This procedure is not intended to cover emergency situations where there is an immediate danger to life and health and an alarm must be sounded and at-risk personnel evacuated promptly. It is meant to apply to situations where a potential danger is observed and where time exists to take the steps prescribed herein to correct that situation.

\subsection{EQUIPMENT AND MATERIALS}

None.

\subsection{PROCEDURE}




$$
\text { Page } \frac{2}{\text { Revision } 0} \frac{10}{0} \text {. }
$$

\subsection{PREREQUISITES}

Potential health and safety hazards to be identified by personnel are specifically above and beyond those hazards previously identified to personnel as being normally associated with their regular duties.

Changes to this procedure must be approved by the Deputy General Manager for Operations.

\subsection{TRAINING}

According to Procedure __ On-Site Safety Training, each employee shall receive training and be instructed to recognize and avoid unsafe conditions and to understand the regulations applicable to their work environment that control or eliminate hazards.

\subsection{SPECIAL PRECAUTIONS}

Employees are encouraged to be cognizant of potential health hazards in their work environment and to bring any hazards to the attention of their immediate supervisor so the workplace can be safe and efficient. Employees that bring attention of potential problems to their supervisors will not be discriminated against in any way as a result of such actions. Supervisors will act promptly on any request in order to quickly eliminar. the potential hazard.

The publication of this procedure does not relieve anyone on the disposal facility from responsibility to promptly warn others of imminent danger by whatever means available.

\section{$3.4 \quad$ INSTRUCTIONS}

1. Recognition and Identification

a. Employees or personnel that recognize and identify potential hazardous situations or conditions will verbally communicate the condition to their immediate supervisor. A potential hazardous situation includes those in which the potential for the following exists: exposure to physical agents such as noise, heat, cold, radiation, or hazardous materials; asphyxiation; mechanical hazards from site equipment or activities; or fire and explosive hazards.

b. The supervisor will determine whether an imminent danger exists. If immediate action is warranted, the supervisor will stop all related activities until further assessment occurs.

c. The supervisor will fill out a Safety Feedback Response, Form Number 2.1.6-1, on which the employee will affirm that his verbal request was documented correctly with his signature affixed to the form. This form will be filled out for all communications to a 
supervisor, written or verbal, about a safety hazard, regardless of how quickly or easily they may be resolved.

d. The supervisor will contact the Health Physics Supervisor, acting as the On-Site Safety Officer, to initiate evaluation and control of the situation.

e. Once the initial response form has been filled out, the resolution process will begin. The form will go to the Health Physics Supervisor, who will assign a response team to evaluate the situation. The Health Physics Supervisor may act alone as the response team.

2. Information Collection

a. The response team will conduct studies and compile all pertinent information regarding the safety hazard. Sampling will be conducted, if appropriate, in the workplace to determine exposure levels.

b. If required, periodic surveillance of the situation will occur to further assess the potential safety hazard.

3. Evaluation

a. The response team will determine the risk that the potential hazard poses to individuals, the environment, or operations at the facility. It will assess the actual risk associated with the reported hazard and determine the benefits of controlling the risk or allowing continuation of the activity in spite of the hazard.

b. All data collected will be analyzed and compared with appropriate government standards and recommended practices to determine whether the hazard requires control in the form of additional equipment, changes in procedures, etc.

c. Should the safety risk be judged low enough to warrant no response, a detailed explanation as to why no action is to be taken will be provided in writing to the supervisor and to the employee initiating the investigation.

\section{Controls}

The response team will apply methods to reduce or control the hazard associated with the situation reported so as to make it acceptable relative to the benefit achieved. The hierarchy of control methods in order of importance will be engineering control, administrative control, and personal protective equipment. 


$$
\text { Page } \frac{4}{\text { Revisio of } \frac{10}{0}}
$$

1. Engineering controls shall eliminate or reduce the exposure to the hazardous situation. Examples of engineering control include the use of an enclosure system to lower noise levels, or provision of increased ventilation when working with potential hazardous materials in an enclosed area. Equipment may be developed to perform required tasks from a remote location that will reduce or eliminate exposure to radiation.

2. Administrative controls will reduce exposure of an individual to a specific hazard while not actually removing the source of the hazard from the workplace. An example of administrative control is limiting the amount of time employees spend in the hazardous environment.

3. The use of personal protective equipment will be the last resort used for avoiding potential hazards. Where it is used, the type of equipment shall be specified and training shall be given to exposed employees in its proper operation and use.

\section{Follow-Up Action}

a. The response team will thoroughly document the actions taken to mitigate or eliminate the hazardous situation. The Health Physics Supervisor will sign the Safety Feedback Response Form, Number OP 2.1.6-1 to indicate agreement with the Summary and Resolution described on that form.

b. Mandatory training will be scheduled to inform all responsible parties of the hazards associated with activities related to the hazardous condition and the procedures imposed during the performance of those activities.

c. Upon completion of the follow-up action, the employee that initiated the process will be informed of the actions taken and will sign a statement indicating whether he or she is satisfied with the action. The employee may express in writing on the Safety Feedback Response, Form OP 2.1.6-1, reasons for his or her dissatisfaction at that time. A copy of the signed statement will be given to the employee. If the employee is not satisfied, a copy of the statement will be forwarded to the Deputy General Manager for Operations. The Deputy General Manager for Operations will provide a written acknowledgement of receipt of the statement of dissatisfaction, on the Safety Feedback Response, Form OP 2.1.6-1. A copy of the form with the signed acknowledgement will be given to the initiating employee. 


$$
\text { Page } \frac{5}{\text { Revislon } \frac{10}{0}}
$$

\subsection{RECORDS}

\subsection{REQUIRED FORMS}

Safety Feedback Response, Form Number OP 2.1.6-1.

\subsection{COMPLETION AND APPROVAL REQUIREMENTS}

The Initial Response portion of the Safety Feedback Response Form, Number OP 2.1.6-1, will be filled out by the immediate supervisor of the employee indicating a safety problem (the initiator) and the initiator.

The Follow-Up Action portion of the Safety Feedback Response Form, Number OP 2.1.6-1, will be filled out by the Health Physics Supervisor, who will sign the form to show his or her agreement with the description of the Summary and Resolution. The initiating employee will indicate whether the safety hazard was addressed to his or her satisfaction and sign Form Number OP 2.1.6-1.

If the initiating employee indicates that he/she does not feel that the safety hazard was addressed satisfactorily, a copy of Form Number OP 2.1.6-1 will be sent to the Deputy General Manager for Operations, and its receipt will be acknowledged by his or her signature.

\subsection{PROCESSING AND ARCHIVAL REQUIREMENTS}

1. Documents required or created in support of this procedure are quality assurance records. The Safety Feedback Response form will be included in the quality assurance records package.

2. The records shall be submitted to the Records Management Technician who, as custodian, will ensure each document is complete, legible, and adequately identifiable. The quality assurance records resulting from the procedure shall be retained in accordance with (Administrative Procedure AP — by the records custodian.

\subsection{REFERENCES}

Code of Federal Regulations Title 29, Parts 1900 to 1910. 


\section{INSTRUCTIONS FOR THE SAFETY FEEDBACK RESPONSE FORM NUMBER OP 2.1.6-1}

1. Enter the date on which the initial safety concern was transmitted in the "Date" box.

2. Enter the name of the employee that expressed the concern on the line in the "initiator" box.

3. Enter the number of the employee who expressed concern in the "Employee No." box.

4. Indicate with a check in the appropriate box how the employee's concern was first transmitted.

5. Enter the time of day when the employee concern was received.

6. Describe the safety problem as reported by the employee in the "Problem Statement" box. Attach additional sheets if necessary.

7. Enter the names and titles of the members of the response team.

8. Indicate with a check in the appropriate box whether the possibility of serious danger to life or health related to the safety issues raised by the employee exists.

9. If the "Yes" box was checked, list the steps taken to eliminate the serious danger to life and health.

10. Indicate with a check in the appropriate box if the Health Physics Supervisor was notified.

11. If the "Yes" box was checked, enter the date and time of the notification.

12. If the employee who initiated the safety feedback agrees with the appraisal of the situation as described on the form, the employee will sign on the "Initiating Employee" line.

13. If the employee signs on the "Initiating Employee" line, then the supervisor will sign on the "Supervisor" line.

14. If the initiating employee disagrees with the appraisal, he or she will indicate their reason for disagreeing in the box and sign and date that statement.

15. List follow-up actions taken to eliminate serious danger to life and health.

16. The Health Physics Supervisor will verify that the summary and resolution are correctly stated by signing the form. 


$$
\text { Page } \frac{7}{\text { Revision } \frac{10}{0}}
$$

17. The employee who initiated the safety feedback will evaluate the resolution of the safety concern and indicate his or her satisfaction with a check in the appropriate box.

18. The initiating employee will sign on the "Employee" line and enter the date.

19. If the employee is not satisfied, he or she will explain their dissatisfaction in the "Provide Explanation" box.

20. If the "No" box was checked, the Deputy General Manager for Operations will sign on the "Deputy General Manager for Operations" line indicating that he or she received the statement of dissatisfaction. 


\section{SAFETY FEEDBACK RESPONSE}

FORM NUMBER OP 2.1.6-1

\section{INITIAL RESPONSE}

\begin{tabular}{|l|l|l|l|}
\hline Date: & Initiator:__ (Print Name) & Employee No: \\
\hline
\end{tabular}

Problem Statement:

\begin{tabular}{|ccc|}
\hline Response Team: & & \\
\hline (Name) & & (Title) \\
\hline (Name) & & (Title) \\
\hline (Name) & & (Title) \\
\hline (Name) & & (Title) \\
\hline
\end{tabular}

\begin{tabular}{|l|}
\hline Is there serious danger to life and health? $\quad \square$ Yes $\quad \square$ No \\
\hline If yes, what steps were taken: \\
\hline
\end{tabular}




\begin{tabular}{|c|c|c|}
\hline $\begin{array}{l}\text { Was the Health and Safety Officer notified? } \\
\square \text { Yes }\end{array}$ & Date & Time \\
\hline
\end{tabular}

This is to the best of my knowledge a correct appraisal of the situation.

\begin{tabular}{|c|c|c|c|}
\hline Initiating Employee & $\overline{\text { Date }}$ & Supervisor & $\overline{\text { Date }}$ \\
\hline \multicolumn{4}{|c|}{ If the initiating employee disagrees with the appraisal of the situation, state why: } \\
\hline Initiating Employee & $\overline{\text { Date }}$ & & \\
\hline
\end{tabular}

\section{FOLLOW-UP ACTION}

Summary \& Resolution:

Attached Pertinent Documentation

I verify that the above description of the summary and resolution is correct: 


\section{SAFETY FEEDBACK RESPONSE}

FORM OP 2.1.6-1

(Continued)

The resolution of this safety hazard has been addressed to my satisfaction?

$\square$ Yes $\square$ No

If no, provide explanation:

Acknowledgement of receipt of statement of dissatisfaction by initiating employee

Initiating Employee Date
Revis: $\frac{10}{\text { if }} \frac{10}{10}$
Acknowledgement of receipt of statement of dissatistaction by initiatin

Deputy General Manager for Operations

Date 


\section{A-2. RADIATION SAFETY PROCEDURES}


A-66 


\title{
OPERATING PROCEDURE
}

\author{
DOSIMETER ISSUANCE
}

Date:

Revision No.: $\frac{0}{14}$

Supersedes:

Page 1 of 14

Approval: Concurrence:

\begin{tabular}{lll}
\hline Title & Date & Title \\
\hline
\end{tabular}

\subsection{PURPOSE AND SCOPE}

This procedure describes the method used to issue radiation dosimetry devices to facility personnel and visitors.

Regulations require that all occupational exposures to radiation be quantified and not be allowed to exceed certain monthly, quarterly, and annual limits. Therefore, all individuals entering the radiologically controlled area of the low-level radioactive waste disposal facility will be issued dosimeters prior to entry and shall wear these dosimeters the entire time they are in the radiologically controlled area.

The Health Physics Supervisor has the overall responsibility of administrating the dosimetry program under the guidance of the Director of Health Physics.

Because knowledge of exposure levels is required for dosimeter issuance, this procedure shall be completed only by the Health Physics Supervisor or a health physics technician.

\subsection{EQUIPMENT}

1. Thermoluminescent dosimeters (TLDs) and holders

2. Direct reading dosimeters-either pocket ion chambers or digital electronic pocket dosimeters

3. Extremity dosimeters-finger rings or patches. 


$$
\text { Page } \frac{2}{\text { Revision } \frac{14}{0}}
$$

\subsection{PROCEDURE}

\subsection{PREREQUISITES}

1. Only health physics staff will perform this procedure.

2. Issue Criteria-Facility Personnel

a. Whole body monitoring dosimeters shall be issued to facility personnel who may receive exposure to the major portion of the whole body, i.e., head and trunk, active blood-forming organs, gonads or lens of eyes, that may be greater than 2 millirem in any one hour or greater than 125 millirem per calendar quarter. Dosimeters shall be issued after the completion of training. Dosimeters shall be picked up when entering the radiologically controlled area. TLDs shall be exchanged and read on a monthly basis.

b. Extremity monitoring dosimeters shall be required when the exposure rate to the extremities, i.e., hands and forearms or feet and ankles, is potentially 50 percent higher than the exposure to the whole body.

3. Issue Criteria-Visitors

All visitors are defined as persons who spend less than 10 working days per month at the low-level radioactive waste disposal facility.

a. All visitors to the disposal facility that enter a radiologically controlled area shall be issued a direct reading dosimeter (DRD).

b. All visitors who are likely to receive $\mathbf{5 0}$ mrem shall be issued a TLD in addition to the DRD.

4. The calibration dates of pocket ion chamber and digital DRD's shall be checked prior to issue. Pocket ion chamber dosimeters shall have been calibrated for accuracy and drift (for ion chambers) within six calendar months prior to issuance. Digital dosimeters shall be recalibrated on an annual basis.

5. Finger rings or tapes shall be issued to individuals when the potential dose rate to any extremity is 50 percent above the whole body dose rate.

6. Unissued TLDs or exposed TLDs turned in early (e.g., because of a vacation) shall be stored in a shielded background area designated by the Health Physics Supervisor.

7. When not in use, dosimeters shall be stored in a shielded low background area specified by the Health Physics Supervisor. 
8. Only National Voluntary Laboratory Accreditation Program (NVLAP) approved TLD vendors and processors shall be used.

\subsection{TRAINING}

1. All disposal facility personnel shall have completed the basic radiation worker training course according to Procedure __, On-Site Safety Training, prior to receiving a dosimeter and entry into the radiologically controlled area of the facility.

2. Prior to receiving a temporary dosimeter and entry into the radiologically controlled area, visitors must attend a brief safety presentation according to Procedure On-Site Safety Training. Visitors must be escorted by trained facility personnel at all times.

\subsection{SPECIAL PRECAUTIONS}

1. Personnel who lose or damage their dosimeter shall immediately leave the radiologically controlled area and notify a member of the health physics staff.

2. If the reading of a person's direct-reading dosimeter is above or below scale limits, the person shall immediately leave the radiologically controlled area and notify health physics personnel.

\section{$3.4 \quad$ INSTRUCTIONS}

This procedure shall be completed only by the Health Physics Supervisor or a health physics technician.

1. Check the Dosimeter Issue Log, Form Number OP 2.2.1-1, to ensure the TLD about to be issued has not been previously used.

2. If a pocket ion chamber pocket direct reading dosimeter (DRD) is issued, ensure that it is zeroed.

3. If a digital electronic direct reading dosimeter is issued, follow the manufacturer's instructions for zeroing and recording exposure levels.

4. Employees of the disposal facility shall be issued a TLD and a DRD.

5. Health physics staff shall complete the Monthly Radiation Exposure Log, Form Number 2.2.1-2, for all employees on a daily basis. These completed forms shall be returned on a monthly basis at the same time their TLD is exchanged.

6. If extremity dosimetry devices are issued, the Extremity Monitoring Log, Form Number OP 2.2.1-3 shall be completed. 


$$
\text { Page } \frac{4}{\text { Revision } \frac{14}{0}}
$$

7. Visitors

a. With the visitor's assistance, complete the Visitor Radiation Exposure Authorization, Form Number OP 2.2.1-4. Assure all information is completed prior to allowing access.

b. The visitor shall be issued dosimetry device(s) according to the criteria listed in 3.1 above.

c. If applicable, the TLD number and issue and return date shall be entered into the appropriate spaces. The device number of the DRD will be entered in the appropriate block along with the date of issue and the pocket dosimeter reading, in and out. A health physics technician shall sign the signature block upon daily return.

8. The Health Physics Supervisor shall complete the results sections of all the forms (numbers OP 2.2.1-1,OP. 2.2.1-2, OP 2.2.1-3, and OP 2.2.1-4) on a monthly basis after the TLDs have been read by the vendor. Radiation exposure reports shall be prepared as indicated in Procedures

Radiation Exposure Records, , Visitor Exposure Reports, and , Exposure Data Review and Reporting.

\subsection{RECORDS}

\subsection{REQUIRED FORMS}

Dosimeter Issue Log, Form Number OP 2.2.1-1

Monthly Radiation Exposure Log, Form Number OP 2.2.1-2

Extremity Monitoring Log, Form Number OP 2.2.1-3

Visitor Radiation Exposure Authorization, Form Number OP 2.2.1-4

\subsection{COMPLETION AND APPROVAL REQUIREMENTS}

The Dosimeter Issue Log, Form Number OP 2.2.1-1 will be completed by the Health Physics Supervisor or a health physics technician.

The Monthly Radiation Exposure Log, Form Number OP 2.2.1-2 will be completed on a daily basis by health physics staff for each facility employee issued dosimetry devices.

Extremity Monitoring Log, Form Number OP 2.2.1-3 will be completed by the Health Physics Supervisor or a health physics technician.

The Visitor Radiation Exposure Authorization, Form Number OP 2.2.1-4 will be completed by the Health Physics Supervisor or a health physics technician with assistance from the visitor. Entries on page 2 of this form will be completed on a daily basis for the duration of the visitor's stay. 


\subsection{PROCESSING AND ARCHIVAL REQUIREMENTS}

1. Documents required or created in support of this procedure are quality assurance records. The Dosimeter Issue Log, Monthly Radiation Exposure Log, Extremity Monitoring Log, and Visitor Radiation Exposure Authorization forms will be included in the quality assurance records package.

2. The records shall be submitted to the Records Management Technician who, as custodian, will ensure each document is complete, legible, and adequately identifiable. The quality assurance records resulting from this procedure shall be retained in accordance with Administrative Procedure AP by the records custodian.

\subsection{REFERENCES}

1. 10 CFR 19

2. 10 CFR 20 


$$
\text { Page } \frac{6}{\text { Revision } \frac{14}{0}}
$$

\section{INSTRUCTIONS FOR FORM NUMBER OP 2.2.1-1 DOSIMETER ISSUE LOG}

TLD issuance is to be recorded in the Dosimeter Issue Log as follows:

1. Enter the device number in the appropriate column.

2. List the reason for issue (i.e. routine, special project, replacement, etc.).

3. Enter the last name, first name, and middle initial of the person receiving the dosimeter.

4. Enter the recipient's social security number.

5. Enter the date the device is issued. .

6. Enter the date the device is returned.

7. Enter the device results in mrem.

8. Enter the results in $\mathrm{mR}$ obtained by pocket dosimeter. 
DOSIMETER ISSUE LOG

FORM NUMBER OP 2.2.1-1

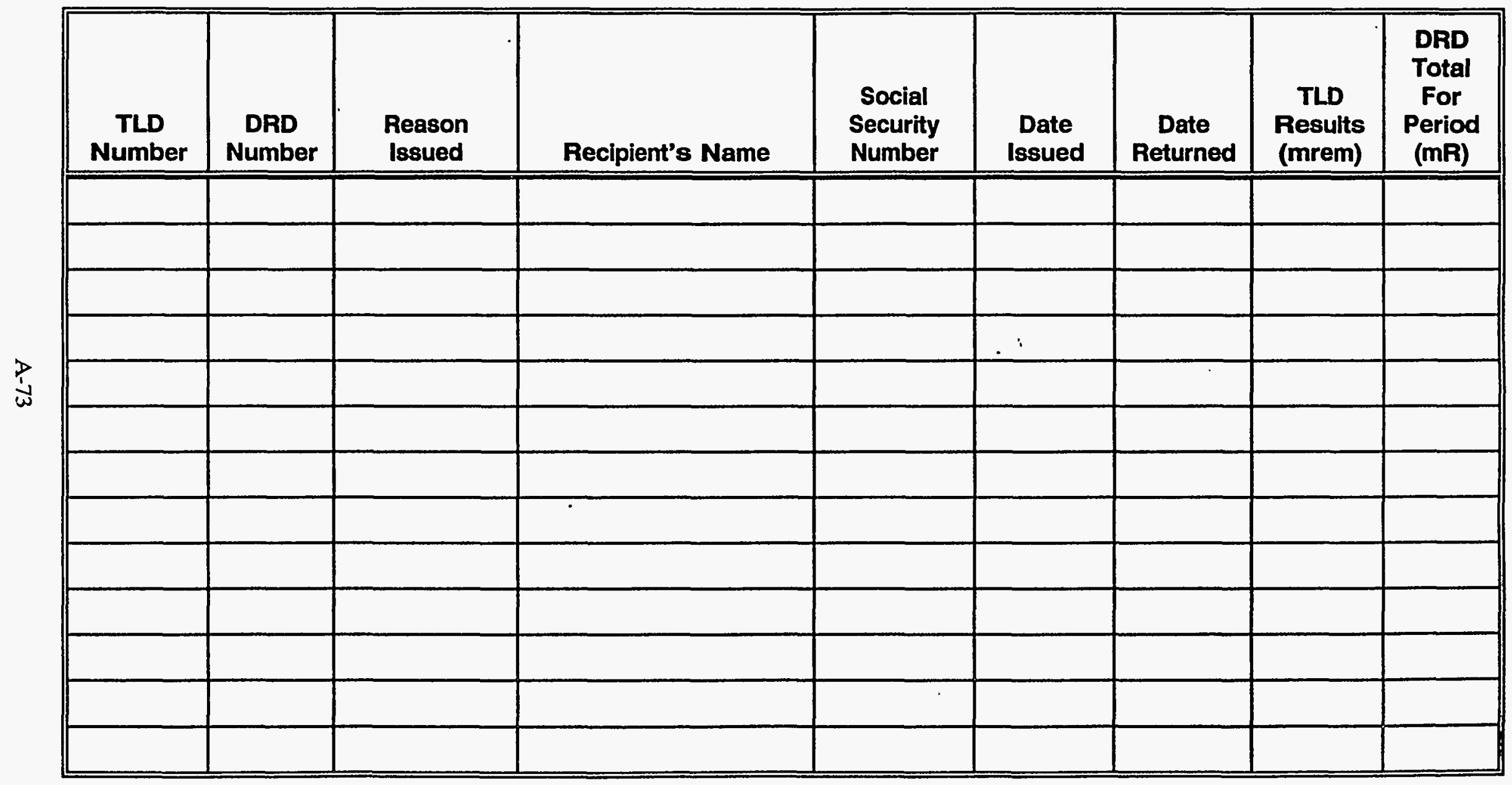



MONTHLY RADIATION EXPOSURE LOG

Facility employees will be issued a Monthly Radiation Exposure Log with their TLD and pocket dosimeter.

1. The issuing health physics technician will enter the name, social security number, and title of the wearer, the month and year, and the pocket dosimeter number blanks.

2. The wearer will be required to maintain the log by recording pocket dosimeter readings on a daily basis.

3. The Health Physics Supervisor will review each individual's dose. 


\section{MONTHLY RADIATION EXPOSURE LOG \\ FORM NUMBER OP 2.2.1-2}

Name:

Title:

Month/Year:

Social Security Number:

Direct Reading Device Number:

\begin{tabular}{|c|c|l|l|l||}
\hline \hline Day & In Reading & Out Reading & $\begin{array}{c}\text { Daily Exposure } \\
\text { (mR) }\end{array}$ & $\begin{array}{c}\text { Total } \\
\text { (mR) }\end{array}$ \\
\hline \hline 1 & & & & \\
\hline 2 & & & & \\
\hline 3 & & & & \\
\hline 4 & & & & \\
\hline 5 & & & & \\
\hline 6 & & & & \\
\hline 7 & & & & \\
\hline 8 & & & & \\
\hline 9 & & & & \\
\hline 10 & & & & \\
\hline 11 & & & & \\
\hline 12 & & & & \\
\hline 13 & & & & \\
\hline 14 & & & & \\
\hline 15 & & & & \\
\hline 16 & & & & \\
\hline 17 & & & & \\
\hline 18 & & & & \\
\hline 19 & & & & \\
\hline 20 & & & & \\
\hline 21 & & & & \\
\hline 22 & & & & \\
\hline 23 & & & & \\
\hline 24 & & & & \\
\hline 25 & & & & \\
\hline 26 & & & & \\
\hline 27 & & & & \\
\hline 28 & & & & \\
\hline 29 & & & & \\
\hline 30 & & & & \\
\hline 31 & & & & \\
\hline
\end{tabular}




\section{INSTRUCTIONS FOR FORM NUMBER OP 2.2.1-3 EXTREMITY MONITORING LOG}

Issuance of extremity dosimetry shall be recorded by either the Health Physics Supervisor or a health physics technician as follows:

1. Enter the device number.

2. Enter recipient's last name, first name, and middle initial.

3. Enter recipient's social security number.

4. List the reason for issue (i.e. routine, special project, replacement, etc.).

5. Enter the location of extremity dosimetry (i.e., hand or foot).

6. Enter the date the device is issued.

7. Enter the date the device is returned.

8. Enter the dose calculated from processing the device (mrem).

During nonworking hours, personnel dosimeters shall be stored in special areas designated by the Health Physics Supervisor. 


\section{EXTREMITY MONITORING LOG}

FORM NUMBER OP 2.2.1-3

\begin{tabular}{|c|c|c|c|c|c|c|c|}
\hline $\begin{array}{l}\text { Device } \\
\text { Number }\end{array}$ & Recipient's Name & $\begin{array}{l}\text { Social Security } \\
\text { Number }\end{array}$ & $\begin{array}{l}\text { Reason for Extremity } \\
\text { Monitoring }\end{array}$ & $\begin{array}{l}\text { Location } \\
\text { on the } \\
\text { Body }\end{array}$ & $\begin{array}{l}\text { Date } \\
\text { Issued }\end{array}$ & $\begin{array}{c}\text { Date } \\
\text { Returned }\end{array}$ & $\begin{array}{l}\text { Device } \\
\text { Results } \\
\text { (mrem) }\end{array}$ \\
\hline & & & & & & & \\
\hline & & & & & & & \\
\hline & & & & & & & \\
\hline & & & & . & & & \\
\hline & & & & & & & \\
\hline & & & & & & & \\
\hline & & & & & & & \\
\hline & & & & & & & \\
\hline & & & & & & & \\
\hline & & & & & & & \\
\hline & & & & & & & \\
\hline & & & & & & & \\
\hline
\end{tabular}




\section{INSTRUCTIONS FOR FORM NUMBER OP 2.2.1-4} VISITOR RADIATION EXPOSURE AUTHORIZATION

Issuance of dosimetry devices to visitors shall be recorded by either the Health Physics Supervisor or a health physics technician as follows:

1. Circle the agency the visitor represents

2. With the visitor's assistance, complete the personal information section, including: name, social security number, address, employer, and employer's address.

3. The visitor shall complete and sign the exposure and qualification statement at the bottom of page 1.

Page 2 of the form is for recording dosimetry device identification number and exposure results, both daily (DRD) and total (TLD). This information will be recorded by health physics personnel.

1. Record the device numbers as issued.

2. Record the dates of issue and return for TLDs.

3. Record the dates and daily exposure levels (in $m R$ ) for the DRDs.

4. Record the dose received (in mrem) after the TLD is processed.

During nonworking hours, personnel dosimetry shall be stored in special areas designated by the Health Physics Supervisor. 


\section{VISITOR RADIATION EXPOSURE AUTHORIZATION \\ FORM NUMBER OP 2.2.1-4}

CIRCLE ONE:

FACILITY STAFF VISITOR SUBCONTRACTOR OTHER

VISITOR'S NAME:

(Last)

(First)

SEX: $M$ F

VISITOR'S SOCIAL SECURITY NUMBER:

VISITOR'S HOME ADDRESS:

BIRTHDATE:

CITY:

STATE:

ZIP:

EMPLOYER (FULL NAME):

EMPLOYER'S ADDRESS:

CITY: STATE:

ZIP:

My known or estimated occupational radiation exposure is mrem for the current calendar quarter and mrem for the calendar year. I know of no medical disqualification which should prevent my receiving a radiation dose within applicable State or Federal Standards.

Visitor's Signature

Date 


\section{VISITOR RADIATION EXPOSURE AUTHORIZATION}

FORM NUMBER OP 2.2.1-4

(Continued)

\section{DOSIMETER (TLD) BADGE INFORMATION}

Badge Number:

Issue Date:

Ending Date:

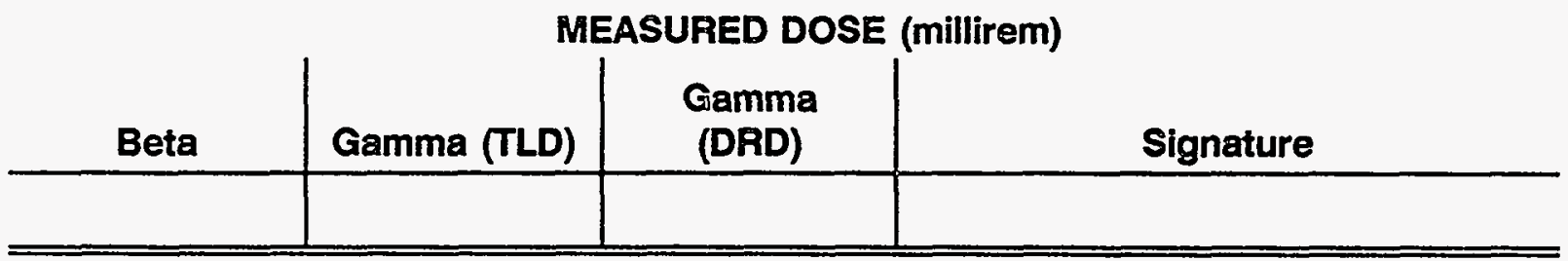

\section{DIRECT READING DOSIMETER INFORMATION}

(For Use Only When DRD is Issued)

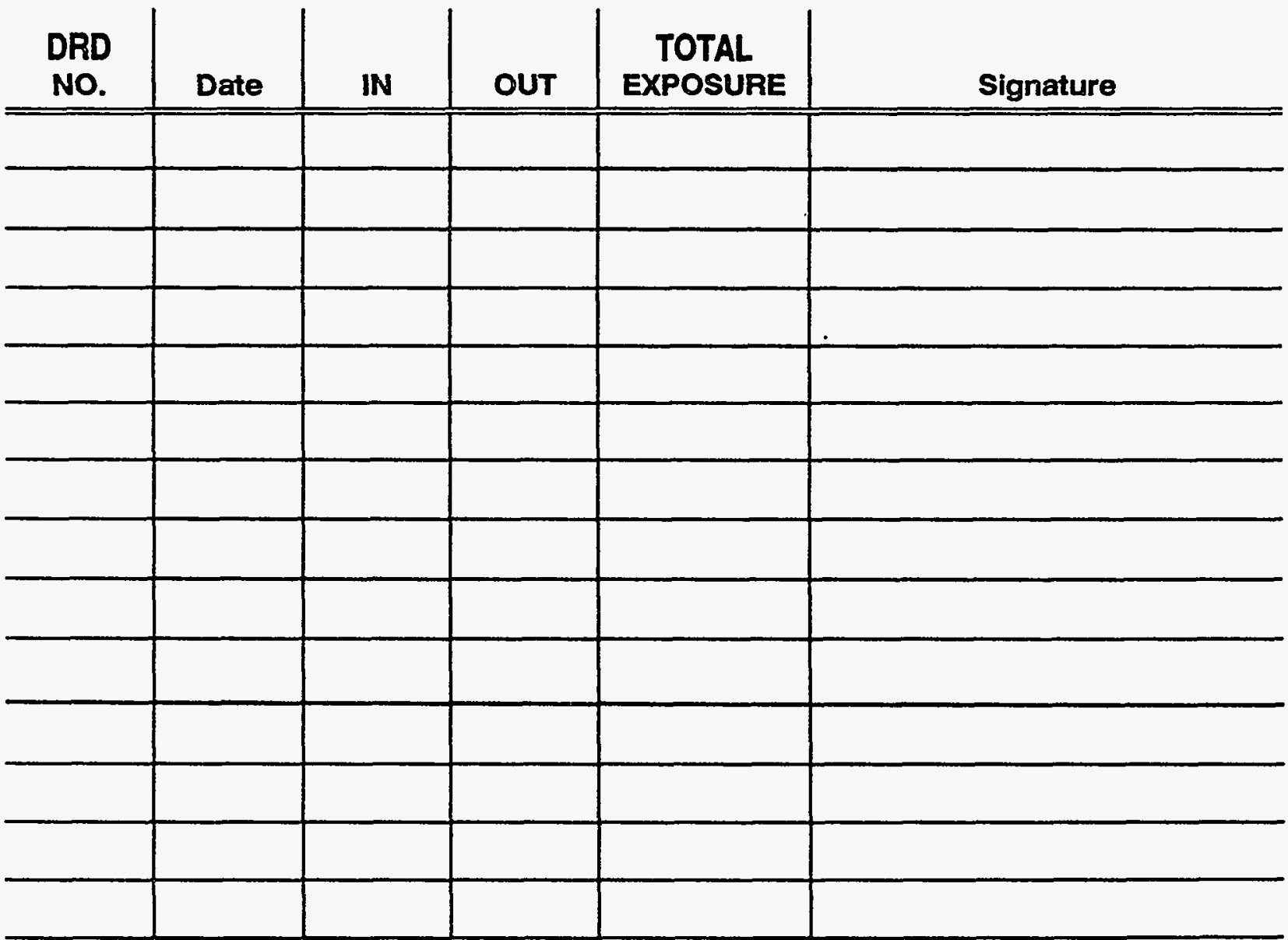




\section{OPERATING PROCEDURE}

\section{INTERNAL RADIATION MONITORING}

Date:

Revision No: $\underline{0}$

Supersedes:

Page 1 of 11

Approval:

Concurrence:

Title

Date

Title

Date

\subsection{PURPOSE AND SCOPE}

This procedure describes the methods for monitoring personnel for internal radiation exposure.

The state and the U.S. Nuclear Regulatory Commission require that all occupational exposures to radiation be measured and not be allowed to exceed certain limits. This includes inhalation and ingestion of radioactive material. All individuals occupationally exposed to radioactive material are required to participate in a program to monitor internal levels of radioactivity.

The Health Physics Supervisor has the overall responsibility of administering the internal radiation monitoring program under the guidance of the Director of Health Physics.

\subsection{EQUIPMENT}

1. Urine sample collection kit-collection container, labels, and instructions

2. Nasal smear collection kit-swabs, vials for the swabs, labels, and instructions.

\subsection{PROCEDURE}

\subsection{PREREQUISITES}

1. The facility will have an agreement with a nuclear power plant to utilize its whole body counting equipment on an as-needed basis. 
2. The facility will use an analytical laboratory to analyze samples (urine, blood, nasal smears, etc.) for internal contamination.

3. Only health physics staff will complete the forms described in this procedure.

\subsection{TRAINING}

None

\subsection{SPECIAL PRECAUTIONS}

None

\section{$3.4 \quad$ INSTRUCTIONS}

This procedure is to be performed by the Health Physics Supervisor or an experienced health physics technician under his or her supervision.

1. Frequency of Monitoring

a. New Employees

Initial baseline internal radioactivity levels shall be established for all personnel who will be exposed to radioactive materials while employed at the facility.

1. A whole body count and urinalysis shall be completed prior to assignment in areas of potential internal exposure. These analyses shall be performed within the first 30 days of employment.

2. If the presence of radioactive material is detected above what is considered background for personnel for the facility, the Director of Health Physics shall be notified, and a letter shall be placed in the individual's dosimetry file indicating that this exposure was received prior to employment with the disposal facility operator.

b. Routine Monitoring

1. Urinalysis

Personnel shall have their urinalyses repeated on an annual basis. The annual urinalysis shall be compared to the initial baseline. The Director of Health Physics shall be notified of any indication of internal ingestion or inhalation above levels previously established for the individual during initial employment. A report shall be placed in the individual's 
dosimetry file stating the probable cause and resultant calculated dose. Investigations shall be conducted as to the cause of the incident and validity of the results.

Additional urinalysis may be required, at the discretion of the Health Physics Supervisor, following any accidental release, decontaminations, and other non-routine operations. Analysis of air samples can also be the basis for requiring additional whole body counts.

\section{Whole Body Count}

Whole body counts may be required, at the discretion of the Director of Health Physics, following any accidental release, decontaminations, and other non-routine operations. Analysis of air samples can also be the basis for requiring whòle body counts.

c. Non-Routine Monitoring

If the facility air sampling program indicates that personnel may have been exposed to levels of radioactivity that may have exceeded 50 percent of the Maximum Permissible Concentrations, the Health Physics Supervisor, in consultation with the Director of Health Physics, may require additional internal monitoring. This monitoring may include, but is not be limited to: whole body counts, urinalysis, nasal smears, and thyroid scans.

d. Exit Monitoring

When employees who have been occupationally exposed while working at the facility leave employment or are permanently transferred to other assignments not involving routine activities at the low-level waste disposal facility, they shall receive a final internal monitoring check. If a terminated or transferred employee refuses to have the analysis conducted, a letter describing the employee's refusal will be prepared by the Health Physics Supervisor and signed by the Director of Health Physics and placed in the employee's dosimetry file.

2. Specific Internal Monitoring Procedures

a. Whole Body Counting

Whole body counts shall be performed at a qualified facility under contract to the facility operator.

Personnel shall be sent to the whole body counting facility with a Whole Body Count Request, Form Number OP 2.2.2-1. 


$$
\text { Page } \frac{4}{\text { Revisirsi of } \frac{11}{0}}
$$

b. Urinalysis

Urine samples shall be collected according to the vendor-supplied instructions in the sample collection kit.

Urine sample kits shall be sent to the vendor along with a Bioassay Analysis Request, Form Number OP 2.2.2-2.

\section{c. Nasal Smears}

Nasal smears shall be used as an additional measure of potentia: internal contamination, and may be used by the Health Physics Supervisor to decide whether to require non-routine monitoring such as: special whole body counting, thyroid scans, special urinalysis, tissue bioassay, etc. Nasal smears shall be performed by the health physics staff as follows:

1. The exposed individual will be directed to place the tip of a dry cotton swab on the inside surface of one nostril. Roll the swab CAREFULLY around the circumference of the nostril. Repeat for the other nostril.

2. Clip the end of each cotton swab and place it in the appropriate container. Depending on the counting equipment available, this may be a planchet for counting in a low-background counter, a liquid scintillation vial for counting in a liquid scintillation analyzer, or a special vial for shipment to an offsite vendor.

3. Typically, if the nasal smear results are greater than twice background, the Health Physics Supervisor will require whole body counting and/or urinalysis. If significant amounts of specific radionuclides are detected, the Health Physics Supervisor may require special types of monitoring, such as a thyroid scan for iodine.

3. The Bioassay Summary Sheet, Form Number OP 2.2.2-3 will be completed by the Health Physics Supervisor as reports are returned from the offsite laboratory. At a minimum, the Health Physics Supervisor will complete these forms concurrent with the quarterly update of dosimetry files and the preparation of radiation exposure reports as indicated in Procedure Review and Reporting. - Radiation Exposure Records, and , Exposure Data

\subsection{RECORDS}

\subsection{REQUIRED FORMS}

Whole Body Count Request, Form Number OP 2.2.2-1 
Page $\frac{5}{\text { Revision } \frac{11}{0}}$

Bioassay Analysis Request, Form Number OP 2.2.2-2

Bioassay Summary Sheet, Form Number OP 2.2.2-3

\subsection{COMPLETION AND APPROVAL REQUIREMENTS}

The Whole Body Count Request, Form Number OP 2.2.2-1 will be completed by the Health Physics Supervisor or a health physics technician.

The Bioassay Analysis Request, Form Number OP 2.2.2-2 will be completed by the Health Physics Supervisor or a health physics technician.

The Bioassay Summary Sheet, Form Number OP 2.2.2-3 will be completed by the Health Physics Supervisor quarterly or as reports are returned from the off-site vendor.

\subsection{PROCESSING AND ARCHIVAL REQUIREMENTS}

1. Documents required or created in support of this procedure are quality assurance records. The Whole Body Count Request, Bioassay Analysis Request, and Bioassay Summary Sheet forms will be included in the quality assurance records package.

2. The records shall be submitted to the Records Management Technician who, as custodian, will ensure each document is complete, legible, and adequately identifiable. The quality assurance records resulting from this procedure shall be retained in accordance with Administrative Procedure AP by the records custodian.

\subsection{REFERENCES}

10 CFR 20 


$$
\text { Page } \frac{6}{\text { Revision } \frac{11}{0}}
$$

\section{INSTRUCTIONS FOR FORM NUMBER OP 2.2.2-1 WHOLE BODY COUNT REQUEST}

This form will be completed by the Health Physics Supervisor on an as-needed basis for the purpose of requesting a whole body count from either a utility or other vendor.

1. Fill in the date.

2. Circle the type of count being requested and describe the reason for the request.

3. Enter the name and social security number of the employee being counted.

4. Provide the date and location of the employee's last whole body count.

(Name and phone number information will be provided at a later date when the facility development is farther along.) 


\section{WHOLE BODY COUNT REQUEST \\ FORM NUMBER OP 2.2.2-1}

DATE:

TYPE (circle one): INITIAL ANNUAL EXIT SPECIAL

REASON FOR WHOLE BODY COUNT:

NAME:

SOCIAL SECURITY NUMBER:

Please provide the above listed employee with a whole body count as indicated. The employee's last whole body count was on of your analysis to:

- Please provide the results

Health Physics Supervisor

Disposal Facility

Address

Address

If you have any questions regarding this request, please contact at 11 . 


\section{INSTRUCTIONS FOR FORM NUMBER OP 2.2.2-2} BIOASSAY ANALYSIS REQUEST

This form will be completed by the Health Physics Supervisor to accompany urine samples or other types of bioassay samples.

1. Provide the name and social security number for each of the employee's sample kits.

2. Provide a sample number. Numbers will have been assigned to each of the kits by the vendor prior to issue.

3. Specify the type of sample medium. Under routine circumstances, this will be urine. Other types of media may include: blood, feces, sputum, or nasal smears.

4. Specify the type of analysis desired. Some examples include: isotopic alpha, gross beta (with a subtraction for potassium 40), gross gamma, tritium, carbon-14, etc.

5. Specify the detection limits. These are usually near background levels. Usually levels for concern are about three times the detection limits. Some examples are:

$\begin{array}{lll}\text { DETECTION LIMITS: } & \text { Isotopic Alpha } & 0.1 \mathrm{pCi} / \mathrm{l} \\ \text { (example only) } & \text { Gross Beta Minus K-40 } & 30 \mathrm{pCi} / \mathrm{l} \\ & \text { Tritium } & 300 \mathrm{pCi} / \mathrm{l} \\ & \text { Carbon-14 } & 100 \mathrm{pCi} / \mathrm{l}\end{array}$

6. Provide the sample date. In some cases this may be a range of dates depending on the type of sample (e.g. a composite urine sample).

7. Indicate any special circumstances or concerns in the remarks section. 
BIOASSAY ANALYSIS REQUEST

FORM NUMBER OP 2.2.2-2

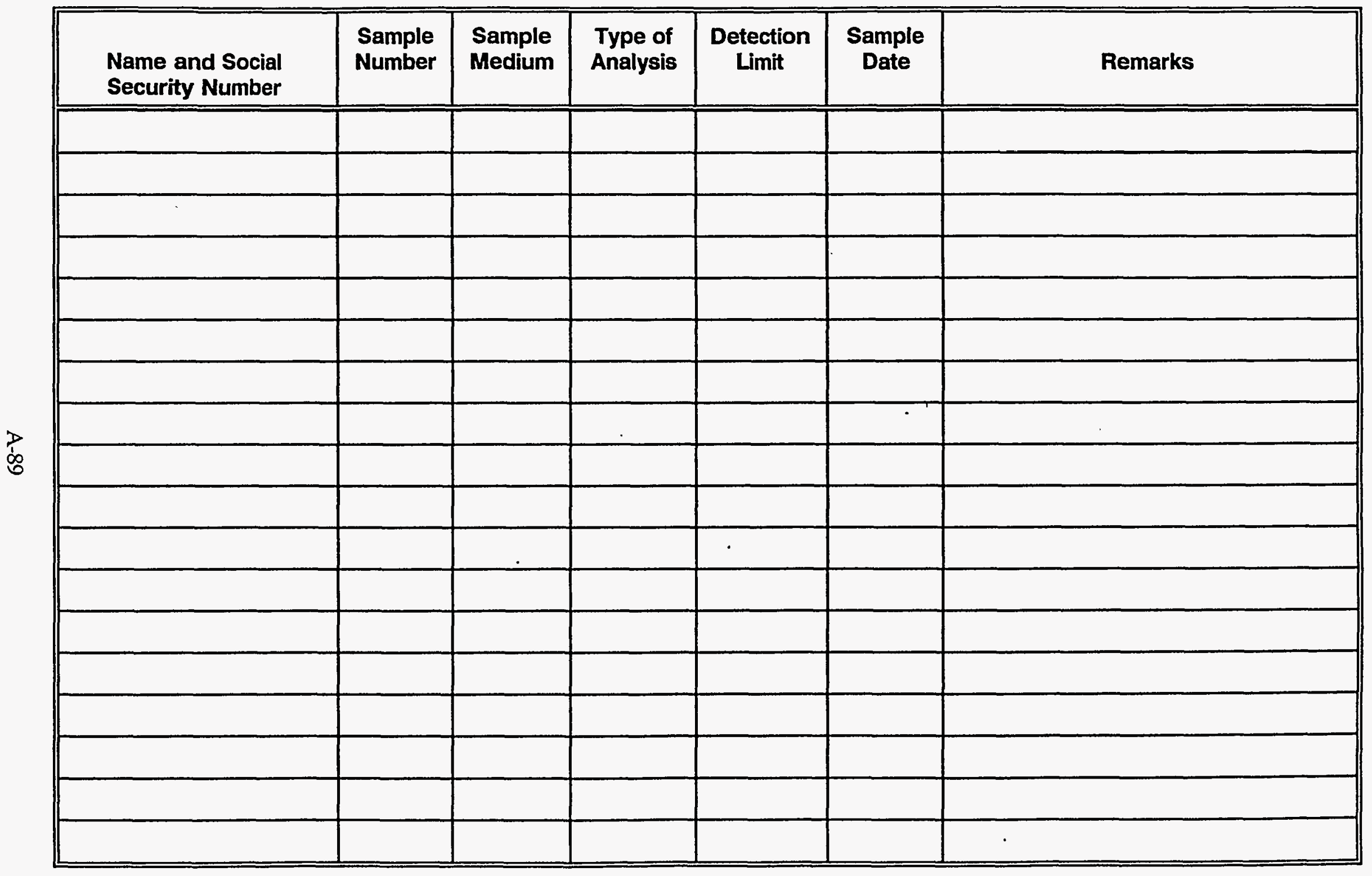




\section{INSTRUCTIONS FOR FORM NUMBER OP 2.2.2-3} BIOASSAY SUMMARY SHEET

This form will be completed by the Health Physics Supervisor as sample reports are returned from the vendor. At a minimum this form will be updated on a quarterly basis after the receipt of any sample reports. The form is kept in the employee's dosimetry file.

1. Provide the name and social security number of the person whose record this is.

2. Provide the sample date.

3. Indicate the reason for the sample (e.g. initial, routine/annual, special).

4. List the results from the various analyses (e.g isotopic alpha, gross beta, gross gamma, tritium, carbon-14, etc.).

5. Identify the person entering the data (signature, initials, social security number, etc.).

6. Provide any comments in the remarks area. 
EMPLOYEE NAME: SOCIAL SECURITY NUMBER:

\begin{tabular}{|c|c|c|c|c|c|c|}
\hline \multirow[b]{2}{*}{ Sample Date } & \multirow[b]{2}{*}{ Reason } & \multicolumn{4}{|c|}{ RESULTS (pCi/l) } & \multirow[b]{2}{*}{ Entry By } \\
\hline & & Isotopic Alpha & Gross Beta & $\mathrm{H}-3$ & C-14 & \\
\hline & & & & & & \\
\hline & & & & & & \\
\hline & & & & & & \\
\hline & & & & & & \\
\hline & & & & & & \\
\hline & & & & $\therefore$ & & \\
\hline & & & & & & \\
\hline
\end{tabular}

ACTION LIMITS:

(example only)
Isotopic Alpha

Gross Beta Minus K-40

Tritium

Carbon-14
$0.3 \mathrm{pCi} / \mathrm{l}$

$90 \mathrm{pCi} / \mathrm{l}$

$900 \mathrm{pCi} / \mathrm{l}$

$300 \mathrm{pCi} / \mathrm{l}$

Remarks: 


\title{
OPERATING PROCEDURE
}

\author{
PERSONNEL DECONTAMINATION
}

Date:

Supersedes:

Revision Ao.: 0

Approval:

Concurrence:

Title

Date

Title

Date

\subsection{PURPOSE AND SCOPE}

This procedure contains guidelines to be followed when decontamination of personnel is required. Decontamination procedures will be performed under the supervision of Health Physics staff. Procedures for skin decontamination, hair decontamination, and major body contamination are described. These steps cover the majority of typical contamination incidents associated with personnel. Combinations of the procedures given here may be used for more specialized (but much less likely) areas of contamination, such as the genitals. Other, more extreme, methods of decontamination as listed in the "Radiological Health Handbook" (1970 edition) may be used at the discretion of and, under the direct supervision of, the Health Physics Supervisor.

\subsection{EQUIPMENT AND MATERIALS}

1. A portable beta-gamma survey instrument equipped with a pancake probe (maximum window thickness of a $2.0 \mathrm{mg} / \mathrm{cm}^{2}$ ). Commonly used examples are the Ludlum $2 A$ and the Eberline RM-14.

2. An alpha contamination survey instrument. Commonly used examples include the Ludlum 61 and the Eberline Pac-4S.

3. Anti-contamination clothing including, but not limited to, cotton gloves to absorb perspiration, rubber gloves, anti-contamination coveralls with hood, water resistant anti-contamination coveralls with hood, apron, lab coat, water resistant shoe covers, protective booties, masking tape to seal interfaces between individual items, and appropriate respiratory protection (as required). 
4. Decontamination materials as required by the method used including, but not limited to, adhesive tape, mild soap, lukewarm water, disposable basins, mild shampoo, disposable towels, plastic sheeting, a decontamination shower, etc.

5. Temporary clothing in several sizes. This could include surgical scrubs, athletic shoes, etc.

6. Other materials deemed appropriate by the Health Physics Supervisor.

\subsection{PROCEDURE}

\subsection{PREREQUISITES}

Typically, a person is considered to be contaminated if the survey instrumentation reads more than 3 times the background count.

It is assumed that prior to the detection of contamination on a person (during an exit survey), any anti-contamination clothing will have been removed, so the steps outlined below for clothing decontamination apply to inner garments (facility owned inner garments and/or personal clothing).

The waste disposal facility will have a dedicated decontamination shower accessible from the controlled area. The shower will have a ready supply of the appropriate temperature water and be equipped to allow collection of all wash water for later analysis and, if necessary, treatment and disposal.

\subsection{TRAINING}

Radiation surveys will be conducted by a Health Physics Technician. The technician will have completed the Health Physics Training Course and will have at least five hours of experience in the use of the type, manufacturer, and model of the instruments they will be using to perform this procedure, or be under the close supervision of someone who has such training and experience.

Training shall be in accordance with Procedure , On-Site Safety Training.

\subsection{SPECIAL PRECAUTIONS}

Special care will be taken when facial contamination is detected. The Health Physics Supervisor will be notified. High levels of facial contamination are an indication of potential internal contamination.

Only tepid (approximately skin temperature) water will be used for decontamination because hot or cold water affects the skin pores. Opening and closing of the pores may allow contamination to become trapped below the skin surface.

During decontamination, only light pressure and motion will be used to remove contamination. Do not scrub. Any damage to the skin may force the contamination 


$$
\text { Page } \frac{3}{\text { Fiovision of } \frac{12}{0}}
$$

farther into a person's body. If the skin is damaged, consult the Health Physics Supervisor.

Because water inhibits detection of radiation, personnel being decontaminated will be dry before a survey is attempted.

Throughout this procedure, proper contamination control techniques will be used as instructed in Procedure , On-Site Safety Training. This includes the donning of anticontamination clothing and respiratory protection (as appropriate), the designation of "contaminated" and "clean" areas, and the use of step-off pads for eniry or exit from these areas.

\section{$3.4 \quad$ INSTRUCTIONS}

To minimize the likelihood of contaminating additional personnel, the steps described here will be completed by the contaminated person whenever possible, with an additional person standing by to offer assistance.as needed. The additional person may be part of the Health Physics staff or someone else, such as a member of the operations staff. If it is required that this person come into physical contact with the contaminated person, and possibly become contaminated themselves, a third person will be called to assist as well so one "clean" assistant is always on hand.

The procedure will be supervised by the Health Physics Supervisor. He will complete the Personnel/Clothing Decontamination Record, Form Number OP 2.2.3-1 and make the appropriate entries in the Personnel Contamination Log, Form Number OP 2.2.3-2.

\section{Contaminated Clothing}

a. Contaminated clothing will be removed in a manner that avoids additional personnel contamination. Refer to the methods used to remove protective clothing described in Procedure , OnSite Safety Training.

b. Contaminated clothing will be segregated for final disposition, depending on whether it will be sent offsite for laundering or collected for disposal.

c. After the contaminated clothing has been removed, the person should again be surveyed to determine if any contamination has been transferred to other clothing items or the skin or hair.

d. If additional contaminated clothing is detected, follow Steps 1 through 3.

e. After decontamination is complete the formerly contaminated person will be given temporary clothing as needed. 


\section{Small Area Skin Decontamination}

Due to the many potential contaminants and the complex nature of skin absorption, no single satisfactory method of skin decontamination can be established for all radioisotopes. The following methods, however, will be satisfactory for most requirements.

\section{a. Adhesive Tape}

Adhesive tape can be used to remove contamination from small areas (up to about 9 square inches) of skin. Adhesive tape should not be used in areas where the tape may cause irritation (e.g., due to excessive body hair, tape adhesive allergy, etc.).

1. Apply the tape to the skin, using uniform pressure over the entire adhesive surface.

2. After a few minutes, remove the tape and check the skin with the survey instrument to see if the contamination has been removed. The tape may also be checked for contamination, being careful not to get the tape with possible attached contamination stuck to the survey probe.

3. If contamination is being removed, as indicated by the measured presence of contamination on the removed tape or lower meter readings from the skin, repeat the process until all contamination has been removed.

4. If this method is unsuccessful in lowering the meter readings, try skin washing.

\section{b. Skin Washing}

Gentle washing of the skin can be used to decontaminate the skin when adhesive tape cannot be used or is unsuccessful, or when the area is of sufficient size to make adhesive tape impractical (e.g., contamination covers entire hands or arm, is between fingers or under nails, etc.). All wash water must be retained for later analysis and, if necessary, treatment and disposal.

1. Using a mild soap and tepid water solution, massage the contaminated area for a few minutes. DO NOT SCRUB!

2. Rinse off the lather, being careful not to spread the lather to noncontaminated parts of the body.

3. Pat the skin dry with disposable towels. Do not rub. Save the towels for proper disposal. 
4. Survey the treated area to check the effectiveness of the treatment. Repeat the treatment until no further contamination can be removed or detected.

5. If contamination persists, consult the Health Physics Supervisor for additional decontamination methods.

3. Large Area Skin Decontamination

The following steps will be used when there is contamination of large areas of skin (such as the upper or lower torso or multiple extremities) or when the volume of wash water needed for a decontamination exceeds manual collection abilities or capacities. The procedure is similar to the small area decontamination described in 3.4.B.2 above, except that the emergency decontamination shower will be used.

As mentioned above, proper contamination control techniques should be used, including segregation of potentially contaminated materials (towels, soap containers, clothing) and the use of step-off pads.

a. If the contaminated area is above the neck, nasal smears will be taken and analyzed. Document the results of the smears on the Personnel/Clothing Decontamination Record, Form OP 2.2.3-1.

b. While using the shower, care will be taken to use tepid water and minimum water pressure. In addition to splashing and splattering, high pressure can cause skin damage.

c. Use a mild soap solution and light pressure on the affected areas.

d. The water needs to be on only long enough to wet the body and then, later, to rinse off the lather. This minimizes the amount of water needing to be treated and conserves water for lengthy or multiple decontaminations.

e. Pat the skin dry with disposable towels. Do not rub. Save the towels for proper disposal.

f. Survey the areas that were contaminated completely to check the effectiveness of the treaiment. Repeat Steps 3 through 5 until no further contamination can be detected or removed.

g. When Steps 1 through 5 are complete, the whole body should be surveyed to make sure the contamination was not simply relocated to another portion of the body.

h. If contamination persists, consult the Health Physics Supervisor for additional decontamination methods. 
i. Supply the person with temporary clothing, as needed.

4. Hair Decontamination

Use the following steps when the hair has been contaminated. The hair decontamination steps can be completed in a disposable wash basin or combined with the large area skin decontamination steps (shower) given in $\mathrm{C}$ above. These steps apply to both head and facial hair but could be adapted for use in other hair-covered parts of the body.

As mentioned above, proper contamination control techniques should be used, including segregation of potentially contaminated materials (towels, shampoo containers, clothing) and the use of step-off pads.

a. If the contaminated area is above the neck, nasal smears shall be taken and analyzed. Document the results on the Personnel/Clothing Decontamination Record, Form OP 2.2.3-1.

b. Wash the hair gently with mild soap or shampoo and tepid water.

c. Whether in a basin or a shower, hold the head back while washing and rinsing to prevent spreading contamination to the face or rest of the body. The plastic sheeting specified in the equipment list may be used to shield uncontaminated parts of the body.

d. Pat the hair dry with disposable towels. Do not rub. Save the towels for proper disposal.

e. Survey the hair to check the effectiveness of the treatment. Repeat Steps 2 through 4 until no further contamination can be detected or removed.

f. If washing does not remove the contamination, the hair may be clipped. DO NOT SHAVE THE SKIN. All hair clippings will be saved for proper disposal.

g. If contamination persists, consult the Health Physics Supervisor for additional decontamination methods.

5. Contaminated Wounds

In rare instances, contaminated personnel may also be injured. Emergency medical assistance will always have priority over decontamination. First aid will be administered immediately, taking care to minimize the spread of contamination. First aid techniques associated with contaminated personnel will be taught in the first aid portion of Procedure , On-Site Safety Training. 


$$
\text { Page } \frac{7}{\text { Revision } 0}
$$

When a contaminated wound is encountered, the Health Physics Supervisor will be contacted for decontamination instructions.

\subsection{RECORDS}

\subsection{REQUIRED FORMS}

Personnel/Clothing Decontamination Record, Form Number OP 2.2.3-1.

Personnel Contamination Log, Form Number OP 2.2.3-2.

\subsection{COMPLETION AND APPROVAL REQUIREMENTS}

The Personnel/Clothing Decontamination Record will be completed by the Healith Physirs Supervisor conducting the inspection. Release signatures will be obtained from the individual that was contaminated, the health physics technician performing decontamination, and the Health Physics Supenvisor.

The Personnel Decontamination Form will be completed by the Health Physics Supervisor.

\subsection{PROCESSING AND ARCHIVAL REQUIREMENTS}

1. Documents required or created in support of this procedure are quality assurance records. The Personnel/Clothing Decontamination Record and Personnel Decontamination Form will be included in the quality assurance records package.

2. The records shall be submitted to the Records Management Technician who, as custodian, will ensure each document is complete, legible, and adequately identifiable. The quality assurance records resulting from this procedure shall be retained in accordance with (Administrative Procedure AP by the records custodian.

\subsection{REFERENCES}

1. 10 CFR 20.

2. U.S. Department of Health, Education, and Welfare, Public Health Service, "Radiological Health Handbook," 1970.

3. National Council on Radiation Protection and Measurements, "Management of Persons Accidentally Contaminated with Radionuclides," NCRP Report Number 65, April 15, 1980. 


\section{INSTRUCTIONS FOR PERSONNEL/CLOTHING DECONTAMINATION RECORD}

\section{FORM OP 2.2.3-1}

1. This form will be completed by the Health Physics Supervisor or by a Health Physics Technician under his supervision.

2. Personal data-Self explanatory.

3. Tracking No.-Enter year and next sequential number taken from the log book.

4. Description of the Occurrence-Describe how and when the person became contaminated. Describe the areas of contamination and levels encountered.

5. Mitigating Actions Taken-Describe any mitigating actions taken to minimize the contamination.

6. Highest Radiation Levels Found-Sketch the locations on the diagram supplied and complete the table, supplying location, counts, and area surveyed in square centimeters.

7. Decontamination Methods Used-Describe the decontamination method (or methods) used and the final survey results.

8. Final Survey Results-Note the locations of any significant areas where radiation levels still measure above background but are considered releasable, uncontaminated, or clean and the count rate in counts per minute. If there are no remaining elevated radiation levels, indicate that.

9. The Health Physics Supervisor will determine whether additional information is required in the form of bioassay or a whole body count. The information gathered from these additional activities is typically used to perform a dose assessment. The decisions to perform these additional activities, as well as their outcome, will be documented.

10. Instrumentation-List the instrumentation data required, for each instrument, including: type, serial number, calibration date, and source check results (whether the instrument was performing properly).

11. Release Signatures-Self explanatory. 


\section{PERSONNEL/CLOTHING DECONTAMINATION RECORD}

\section{Form Number OP 2.2.3-1}

Tracking No:

Date:

Name:

Location:

SS No:

Description of the Occurrence:

Mitigating Actions Taken:

Highest Radiation Level Found: (Sketch Locations on the Figure on the Next Page)

\begin{tabular}{|c|c|c|}
\hline Location & Counts & Area Surveyed $\left(\mathrm{cm}^{2}\right)$ \\
\hline & & \\
\hline & & \\
\hline & & \\
\hline
\end{tabular}

Instrumentation:

\begin{tabular}{|l|l|l|l|}
\hline Type & & & \\
\hline Serial Number & & & \\
\hline Calibration Date & & & \\
\hline Source Check & & & \\
\hline
\end{tabular}

Decontamination Methods Used:

Final Survey Results:

Bioassay Required:

yes / no completed

Whole Body Count Required:

yes / no completed 
Page $\frac{10}{\text { Revision } \frac{12}{0}}$

Dose Assessment (if applicable):

Release Signatures:

Individual:

HP Tech:

HPS:

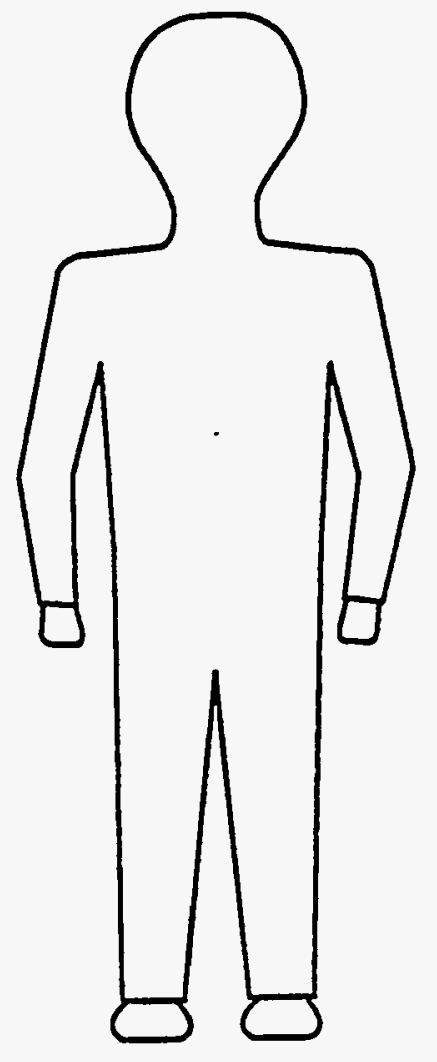

FRONT

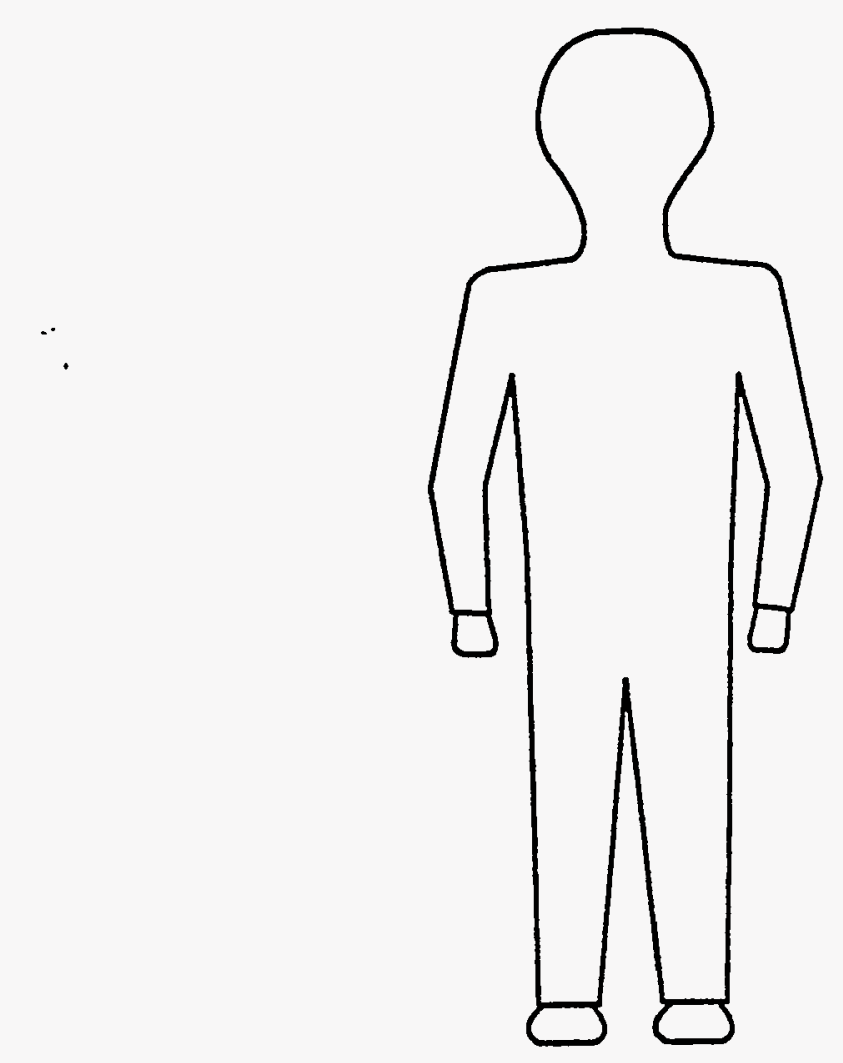

REAR

RAE - 104602 


$$
\text { Page } \frac{11}{\text { Revision } \frac{12}{0}}
$$

\section{INSTRUCTIONS FOR PERSONNEL CONTAMINATION LOG FORM OP 2.2.3-2}

1. Number-The first two numbers are the last two in the year of occurrence. Next three numbers are the order of occurrence. For example, the third contamination incident in 1993 would be 93003 .

2. Name and Social Security Number-The contaminated individual's name and soci: 1 security number, respectively.

3. Clothing/Skin or Hair Contaminated?-Specify whether the person's clothing or skin or hair or both were contaminated.

4. Specify whether beta/gamma contamination was greater than 10,000 DPM, yes or no.

5. Specify whether alpha contamination was greater than 1,000 DPM, yes or no.

6. Indicate if the Health Physics Supervisor was notified, yes or no. 
Page $\frac{12}{\text { Revision } 0}$

ATTACHMENT 2

PERSONNEL CONTAMINATION LOG

Form OP 2.2.3-2

\begin{tabular}{|c|c|c|c|c|c|c|}
\hline$\underset{r}{\text { Numbe }}$ & Name & $\begin{array}{l}\text { Social } \\
\text { Security } \\
\text { Number }\end{array}$ & $\begin{array}{c}\text { Clothing, } \\
\text { Skin or Hair } \\
\text { Contaminate } \\
\text { d? }\end{array}$ & $\begin{array}{c}\text { Beta/gam } \\
\text { ma } \\
>10,000 \\
\text { DPM }\end{array}$ & $\begin{array}{c}\text { Alpha } \\
>1,0 \\
00 \\
\text { DPM }\end{array}$ & $\begin{array}{c}\text { Health } \\
\text { Physics } \\
\text { Supervis } \\
\text { or } \\
\text { Notified } \\
\end{array}$ \\
\hline & & & & yes/no & $\begin{array}{c}\text { yes } / n \\
0\end{array}$ & yes/no \\
\hline & & &. & & & \\
\hline & & & & & & \\
\hline & & & & & & \\
\hline & & & & & & \\
\hline & & & & & & \\
\hline & & & & & & \\
\hline & & & & & & \\
\hline & & & & & & \\
\hline & & & & & & \\
\hline & . & & & & & \\
\hline & & & & & & \\
\hline & & & & & & \\
\hline & & & & & & \\
\hline & & & & & & \\
\hline & & & & & & \\
\hline & & & & & & \\
\hline & & & & & & \\
\hline
\end{tabular}




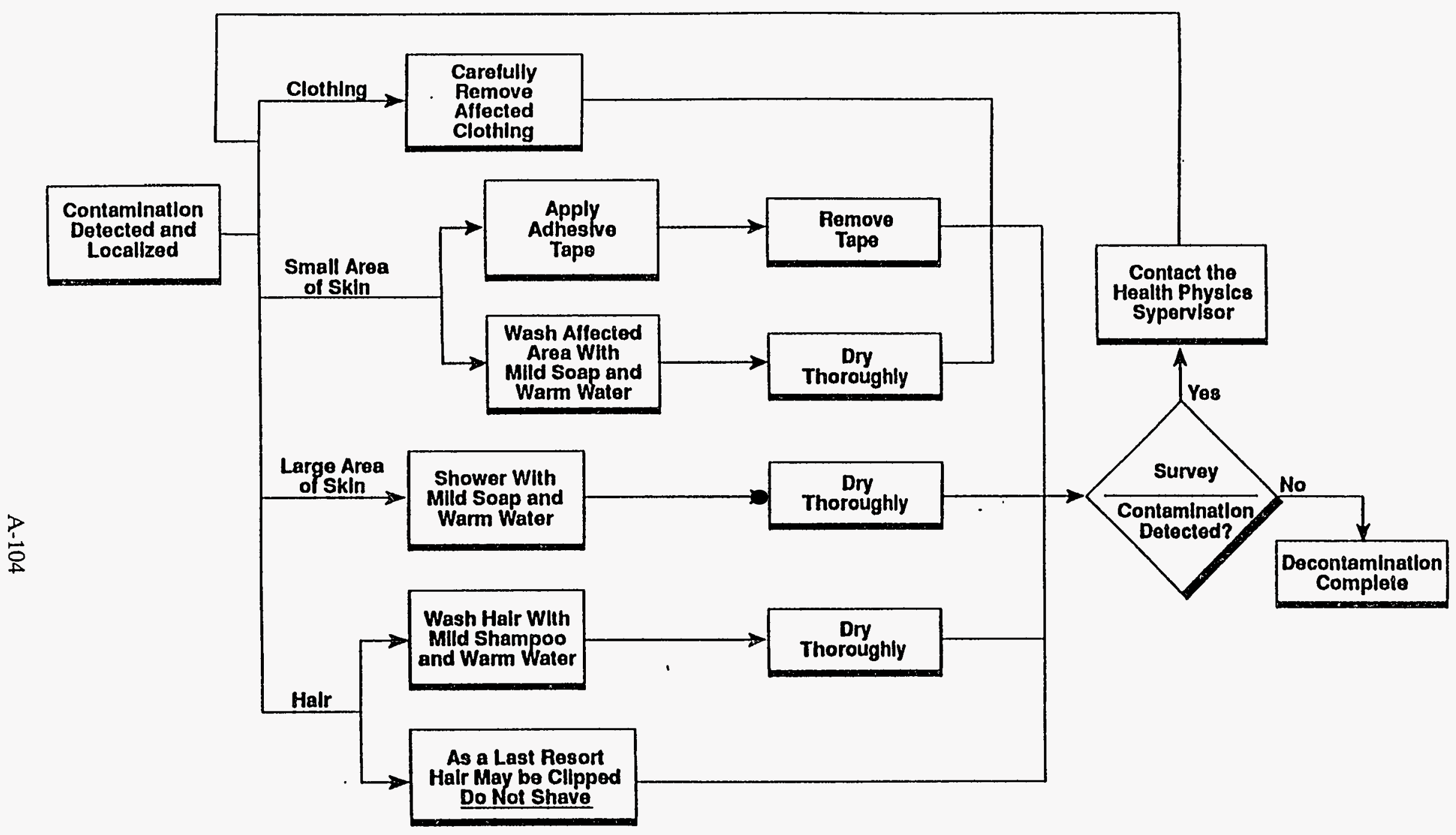

Note: For contaminatlon above the neck the Healli, Physlcs Supervlsor should supplement the survey with nasal smears.

Flowchart for Personnel Decontaraination. 


\section{OPERATING PROCEDURE}

\section{RESPIRATORY PROTECTION EQUIPMENT ISSUANCE}

Date:

Revision No.: $\underline{0}$

Supersedes:

Page 1 of 6

Approval:

Concurrence:

Title

Date

Title

Date

\subsection{PURPOSE AND SCOPE}

The following procedure describes the method used to issue respiratory protection equipment to facility personnel.

Under normal circumstances, the low-level radioactive waste disposal facility will operate under non-contaminated conditions. In the event of an emergency or other incident involving the release of radioactive contamination, personnel may be required to wear respiratory protection equipment either for the duration of an emergency or to clean up after the incident.

The Health Physics Supervisor (HPS) has overall responsibility for administrating the respiratory protection program under the guidance of the Director of Health Physics.

\subsection{EQUIPMENT}

Appropriate respiratory protection equipment. At a minimum, this shall include negative pressure air-purifying respirators and self-contained breathing apparatus.

\subsection{PROCEDURE}

\subsection{PREREQUISITES}

1. The person to which the respiratory protection equipment is being issued shall have successfully completed a physical examination within the last year and shall have been judged physically capable of wearing a respirator by a qualified physician. A record of this physical exam, signed by the 
physician, shall have been placed in the wearer's training file at the time of the respirator training course.

2. The person shall have a valid fit test. To be valid, the test will have been conducted within the past 12 months and none of the changes that are listed in Procedure , Respirator Fit Test, that require retest will have occurred.

3. Health physics personnel shall have sufficiently quantified the levels of airborne contamination such that the appropriate respiratory protection device can be chosen.

\subsection{TRAINING}

1. Prior to receiving a respirator, all personnel shall complete the respirator training course according to Procedure , On-Site Safety Training.

2. The person issuing respirators shall have attended a 40 hour respirator course offered by either the National Institute of Occupational Safety and Health (NIOSH) or the Occupational Safety and Health Administration (OSHA), or equivalent, and be currently certified.

\subsection{SPECIAL PRECAUTIONS}

1. Only respiratory protection equipment that has received joint MSHA/NIOSH approval shall be used.

2. Only the Health Physics Supervisor or a properly trained designee shall issue respiratory protection equipment.

3. Personnel shall only be issued the respirator(s) (model and size) on which they have been fit-tested.

4. Respiratory protection equipment shall not be issued to an individual who has facial hair that may interfere with the sealing periphery of the respirator.

5. Contact lenses shall not be worn with respiratory equipment.

6. Eye glasses with temple bars shall not be used with respiratory equipment. Only eye glasses designed for the respirator being used may be worn.

\subsection{INSTRUCTIONS}

1. Respirators shall be selected and issued based on the protection factor required to ensure protection of the wearer from unacceptable levels of airborne contaminants. The kind of respirator issued will be at the discretion of the Health Physics Supervisor and will depend on the potential for contamination. 
2. Records of respirator issuance shall be recorded in the Respirator Issue Log, Form Number OP 2.2.4-1.

3. The wearer shall inspect the respirator prior to use. The inspection shall include examination of the facepiece for distortion and rubber deterioration, worn or broken straps, cleanliness, and proper exhalation valve function.

4. After donning and prior to entering the area where respiratory protection is required, the wearer shall perform a negative or positive pressure leak check (depending on the type of respirator being worn) as demonstrated in the respirator training course.

a. A negative pressure leak check is performed by covering the cartridge inlets and inhaling slightly, producing negative pressure (vacuum) inside the facepiece. If the vacuum is lost, do not use the respirator.

b. A positive pressure leak check is performed by covering the inlet hose and exhaling slightly, producing a positive pressure inside the facepiece. If pressure is lost, do not use the respirator.

5. After use, respirators shall be cleaned and sanitized prior to return according to Procedure , Respirator Maintenance and Cleaning.

\subsection{RECORDS}

\subsection{REQUIRED FORMS}

Respirator Issue Log, Form Number OP 2.2.4-1.

\subsection{COMPLETION AND APPROVAL REQUIREMENTS}

The Respirator Issue Log will be completed by the Health Physics Supervisor or properly trained designee.

\subsection{PROCESSING AND ARCHIVAL REQUIREMENTS}

1. Documents required or created in support of this procedure are quality assurance records. The Respirator Issue Log will be included in the quality assurance records package.

2. The records shall be submitted to the Records Management Technician who, as custodian, will ensure each document is complete, legible, and adequately identifiable. The quality assurance records resulting from this procedure shall be retained in accordance with Administrative Procedure AP by the records custodian. 


\subsection{REFERENCES}

1. TRCR Part 21.

2. 29 CFR 1910.134 US Occupational Safety and Health Administration, Personal Protective Equipment, Respiratory Protection.

3. NUREG-0041, Manual of Respiratory Protection Against Airborne Radioactive Materials.

4. ANSIZ88.2American National Standards Institute, Practices for Respiratory Protection. 


\section{Page $\frac{5}{\text { Revision }} \frac{6}{0}$}

\section{INSTRUCTIONS FOR RESPIRATOR ISSUE LOG \\ FORM NUMBER OP 2.2.4-1}

1. Enter the date.

2. Enter the name of the respirator wearer.

3. Enter the recipient/wearer's social security number.

4. Enter the model and serial numbers of the respirator being issued.

5. Enter the reason for issuance (e.g vehicle/personnel decontamination, breached waste container, package inspection, etc.).

6. Enter the signature of the person issuing the respirator. 
RESPIRATOR ISSUE LOG

Form Number OP 2.2.4-1

\begin{tabular}{|c|c|c|c|c|c|}
\hline Date & Name & $\begin{array}{l}\text { Recipient Social } \\
\text { Security } \\
\text { Number }\end{array}$ & $\begin{array}{c}\text { Model/ } \\
\text { Serial Number }\end{array}$ & Issue Reason & $\begin{array}{l}\text { Issuer } \\
\text { Signature }\end{array}$ \\
\hline & & & & & \\
\hline & & & & & \\
\hline & & & & & \\
\hline & & & & & \\
\hline & & & & & \\
\hline & & & & & \\
\hline & & & & & \\
\hline & & & & & \\
\hline & & & & & \\
\hline & & & & & \\
\hline & & & & & \\
\hline & & & & & \\
\hline & & & & & \\
\hline & & & & & \\
\hline & & & & & \\
\hline & & & & & \\
\hline
\end{tabular}




\section{OPERATING PROCEDURE}

\section{RESPIRATOR MAINTENANCE AND CLEANING}

Date:

Revision No.: 0

Supersedes:

Page 1 of 14

Approval:

Concurrence:

Title

Date.

Title

Date

\subsection{PURPOSE AND SCOPE}

This procedure describes the methods used by facility health physics personnel to clean and inspect respiratory protection equipment. The purpose of the cleaning described here is to maintain normal sanitary conditions, not to remove radioactive contamination.

Under normal circumstances, the low-level radioactive waste disposal facility will operate under non-contaminated conditions. Under these conditions, only routine, monthly inspections of respiratory protection equipment are required.

In the event of an emergency or other incident involving the release of radioactive contamination, personnel may be required to wear respiratory protection equipment either for the duration of an emergency or to clean up after an incident. Under these conditions, respiratory protection equipment will be cleaned and inspected after each daily use.

The Health Physics Supervisor has the overall responsibility of administering the respiratory protection program under the guidance of the Director of Health Physics.

\subsection{EQUIPMENT}

1. Clean bucket or sink.

2. Cleaner/sanitizer concentrate.

3. A soft brush or sponge.

4. Clean towels. 
5. A supply of spare parts for the various respiratory protection devices used at the facility.

\subsection{PROCEDURE}

\subsection{PREREQUISITES}

Only health physics staff will perform this procedure.

The disposal facility shall have a dedicated area for cleaning, inspection, anc. maintenance of respiratory protection equipment, including a dust-free drying area anui a warm water supply.

\subsection{TRAINING}

1. Prior to performing cleaning and maintenance activities on respiratory protection equipment, all personnel shall complete the respirator training course according to Procedure , On-Site Safety Training.

2. The person supervising the cleaning and inspection of respiratory protection equipment shall have attended a 40 hour respirator course offered by the National Institute of Occupational Safety and Health (NIOSH), Occupational Safety and Health Administration (OSHA), or equivalent, and be currently certified.

3. Personnel performing maintenance (replacing damaged or defective parts) on respiratory protection equipment shall have attended a 40 hour respirator course offered by the $\mathrm{NIOSH}, \mathrm{OSHA}$, or equivalent, be currently certified, and have experience on the specific equipment being worked on.

\subsection{SPECIAL PRECAUTIONS}

1. Water temperatures shall not exceed 120 degrees $F$. Temperatures above this level can distort or damage respirator facepieces.

2. The facepieces must be thoroughly rinsed twice after cleaning to ensure all cleaner/sanitizer residue is removed.

3. Respirators and equipment shall be surveyed for radioactive contamination prior to cleaning according to Procedure , Routine Surveys and Reviews. Contaminated respiratory protection equipment should first be decontaminated according to the "equipment decontamination" section of Procedure , Non-Routine Operations. Decontaminated respirators may then be cleaned and sanitized using this procedure. 


\section{$3.4 \quad$ INSTRUCTIONS}

The cleaning and inspection of respiratory protection equipment will be conducted by health physics staff.

\section{Criteria}

All respiratory protection equipment shall be inspected on a monthly basis. Inspections shall be documented on Form Number OP 2.2.5-1, "Monthly Inspection Record, Respiratory Protection Devices." Since they are used for emergency responses, Self Contained Breathing Apparatus (SCBA) inspections must also be documented on Form Number OP 2.2.5-2, "Monthly Inspection Record, Emergency Respiratory Protection Equipment."

All respiratory protection equipment shall be cleaned at least annually.

All respiratory protection equipment shall be cleaned, sanitized, and inspected daily when in use.

2. Facepiece Cleaning and Inspection

These instructions apply to both air purifying and air supplying respirators (e.g., SCBAs).

a. Dilute the cleaner/sanitizer concentrate with water according to the manufacturer's instructions.

b. Completely immerse the facepiece in the cleaner/sanitizer solution. Soak the facepiece for at least two minutes.

c. Wash the facepiece thoroughly, including O-rings, valves and seals, inside and out. Use a soft brush or sponge to scrub any soiled areas.

d. Thoroughly rinse each facepiece twice in clean, warm water.

e. Place the facepieces on a clean surface and cover with clean towels to minimize exposure to dust, dirt, sunlight, etc. Allow 8 to 12 hours drying time. An air drying cabinet designed specifically for respiratory protection equipment may also be used for this purpose. If the facepiece must be reused immediately, it may be wiped dry with a clean towel.

f. After the facepiece is dry, remove the protective exhalation valve cover and examine it for foreign objects or substances (i.e. hair or cleaner/sanitizer residue) and ensure there is no damage to the valve or seating surface. If the valve is not functioning properly, contaminated air may enter through it during inhalation. 
g. Examine each individual facepiece for defects (missing O-rings, tears, gouges, holes in breathing tube for SCBAs, etc.). Ensure air purifying devices have the proper cartridge installed prior to storage.

h. After each facepiece has been inspected for defects as described above in steps $f$ and $g$, place the respirator in a clean plastic bag for storage and future use. Air purifying devices should be placed in a sealed bag.

Note: Avoid damaging the facial sealing surfaces by storing the facepiece with the viewing lens facing down.

i. Self-Contained Breathing Apparatus breathing tubes should be cleaned and sanitized according to the manufacturer's instructions.

j. Cleaning, inspection, and repair activities shall be documented on Form Number OP 2.2.5-1, "Monthly Inspection Record, Respiratory Protection Devices."

3. Additional Inspection Criteria for Seli-Contained Breathing Apparatus

Monthly inspections will be performed on emergency respiratory protection equipment. Inspections shall be documented on Form Number OP 2.2.5-2, "Monthly Inspection Record, Emergency Respiratory Protection Equipment."

Proper inspection includes the following:

a. Prior to Inspection

1. Ensure that the high pressure hose connector is tight on the cylinder fitting.

2. Ensure that the bypass valve is in the closed position.

3. Ensure that the mainline valve is closed.

4. There should be no cover or obstruction on the regulator outlet other than a readily removable dust cover.

b. Back Pack and Harness Assembly

1. Straps

Visually inspect for a complete set of harness straps. 
Visually inspect for frayed or damaged straps that may break during use. Replace if needed.

\section{Buckles}

Visually inspect for mating ends (male \& female).

Check buckle locking function.

3. Backplate and Cylinder Lock

Visually inspect the backplate for cracks and for missing rivets or screws.

Visually inspect the cylinder hold-down strap and physically check the strap tightener and lock to assure that it is fully engaged.

\section{c. Cylinder}

Ensure that the cylinder is tightly fastened to the backplate.

Ensure that the cylinder has had a hydrostatic test within five years, or as required by the manufacturer (some are three years). Enter the next inspection due date on the inspection form.

Visually inspect the cylinder for damage.

Document the inspection of spare (unattached) cylinders on Form Number OP 2.2.5-3, "Monthly Inspection Record, SCBA Bottles."

d. Facepiece and Corrugated Breathing Tube

1. Facepiece

Visually inspect the head harness for damaged serrations and deteriorated rubber. Inspect the rubber facepiece body for signs of deterioration or extreme distortion.

Visually inspect the lens for proper seal in the rubber facepiece, cracks or large scratches, and ensure that the retaining clamp is in its proper place.

Visually inspect the exhalation valve for visible deterioration or buildup of foreign materials. 


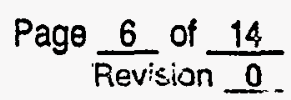

2. Breathing Tube and Connector

Stretch the breathing tube and visually inspect it for deterioration and holes.

Visually inspect the connector for the condition of threads and for the presence and proper condition of the "O" ring or rubber gasket seal.

Inspect the hose clamps for deformation or weakening.

e. Storage of Units

1. Cylinders shall be filled if the pressure falls below 1500 psi. The unit shall be cleaned and inspected at the same time.

2. Cylinder valves shall be closed.

3. The high pressure hose connector shall be tight on the cylinder.

4. There shall be no pressure on either the high pressure hose or the regulator.

5. The bypass valve shall be closed.

6. The main line valve shall be closed.

7. All straps shall be completely loosened and laid straight.

8. The face piece shall be properly stored to protect against dust, sunlight, heat, extreme cold, excessive moisture, and damaging chemicals.

f. Regulator and High Pressure Hose

1. High Pressure Hose and Connector

Listen or feel for leakage in the hose or at the hose to cylinder connector. (A bubble in the outer hose covering may be caused by seepage of air through the hose when stored under pressure).

2. Regulator and Low Pressure Alarm

Cover the outlet of the regulator with the palm of the hand. Open the main line valve and read the regulator gauge (it must read at least 1800 psi and not more than the rated cylinder pressure). 
Close the cylinder valve and slowly remove the hand from regulator outlet to allow a slow flow of air. The gauge should begin to show immediate loss of pressure as the air flows. The low pressure alarm should sound between 650 and $550 \mathrm{psi}$. Remove the hand completely from the outlet and close the main line valve.

Place the mouth on or over the regulator outlet and blow. A positive pressure should be created and maintained for 5 to 10 seconds without any loss of air. Next draw a slight negative pressure on the regulator and hold it for 5 to 10 seconds. The vacuum should remain constant. (This check tests the integrity of the diaphragm. Any loss of pressure or vacuum during this test indicates a leak in the apparatus.)

Open the cylinder valve.

Place a hand over regulator outlet and open the main line valve. Remove the hand from outlet and replace it in a rapid movement. Repeat this twice. Air should escape when the hand is removed each time, indicating a positive pressure in the chamber. Close the main line valve and remove the hand from the outlet.

Listen for air leaking (hissing) from the unit. At this point, there should be no air leaking from any point on the pressurized unit.

g. After use of the Self-Contained Breathing Apparatus, perform the activities described in Section 3.4.2. Then perform an inspection and cleaning of the low pressure side of the regulator required by the manufacturer.

h. Complete Form Number OP 2.2.5-2, "Monthly Inspection Record, Emergency Respiratory Protection Equipment," and place the unit in service.

\subsection{RECORDS}

\subsection{REQUIRED FORMS}

Monthly Inspection Record, Respiratory Protection Devices, Form Number OP 2.2.5-1.

Monthly Inspection Record, Emergency Respiratory Protection Equipment, Form Number OP 2.2.5-2.

Monthly Inspection Record, SCBA Bottles, Form Number OP 2.2.5-3. 


\subsection{COMPLETION AND APPROVAL REQUIREMENTS}

The Monthly Inspection Record forms will be completed by the member of the health physics staff conducting the inspection. The forms shall be reviewed and signed by the Health Physics Supervisor.

\subsection{PROCESSING AND ARCHIVAL REQUIREMENTS}

1. Documents required or created in support of this procedure are quality assurance records. The Monthly Inspection Records will be included in the quality assurance records package.

2. The records shall be submitted to the Records Management Technician who, as custodian, will ensure each document is complete, legible, and adequately identifiable. The quality assurance records resulting from this procedure shall be retained in accordance with Administrative Procedure AP by the records custodian.

\subsection{REFERENCES}

1. 10 CFR 21

2. 29 CFR 1910.134 US Occupational Safety and Health Administration, Personal Protective Equipment, Respiratory Protection.

3. NUREG 0041, Manual of Respiratory Protection Against Airborne Radioactive Materials.

4. ANSI Z88.2 American National Standards Institute, Practices for Respiratory Protection. 


\section{INSTRUCTIONS FOR \\ MONTHLY INSPECTION RECORD \\ RESPIRATORY PROTECTION DEVICES \\ FORM NUMBER OP 2.2.5-1}

1. Enter the date of the inspection.

2. Enter the inspection date.

3. Enter the respirator facepiece serial number.

4. Enter the purpose (sanitize, inspect, repair).

5. Specify the facepiece condition as either satisfactory or unsatisfactory (SAT or UNSAT).

6. Indicate whether the device requires repair (yes/no).

7. Specify whether the facepiece is for an air purifying respirator (APR) or an SCBA.

8. Specify the repair performed, if applicable.

9. The form will be reviewed and signed by the Health Physics Supervisor. 
MONTHLY INSPECTION RECORD

RESPIRATORY PROTECTION DEVICES

FORM NUMBER OP 2.2.5-1

\begin{tabular}{|c|c|c|c|c|c|c|}
\hline Date & Serial Number & Purpose & Condition & $\begin{array}{l}\text { Repair } \\
\text { Needed? }\end{array}$ & $\begin{array}{l}\text { APR or } \\
\text { SCBA? }\end{array}$ & Repair Performed \\
\hline & & & & & & \\
\hline & & & & & & \\
\hline & & & & & & \\
\hline & & & & & & \\
\hline & & & & & & \\
\hline & & & & & & \\
\hline & & & & & & \\
\hline & & & & & & \\
\hline & & & & & & \\
\hline & & & & & & \\
\hline & & & & & & \\
\hline
\end{tabular}

Reviewed by:

Health Physics Supervisor 


\section{INSTRUCTIONS FOR \\ MONTHLY INSPECTION RECORD \\ EMERGENCY RESPIRATORY PROTECTION EQUIPMENT \\ FORM NUMBER OP 2.2.5-2}

1. Provide the date of the inspection.

2. Enter the serial number from the regulator. This identifies a specific system.

3. Specify the location (e.g, the room and building) where the SCBA is stored.

4. The facepiece assembly, harness assembly, cylinder pressure above $2000 \mathrm{PSI}$, and functional alarm check, shall each be marked satisfactory or unsatisfactory (SAT or UNSAT).

5. Provide the due date for the next hydrostatic test. If the unit is overdue, remove it from service.

6. Provide the signature of the person inspecting the equipment.

7. Provide remarks as appropriate.

8. The inspection record shall be reviewed by the Health Physics Supervisor. 
MONTHLY INSPECTION RECORD

EMERGENCY RESPIRATORY PROTECTION EQUIPMENT

Form Number OP 2.2.5-2

\begin{tabular}{|c|c|c|c|c|c|c|c|c|}
\hline Date & $\begin{array}{l}\text { Regulator Serial } \\
\text { Number }\end{array}$ & Location & $\begin{array}{l}\text { Faceplece } \\
\text { Assembly }\end{array}$ & $\begin{array}{l}\text { Harness } \\
\text { Assembly }\end{array}$ & $\begin{array}{l}\text { Cylinder } \\
\text { Pressure } \\
\text { Above } \\
2000 \text { psi }\end{array}$ & $\begin{array}{l}\text { Functional } \\
\text { Alarm } \\
\text { Check }\end{array}$ & $\begin{array}{l}\text { Hydrostatic } \\
\text { Test Due } \\
\text { Date }\end{array}$ & $\begin{array}{l}\text { Signature } \\
\text { of the } \\
\text { Inspector }\end{array}$ \\
\hline & & & & & & & & \\
\hline & & & & & & & & \\
\hline & & & & & & & & \\
\hline & & & & & & & & \\
\hline & & & & & & & & \\
\hline & & & & & & & & \\
\hline & & & & & & & & \\
\hline & & & & & & & & \\
\hline & & & & & & & & \\
\hline & & & & & & & & \\
\hline & & & & & & & & \\
\hline
\end{tabular}

COMMENTS:

Reviewed by: 


\section{INSTRUCTIONS FOR \\ MONTHLY INSPECTION RECORD, SCBA BOTTLES \\ FORM NUMBER OP 2.2.5-3}

1. Provide the bottle serial number.

2. Specify the location (e.g, room and building) where the SCBA bottles are stored.

3. Provide the due date for the next hydrostatic test. If the bottle is overdue, remove it from service.

4. Indicate whether cylinder pressure is above 2000 psi. Either yes or no. Bottles not fully charged shall be removed from service and refilled.

5. Provide the signature of the person inspecting the equipment.

6. Provide remarks as appropriate.

7. Inspection record shall be reviewed by the Health Physics Supervisor. 
MONTHLY INSPECTION RECORD

SCBA BOTTLES

Form Number OP 2.2.5-3

Date:

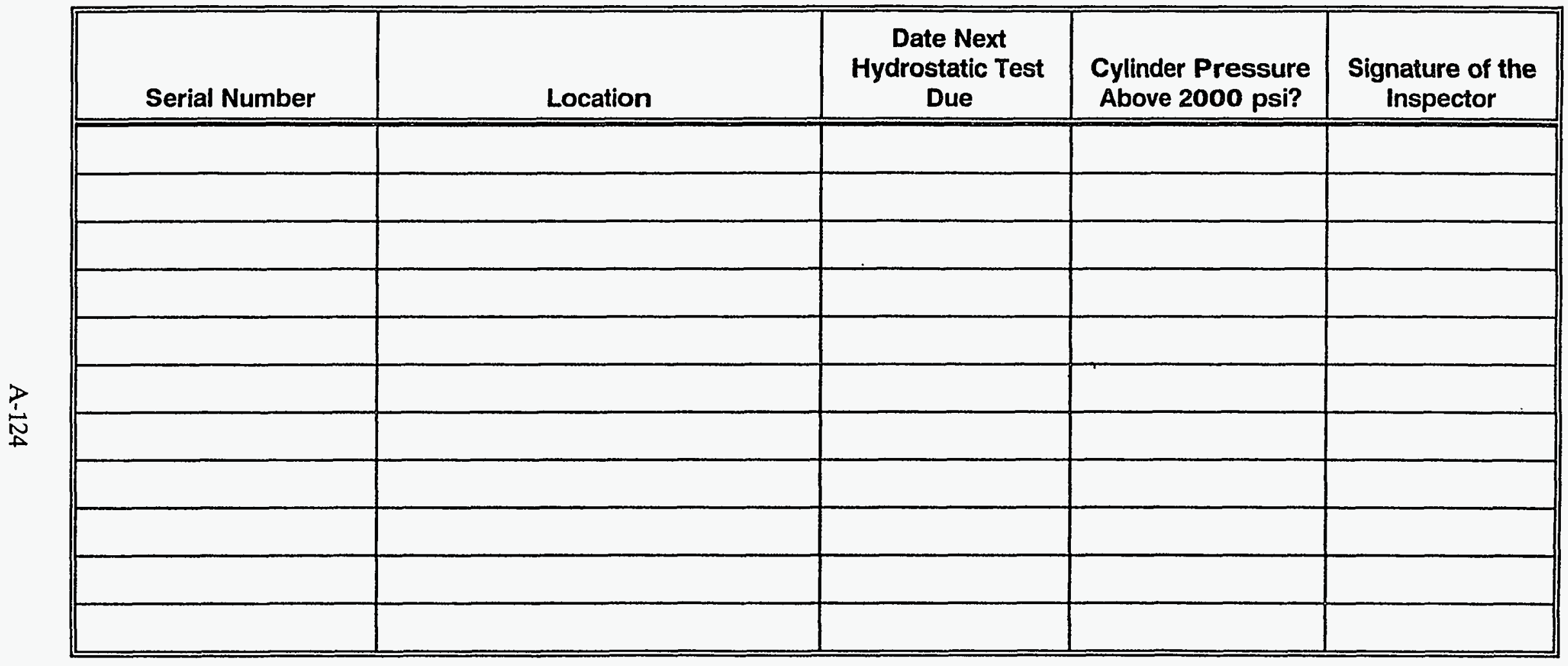

COMMENTS:

Reviewed by: 


\section{OPERATING PROCEDURE}

\section{RESPIRATORY PROTECTION FIT TESTING}

Date:

Revision No.: $\underline{0}$

Supersedes:

Page 1 of 7

Approval: $\quad$ Concurrence:

Title

Date

Title

Date

\subsection{PURPOSE AND SCOPE}

\subsection{PURPOSE}

The purpose of this procedure is to describe the process of fit testing for negative pressure respiratory protection devices.

The Health Physics Supervisor (HPS) has overall responsibility for administering the respiratory protection program under the guidance of the Health Physics Director.

\subsection{SCOPE}

Respirator tests are required for all negative pressure respirators. The test is required on an annual basis. Records are kept of the tests and which respirators each person is certified to use.

A fit test can either be qualitative or quantitative. Both require that subjects follow an exercise to simulate movements they would make while working.

A qualitative fit test is performed by exposing a subject to an irritant smoke, an odorous vapor, or other suitable test agent while wearing a respirator. If the subject is unable to detect penetration of the test agent in the respirator, it has achieved a satisfactory fit. This, however, is a subjective test.

The National Institute of Occupational Safety and Health (NIOSH) recommends that only a program of quantitative fit testing can provide adequate worker protection. A quantitative fit test actually measures and records the level of concentration that leaks into 
the facepiece and compares it to that in the atmosphere outside the facepiece or ambient air. This type of fit test is outlined in this procedure.

\subsection{EQUIPMENT AND MATERIALS}

1. Respirator Fit Testing Apparatus. An example is the TSI, Inc., Poriacount.

2. A selection of approved respirators from at least two manufacturers and in several sizes, fitted with sampling ports. Respirators are approved jointly by NIOSH and MSHA under provision of 30 CFR 11 and are listed in "NIOSH Certified Personal Protective Equipment," which is periodically updated.

3. Sanitizer/cleaner.

4. An enclosure or room in which to perform the test, depending on the test apparatus used.

\subsection{PROCEDURE}

\subsection{PREREQUISITES}

1. The test subject shall have successfully completed a physical examination and bo physically qualified to wear a respirator by a qualified physician.

2. The subject shall have no new facial hair growth in the area of the facepiece seal.

\subsection{TRAINING}

1. Safety training shall be according to Procedure , Onsite Safety Training.

2. The instructor performing the fit test shall have attended a 40 hour respirator course offered by the National Institute of Occupational Safety and Health or the Occupational Safety and Health Administration, United States Department of Labor, or equivalent, and be currently certified.

\subsection{SPECIAL PRECAUTIONS}

1. Personnel shall undergo a new fit test when significant physical changes occur, including:

a. A weight change of 20 or more pounds

b. Significant facial scarring in the area of the facepiece seal

c. Significant dental changes, such as multiple extractions without prosthesis, or acquiring dentures

d. Reconstructive or cosmetic surgery 


$$
\text { Page } \frac{3}{\text { Revision }} \frac{7}{0}
$$

e. Any other condition that may interfere with facepiece sealing.

2. Respiratory equipment shall not be issued to an individual who has facial hair that may interfere with the sealing periphery of the respirator.

3. Contact lenses shall not be worn with respiratory protection equipment.

4. Eye glasses with temple bars shall not be used with respiratory protection equipment. Only eyeglasses designed for the respirator being used may be worn.

5. The subject shall not eat, drink, or smoke for $\mathbf{3 0}$ minutes prior to testing.

\section{$3.4 \quad$ INSTRUCTIONS}

1. Respirator fit testing will be conducted by the Health Physics Supervisor or his or her designee. The fit testing apparatus will be set up and tested according to the manufacturer's instructions.

2. The respirator will be rechecked before the test, paying particular attention to the sampling probe and line attached to the facepiece. Respirator inspection instructions are found in Procedure , Respirator Maintenance and Cleaning.

3. The test will be described to the subject, making sure the purpose, the procedures, and the expected actions are fully understood. Methods to check for defects and to clean and sanitize the respirators will be reviewed with the test subject. The subject will be given the opportunity to clean and sanitize its own respirator before use, and will be required to clean and disinfect it after use. Respirator cleaning and sanitizing instructions are given in Procedure Respirator Maintenance and Cleaning.

4. If the subject is not familiar with wearing respirators, the correct wearing procedures will be demonstrated. The subject's level of expertise usually becomes apparent when putting on the respirator; the untrained or poorly trained subject will often put the respirator on incorrectly or have hesitant movements.

Depending on the subject's degree of difficulty, it may be useful to review the respiratory protection instructions given in accordance with Procedure Onsite Safety Training. This review will be at the discretion of the person administering the fit test.

5. The subject will put on the respirator, according to the manufacturer's instructions. Be sure the headstraps are not tightened to the point of discomfort. This test should approximate working conditions in which the subject might have to wear the respirator for an hour or two at a time.

6. Once it has been determined that the respirator is worn properly, the fit will be checked quickly using a negative-pressure-leak-test. This test will be performed by having the subject place palms over the filter intakes, pinch off the sampling 
hose, and inhale. If leakage is detected, try to determine its source and cause. If the leakage is from a poorly fitting facepiece, try another brand of the same type of respirator. Several different brands of respirators will be made available so the subject may choose the most comfortable-a very important aspect of fitting respirators.

7. After the best possible qualitative fit has been obtained, a quantitative fit lest will be performed.

A quantitative fit test will be performed by either introducing a challenge agent into a special test enclosure or by using ambient contaminants that the respirator is designed to filter out (e.g., carbon monoxide from a burning candle). In either case, concentrations are measured and compared both inside and outside the facepiece.

The choice of test agents and conditions is dependent on the testing apparatus used and the manufacturer's instructions should be followed carefully.

8. Whether the subject is tesied in the same room or in a special enclosure, allow 2 to 3 minutes for concentrations to stabilize after donning the respirator, before beginning the test.

9. In response to verbal instructions, the subject will begin head and facial movements simulating those made during normal work; i.e., breathe normally, smile, frown, read the "Rainbow Passage" (see Attachment 1) passage aloud, move head vertically and horizontally, walk in place, bend over and touch toes, and breathe deeply.

10. After the test, the subject will remove the respirator. Ask the subject about comfort. Note any marks on the subject's face. Facial markings will indicate pressure points from the respirator being overly tight. If the test indicated a good fit, any discomfort may be due to a mismatch between the subject and the facepiece, or to headstraps that were too tight. Every effort must be made to provide the most comfortable respirator possible.

11. Respiratory protection devices are assigned protection factors that represent their expected ability to reduce the concentration of contaminants in the atmosphere. The respirator fit test will not be considered successful unless a fit factor at leasi 10 times the protection factor that is ascribed to the respirator being tested is achieved.

Fit factor is defined as the concentration outside (Co) the respirator divided by the concentration inside $(\mathrm{Ci})$ the mask, thus:

$$
\mathrm{ff}=\mathrm{Co} / \mathrm{Ci}
$$

Most commercially available fit-test equipment, such as the TSI Portacount, is computer driven and fit factor is automatically calculated. The computer will also print out a copy of the test results. 


$$
\text { Page } \frac{5}{\text { Revision }} \frac{7}{0}
$$

When choosing respiratory protection devices appropriate to a given situation, the protection factors ascribed to different devices will be used in making the selection, not the fit factors that were measured during the fit.

\subsection{RECORDS}

\subsection{REQUIRED FORMS}

Copies of the fit test results shall be maintained in the individual's dosimetry, personnel, and training files. Most commercial fit test packages generate a report that can be used for this purpose. At a minimum, the following information shall be recorded:

1. Name of the test operator

2. Make, model number, and size of the specific respiratory protection device tested

3. Name and social security number of the person tested

4. Date of test

5. Results of respirator fit test:

a. Fit factor calculated from the quantitative fit test

b. Any special considerations or difficulties pertinent to the wearer (protective equipment worn, prescription lenses, dentures, forehead scars, etc.).

\subsection{COMPLETION AND APPROVAL REQUIREMENTS}

The record of fit test results will be approved and signed by the Health Physics Supervisor. A release signature will also be obtained from the individual that was tested.

\subsection{PROCESSING AND ARCHIVAL REQUIREMENTS}

1. Documents required or created in support of this procedure are quality assurance records. The record of fit test results will be included in the quality assurance records package.

2. The records shall be submitted to the Records Management Technician who, as custodian, will ensure each document is complete, legible, and adequately identifiable. The quality assurance records resulting from this procedure shall be retained in accordance with (Administrative Procedure AP by the records custodian.

\subsection{REFERENCES}

1. 10 CFR 20, US Nuclear Regulatory Commission, Standards for Protection Against Radiation. 


$$
\text { Page } \frac{6}{\text { Revision of }} \frac{7}{0}
$$

2. 29 CFR 1910.134, US Occupational Safety and Health Administration, Personal Protective Equipment, Respiratory Protection.

3. 30 CFR 11, Mine Safety and Health Administration.

4. NIOSH Guide to Industrial Respiratory Protection, 1987, U.S Department of Health and Human Services, N.J. Bolinger and R.H. Schutz.

5. NUREG 0041, Manual of Respiratory Protection Against Airborne Radioactive Materials.

6. ANSI Z88.2 American National Standards Institute, Practices for Respiratory Protection. 


$$
\text { Page } \frac{7}{\text { Revision } \frac{7}{0}}
$$

\section{ATTACHMENT 1}

\section{Rainbow Passage}

When the sunlight strikes raindrops in the air, they act like a prism and form a rainbow. The rainbow is a division of white light into many beautiful colors. These take the shape of a long round arch, with its path high above, and its two ends apparently beyond the horizon. There is, according to legend, a boiling pot of gold at one end. People look, but no one ever finds it. When a man looks for something beyond his reach, his friends say he is looking for the pot of gold at the end of the rainbow. 
A-132 


\section{A-3. SECURITY PROCEDURES}


A-134 


\title{
OPERATING PROCEDURE
}

\author{
FACILITY SECURITY
}

Date:

Revision No.: 0

Supersedes:

Page 1 of 11

Approval:

Concurrence:

Title

Date

Title

Date

\subsection{PURPOSE AND SCOPE}

\subsection{PURPOSE}

The purpose of this procedure is to describe the security program to be used in safeguarding facility property and radioactive materials and in ensuring personnel safety.

\subsection{SCOPE}

This procedure addresses routine security patrol of the facility to provide protection of nuclear materials against vandalism, theft, tampering, or radiological sabotage. It does not address other duties of security employees that are described in other Operating Procedures, such as Procedure , Security Incidents, including criminal, traffic and general law enforcement activities, investigation of criminal and safety offenses, crowd control and emergency evacuation of the facility, inspection of waste shipment vehicles for road worthiness, and security and emergency response training.

\subsection{EQUIPMENT AND MATERIALS}

1. Communications equipment (e.g., telephones and radios).

2. Security equipment (e.g., vehicles, weapons, etc.).

3. Keys and locks. 


\subsection{PROCEDURE}

\subsection{PREREQUISITES}

1. The facility will employ both passive security systems (i.e., fences and gates) and direct surveillance to achieve security.

2. A passive security system will be provided by two fences: an outer fence that surrounds the entire facility, and an inner fence that separates the controlled area from the support area. The fence surrounding the perimeter of the controlled area will consist of a continuous 8-foot-high chain-link fence topped with barbed wire. The fence will be posted with cautionary signs. In order to reach the controlled area from outside the facility, it will be necessary to pass through a guard station at the facility entrance gate and continue through the support area to the controlled area gate.

\subsection{TRAINING}

The Chief of Security will be a currently certified Peace Officer with an advanced certificate. The facility security officers will be currently certified Peace Ofícers. All security personnel will be trained in accordance with Procedure , On-Site Safety Training.

Security personnel will receive quality assurance training in the implementation of this operating procedure prior to performing their duties. Security personnel operating vehicles on the disposal facility will have valid certification by the Director of Operations that they are current in all operations and safety training for the vehicle.

\subsection{SPECIAL PRECAUTIONS}

1. All visitors will be escorted at all times by at least one facility employee.

2. Strict control of the use and access to keys will be maintained by the Director of Operations.

\section{$3.4 \quad$ INSTRUCTIONS}

1. Only the Director of Operations, Health Physics Supervisor, Operations Supervisor, Chief of Security, and security officers may possess keys to facility controlled area. Distribution of keys is the responsibility of the Director of Operations. Prior to employee termination, all keys will be returned to the Director of Operations.

2. The guard house at the entrance gate to the facility will be operated at all times by a security officer. The security officer in the guard house will direct all visitors passing through the entrance gate to the Administration/Health Physics Building for registration during working hours. No persons will be permitted through the entrance gate during 
non-working hours unless permission is received from the Director of Operations or the Chief of Security.

3. All visitors to the facility will register at the Administration/Health Physics Building prior to entering the controlled area. At the registration desk, the visitor will obtain a Visitor's Badge and pocket dosimeter, read and sign the Visitor Safety Form, Form Number OP 5.1-1, and sign the Visitor Log, Form Number OP 5.1-2. Visitors will be escorted by a facility employee at all times.

4. A security officer will control access to the controlled area during working hours. All doors and gates for access to the controlled area will be locked when not attended and during non-working hours. Only personnel authorized to possess keys are authorized to open locked doors and gates.

5. The security officer at the controlled area access gate will not allow access of personnel into the controlled area until he/she has verified that:

a. The individual has a Site Security Badge and thermoluminescent dosimeter

b. The individual is a visitor being escorted by a disposal facility employee and the visitor has:

1. Read and signed the Visitor Safety Form, Form Number OP 5.1-1

2. Been issued a pocket dosimeter and Visitor's Badge

3. Signed the Visitor Log, Form Number OP 5.1-2.

6. Visitors or personnel discovered in the controlled area without proper clearance or equipment will be escorted out of the controlled area and the Director of Operations and the Health Physics Supervisor will be notified. Radio communication between security personnel, the operating crews, and the administrative building will be maintained so that information and direction regarding security matters can be relayed quickly.

a. The individual will be frisked and then questioned by the security officer as to the reason they were in the controlled area, their name will be taken, and the local law enforcement authorities will be notified if the person does not have a valid reason for being in the controlled area.

b. The Chief of Security will try to determine the route the uncleared person followed during incursion into the controlled area. 
c. When the uncleared person was not wearing a dosimeter, the Health Physics Supervisor will estimate the radiation dose received by that individual. This estimate will become part of the record of the security incursion.

7. Upon leaving the controlled area, all site personnel and visitors will be frisked by the security officer at the controlled area gate. Personnel and visitors will then surrender their Site Security Badge or Visitor Badge and pocket dosimeter at the registration desk in the Administration/Health Physics Building. Prior to departure, visitors will sign out on the Visitor Log by indicating the departure time.

8. Security officers will make periodic patrols at least every 4 hours inside and outside the controlled area, including buildings and equipment storage areas, to search for any signs of unauthorized access to the site or any buildings. During facility working hours these patrols will be conducted by the security officer normally at the guard house at the facility entrance gate. That officer will be replaced at the guard house by the Chief of Security when he or she is conducting patrols. For shifts other than during facility working hours, the lone security officer onsite will conduct the patrols. Communication will be maintained between the patrolling security officer and the guard house during the patrol. A log will be maintained at the guard station to record these patrols (Form Number OP 5.1-3, Security Patrol Log). Upon completion of each patrol, the security officer who performed the patrol will enter information in the log book on the date, time the patrol was completed, findings, actions taken, and signature of the security officer. The Chief of Security will review the log daily and sign it to indicate that the patrols have been completed and appropriate actions have been taken when required.

9. Security officers will have telephone access to facility management and local law enforcement agencies. If any signs of unauthorized access to the site or any buildings are discovered, the local law enforcement authorities will be notified immediately in accordance with Operating Procedure OP 6.3.3, Security Incidents. Concurrent notifications will be given to the Director of Operations and Health Physics Supervisor.

\subsection{RECORDS}

\subsection{REQUIRED FORMS}

Visitor Safety Form, Form Number OP 5.1-1.

Facility Visitor Log, Form Number OP 5.1-2.

Security Patrol Log, Form Number OP 5.1-3. 


\subsection{COMPLETION AND APPROVAL REQUIREMENTS}

The Visitor Safety Form, Form Number OP 5.1-1, will be completed by each visitor upon arrival at the facility and will be approved by the Health Physics Supervisor.

The Visitor Log, Form Number OP 5.1-2, will be completed by the visitor upon arrival at the facility and signed by the employee escort and the security officer. Upon departure, the visitor will indicate the departure time on the log.

The Security Patrol Log, Form Number OP 5.1-3, will be completed and signed by the security officer conducting the security patrol. The Chief of Security will review the entries daily and sign the Security Patrol Log form.

\subsection{PROCESSING AND ARCHIVAL REQUIREMENTS}

1. Documents required in support of this procedure are quality assurance records. The Visitor Safety Form, the daily copies of the Facility Visitor Log, and the Security Patrol Log will be included in the quality assurance records package.

2. The records will be submitted to the Records Management Technician who, as custodian, will ensure each document is complete, legible, and adequately identifiable. The quality assurance records resulting from this procedure will be retained in accordance with Administrative Procedure by the records custodian.

\subsection{REFERENCES}

None. 


\section{VISITOR SAFETY FORM}

FORM NUMBER OP 5.1-1

I, following topics relating to my visit to the , certify that I have received instruction on the disposal facility:

1. The location of restricted areas.

2. Methods of marking and posting radiological areas and packages.

3. Requirements for personnel dosimetry.

4. Escort requirements.

5. Visitor Radiation Exposure Authorization Form.

6. Regulatory Guide 8.13, "Instructions Regarding Prenatal Radiation Exposure", Appendix A (Required only by female visitors).

7. Procedures to be taken in response to warnings made in the event of an unusual occurrence or malfunction.

I have been advised that I will receive a written report on any radiation dose received during the course of this visit.

Name of Visitor (print)

Signature of Visitor

Date

Health Physics Supervisor

Date 


\section{INSTRUCTIONS FOR COMPLETION OF VISITOR SAFETY FORM FORM NUMBER OP 5.1-1}

This form will be completed by each visitor upon arrival at the facility.

Prior to signing the form, the visitor will be provided with the following information for review:

a. A map showing the location of the restricted areas

b. A description and drawings showing methods of marking and posting radiological areas and packages

c. Operating Procedure OP 2.6 on requirements for personnel dosimetry

d. A description of escort requirements

e. A Visitor Radiation Exposure Authorization Form for his/her signature, in accordance with Operating Procedure OP 2.6

f. Females and their escorts will be provided with a copy of Regulatory Guide 8.13, "Instructions Regarding Prenatal Radiation Exposure", Appendix A

g. Instructions on the procedures to be taken in response to warnings made in the event of an unusual occurrence or malfunction.

The visitor will also be advised that he or she is entitled, upon request, to receive a written report on any radiation exposure received during the course of the visit.

After the visitor has reviewed and understands all of the material provided, he or she will print his or her name on the first line of the form.

1. Name of Visitor (print)-To be completed after the visitor has reviewed and understands all of the material provided.

2. Signature of Visitor and Date-To be completed after the visitor has reviewed and understands all of the material provided; date should include day, month, and year.

3. Health Physics Supervisor and Date-To be completed after the form has been signed by the visitor. 
FACILITY VISITOR LOG

FORM NUMBER OP 5.1-2

\begin{tabular}{|c|c|c|c|c|c|c|c|c|}
\hline Visittor Name & Representing & $\begin{array}{l}\text { Employee Escort } \\
\text { Signature }\end{array}$ & $\begin{array}{c}\text { Securtty } \\
\text { Officer } \\
\text { Intitals }\end{array}$ & Date & $\begin{array}{c}\text { Badge } \\
\text { Number }\end{array}$ & $\begin{array}{c}\text { Dosimeter } \\
\text { Number }\end{array}$ & $\begin{array}{c}\text { Time } \\
\text { Entered }\end{array}$ & $\begin{array}{c}\text { Time } \\
\text { Departed }\end{array}$ \\
\hline & & & & & & & & \\
\hline & & & & & & & & \\
\hline & & & & & & & & \\
\hline & & & & & & & & \\
\hline & & & & & & & & \\
\hline & & & & & & & & \\
\hline & & & & & & & & \\
\hline & & & & & & & & \\
\hline & & & & & & & & \\
\hline & & & & & & & & \\
\hline & & & & & & & & \\
\hline & & & & & & & & \\
\hline & & & & & & & & \\
\hline & & & & & & & & \\
\hline & & & & & & & & \\
\hline & & & & & & & & \\
\hline & & & & & & & & \\
\hline & & & & & & & & \\
\hline & & & & & & & & \\
\hline
\end{tabular}




\section{INSTRUCTIONS FOR FACILITY VISITOR LOG \\ FORM NUMBER OP 5.1-2}

This form will be completed by each visitor entering the facility.

1. Visitor Name-Enter the full name of the visitor.

2. Representing-Enter the name of the organization that the visitor is representing.

3. Employee Escort Signature-Enter the full name of the escort.

4. Security Officer Initials-Enter the initials of the security officer on duty.

5. Date-Enter the date of the visit; include day, month, and year.

6. Badge Number-Enter the number of the Visitor's Badge.

7. Dosimeter Number-Enter the number of pocket dosimeter issued to visitor.

8. Time Entered-Enter the time at which the visitor is signing in on this form; enter hour, minutes, and "a.m." or "p.m."

9. Time Departed-Enter the time at which the visitor departs from the registration desk at the Administration/Health Physics Building; enter hour, minutes, and "a.m." or "p.m." 
SECURITY PATROL LOG

FORM NUMBER 5.1-3

\begin{tabular}{|c|c|c|c|c|c|}
\hline Date & $\begin{array}{l}\text { Time the } \\
\text { Patrol was } \\
\text { Completed }\end{array}$ & Patrol Findings & Actions Taken & $\begin{array}{l}\text { Securtly Offlcer } \\
\text { Slgnature }\end{array}$ & $\begin{array}{l}\text { Revilewed } \\
\text { by the Chlef } \\
\text { of Securrty }\end{array}$ \\
\hline & & & & & \\
\hline & & & & & \\
\hline & & & & & \\
\hline & & & & & \\
\hline & & & & & \\
\hline & & & & & \\
\hline & & & & & \\
\hline & & & & & \\
\hline & & & & & \\
\hline & & & & & \\
\hline & & & & & \\
\hline & & & & & \\
\hline & & & & & \\
\hline & & & & & \\
\hline & & & & & \\
\hline & & & & & \\
\hline & & & & & \\
\hline & & & & & \\
\hline
\end{tabular}


Page $\frac{11}{\text { Revision } \frac{11}{0}}$

\section{INSTRUCTIONS FOR SECURITY PATROL LOG}

FORM NUMBER OP 5.1-3

This form will be completed by the security officer after each security patrol of the facility.

1. Date-Enter the date of the patrol.

2. Time the Patrol was Completed-Enter the time that the security patrol was completed; enter hour, minutes, and "a.m." or "p.m.".

3. Patrol Findings-Enter a description of the results of the security patrol, including normal conditions and abnormal conditions, such as evidence of vandalism, theft, tampering, or radiological sabotage.

4. Actions Taken-Enter a description of-the actions taken if any abnormal conditions were encountered during the security patrol.

5. Security Officer Signature-The security officer conducting the patrol will sign here.

6. Reviewed by Chief of Security -The Chief of Security will review the log daily and will verify, by his or her signature, that the patrols have been completed and appropriate actions taken when required. 
Date:

Revision No.:

Supersedes:

Approval:

Concurrence:

Title Date Title Date

\subsection{PURPOSE AND SCOPE}

Tractors with loaded trailers will sometimes be left unmanned at the facility so the driver need not remain with the vehicle at all times. This procedure covers the steps to be taken to ensure the security of these vehicles while parked at the facility during non-working hours. Loaded vehicles will be left at the Truck Staging Area. Those that have been unloaded, surveyed, and washed will be left at the vehicle waiting area.

\subsection{EQUIPMENT AND MATERIALS}

1. Chains.

2. Locks.

3.0 PROCEDURE

\subsection{PREREQUISITES}

None.

\subsection{TRAINING}

None. 


\subsection{SPECIAL PRECAUTIONS}

None.

\subsection{INSTRUCTIONS}

A security officer shall ensure that all loaded trailers are secure at the end of each work day as follows:

1. If a tractor bringing a loaded trailer must be left at the facility, ensure the tractor is detached from the trailer, the keys are removed from the cab, and all doors and lockable openings are locked.

2. A chain will be passed through the trailer landing gear strut and wrapped around the crank, thereby immobilizing the crank and preventing the gear from being raised. The chain will then be padlocked, thereby securing the chain.

3. When the trailer is to be taken to the disposal unit for off-loading, the Authority driver will obtain a key from the receiving health physics technician, unlock and remove the chain and return the lock, key, and chain to the Administration/Health Physics Building.

\subsection{RECORDS}

\subsection{REQUIRED FORMS}

None.

\subsection{COMPLETION AND APPROVAL REQUIREMENTS}

None.

\subsection{PROCESSING AND ARCHIVAL REQUIREMENTS}

None.

\subsection{REFERENCES}

None. 


\section{A-148}




\section{A-4. RADIATION INSTRUMENTATION PROCEDURES}


A-150 


\section{OPERATING PROCEDURE}

\section{LIQUID SCINTILLATION COUNTER OPERATION}

Date:

Supersedes:

Revision No.: 0

Supersedes:

Approval:

Concurrence:

Page 1 of 7

\begin{tabular}{lll}
\hline Title & Date & Title \\
\hline
\end{tabular}

\subsection{PURPOSE AND SCOPE}

This procedure outlines an important common activity in liquid scintillation analysis of materials that may contain radionuclides. It does not cover sample preparation or the selection of appropriate liquid scintillation cocktails. This procedure does not provide instructions for operating a liquid scintillation counter because they are specific to the make and model of the particular instrument and will be provided by the manufacturer when the instrument is purchased.

Liquid scintillation is a widely used technique for the detection and quantification of radioactivity. It measures radioactivity at a much higher efficiency than other types of counting techniques, especially for alpha and beta samples with low specific activities. Liquid scintillation, as the name implies, measures the amount of light produced in a liquid. This light is produced by interactions with radioactivity in the solution. The light can then be detected, amplified, and converted to an electronic signal that can be counted.

Because knowledge of radiation detection instrumentation theory is required for a detailed understanding of liquid scintillation analysis, the steps in this procedure should only be conducted by an experienced health physics technician. Once programmed, however, most modern liquid scintillation analyzers are very simple to operate.

The Health Physics Supervisor has responsibility for all radiation detection instrumentation, such as the liquid scintillation analyzer. 


\subsection{EQUIPMENT AND MATERIALS}

1. Liquid scintillation analyzer and appropriate operation/instruction manual.

2. Liquid scintillation vials and caps.

3. Liquid scintillation cocktails.

4. Quench agent.

5. Liquid radionuclide standards.

6. Measuring device (micropipette).

\subsection{PROCEDURE}

\subsection{PREREQUISITES}

This procedure is for a liquid scintillation analyzer that has an internal device used to measure light absorption within the sample vial.

\subsection{TRAINING}

The operator of the analyzer will have completed a training course in the theory and operation of liquid scintillation analyzers or appropriate, supervised on-the-job-training.

\subsection{SPECIAL PRECAUTIONS}

Although emphasis in recent years has been on using environmentally benign liquid scintillation cocktails, many older formulations are still in use. These older cocktails contain hazardous solvents and as such are usually highly flammable. Appropriate care should be taken in their use and subsequent disposal.

\subsection{INSTRUCTIONS}

This procedure will only be conducted by a trained health physics technician.

A common problem encountered with liquid scintillation analysis is that introduction of a sample into a scintillation solution causes a reduction in the light output, with a corresponding reduction in detection efficiency. This phenomena, called quenching, can result from an alteration of the optical properties of the solution (color quenching) or interference with the energy transfer process within the scintillation solution itself, due to impurities. Efficiency calibration is accomplished by the construction of a quench curve. A quench curve is constructed by measuring the amount of quench in a vial of liquid scintillation solution and plotting this information as a function of detection efficiency. This quench curve indicates the efficiency of the analysis at various levels of quench and is used to correct for differences in samples.

Most newer liquid scintillation analysis instruments use a known external (external to the sample, inside the instrument) standard to irradiate the scintiliation solution from below. 
The computer adjusts the detected light spectrum to what it should be and this adjustment value is an indication of quench in the sample. The computer reports not only the count rate detected, but also the degree to which the light emitted from the vial is quenched. The degree to which emissions from a particular vial are quenched (the "measure of quench") is a dimensionless value.

The steps in preparing a quench curve are given below.

1. Fill an empty vial with scintillation cocktail. This is the background vial.

2. For each sample vial to be used, place a small amount of radioactive standard (e.g., a known concentration) in a liquid scintillation vial using the micropipette. Record the amount of material added to the vial and its activity.

3. Add cocktail to the vial, being careful to not overfill. Leave room for the addition of the quench agent.

4. According to the manufacturer's instructions, set the instrument energy regions or channels for the radionuclides contained in the sample vials.

5. Count the background and sample vials for a preselected time period (e.g., 10 minutes), recording the count rate and the measure of quench provided by the instrument on the Quench Curve Worksheet, Form Number OP 3-1.

6. When counting is complete, add a small amount ( 1 to 2 drops) of quench agent to each sample vial and count them and the background vial again. Repeat this until 10 to 12 data points are collected for each sample vial. The quench agent can be a complex hydrocarbon such as carbon tetrachloride or just water, depending on the amount of quench desired.

7. Subtract background counts and calculate the efficiency for each of the samples counted by:

$$
\begin{aligned}
& \text { Sample CPM }- \text { Background CPM }=\text { Reported CPM } \\
& \text { Reported CPM/DPM expected } \times 100=\text { Efficiency }
\end{aligned}
$$

where: $\mathrm{CPM}=$ measured counts per minute

$D P M=$ disintegrations per minute

The DPM expected comes from the activity of the sample.

8. Plot the efficiency as a function of quench on the back of the Quench Curve Worksheet, Form Number OP 3-1.

9. The curve plotted will be used to determine efficiency at a specific level of quench in subsequent sample measurements. Efficiency is used to convert CPM into DPM to determine the sample activity. 
Most newer liquid scintillation analyzers (those introduced after the mid-1980s) have an automatic background subtraction feature. Also, most newer machines allow the quench curve to be input back into the instrument so the instrument will automatically calculate DPM. In that case, some of the calculation steps performed above may be done by the computer controlling the instrument.

\subsection{RECORDS}

\subsection{REQUIRED FORMS}

Quench Curve Worksheet, Form Number OP 3-1.

\subsection{COMPLETION AND APPROVAL REQUIREMENTS}

The Quench Curve Worksheet, Form Number OP 3-1, will be completed by a health physics technician.

\subsection{PROCESSING AND ARCHIVAL REQUIREMENTS}

1. Documents required or created in support of this procedure are quality assurance records. The Quench Curve Worksheet will be included in the quality assurance records package.

2. The records shall be submitted to the Records Management Technician who, as custodian, will ensure each document is complete, legible, and adequately identifiable. The quality assurance records resulting from this procedure shall be retained in accordance with Administrative Procedure AP by the records custodian.

\subsection{REFERENCES}

None. 
Date:

Technician:

Liquid Scintillation Analyzer:

Model:

Serial Number:

Radionuclide:

Source of Standard:

Standard Serial Number:

Concentration:

Volume Added:

Activity Added:

LSA Cocktail Vendor and Type:

LSA Cocktail Lot/Batch Number:

Quench Agent:

Data

\begin{tabular}{||l|l|l|l||}
\hline \multicolumn{1}{|c|}{ Run Number } & Quench & Counts Per Minute & Efficiency \\
\hline 1 & & & \\
\hline 2 & & & \\
\hline 3 & & & \\
\hline 5 & & & \\
\hline 6 & & & \\
\hline 7 & & & \\
\hline 8 & & & \\
\hline 9 & & & \\
\hline 10 & & & \\
\hline
\end{tabular}

Plot this data as efficiency vs quench on the second page of this form. 
Page $\frac{6}{\text { Revision }} \frac{7}{0}$

QUENCH CURVE WORKSHEET

FORM NUMBER OP 3-1

(Continued)

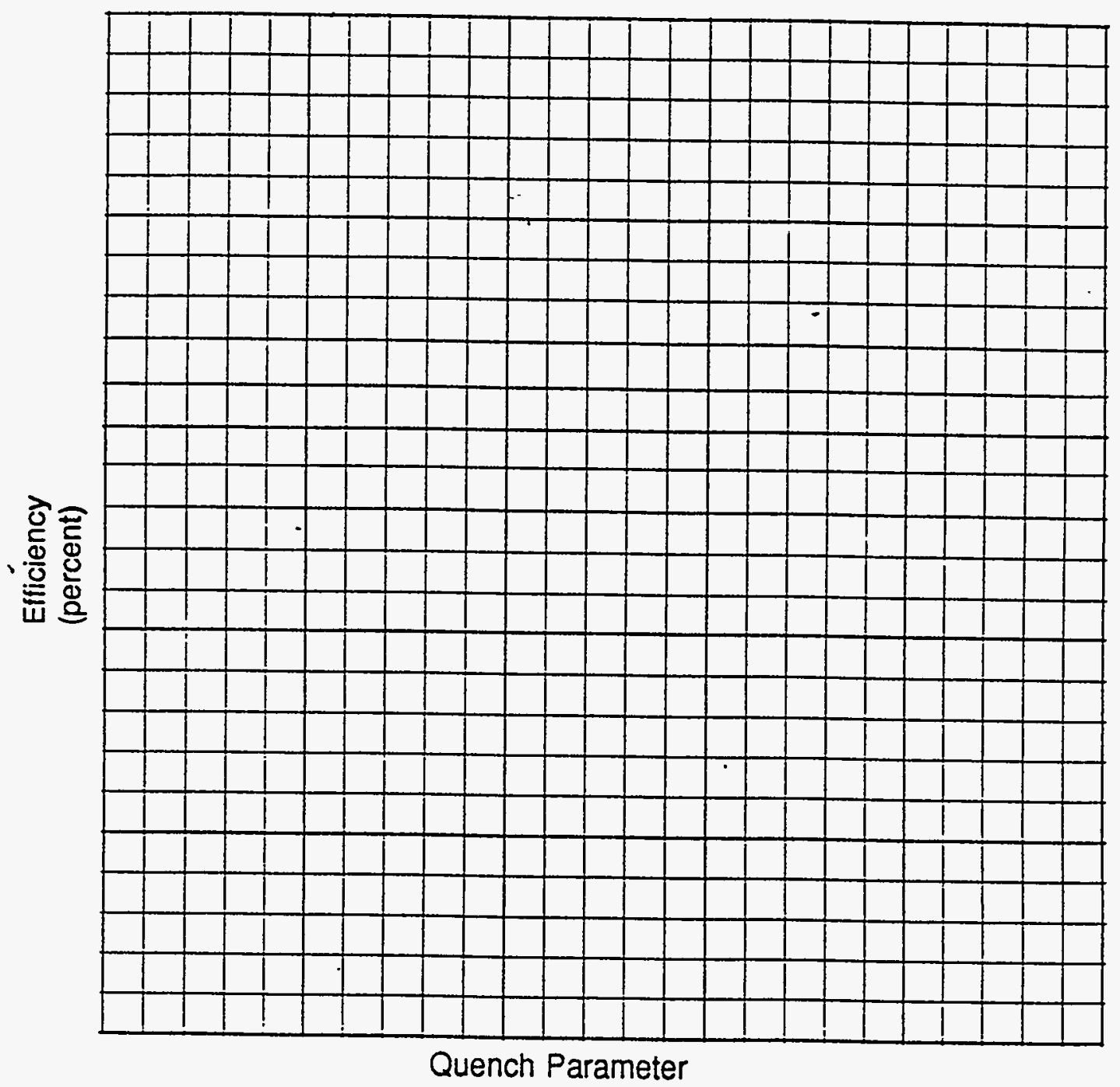




\section{INSTRUCTIONS FOR \\ QUENCH CURVE WORKSHEET \\ FORM NUMBER OP 3-1}

1. Enter the date.

2. Enter the technician's name.

3. Specify the liquid scintillation analyzer model and serial number.

4. Specify the radionuclide being used for the quench calibration.

5. Specify the source of the standard being used (e.g., the vendor or supplier).

6. Enter the serial number and radionuclide concentration of the standard.

7. Specify the volume of the standard added to the vial.

8. Calculate the activity added by:

$$
\mathrm{DPM}=\mathrm{DPM} / \mathrm{ml} \text { of the standard } \mathrm{x} \mathrm{ml} \text { of the standard added }
$$

Enter the activity.

9. Specify the vendor, type, and lot number of the scintillation cocktail being used.

10. Specify the quench agent used to develop the data for the quench curve.

11. Record the quench parameter provided by the equipment and counts per minute for each run of the quenched sample.

12. Calculate the efficiency by:

Efficiency $=$ CPM reported/DPM expected $\times 100$

Subtract background as appropriate. Some models may do this automatically.

Enter the efficiency values.

13. Plot the data on the second page of the form. Put appropriate scales on the graph. 


\section{OPERATING PROCEDURE}

\section{MULTICHANNEL ANALYZER OPERATION}

Date:

Revision No.: $\underline{0}$

Supersedes:

Page 1 of $\frac{0}{4}$

Approval:

Concurrence:

\begin{tabular}{llll}
\hline Title & Date & Title & Dare \\
\hline \hline
\end{tabular}

\subsection{PURPOSE AND SCOPE}

This procedure describes some common activities in the use of multichannel analyzers in radiation spectroscopy. It does not cover analyzer operation, because that is specific to the make and model of the particular analyzer; those instructions will be provided by the manufacturer.

Multichannel analyzers (MCAs) are commonly used instruments for radiation spectroscopy. MCAs can be used with a variety of detectors, such as germanium, sodium-iodide, solid scintillator, and semiconductors. With the appropriate detector and supporting hardware, an MCA can be used to measure gamma, alpha, neutron, and even beta radiation.

Typically, a low-level radioactive waste disposal facility uses an MCA to examine a gamma ray spectrum from a sample to determine its radioisotopic composition. MCAs are usually large, relative to survey instruments. Although some portable units have been developed, they usually cannot be hand held. The typical spectroscopy system consists of a detector (usually shielded from background radiation), an instrumentation module with filters, amplifiers, and power supplies for the detector/instruments, and the MCA. The latter can either be a stand-alone console, or in more recent models, a modified personal computer.

In a spectroscopy system, the energy of the radiation incident on the detector is measured and converted into a graphical display showing spectral peaks corresponding to the energies of the incident radiation. These energy peaks usually correspond to specific radionuclides. 
Most modern MCAs have on-board libraries of stored spectra, which can be used to determine which radionuclides are present, as long as the spectroscopy system (MCA, detector, and associated support hardware) has been adequately calibrated. In routine use, one of the more common steps in MCA operation is an energy/efficiency calibration. The steps for this calibration are given in this procedure.

\subsection{EQUIPMENT AND MATERIALS}

1. Multichannel analyzer, Model Number

2. Appropriate operation/instruction manual.

3. Radiation detector, Model Number

4. Support hardware, as appropriate.

5. Radionuclide standards.

\subsection{PROCEDURE}

\subsection{PREREQUISITES}

None.

\subsection{TRAINING}

The operator of the multichannel analyzer must complete a training course in the theory and operation of multichannel analyzers and their use in radiation spectroscopy, or appropriate, supervised on-the-job-training.

\subsection{SPECIAL PRECAUTIONS}

None.

\subsection{INSTRUCTIONS}

Because knowledge of radiation detection instrumentation theory is required for a detailed understanding of multichannel pulse analysis, the steps in this procedure and the operations manual referred to should only be completed by an experienced health physics technician.

The Health Physics Supervisor has overall responsibility for all radiation detection instrumentation, such as the multichannel analyzer.

In routine use, one of the more common steps in MCA operation is an energy/efficiency calibration. The steps for this activity are outlined below. 


$$
\text { Page } \frac{3}{\text { Revision }} \text { of } \frac{4}{?}
$$

1. Efficiency calibration

a. Acquire a spectrum (count) of the radiation standard for a preset count time. The count time depends on the type of radiation being measured and could range from as little as 15 minutes for gamma rays to 24 hours for alpha particles.

b. After the spectrum is acquired, a determination is made as to which peaks correspond to which energies for the radionuclides of interest.

c. Lower and upper channel limits are specified for each region of interest (ROI or peak) and the counts under that peak are integrated. Using the time interval, this can be converted to a count rate (i.e., counts per minute (CPM)).

NOTE: Most newer MCAs have a provision for background subtraction. Refer to the manufacturer's operations manual to determine if this feature is applicable. On older systems, a separate background spectrum had to be acquired and the counts in each of the ROls would have to be subtracted from the sample counts.

d. Using information supplied with the standard, determine the number of disintegrations that should have occurred during the count time interval or a disintegration rate (i.e., disintegrations per minute (DPM)).

e. From these values, a calculated efficiency for a specific ROI (peak) using:

CPM reported/DPM expected $\times 100=$ Efficiency

f. Steps a through e are repeated for several energies (if the standard has more than one; most gamma standards do).

g. Most newer (mid 80s) MCAs allow this efficiency information to be input back into the instrument. The instrument's software then automatically corrects for efficiency and lets the user know what energies (and therefore radionuclides) the peaks correspond to.

\subsection{RECORDS}

\subsection{REQUIRED FORMS}

None. 


\subsection{COMPLETION AND APPROVAL REQUIREMENTS}

The Scaler Efficiency Calculation Worksheet, Form Number OP 5-1, and the Chi-Squared Equipment Test, Form Number OP 5-2, both from Procedure Number , Scaler Operation, will be completed by the health physics technician. They will then be reviewed and approved by the Health Physics Supervisor.

\subsection{PROCESSING AND ARCHIVAL REQUIREMENTS}

1. Documents required or created in support of this procedure are quality assurance records. The Scaler Efficiency Calculation Worksheet and the Chi-Squared Equipment Test Form will be included in the quality assurance records package.

2. The records shall be submitted to the Records Management Technician who, as custodian, will ensure each document is complete, legible, and adequately identifiable. The quality assurance records resulting from this procedure shall be retained in accordance with (Administrative Procedure AP _ by the records custodian.

\subsection{REFERENCES}

1. Knoll, "Radiation Detection and Measurement," John Wiley \& Sons, New York, 1989. 


\title{
OPERATING PROCEDURE
}

\author{
SCALER OPERATION
}

Date:

Revision No.: $\frac{0}{11}$

Supersedes:

Page 1 of 11

Approval:

Concurrence:

\begin{tabular}{llll}
\hline Title & Date & Title & Daie \\
\hline
\end{tabular}

\subsection{PURPOSE AND SCOPE}

This procedure describes some common activities in the use of scalers or single-channel analyzers in radiation detection. It does not cover scaler operation, because that is specific to the make and model of the particular instrument; those instructions will be provided by the manufacturer.

Scalers are commonly used instruments for radiation detection. Typically, scalers can more precisely quantify amounts of radioactivity than other instruments, such as dose/exposure or count rate meters. Scalers can be used with a variety of detectors, such as germanium, sodium-iodide, solid scintillator, semiconductors, and proportional detectors. With the appropriate detector and supporting hardware, a scaler can be used to measure gamma, alpha, beta, and neutron radiation.

Typically, a low-level radioactive waste disposal facility uses a scaler and a proportional detector to count smears, air sample filters and cartridges, nose swipes, water samples, etc. The typical scaler counting system consists of a detector (usually shielded from background radiation), an instrumentation module with filters, amplifiers, and power supplies for the detector/instruments, and the scaler.

\subsection{EQUIPMENT AND MATERIALS}

1. Scaler/single-channel analyzer, Model Number

2. Appropriate operation/instruction manual.

3. Radiation detector, Model Number 
4. Support hardware, as appropriate.

5. Radionuclide standards.

\subsection{PROCEDURE}

\subsection{PREREQUISITES}

None.

\subsection{TRAINING}

The operator of the scaler must complete a training course in the theory and operation of multichannel analyzers and their use in radiation spectroscopy, or appropriate, supervised on-the-job-training.

\subsection{SPECIAL PRECAUTIONS}

None.

\section{$3.4 \quad$ INSTRUCTIONS}

Because knowledge of radiation detection instrumentation theory is required for a detailed understanding of scaler operation, the steps in this procedure and the operations manual referred to should be completed only by an experienced health physics technician.

The Health Physics Supervisor has overall responsibility for all radiation detection instrumentation, such as the scaler.

In routine use, one of the more common steps in scaler operation is an efficiency calibration. The steps for this activity are outlined below.

1. Efficiency calibration

a. Adjust the window settings and the count time on the scaler for the type of radiation being measured. Follow the manufacturer's instructions in making these adjustments.

b. Perform a background count for the preset count time. Record this value on the Efficiency Calculation Worksheet, Form OP 5-1.

c. Count the radiation standard for the preset count time. The count time depends on the type of radiation being measured and could range from as little as 15 minutes for gamma rays to 24 hours for alpha particles.

d. After the count is complete, subtract the background counts, and determine the count rate by dividing the remaining number of counts by the time interval to get a measure of counts per minute (CPM). 
e. Using information supplied with the radionuclide standard, determine the number of disintegrations that should have occurred during the count time interval (i.e., the disintegration rate in disintegrations per minute (DPM)). The standard should indicate the number of disintegrations per minute for a particular geometry. If this information is not supplied with the standard, make a correction for geometry.

f. From the values calculated in steps $d$ and e above, calculate an efficiency for the specific radionuclide using:

$$
\text { CPM reported/DPM expected } \times 100=\text { Efficiency }
$$

This efficiency is a correction factor to be applied to subsequent sample measurements.

\section{Chi Square Test-Routine Reliability Test.}

The process of radionuclide disintegration is a random process. Measurements of radioactivity taken over long periods of time show a statistical consistency with only slight variations from one long period of observation to another. Statistics of radioactivity measurements taken over short periods of time will show a greater degree of variation from one period of observation to another. This reflects the much smaller statistical data base when only short observation periods are used. If sequential sets of observations show too much variation, it is an indication that the data are being influenced by some factor other than the rate of emissions from the radioactive source, such as high frequency fluctuations to input power, high amplifier gain, electromagnetic fields created by welders or motors, etc.

For short counting periods encountered in typical operations, the random distribution of radionuclide emissions can be expected to fall within a typical Poisson curve.

The Chi-Squared Reliability Test is used to verify the distribution of the radioactive decay event being measured to confirm proper functioning of the scaler and associated instrumentation. The steps in a Chi-Squared Reliability Test are outlined in the following series of instructions:

a. A series of counts per unit time from a radioactive source will be recorded monthly on Form Number OP 5-2, Chi Squared Equipment Test. The Chi Squared Equipment Test form will be kept in the appropriate scaler data log.

b. Each list of experimental numbers is considered to fit the Poisson distribution if the value of $p$, determined by the value of $\chi^{2}$ calculated, falls between 0.1 and 0.9 . This indicates a 90 percent "confidence level". 
The fit is considered atypical if $p$ falls between 0.05 and 0.1 or 0.90 and 0.95 .

The fit is unsatisfactory if $p$ is less than 0.05 or more than 0.95 .

Values of $p$ may be obtained from standard mathematical tables. The following table has been extracted from the Handbook of Chemistry and Physics. The entries are values of $\chi^{2}$ from the Chi-Squared Equipment Test, Form Number OP 5-2. $N$ is the number of intervals over which counts were taken.

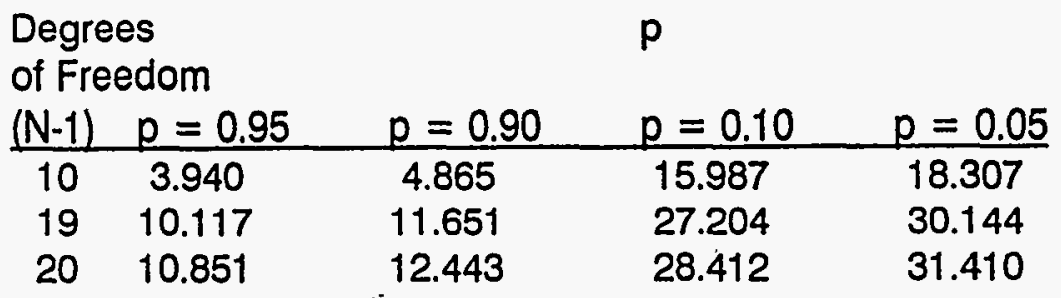

c. If the Chi-Squared Test is unsatisfactory, the cause will be determined and corrected. If no cause is apparent, or the if cause has been corrected, a second Chi-Squared test will be performed. Failure of this second test requires that the instrument to be sent to a licensed repair facility for corrective action.

3. Quick Reliability Test

When counting equipment is suspected of recording spurious counts arising from factors other than nuclear radiation (e.g., large changes in daily background counts), a comparison of the deviations in the results of successive measurements may be used to make a quick determination of reliability.

The Quick Reliability Test is similar to a Chi-Squared Test in that it uses probabilities of separate counts of identical samples or standards as a measure of instrument performance and, therefore, reliability. The steps in this test are explained in the following instructions:

a. This method consists of calculating the standard error of the difference between two counting rate determinations made on the same source and comparing this with the observed difference between the two determinations. The standard error $(\sigma)$ of the difference of two count rates $\left(r_{1}\right.$ and $\left.r_{2}\right)$ taken in time intervals $t_{1}$, and $t_{2}$, respectively, is:

$$
\sigma=\left[\left(r_{1} / t_{1}\right)+\left(r_{2} / t_{2}\right)\right]^{1 / 2}
$$

The probability of observing an absolute difference $\left|r_{1}-r_{2}\right|$ in counting rates equal to or greater than $k$ is given in the following table for several values of $k$. 


$$
\begin{array}{llllllllll}
\multicolumn{1}{c}{\text { PROBABILITY OF OBTAINING }} & \left|r_{1}-r_{2}\right| \geq k \\
k & 1.0 & 1.2 & 1.4 & 1.6 & 2.0 & 2.5 & 3.0 & 4.0 \\
p & 0.159 & 0.115 & 0.081 & 0.055 & 0.023 & 0.006 & 0.001 & <0.001 \\
\text { Where: } k= & \left|r_{1}-r_{2}\right| / \sigma \\
& p=\text { probability }
\end{array}
$$

b. If the probability of the observed deviation is less than 0.05 , it is likely that the deviations are due to causes other than the statistically random nature of the radionuclide disintegration process.

Example: Two counting rates of 1,010 and 1,069 counts per minute are recorded by two 10-minute counts of a radioactive check source.

$$
\begin{aligned}
& \text { Absolute difference }\left|r_{1}-r_{2}\right|=1069-1010=59 \mathrm{CPM} \\
& \sigma=\left[\left(r_{1} / t_{1}\right)+\left(r_{2} / t_{2}\right)\right]^{1 / 2}=14.4 \mathrm{CPM} \\
& k=59 / 14.4 \approx 4
\end{aligned}
$$

From the above table, the probability of obtaining this difference because of statistical fluctuation is less than 0.05 . Therefore, there appears to be a problem with the instrument.

c. A full Chi-Squared Test should be conducted if the quick reliability test is unsatisfactory.

\section{Daily Reliability Test}

The deterioration of electronic counting equipment often occurs slowly enough that day-to-day changes are imperceptible.

The following test gives a daily check of instrument performance and also shows trends indicating that an instrument's performance is deteriorating and may soon be yielding unacceptable results.

a. After performing the routine monthly Chi-Squared Test, construct a daily graph sheet showing the mean value of the net counts per minute, $\bar{x}$, and showing lines $2 \sigma$ and $3 \sigma$ above and below the mean.

Each day that the instrument is used, and at least weekly, count the same source used for the Chi-Squared Test for a period of one minute. Subtract background from the day's count and plot the net 
counts per minute on the graph sheet on the appropriate column for the date. The instrument is considered reliable if the plotted points stay within the $2 \sigma$ area of the graph.

The graph will be kept with its corresponding Chi-Squared Test.

If a plotted point falls between $2 \sigma$ and $3 \sigma$, repeat the count and plot the results again.

b. If a plotted point falls outside $2 \sigma$ twice or outside the $3 \sigma$ once, the instrument should be considered inoperable. It is very unlikely that a true count rate would be that different from the mean.

\section{Counting with Scaler Instruments}

The scaler instruments may be used for counting a variety of different sample media. The counting procedures are as follows:

\section{a. Background Counting}

1. When taking background counts the instrument and probe will be in the exact configuration as for counting samples. Changes in configuration to accommodate different samples will be accompanied by a new background count.

2. A background count rate is calculated as:

CPM background $=$ Total Counts/Minutes Counted

b. Sample Counts

1. The sample will be placed in the appropriate holder (is applicable) and placed in front of the detector, taking care to not touch (i.e., contaminate) the front of the detector probe or end window with the sample.

2. The configuration of the detector and sample holder may be changed to accommodate different sized samples (e.g., air sample filter cartridges), but this will change the efficiency and possibly the background count for the apparatus. Both will need to be recalculated per Sections 3.4.1 and 3.4.5.a of this procedure, respectively.

3. Count the sample for an amount of time appropriate for the purpose of the counting. For example, smear samples may be counted for as little as 30 seconds for screening purposes. Those smear samples that exceed a predetermined action level may then be recounted for one minute to obtain a more precise count rate. 


$$
\text { Page } \frac{7}{\text { Revision }} \frac{11}{0 .}
$$

4. Calculate the sample activity as follows:

$$
\begin{aligned}
& \text { DPM = CPM corrected/efficiency } \\
& \text { CPM corrected = CPM sample - CPM background } \\
& \text { For example: A smear is counted in a detector } \\
& \text { configuration that has an efficiency of } 10 \text { percent resulting } \\
& \text { in } 12 \text { counter per minute. Background is } 2 \text { counts per } \\
& \text { minute. } \\
& \text { CPM corrected }=12-2=10 \mathrm{CPM} \\
& D P M=10 \mathrm{CPM} / 0.10 \text { efficiency }=100 \mathrm{DPM}
\end{aligned}
$$$$
\text { For example: A smear is counted in a detector }
$$
configuration that has an efficiency of 10 percent resulting in 12 counter per minute. Background is 2 counts per

\subsection{RECORDS}

\subsection{REQUIRED FORMS}

Scaler Efficiency Calculation Worksheet, Form Number OP 5-1.

Chi-Squared Equipment Test, Form Number OP 5-2.

\subsection{COMPLETION AND APPROVAL REQUIREMENTS}

The Scaler Efficiency Calculation Worksheet and the Chi-Squared Equipment Test Form will be completed by the health physics technician operating the scaler. They will then be reviewed and approved by the Health Physics Supervisor.

\subsection{PROCESSING AND ARCHIVAL REQUIREMENTS}

1. Documents required or created in support of this procedure are quality assurance records. The Scaler Efficiency Calculation Worksheet and the Chi-Squared Equipment Test Form will be included in the quality assurance records package.

2. The records shall be submitted to the Records Management Technician who, as custodian, will ensure each document is complete, legible, and adequately identifiable. The quality assurance records resulting from this procedure shall be retained in accordance with (Administrative Procedure AP _ by the records custodian.

\subsection{REFERENCES}

1. Operating manuals for scalers.

2. Nuclear Radiation Detection, second edition, McGraw-Hill Book Company, New York, 1964.

3. Knoll, Radiation Detection and Measurement, John Wiley \& Sons, New York, 1989. 


\section{SCALER EFFICIENCY CALCULATION WORKSHEET} FORM NUMBER OP 5-1

Date:

Technician:

Scaler:

Model:

Serial Number:

Detector:

Model:

Serial Number:

Standard Vendor:

- Radionuclide:

Standard Serial Number:

Activity (curies):

Expected Disintegrations Per Minute (DPM):

Count Time:

Window Settings:

upper

lower

Background Counts:

Standard Counts:

Calculation:

(Standard - Background) / time $=$ counts per minute $(C P M)$

CPM/DPM $\times 100=$ efficiency

Calculated CPM:

Calculated Efficiency:

Completed by:

\section{Date}

Approved by:

Health Physics Supervisor

Date 


\section{INSTRUCTIONS FOR SCALER EFFICIENCY CALCULATION WORKSHEET \\ FORM NUMBER OP 5-1}

1. Enter the date.

2. Enter the technician's name.

3. Specify the scaler model and serial number.

4. Specify the model and serial number of the detector being used with the scaler.

5. Specify the vendor, serial number, radionuclide, and activity of the standard being used for the efficiency calculation.

6. Specify the number of disintegrations per minute (DPM) expected for the standard. This may be specified on the source or may have to be calculated. If the latter is the case, make sure to account for geometry.

7. Specify the count time to which the scaler has been set. See the manufacturer's instructions.

8. Specify the upper and lower window settings being used for the type of radiation being measured. See the manufacturer's instructions.

9. Specify the number of counts recorded for the background count (if required; some instruments automatically subtract background).

10. Specify the number of counts recorded for the standard count.

11. Subtract background if appropriate.

12. Calculate and enter the counts per minute and the efficiency.

13. The form will be signed and dated by the health physics technician conducting the efficiency calibration and signed and dated as approved by the Health Physics Supervisor. 


\section{CHI-SQUARED EQUIPMENT TEST}

FORM NUMBER OP 5-2

$\mathrm{N}=$ Number of counts. If all the lines on this form are used, $\mathrm{N}=20$.

Count

Number $x$

background

1

2

3

$\underline{4}$

$\underline{5}$

6

7

8

$\underline{9}$

10

11

12

13

14

15

16

17

18

19

20 $(x-\bar{x}) \quad(x-\bar{x})^{2}$

$x=$ Gross CPM less

$\bar{x}=\frac{\Sigma x}{N} \doteq$

$\chi^{2}=\frac{\Sigma(x-\bar{x})^{2}}{\bar{x}}=$

$\Sigma$ means the sum of

\section{INSTRUMENT}

SERIAL NO.

DATE

NAME

\section{SATISFACTORY}

UNSATISFACTORY

$$
\begin{aligned}
& \sigma=\left[\frac{\Sigma(x-\bar{x})^{2}}{N-1}\right]^{1 / 2}= \\
& \bar{x}+2 \sigma= \\
& \bar{x}-2 \sigma= \\
& \bar{x}+3 \sigma= \\
& \bar{x}-3 \sigma=
\end{aligned}
$$

Completed by:

Approved by:

\section{Date}

Date 


\section{INSTRUCTIONS FOR CHI-SQUARED EQUIPMENT TEST WORKSHEET FORM NUMBER OP 5-2}

This form is designed to assist with the calculation of chi-squared. It includes a data table and the intermediate calculations necessary to calculated chi-squared and sigma.

1. Enter the instrument model and serial number.

2. Enter the date the Chi-squared test is being conducted.

3. Enter the name of the person conducting the test.

4. After the calculations are complete, specify whether the results were satisfactory or not.

5. Conduct a series of counts (the worksheet is set up for 20) recording the net count rate (background subtracted) for each count.

6. As each sequential count is recorded, calculate values for the mean count rate, $\bar{x},(x-\bar{x})$, and $(x-\bar{x})^{2}$.

7. Calculate chi-squared.

8. Spaces are also provided to enter the standard deviation $(\sigma)$ and values for the purpose of determining error bar widths, if the technician chooses to plot the data.

9. The form will be signed and dated by the health physics technician conducting the test and signed and dated as approved by the Health Physics Supervisor. 


\section{OPERATING PROCEDURE}

\section{PORTABLE INSTRUMENTATION OPERATION}

Date:

Revision No.: 0

Concurrence:

\begin{tabular}{llll}
\hline Title & Date & $\overline{\text { Title }}$ & Date \\
\hline
\end{tabular}

\subsection{PURPOSE AND SCOPE}

A variety of portable radiation detection instrumentation is used at the disposal facility. These instruments are used to perform personnel surveys, contamination surveys, and to map radiation fields within and around the facility. This procedure provides guidelines for basic operation of portable instrumentation. Detailed operating instructions are provided with each specific instrument model.

\subsection{EQUIPMENT AND MATERIALS}

1. Portable instruments.

2. Appropriate radiation sources for each instrument.

\subsection{PROCEDURE}

\subsection{PREREQUISITES}

Perform the following steps prior to using any instrument:

1. Ensure that the instrument has been calibrated and operation checked. Use only instruments possessing a current calibration.

2. Ensure the instrument has been response checked per Procedure Number , Portable Instrumentation Response and Source Check.

3. Inspect for damage. 
4. Enter areas of unknown radiation fields with instruments on high scale to avoid off-scale readings and subsequent recovery time.

\subsection{TRAINING}

None.

\subsection{SPECIAL PRECAUTIONS}

1. Handle instruments with care: do not drop them or allow them to bang against hard surfaces.

2. Be particularly careful when using thin window detectors (pancake and scintillation detectors) near sharp objects to prevent the window and detector.

3. Although incidental contact with the surface being surveyed will generally not contaminate the detector, minimize such contacts.

\subsection{INSTRUCTIONS}

1. Exposure rate instruments (any survey instrument that reads $\mathrm{R} / \mathrm{hr}, \mathrm{mR} / \mathrm{hr}$ or $\dot{\mu} R / h r)$.

a. General area surveys; surveys of ground areas and large objects such as casks, trucks, etc.

Start with the detector held at waist level with the most sensitive areas of the detector facing the item or areas being surveyed. Unless the radiation level on the item being surveyed is known, start on the high scale and work down scale until the instrument reading is between $1 / 4$ and $3 / 4$ scale, if possible.

b. Direct surveys; surveys of specific areas of contamination and small items such as tools.

Hold the detector about one inch from the surface of the item or area being surveyed.

2. Beta-gamma friskers (instruments that read counts per minute).

a. Counting smears and air sample filters.

Hold the detector no farther than $1 / 2$ inch from the smear or filter. Count the smear for a minimum of 5 seconds or, if a positive indication is noted, count for at least 15 seconds and until the meter indication stabilizes. 
b. Frisking.

Hold the detector within $1 / 2$ inch of the surface being frisked. Move the detector no faster than 3 inches per second. Stop when a positive indication is noted. Allow the meter indication to stabilize and record that value. Readings of less than 100 counts per minute (CPM) above background with background less than 300 counts per minute shall be recorded as less than $100 \mathrm{CPM}$ over the probe area. Disintegrations per minute (DPM) can be calculated from CPM:

$$
D P M=C P M / e f f i c i e n c y
$$

Efficiency is calculated as described in Procedure Number Scaler Operation.

3. Alpha survey meters.

a. Hold the detector within $1 / 8$ to $1 / 16$ inch of the surface being surveyed. Move the detector no faster than 3 inches per second. Stop when a positive indication is noted and allow the meter indication to stabilize; record that value.

4. Operability checks of portable radiation detection instruments.

a. Each instrument shall be checked for operability daily.

b. Routine and baseline operability checks shall be performed as follows:

- Check the battery condition. If batteries are not in the allowed range, replace the batteries or clean the contacts, as necessary. If the battery check is not satisfactory after those corrective actions, place the instrument out of service and send it to an authorized repair facility.

- Follow the operability check guidelines provided with specific instrument.

- Record the operability check results in the Health Physics Logbook.

c. Check the calibration sticker on the instrument to determine when the calibration is due.

d. When an instrument has reached its calibration due date:

Remove the instrument from service and record this information on Form Number OP , Out of Service 


$$
\text { Page } \frac{4}{\text { Revision }} \frac{4}{0}
$$

Tracking Log, from Procedure Number Portable Instrumentation Response and Source Check.

Remove the batteries from the instrument. Secure the probe in holder (if applicable). Any special instructions should be secured to the instrument itself.

- $\quad$ Carefully package the instrument in a container with shock absorbing material to prevent movement and damage.

Securely tape the package and label it for shipment to the calibration facility.

- $\quad$ Request a backup instrument for use.

\subsection{RECORDS}

\subsection{REQUIRED FORMS}

Out of Service Tracking Log, Form Number OP Portable Instrumentation Response and Source Checks.

\subsection{COMPLETION AND APPROVAL REQUIREMENTS}

The Out of Service Tracking Log will be completed by the technician conducting the source checks. It will be reviewed and approved by the Health Physics Supervisor.

\subsection{PROCESSING AND ARCHIVAL REQUIREMENTS}

1. Documents required or created in support of this procedure are quality assurance records. The Health Physics Logbook will be included in the quality assurance records package.

2. The records shall be submitted to the Records Management Technician who, as custodian, will ensure each document is complete, legible, and adequately identifiable. The quality assurance records resulting from this procedure shall be retained in accordance with (Administrative Procedure AP __ by the records custodian.

\subsection{REFERENCES}

None. 


\section{OPERATING PROCEDURE}

\section{PORTABLE INSTRUMENTATION RESPONSE AND SOURCE CHECKS}

Date:

Revision No.: 0

Supersedes:

Page 1 of $\frac{1}{8}$

Approval:

Concurrence:

\begin{tabular}{llll}
\hline Title & Date & Title & Date \\
\hline \hline
\end{tabular}

\subsection{PURPOSE AND SCOPE}

A variety of portable radiation detection instruments are used at the disposal facility. These instruments are used to perform personnel surveys and contamination surveys, and to map radiation fields within and around the facility.

This procedure provides guidance for the response and source checks of portable instrumentation. Response and source checks are the periodic checks to ensure that the instrument is properly functioning within the manufacturer's specifications. The disposal facility will use an offsite vendor for the calibration and repair of portable radiation detection instrumentation. This procedure includes guidance for removing an instrument from service, and shipping and receiving instruments to and from the offsite calibration and repair vendor.

Detailed operating instructions are provided with each specific instrument model. Those instructions will be supplied by the instrument manufacturer.

\subsection{EQUIPMENT AND MATERIALS}

1. Appropriate sources for each instrument. The source label will specify the count rates and exposure rates at contact and at 1 meter and an allowable range of readings from the instruments the source is used to check. The label will specify when the source shall be returned for decay correction. An expired source shall not be used.

2. Source holder. 


\subsection{PROCEDURE}

\subsection{PREREQUISITES}

1. Prior to using a new calibration facility, the Health Physics Director or designee shall perform an audit of that facility. Based on the audit results, the Health Physics Director, in conjunction with the Quality Assurance Department, shall issue a memo giving authorization to use that facility. The audit shall include a verification that the calibration facility meets requirements for instrument calibration.

2. Radiation survey instruments and count rate instruments shall be calibrated every six months or after being repaired.

\subsection{TRAINING}

None.

\subsection{SPECIAL PRECAUTIONS}

None.

\subsection{INSTRUCTIONS}

The following activities will be performed by a health physics technician:

1. Routine source checks of count rate survey instruments shall be performed daily when in use. Routine source checks of radiation survey instruments including area monitors shall be performed weekly. These source checks shall be documented on form OP 7-1, Instrument Source Check Log Sheet.

2. Additionally, any portable survey instrumentation shall be checked for response prior to use. Documentation of these response checks is not required.

3. Routine source checks shall be performed as follows:

a. Check the sticker on the instrument to determine if it has a current calibration certificate on file. If an instrument requires calibration, follow the steps outlined in Section 3.4.6 of this procedure for shipping the instrument to the calibration/repair facility.

b. Check the battery condition. If batteries are not in the allowed range, replace the batteries or clean the contacts, as necessary. If the battery check is not satisfactory after those corrective actions, place the instrument out of service and send it to an authorized calibration facility for repair and calibration. 
c. Perform source checks with appropriate sources. For on-contact readings, ensure that the source is centered on the probe, in direct contact and facing the probe.

d. Record the source check results (satisfactory or unsatisfactory) on the Instrument Source Check Log Sheet, Form Number OP 7-1.

4. Should the battery, source, or response check be unsatisfactory, the instrument shall be removed from service. Record this on the Instrument Source Check Log Sheet, Form Number OP 7-1. Send the instrument to an authorized calibration facility for repair and/or calibration.

5. When an instrument has reached its calibration due date, the instrument shall be sent to an authorized calibration facility.

6. All instruments requiring calibration or repair at an offsite facility shall be treated as follows:

a. Remove the instrument from service and record this information as detailed in Section 3.4.4 of this procedure. In addition, fill out the appropriate information in the Out of Service Tracking Log, Form Number OP 7-2.

b. Remove the batteries from the instrument. Secure the probe in holder (if applicable). Any special instructions will be secured to the instrument itself.

c. Carefully package the instrument in a container with shock absorbing material to prevent movement and damage.

d. Securely tape the package and label it for shipment to the calibration facility.

7. Upon receipt of a repaired or calibrated instrument, the following actions will be taken:

a. Perform a receipt inspection.

b. Perform a source check of the instrument using the appropriate source.

c. Record the source check on the Instrument Source Check Log Sheet, Form Number OP 7-1.

d. Record the calibration due date on the calibration sticker.

e. Record the check source number and the exposure/dose rate (for exposure/dose rate instruments) or the counts per minute (for count rate instruments) obtained from the source check on the instrument calibration sticker. Also specify the correction factor for 
the specific radionuclide source on the sticker. Apply the sticker to the instrument.

f. The exposure rate/count rate obtained shall be used as the baseline value for that instrument.

8. Place the date the instrument was returned to service on column 6 of the appropriate line in the Out of Service Tracking Log, Form Number OP 7-2.

\subsection{RECORDS}

\subsection{REQUIRED FORMS}

Instrument Source Check Log Sheet, Form Number OP 7-1.

Out of Service Tracking Log, Form Number OP 7-2.

\subsection{COMPLETION AND APPROVAL REQUIREMENTS}

The Instrument Source Check Log Sheet and the Out of Service Tracking Log forms will be completed by the technician conducting the source checks. The Instrument Source Check Log Sheet will be reviewed and approved by the Health Physics Supervisor.

\subsection{PROCESSING AND ARCHIVAL REQUIREMENTS}

1. Documents required or created in support of this procedure are quality assurance records. The Instrument Source Check Log Sheet and the Out of Service Tracking Log forms will be included in the quality assurance records package.

2. The records shall be submitted to the Records Management Technician who, as custodian, will ensure each document is complete, legible, and adequately identifiable. The quality assurance records resulting from this procedure shall be retained in accordance with (Administrative Procedure AP _ by the records custodian.

\subsection{REFERENCES}

None. 
INSTRUMENT SOURCE CHECK LOG SHEET

FORM NUMBER OP 7-1

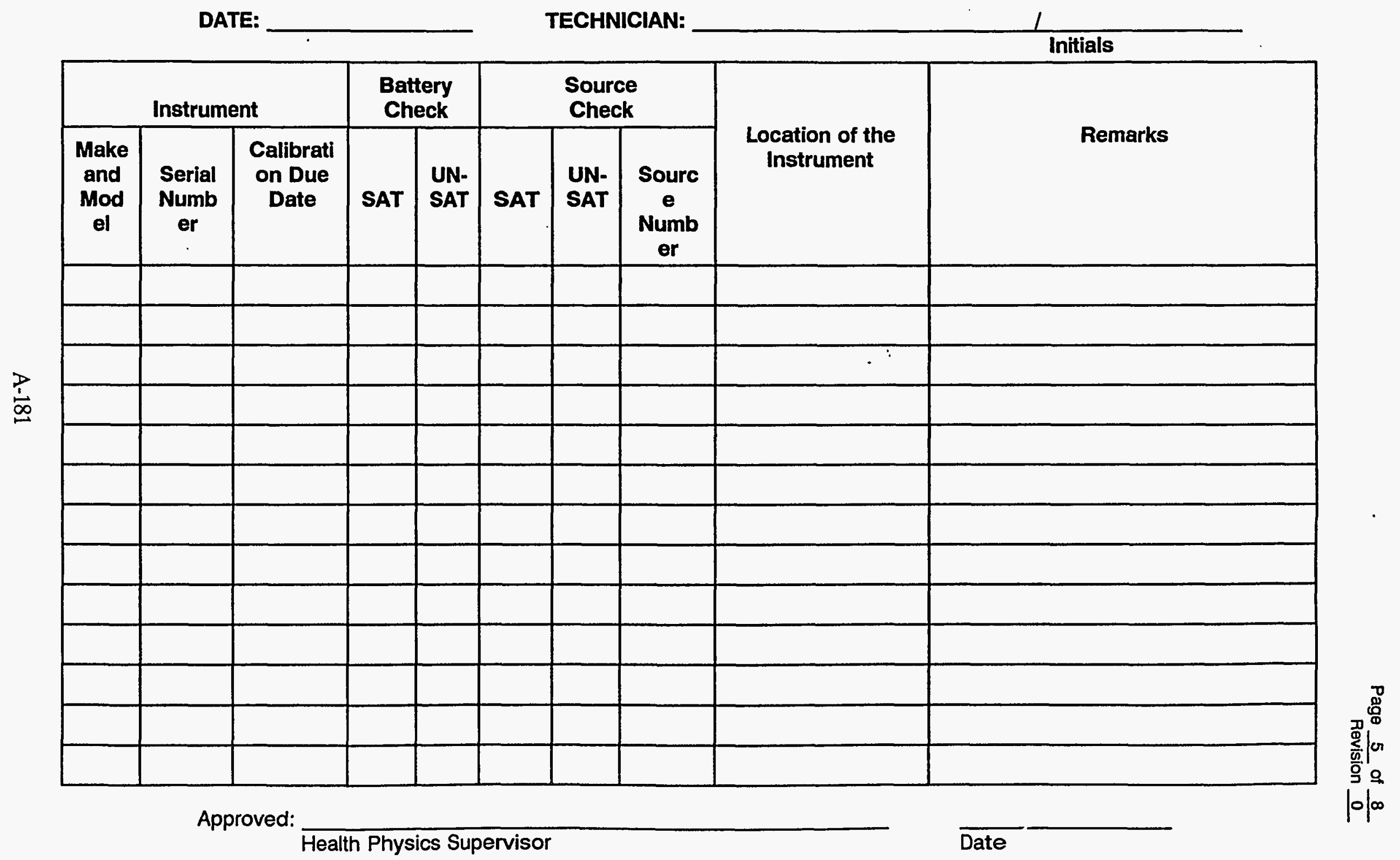




\section{INSTRUCTIONS FOR INSTRUMENT SOURCE CHECK LOG SHEET}

FORM NUMBER OP 7-1

1. Enter the date the source checks were conducted.

2. Enter the name of the technician conducting the check.

3. For each instrument, enter:

- The instrument model

- The serial number

- The calibration due date from the sticker on the instrument.

4. Specify the results of the battery check (satisfactory or unsatisfactory) by putting an $X$ in the appropriate column.

5. Specify the results of the source check: satisfactory (within the specified range) or unsatisfactory by putting an $\mathrm{X}$ in the appropriate column.

6. Enter the facility tracking number for the source used for each instrument or check.

7. Specify the normal location of the instrument (e.g., guard shack, health physics workroom, disposal unit supply box).

8. Add remarks as appropriate.

9. The technician conducting the checks will initial the form and the Health Physics Supervisor will indicate approval of the data entered by signing and dating the form. 
OUT OF SERVICE TRACKING LOG

FORM NUMBER OP 7-2

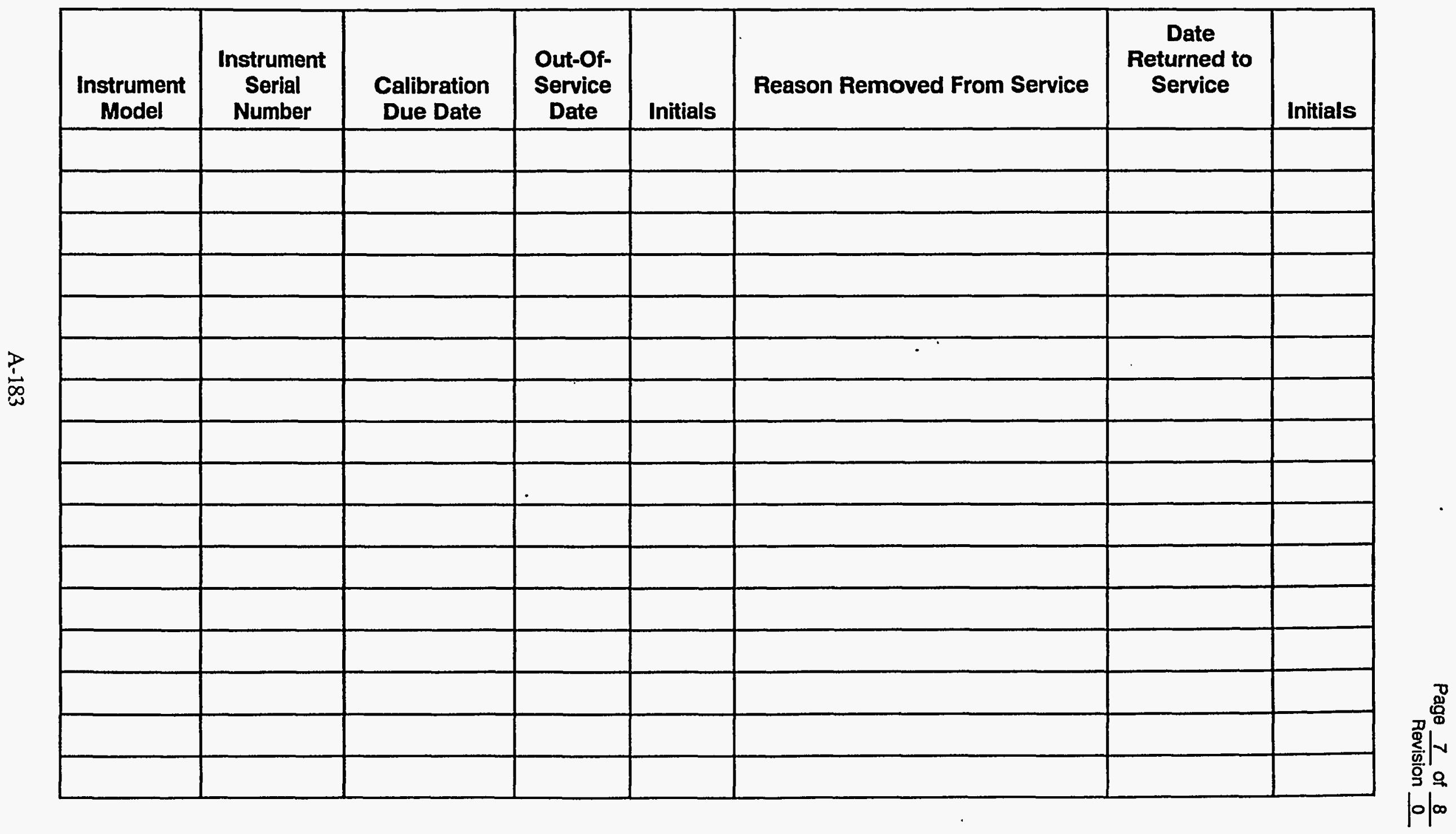




\section{INSTRUCTIONS FOR OUT OF SERVICE TRACKING LOG \\ FORM NUMBER OP 7-2}

1. Enter the instrument model.

2. Enter the instrument serial number.

3. Enter the instrument calibration due date from the sticker on the instrument.

4. Enter the date the instrument was taken out of service and initial the form.

5. Indicate why the instrument was removed from service.

6. Enter the date the instrument was returned to service and initial the form. 


\section{A-5. PROCEDURES FOR OTHER ACTIVITIES}


A-186 


\section{OPERATING PROCEDURE}

\section{SHIPMENT DOCUMENT REVIEW}

Date:

Revision No.: $\underline{0}$

Supersedes: Page 1 of 11

Approval: Concurrence:

Deputy General Manager

Date

QA Specialist

Date

\subsection{PURPOSE AND SCOPE}

\subsection{PURPOSE}

The purpose of this procedure is to describe the methods for review of the waste generator's or waste broker's shipping papers. Shipment documents are required to be properly completed by the waste generator and/or broker per Department of Transportation, U.S. Nuclear Regulatory Commission, and State of requirements prior to shipping for disposal.

\subsection{SCOPE}

This procedure applies to all shipping papers for low-level radioactive waste received by the disposal facility. It provides a checklist to ensure that the waste generator's shipping documents have been properly inspected and reviewed for accuracy. These document reviews are the responsibility of the Operations Supervisor. Any deviations from the requirements of this procedure must be approved by the Deputy General Manager for Operations.

\subsection{EQUIPMENT AND MATERIALS}

None required. 


\subsection{PROCEDURE}

\subsection{PREREQUISITES}

1. If the certification on each manifest is not signed, the shipment cannot be accepted until the certification is received or the final disposition is provided by the state inspector.

2. The following procedures may be applicable during the process of reviewing the consignor's shipping papers:

a. Pre-Shipment Approval, Procedure Number

b. Waste Shipment Acceptance, Procedure Number

c. Notification of Regulatory Agencies, Procedure Number

\subsection{TRAINING}

None required.

\subsection{SPECIAL PRECAUTIONS}

None required.

\subsection{INSTRUCTIONS}

1. The Operations Supervisor or designee will conduct the shipment document review using the Shipment Document Review Form, Form Number OP 4.1.3-1, which identifies the specific documents to be reviewed. The Operations Supervisor or designee will fill out the Shipment Document Review form per the instruction sheet and initial and date either "satisfactory" or "unsatisfactory" for each item. If the item is not applicable to the shipping papers being reviewed, the Operations Supervisor or designee will check the "N/A" (not applicable) column.

2. Unsatisfactory items will generally result in an "unsatisfactory" mark on the Shipment Document Review form, Form Number OP 4.1.3-1, along with applicable comments. Generally, the form of corrective action required is notification of the waste generator or broker, who in turn will submit a copy of corrected shipping papers (e.g., manifest) with the unsatisfactory problem resolved. The Operations Supervisor will request that a Nonconformance Report be issued per Quality Assurance Procedure Number QAP , Control of Nonconforming Items and Activities, if he or she feels such action is necessary. This will start the process to determine and document the appropriate corrective action (the date when the nonconformance is resolved). The Nonconformance Report number and closure date will be entered in the Satisfactory column of the Shipment Document Review, Form Number OP 4.1.3-1, by the Operations Supervisor. 
3. The Operations Supervisor or designee will verify the following information upon review of the shipping papers:

a. Department of Transportation proper shipping name.

The Operations Supervisor or designee will verify that one of the following DOT shipping names has been used:

1. Radioactive material, empty packages

2. Radioactive material, limited quantity, not otherwise specified (n.o.s.)

3. Radioactive material, n.o.s.

4. Radioactive material, fissile, n.o.s.

5. Radioactive material, Low Specific Activity (LSA), n.o.s.

6. Radioactive material, special form, n.o.s.

7. Radioactive material, instruments and articles.

b. Hazard class per 49 CFR 172.202 (a) (2), 172.101, Column 1.

Radioactive Material (for radiological shipments).

c. Shipment identification number.

The shipment identification number (preceded by "UN") prescribed for the material is listed below or is found in the 49 CFR 172.101, Hazardous Materials Table:

1. Radioactive material, empty packages (UN2908)

2. Radioactive material, limited quantity, n.o.s. (UN2910)

3. Radioactive material, n.o.s. (UN2982)

4. Radioactive material, fissile, n.o.s. (UN2918)

5. Radioactive material, LSA, n.0.s. (UN2912)

6. Radioactive material, special form, n.o.s. (UN2974)

7. Radioactive material, instruments and articles (UN2911).

d. The total amount of shipment by weight or volume. 
e. The quantity of packaging, including number of packages, type and volume, and specification number or certificate of compliance number as applicable. For example: (12) 55-gallon $7 \mathrm{~A}$ drums or (1)-Type B Cask No. 6773 [see 49 CFR 172.202 (a) (4), $173.471(b)]$.

f. The name of each radionuclide present [see 49 CFR 172.203 (d) (i)].

g. A description of the physical and chemical form of the radioactive material [see 49 CFR 172.203 (d) (ii)].

h. The activity of the material in each package [see 49 CFR 172.203 (d) (iii)].

i. The category of label applied to each package in the shipment [see 49 CFR 172.203 (d) (iv)]. (e.g., RADIO, CTIVE WHITE-I, RADIOACTIVE YELLOW-II, Or RADIOACTIVE YELLOW-III).

j. - The transport index of each package with a Radioactive Yellow-ll or Radioactive Yellow-IIl label (the radiation level in millirem per hour at 3 feet) [see 49 CFR 172.203(f)].

k. For a shipment of fissile radioactive materials [see 49 CFR 172.203 (d) (vi)]:

1. The words "Fissile Exempt" if the package is exempt, pursuant to 49 CFR 173.453

2. The fissile class of each package when not exempt, pursuant to 49 CFR 173.455

3. For a Fissile Class III Shipment, the additional warning:

Warning--Fissile Class III Shipment. Do not load more than packages per vehicle. In loading and storage areas, $\overline{k e e p}$ at least 20 feet ( 6 meters) from other packages bearing radioactive labels."

I. Chelating Agents

Verify by reviewing the manifest that wastes containing more than 0.1 percent chelating agents by weight.are identified and that the percent weight has been estimated.

m. Vehicle driver's instructions

For exclusive-use shipments, specific instructions will be furnished by the waste generator or waste broker to the driver of the transport vehicle explaining how to maintain the exclusive-use 
(sole-use) shipment controls. Verify from the package of shipping paper documentation whether or not the shipment is exclusive-use and whether or not any of the criteria stated below are met. If the waste shipment is exclusive-use and any of the criteria below are met, verify that the driver's instructions are present. These instructions apply for exclusive-use shipments whenever one of the following occurs, per 49 CFR 173.441:

1. The following dose rate limits are exceeded:

a. 200 millirem per hour at any point on the external surface of the package

b. A Transport Index of 10.

2. The following dose rate limits are not exceeded [see 49 CFR 173.441 (b)]:

a. 1,000 millirem per hour on contact with the external surface of the package (closed transport vehicle only)

b. 200 millirem per hour at any point on the external surface of the car or vehicle (closed transport vehicle only)

c. 10 millirem per hour at any point 6 feet (2 meters) from the vertical planes projected by the outer lateral surface of the car or vehicle or if the load is transported in an open transport vehicle, at any point 6 feet $(2$ meters) from the vertical planes projected from the outer edges of the vehicle

d. $\quad 2$ millirem per hour in any normally occupied position in the cab of the vehicle, except that this provision does not apply to private motor carriers.

n. Shipper's certification statement

The certification at the bottom of a shipping paper form provided by the licensee (disposal facility) is preprinted and complies with the exact wording as required by DOT regulation 49 CFR 172.204.

1. The certification must be legibly signed by a principal, officer, partner, or employee of the waste generator or waste broker (shipper or shipper's agent).

2. The certification may be written legibly by hand, by typewriter, or by other mechanical means. In addition, it 
must be signed (freehand) and may also have the name of the signor typed on the sheet.

Example: "This is to certify that the above named materials are properly classified, described, packaged, marked, and labeled and are in proper condition for transportation according to the applicable regulations of the Department of Transportation." (Written by hand or typewriter.)

John B. Doe (Must be handwritten signature)

John B. Doe (May be typed underneath handwritten signature for legibility purposes)

3. In the event any discrepancies are detected, the operations worker conducting the review will advise the Operations Supervisor of the extent of the discrepancy and request further instructions.

4. For discrepancies that are immediately correctable:

a. Corrections will be made by the waste generator/broker

b. The Corrective Actions section of Form Number OP $4.1 .3-1$ will be completed by the Operations Supervisor or designee

c. The item will be rechecked by the Operations Supervisor or designee

d. For items that pass the reinspection, the Operations Supervisor will check the "Satisfactory" column of Form Number OP 4.1.3-1 and initial and date this column.

5. For all discrepancies that are not immediately correctable, the Operations Supervisor will request that a Nonconformance Report be issued per Quality Assurance Procedure Number QAP, Control of Nonconforming ltems and Activities, if he or she feels it is necessary. This will start the process to determine and document the appropriate corrective action. The Nonconformance Report number and closure date (the date when the nonconformance is resolved) will be entered in the "NCR Number/Date" column of Form Number OP 4.1.3-1. When the Nonconformance has been resolved, the Operations Supervisor will enter the Nonconformance Number and the date it was resolved in the "NCR Number/Date Closed" column of Form Number OP 4.1.3-1.

\subsection{RECORDS}

\subsection{REQUIRED FORMS}

Shipment Document Review, Form Number OP 4.1.3-1. 


$$
\text { Page } \frac{7}{\text { Revision } \frac{11}{0}}
$$

\subsection{COMPLETION AND APPROVAL REQUIREMENTS}

1. The Shipment Document Review, Form Number OP 4.1.3-1, will be completed by the operations worker conducting the review of the shipping papers. It will be reviewed and approved by the Operations Supervisor and the Health Physics Supervisor.

2. All shipping documents will be submitted to the onsite state inspector for review with a legible copy of the manifest.

\subsection{PROCESSING AND ARCHIVAL REQUIREMENTS}

1. Documents required or created in support of this procedure are quality assurance records. The Shipment Document Review, Form Number OP 4.1.3-1, notifications to or authorizations from the waste generator (shipper), or any other correspondence or memos relating to resolution of discrepancies, repairs, or other matters will be included in the quality assurance records package.

2. The records will be submitted to the Records Management Technician who, as custodian, will ensure that each document is complete, legible, and adequately identifiable. The quality assurance records resulting from this procedure will be retained in accordance with Administrative Procedure AP by the records custodian.

\subsection{REFERENCES}

1. 10 CFR Part 20.311, Federal Regulations for transfer for disposal and manifests.

2. 49 CFR Parts 100-177, Federal Regulations for Transportation.

3. 49 CFR Parts 178-199, Federal Regulations for Transportation. 


\section{SHIPMENT DOCUMENT REVIEW \\ FORM NUMBER OP 4.1.3-1}

Each of the items listed below must be deemed SATISFACTORY prior to the waste shipmer.. being authorized for emplacement in a disposal unit. If an UNSATISFACTORY is checked, it must be documented and corrected prior to release.

SHIPPER NAME

Manifest \#

SHIPMENT RECEIVED (DATE)

Time

INSPECTION RESULTS

\begin{tabular}{||l|l|l|l|l||}
\hline \multicolumn{1}{|c|}{ MEM } & $\begin{array}{c}\text { SATSFACTORY } \\
\text { INTALIDATE }\end{array}$ & $\begin{array}{c}\text { UNSATSFACTORY } \\
\text { INIMALIDATE }\end{array}$ & $\begin{array}{c}\text { NCR NUMBER/ } \\
\text { DATE CLOSED }\end{array}$ & N/A \\
\hline Shipping Name & & & & \\
\hline Hazard Class & & & & \\
\hline Shipment ID \# & & & & \\
\hline Shipment Total Weight or Volume & & & & \\
\hline Radionuclide(s) & & & & \\
\hline Physical and Chemical Description & & & & \\
\hline Activity & & & & \\
\hline $\begin{array}{l}\text { Package Information: (Type, } \\
\text { Quantity, Number, Volume) }\end{array}$ & & & & \\
\hline Transport Index & & & & \\
\hline Fissile Shipment Class I, II, III & & & & \\
\hline Driver's Instructions & & & & \\
\hline Chelating Agents & & & & \\
\hline Shipper's Certification Statement & & & & \\
\hline $\begin{array}{l}\text { Shipper's Certification Signature } \\
\text { (Legible) }\end{array}$ & & & & \\
\hline
\end{tabular}

DISCREPANCIES:

NCR NUMBER: 


\section{SHIPMENT DOCUMENT REVIEW}

FORM NUMBER OP 4.1.3-1

(Continued)

CORRECTIVE ACTIONS:

COMMENTS:

Completed by:

Operations Worker

Date

Shipment documentation is acceptable.

Operations Supervisor

$\overline{\text { Date }}$

Health Physics Supervisor

$\overline{\text { Date }}$ 
Page $\frac{10}{\text { Revision of } \frac{11}{0}}$

\section{INSTRUCTIONS FOR SHIPMENT DOCUMENT REVIEW \\ FORM NUMBER OP 4.1.3-1}

When completing the Shipment Document Review, verify that the entry is appropriate (e.g., in Instruction 6: If $\mathrm{Cz}-137$ was listed on the manifest, this would indicate a typographical error, . Also, check the information for accuracy (e.g., in Instruction 8: A shipment with a total activity

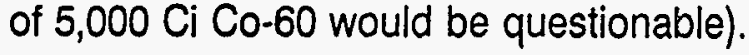

1. Verify that the proper shipping name is listed on the manifest (e.g., radioactive material. n.o.s.).

2. Verify that the proper hazard class is listed on the manifest (e.g., radioactive . material-limited quantity).

3. Verify that the proper shipment identification number was listed on the manifest (e.৫., radioactive material, limited quantity, n.o.s. UN2982).

4. Verify that the shipment manifest has a unique shipment identification number listed.

5. Verify that the shipment total weight or volume is listed in the manifest (e.g., $3500 \mathrm{lb}$ or 350 gallons).

6. Verify that the proper radionuclide abbreviated names are listed in the manifest (e.g., Mn-54, Fe-59, Cs-137, Pu-239).

7. Verify that the proper physical and chemical forms are listed in the manifest (e.g., Metallic Oxides).

8. Verify that the activity of the shipment is listed in the manifest (e.g., $500 \mathrm{mCi}$ ).

9. Verify that the quantity of packaging, including the number of packages, type of the packages, volume or weight, and specification number or certificate of compliance number is listed on the manifest [e.g., (12) 55-gallon DOT 7A drums].

10. Verify that the appropriate transport index was used on the manifest (e.g., 1 meter reading in $\mathrm{mrem} / \mathrm{hr}$ ).

11. Verify that the appropriate fissile class was used on the manifest (e.g., "Fissile Exempt").

12. Verify that the manifest includes specific driver's instructions for exclusive-use shipments.

13. Verify that the bottom of the manifest is preprinted with the following certification statement or similar words:

"This is to certify that the above named materials are properly classified, described, packaged, marked, and labeled and are in proper condition for transportation according to the applicable regulations of the Department of Transportation." 


\section{INSTRUCTIONS FOR SHIPMENT DOCUMENT REVIEW \\ FORM NUMBER OP 4.1.3-1 \\ (Continued)}

14. Verify that the shipper's certification signature is legible.

15. List any discrepancies found (e.g., shipper's certification signature is illegible).

16. List the nonconformance number (if applicable).

17. List any corrective actions (e.g., waste generator notified).

18. List any comments (e.g., waste generator faxed legible copy of the shipper's certification signature).

19. The operations worker completing the inspection will sign the form.

20. The Operations Supervisor and Health Physics Supervisor will sign the form indicating authorization of the shipment for acceptance.

21. Forward the completed form to the Records Management Technician for records retention. 


\section{OPERATING PROCEDURE}

\section{RADIOACTIVE WASTE CLASSIFICATION VERIFICATION}

Date:

Revision No.: 0

Supersedes:

Page 1 of $\frac{0}{12}$

Approval:

Concurrence:

Title

Date

Title

Date

\subsection{PURPOSE AND SCOPE}

\subsection{PURPOSE}

The purpose of this procedure is to specify the process of verifying the waste classifications for radioactive waste. It fulfills the requirement of implementing a compliance program to assure proper classification of the waste received by the disposal facility.

\subsection{SCOPE}

This procedure applies to all radioactive waste recieived by the disposal facility. It prescribes a methodology for determining and/or verifying the appropriate waste class for radioactive waste. Waste class verification is required by the regulations and must be accomplished before a waste shipment can be accepted for disposal.

Waste class verification will be the primary responsibility of the Health Physics Supervisor. Any deviations from the requirements of this procedure must be approved by the Deputy General Manager for Operations.

\subsection{EQUIPMENT AND MATERIALS}

None required. 


\subsection{PROCEDURE}

\subsection{PREREQUISITES}

1. The concentration of the radioactive nuclide has previously been determined by the generator or a designee of the generator.

2. A qualified health physics technician will be present to perform radiation and contamination surveys, check for violations to operating licenses and U.S. Department of Transportation regulations, and correlate packages to the manifest. Off-loading activities will not commence until Health Physics has completed all necessary health physics surveys and is in place to monitor radiation levels.

3. The following procedures may be applicable during the process:

a. Radioactive Waste Verification Testing, Procedure Number

b. Waste Containers Not Acceptable Upon Arrival, Procedure Number

c. Damaged Waste Container Handling, Procedure Number

d. Shipment Document Review, Procedure Number

e. Preshipment Approval, Procedure Number

f. Waste Shipment Acceptance, Procedure Number

\subsection{TRAINING}

1. Safety training will be according to Procedure Number , On-Site Safety Training.

2. Personnel operating equipment and vehicles on the disposal facility will have valid certification by the Director of Operations that they are current in all operations and safety training for the types of vehicles they are operating.

\subsection{SPECIAL PRECAUTIONS}

None required.

\section{$3.4 \quad$ INSTRUCTIONS}

1. Obtain the manifest and determine which of the following categories the waste falls into and proceed to the indicated step. 
a. If the manifest only lists long-lived radionuclides found in Form Number OP 3.2.1-1, go to 3.4 .2 below to determine the waste classification.

b. If the manifest only lists short-lived radionuclides found in Form Number OP 3.2.1-2, go to 3.4.3 below to determine the waste classification.

c. If the manifest lists radionuclides but they are not radionuclides listed in Form Number OP 3.2.1-1 or Form Number OP 3.2.1-2, go to 3.4 .4 below to determine the waste classification.

d. If the manifest lists a mixture of radionuclides, some from Form Number OP 3.2.1-1 and some from Form Number OP 3.2.1-2, go to 3.4 .5 below to determine the waste classification.

2. Determine the waste classification based on the long-lived radionuclides using Form Number OP 3.2.1-1, Radioactive Waste Classification Verification Form, Long-lived Radionuclides.

a. If the total of column 4 of Form Number OP 3.2.1-1 is less than 1, the waste is Class $A$.

b. If the total of column 4 is greater than 1 and the total of column 5 is less than or equal to 1 , the waste is Class $C$.

c. If the total of column 5 is greater than 1 , the waste is not generally acceptable for disposal at the facility.

On Form Number OP 3.2.1-3 enter the waste classification on the manifest and the waste classification determined by Form Number OP 3.2.1-1; if they match, complete Form Number OP 3.2.1-3 and process the waste for disposal. However, if the waste classification on the manifest does not match the waste classification recorded on the form, contact the Operations Supervisor who will note the classification discrepancy on a Nonconformance Report (NCR) per Quality Assurance Plan Section , Control of Nonconforming Items and Activities. The NCR will start the process to determine and document the appropriate corrective action.

3. Determine the waste classification based on the short-lived radionuclides using Form Number OP 3.2.1-2, Radioactive Waste Classification Verification Form, Short-lived Radionuclides.

a. If the total of column 5 of Form Number OP 3.2.1-2 is less than 1, the waste is Class $A$.

b. If the total of column 5 is greater than 1 and the total of column 6 is less than or equal to 1 , the waste is Class $B$. 
c. If the total of column 6 is greater than 1 and the total of column 7 is less than or equal to 1 , the waste is Class $C$.

d. If the total of column 7 is greater than 1 , the waste is not generally acceptable for disposal at the facility.

On Form Number OP 3.2.1-3 enter the waste classification on the manifest and the waste classification determined by Form Number OP 3.2.1-2; if they match, complete Form Number OP 3.2.1-3 and process the waste for disposal. However, if the waste classification on the manifest does not match the waste classification recorded on the form, contact the Operations Supervisor who will note the classification discrepancy on a Nonconformance Report (NCR) per Quality Assurance Plan Section , Control of Nonconforming ltems and Activities. The NCR will start the process to determine and document the appropriate corrective action.

4. Radioactive waste is considered Class $A$ if it does not contain any nuclides listed in either Form Number OP 3.2.1-1 or Form Number OP 3.2.1-2. Indicate on Form OP 3.2.1-3 that the waste is Class A per this procedure by placing a check mark in the appropriate box.

On Form Number OP 3.2.1-3 enter the waste classification on the manifest and the waste classification determined by this step of the procedure; if they match, complete Form Number OP 3.2.1-3 and process the waste for disposal. However, if the waste classification on the manifest does not match the waste classification recorded on the form, contact the Operations Supervisor who will complete a Nonconformance Report (NCR) per Quality Assurance Plan Section Control of Nonconforming Items and Activities. The NCR will start the process to determine and document the appropriate corrective action.

5. Determine the waste classification of a mixture of both long-lived and short-lived radionuclides, some of which are listed in Form Number OP 3.2.1-1 and some of which are listed in Form Number OP 3.2.1-2 per the following steps:

a. Using the form instructions, complete Form Number OP 3.2.1-1.

b. Using the form instructions, complete Form Number OP 3.2.1-2.

c. If the total of column 4 of Form Number OP 3.2.1-1 is less than 1, the waste class will be determined by the concentrations of the short-lived radionuclides of Form Number OP 3.2.1-2 as follows:

1. If the total of column 5 of Form OP 3.2.1-2 is less than 1, the waste is Class $A$. 
2. If the total of column 5 of Form Number OP 3.2.1-2 is greater than 1, and the total of column 6 of Form Number OP 3.2.1-2 is less than or equal to 1 , the waste is Class $B$.

3. If the total of column 6 of Form Number OP 3.2.1-2 is greater than 1, and the total of column 7 of Form Number OP 3.2.1-2 is less than or equal to 1 , the waste is Class $C$.

d. If the total of column 4 of Form OP 3.2.1-1 is greater than 1, but the total of column 6 of the same for is less than or equal to 1 , and the total of column 7 of Form Number OP 3.2.1-2 is less than or equal to 1 , the waste is Class $\mathrm{C}$.

e. If the total of column 5 of Form Number OP 3.2.1-1 or the total of column 7 of Form Number OP 3.2.1-2 is greater than 1, the waste is not generally acceptable for disposal at the facility.

On Form Number OP 3.2.1-3 enter the waste classification on the manifest and the waste classification determined by Form Number OP 3.2.1-1 and/or Form Number OP 3.2.1-2; if they match, complete Form Number OP 3.2.1-3 and process the waste for disposal. However, if the waste classification on the manifest does not match the waste classification recorded on the form, contact the Operations Supervisor who will note the classification discrepancy on a Nonconformance Report (NCR) per Quality Assurance Plan Section , Control of Nonconforming items and Activities. The NCR will start the process to determine and document the appropriate corrective action.

\subsection{RECORDS}

\subsection{REQUIRED FORMS}

1. Radioactive Waste Classification Verification, Long-lived Radionuclides, Form Number OP 3.2.1-1.

2. Radioactive Waste Classification Verification, Short-lived Radionuclides, Form Number OP 3.2.1-2.

3. Radioactive Waste Classification Verification, Form Number OP 3.2.1-3.

\subsection{COMPLETION AND APPROVAL REQUIREMENTS}

The Health Physics Supervisor will complete and sign Form Number OP 3.2.1-1 and Form Number OP 3.2.1-2, if used, and Form Number OP 3.2.1-3. The Operations Supervisor will review and sign Form Number OP 3.2.1-3. 


$$
\text { Page } \frac{6}{\text { Revision } \frac{12}{0}}
$$

\subsection{PROCESSING AND ARCHIVAL REQUIREMENTS}

1. Documents required or created in support of this procedure are quality assurance records. The Radioactive Waste Classification Verification Forms, Forms Number OP 3.2.1-1, OP 3.2.1-2, and OP 3.2.1-3 will be included in the quality assurance records package.

2. The records will be submitted to the Records Management Technician who, as custodian, will ensure each document is complete, legible, and adequately identifiable. The quality assurance records resulting from this procedure will be retained in accordance with Administrative Procedure by the records custodian.

\subsection{REFERENCES}

10 CFR 61.55, Waste Classification. -- 
RADIOACTIVE WASTE CLASSIFICATION VERIFICATION

LONG-LIVED RADIONUCLIDES

FORM NUMBER OP 3.2.1-1

Waste Tracking Number

\begin{tabular}{|c|c|c|c|c|c|}
\hline Column & 1 & 2 & 3 & 4 & 5 \\
\hline Nuclide & $\begin{array}{c}\text { Class A } \\
\text { Concentration } \\
\text { Limit }\end{array}$ & $\begin{array}{c}\text { Class C } \\
\text { Concentration } \\
\text { Limit }\end{array}$ & $\begin{array}{c}\text { Manifest } \\
\text { Concentration }\end{array}$ & $\begin{array}{l}\text { Divide Column } \\
3 \text { by Column } 1\end{array}$ & $\begin{array}{l}\text { Divide Column } \\
3 \text { by Column } 2\end{array}$ \\
\hline $\mathrm{C}-14$ & $0.8^{*}$ & $0.8^{\star}$ & & & \\
\hline C-14 in activated metal & $8^{*}$ & $80^{\star}$ & & & \\
\hline Ni-59 in activated metal & $22^{*}$ & $220^{*}$ & & & \\
\hline $\mathrm{Nb}-94$ in activated metal & $0.02^{*}$ & $0.2^{*}$ & & & \\
\hline Tc-99 & $0.3^{*}$ & $3^{*}$ & & & \\
\hline $1-129$ & $0.008^{*}$ & $0.08^{*}$ & $\cdot$ & & \\
\hline $\begin{array}{l}\text { Alpha emitting transuranic nuclides } \\
\text { with half-life greater than five years }\end{array}$ & $10^{* *}$ & $100^{* *}$ & & & \\
\hline Pu-241 & $350^{\star \star}$ & $3,500^{* *}$ & & & \\
\hline $\mathrm{Cm}-242$ & $2,000^{\star \star}$ & $20,000^{* *}$ & & & \\
\hline $\begin{array}{l}\text { * } \quad \text { curies per cubic meter } \\
\text { nanocuries per gram }\end{array}$ & & & Total & & \\
\hline
\end{tabular}

Completed By: 


\section{INSTRUCTIONS FOR RADIOACTIVE WASTE CLASSIFICATION VERIFICATION, LONG-LIVED RADIONUCLIDES \\ FORM NUMBER OP 3.2.1-1}

This form will be completed by the Health Physics Supervisor.

1. Write the current date, name of the person completing the form, and the waste tracking number from waste manifest in the designated spaces.

2. Waste classification based on the long-lived radionuclides

a. Record in column 3 the concentration of the radionuclides reported on the manifest.

b. For each radionuclide recorded in column 3 , divide the number entered in column 3 by the number in collumn 1 and place the result in column 4 .

c. Total the numbers entered in column 4 .

d. If the total of column 4 is greater than 1 , then for each radionuclide recorded in column 3 , divide the number entered in column 3 by the number in column 2 , and enter the result in column 5 .

e. Total the numbers in column 5 . 


\section{RADIOACTIVE WASTE CLASSIFICATION VERIFICATION SHORT-LIVED RADIONUCLIDES \\ FORM OP 3.2.1-2}

Waste Tracking Number

\begin{tabular}{|c|c|c|c|c|c|c|c|}
\hline Column & 1 & 2 & 3 & 4 & 5 & 6 & 7 \\
\hline Nuclide & $\begin{array}{c}\text { Class A } \\
\text { Concentration } \\
\text { Limit } \\
\text { (curies per } \\
\text { cubic meter) } \\
\end{array}$ & $\begin{array}{c}\text { Class B } \\
\text { Concentration } \\
\text { Limit } \\
\text { (curies per } \\
\text { cubic meter) } \\
\end{array}$ & $\begin{array}{c}\text { Class C } \\
\text { Concentration } \\
\text { Limit } \\
\text { (curies per } \\
\text { cubic meter) } \\
\end{array}$ & $\begin{array}{c}\text { Manifest } \\
\text { Concentration }\end{array}$ & $\begin{array}{l}\text { Divide } \\
\text { Column } 4 \text { by } \\
\text { Column } 1\end{array}$ & $\begin{array}{l}\text { Divide } \\
\text { Column } 4 \text { by } \\
\text { Column } 2\end{array}$ & $\begin{array}{l}\text { Divide } \\
\text { Column } 4 \text { by } \\
\text { Column } 3\end{array}$ \\
\hline $\begin{array}{l}\text { Total of all nuclides } \\
\text { with less than } 5 \text { year } \\
\text { half-life }\end{array}$ & 700 & $* *$ & $\hbar \star$ & & & & \\
\hline $\mathrm{H}-3$ & 40 & $* *$ & $* *$ & & & & \\
\hline Co- 60 & 700 & ** & ** & . & & & \\
\hline $\mathrm{Ni}-63$ & 3.5 & 70 & 700 & & & & \\
\hline $\begin{array}{l}\text { Ni-63 in activated } \\
\text { metal }\end{array}$ & 35 & 700 & 7,000 & & & & \\
\hline Sr-90 & 0.04 & 150 & 7,000 & & & & \\
\hline Cs-137 & 1 & 44 & 4,600 & & & & \\
\hline & & & Total & & & & \\
\hline
\end{tabular}

"There are no limits established for these radionuclides in Class B or $\mathrm{C}$ wastes. Practical considerations such as the effects of external radiation and internal heat generation on transportation, handling, and disposal will limit the concentrations for these wastes. These wastes will be Class B unless the concentrations of other nuclides in Form OP 3.2.1-2 determine the waste to be Class $C$ independent of these nuclides.

Completed By: 


\section{INSTRUCTIONS FOR RADIOACTIVE WASTE CLASSIFICATION VERIFICATION, SHORT-LIVED RADIONUCLIDES \\ FORM NUMBER OP 3.2.2-1}

This form will be completed by the Health Physics Supervisor.

1. Write the current date, name of the person completing the form, and the waste tracking number from waste manifest in the designated spaces.

2. Waste classification based on the short-lived radionuclides

a. Record in column 4 the concentration of the radionuclides reported on the manifest.

b. For each radionuclide recorded in column 4 , divide the number entered in column 4 by the number in column 1 and place the result in column 5 .

c. Total the numbers entered in column 5 .

d. If the total of column 5 is greater than 1, then for each radionuclide recorded in column 4 , divide the number entered in column 4 by the number in column 2 , and enter the result in column 6.

e. Total the numbers in column 6 .

f. If the total of column 6 is greater than 1 , then for each radionuclide recorded in column 4 , divide the number entered in column 4 by the number in column 3 , and enter the result in column 7.

g. Total the numbers in column 7 . 


\section{RADIOACTIVE WASTE CLASSIFICATION VERIFICATION FORM NUMBER OP 3.2.1-3}

1. Waste Tracking Number

2. According to the waste manifest, the waste is:

$\begin{array}{ll}\square & \text { Class A } \\ \square & \text { Class B } \\ \square & \text { Class C } \\ \square & \text { Greater than Class C }\end{array}$

3. Per this procedure, the waste is:

$\begin{array}{ll}\square & \text { Class A } \\ \square & \text { Class B } \\ \square & \text { Class C } \\ \square & \text { Greater than Class C }\end{array}$

4. Do the waste classification per the manifest and this procedure agree?

Yes - Complete the remaining portion of this form and process waste for disposal.

No - Do not complete this form. A Nonconformance Report must be issued.

5. Basis for determining waste classification by this procedure.

Only long-lived radionuclides per Form Number OP 3.2.1-1.

Only short-lived radionuclides per Form Number OP 3.2.1-2.

Radionuclides other than those on Forms Number OP 3.2.1-1 and OP 3.2.1-2.

Mixture of long-lived and short-lived radionuclides per Forms Number OP 3.2.1-1 and OP 3.2.1-2.

6. Approvals:

Health Physics Supervisor

Operations Supervisor
Date

Date 


\section{INSTRUCTIONS FOR RADIOACTIVE WASTE CLASSIFICATION VERIFICATION FORM NUMBER OP 3.2.1-3}

This form will be completed by the Health Physics Supervisor and reviewed by the Operations Supervisor.

1. Enter the waste tracking number.

2. Check the appropriate box for the waste class as stated on the waste manifest.

3. Check the appropriate box for the waste class as determined by this procedure.

4. Compare the two waste classifications and, if they are the same, check the "Yes" box and complete the form. If they are different, check the "No" box and initiate a Nonconformance Report.

5. Check the appropriate box to identify the basis used for determining the waste classification per this procedure.

6. The Health Physics Supervisor and the Operations Supervisor will sign and date the form. 


\title{
OPERATING PROCEDURE
}

\author{
TRUCK WASH FACILITY
}

Date:

Revision No: ?

Supersedes:

Page 1 of 3

Approval:

Concurrence:

\begin{tabular}{llll}
\hline Title & Date & Title & Date \\
\hline
\end{tabular}

\subsection{PURPOSE AND SCOPE}

This following procedure outlines the use of the truck wash facility. The facility envisioned here is an uncovered washpad where trucks are washed using a high-pressure hose.

\subsection{EQUIPMENT AND MATERIALS}

1. Concrete wash pad with a sump tank that collects all drainage.

2. High-pressure wash hose.

3. Bailer for drawing water samples from the sump tank.

4. Spoon capable of removing sediment samples from the bottom of the sump tank.

5. Rinsed plastic closeable container (approximately one gallon capacity).

6. Rinsed plastic closeable wide-necked container (approximately one pint capacity).

\subsection{PROCEDURE}

\subsection{PREREQUISITES}

None. 


\section{$3.2 \quad$ TRAINING}

Personnel operating equipment and vehicles on the disposal facility must have valid certification, by the site manager, or his or her authorized representative, that they are current in all safety and operation training for the types of machinery and vehicles they are operating.

\subsection{SPECIAL PRECAUTIONS}

1. Personnel shall not remain inside the truck while it is being washed.

2. Contaminated transport trucks shall not be washed at this facility. See Procedure Number - Decontamination of Operational Equipment and Transport Vehicles for decontamination procedures.

\subsection{INSTRUCTIONS}

This procedure will be performed by an operations worker.

1. Check the sump tank where the truck wash water will drain to ensure that all water and sediment have been removed. If water or sediment are found, refer to Section 3.4.7 of this procedure before proceeding.

2. Place the truck on the wash pad.

3. Ensure that all personnel have vacated the wash area.

4. Wash the truck.

5. Allow adequate time for water from the truck to drain.

6. Remove the truck from the wash pad. Keep the truck in the wash area until the water and sediment from the sump tank are screened for possible contamination.

7. Test the wash water and sediment for possible contamination.

a. Bail approximately one gallon of truck wash water from the sump tank into a clean plastic closeable container. Send the water sample to the environmental laboratory and screen it for gross alpha, gross beta, and gamma radiation.

b. Scoop approximately one pint of sediment from the bottom of the sump tank into a clean plastic closeable wide-mouthed container. If a pint of sediment can't be removed from the sump, remove what amount is available. Send the sediment sample to the environmental laboratory and screen it for gross alpha, gross beta, and gamma scan.

Turn-around time from sampling to obtaining results should not be longer than four hours. 
Page 3 of 3 Revision $\frac{3}{0}$

8. Take the following actions based on the results from testing the water and sediment for possible contamination:

a. If the water and sediment are not contaminated:

- $\quad$ Release the washed truck from the truck wash facility.

- $\quad$ Transfer the truck wash water from the sump tank to the disposal facility central holding tank.

Remove the sediment from the bottom of the sump tank and dispose of it properly.

b. If the water or sediment are contaminated:

- Survey the washed truck to discover the source of contamination according to Procedure Number - Transport Vehicle Release Surveys.

Transfer the contaminated truck wash water to for treatment.

- $\quad$ Remove the contaminated sediment from the bottom of the sump tank and dispose of it according to Procedure Number On-Site Generated Waste Disposal.

\subsection{RECORDS}

\subsection{REQUIRED FORMS}

None.

\subsection{COMPLETION AND APPROVAL REQUIREMENTS}

None.

\subsection{PROCESSING AND ARCHIVAL REQUIREMENTS}

None.

\subsection{REFERENCES}

None. 


\section{OPERATING PROCEDURE}

\section{EQUIPMENT OPERATION AND MAINTENANCE}

Date:

Revision No.: 0

Supersedes:

Page 1 of 4

Approval:

Concurrence:

\begin{tabular}{llll}
\hline Title & Date & Title & Date \\
\hline
\end{tabular}

\subsection{PURPOSE AND SCOPE}

This procedure describes activities for equipment maintenance and operation at the disposal facility.

\subsection{EQUIPMENT AND MATERIALS}

Ready condition tags.

\subsection{PROCEDURE}

\subsection{PREREQUISITES}

Preventive and periodic maintenance shall only be performed by the Mechanic.

\subsection{TRAINING}

Personnel operating equipment and vehicles on the disposal facility must have valid certification by the site manager that they are current in all operations and safety training for the types of vehicles or equipment they are operating.

\subsection{SPECIAL PRECAUTIONS}

- None.

\subsection{INSTRUCTIONS}

1. Equipment Operation 


\section{a. Pre-operation Check}

The following checks will be made by the operator on all motorized equipment prior to operation, in accordance with the manufacturer's instructions:

1. General condition of the equipment (condition tag). The presence of a ready condition tag indicates the equipment is ready for service and calibrated (if applicable). If the condition tag is not in place, the Mechanic shall be informed and the equipment will not be operated until the ready condition tag is replaced.

2. Tires or tracks (if applicable).

3. Fluid levels.

4. Safety equipment (including fire extinguisher).

5. Other checks as required by manufacturer's literature.

b. Operation

1. All motorized equipment will only be operated in accordance with manufacturer's instructions.

2. Operators will ensure that operating conditions and pressures are within tolerances at all times.

3. Operators will note equipment malfunctions and inform the Mechanic.

4. If equipment becomes unserviceable, it will be "red tagged" by the operator, and the Mechanic will be informed. A red tag signifies the equipment is not to be used. Nobody except the Mechanic is authorized to remove red tags.

\section{Equipment Maintenance}

Maintenance will be performed by the Mechanic in accordance with the manufacturer's manuals, and documented on the maintenance form specific to the type of equipment.

a. Vehicles

1. The Operations Foreman will schedule preventive and periodic maintenance as required by the vehicle owner's manual.

2. Major repairs will be performed by a vendor with the approval of the Director of Operations. 


$$
\text { Page } \frac{3}{\text { Revision }} \frac{4}{0}
$$

b. Heavy Equipment

1. The Operations Supervisor will schedule preventive and periodic maintenance so that disposal operations are not disrupted.

2. Major repairs will be performed by a vendor with the approval of the Director of Operations. The Operations Supervisor will secure a temporary replacement for critical equipment undergoing major maintenance, or will notify the Director of Operations that certain functions at the disposal facility will be suspended until the equipment is repaired.

c. Fire Truck

1. The Operations Supervisor will schedule all preventive and periodic maintenance. . The Director of Operations, the Health Physics Supervisor, and the Chief of Security will be notified when the fire truck is undergoing preventive or periodic maintenance.

2. Major repairs will be performed by a vendor with the approval of the Director of Operations. The Operations Supervisor will secure a temporary replacement for the fire truck during major maintenance.

3. The fire truck will be operationally checked and driven weekly by the Fire Response Team. The fire truck will be housed in a heated bay in the Maintenance Building.

\subsection{RECORDS}

\subsection{REQUIRED FORMS}

Various maintenance forms specific to types of equipment.

\subsection{COMPLETION AND APPROVAL REQUIREMENTS}

The maintenance forms will be completed by the Mechanic. They will then be reviewed and approved by the Operations Supervisor. 


$$
\text { Page } \frac{4}{\text { Revision of } \frac{4}{r}}
$$

\subsection{PROCESSING AND ARCHIVAL REQUIREMENTS}

1. Documents required or created in support of this procedure are quality assurance records. The maintenance forms will be included in the quality assurance records package.

2. The records shall be submitted to the Records Management Technician who, as custodian, will ensure each document is complete, legible, and adequately identifiable. The quality assurance records resulting from this procedure shall be retained in accordance with (Administrative Procedure AP —) by the records custodian.

\subsection{REFERENCES}

None. 
OPERATING PROCEDURE

\section{ENVIRONMENTAL MONITORING DATA REVIEW AND EVALUATION}

Date:

Revision No.: $\frac{0}{16}$

Supersedes:

Page 1 of 16

Approval:

Concurrence:

Title

Date

Title

Date

\subsection{PURPOSE AND SCOPE}

This procedure gives instructions for recording, reviewing, and reporting the low-level radioactive waste disposal facility's environmental monitoring program data. The environmental sampling program includes soil, sediment, vegetation, fauna, air, surface water, groundwater, and direct radiation. Samples will be analyzed for gross alpha, gross beta, tritium, carbon-14, gamma activity, and direct gamma radiation as appropriate and as specified in individual sampling procedures. These data help demonstrate that the disposal facility meets regulatory offsite dose limits and also support the disposal facility's as low as reasonably achievable program.

\subsection{EQUIPMENT AND MATERIALS}

None.

\subsection{PROCEDURE}

\subsection{PREREQUISITES}

Only health physics staff will perform this procedure.

\subsection{TRAINING}

Safety training shall be according to Procedure Number OP 2.1.4, On-Site Safety Training.

\subsection{SPECIAL PRECAUTIONS}

None. 


\subsection{INSTRUCTIONS}

1. Recording Data.

a. Soil, sediment, vegetation, fauna, air, surface water, and groundwater sample laboratory analysis results and environmental TLD readings reported by the TLD supplier will be recorded by health physics staif on their respective forms, which are:

1. Soil Sampling Data, Form Number OP EM1-1.

2. Sediment Sampling Data, Form Number OP EM1-2.

3. Vegetation Sampling Data, Form Number OP EM1-3.

4. Fauna Sampling Data, Form Number OP EM1-4.

5. Air Sampling Data, Form Number OP EM1-5.

6. Surface Water Sampling Data, Form Number OP EM1-6.

7. Groundwater Sampling Data, Form Number OP EM1-7.

8. Environmental TLD Data, Form Number OP EM1-8

b. The data to be recorded on each form include calendar year of sampling data, analytical laboratory performing sample analyses, sampling location, date sample was collected, date each sample was analyzed, minimum detectable activity (MDA) for each type of sample analysis, and the results of each analysis with the correct units (e.g., $\mathrm{pCi} / \mathrm{g}$ ) and standard deviations of results, if known.

2. Review of Environmental Monitoring Data.

a. All data forms will be reviewed, signed and dated by the Health Physics Supervisor after each sampling period's data are entered on the appropriate form. The review will take place within 5 days of receipt of the sampling results from the analytical laboratory. The sampling data will be reviewed to assess actual or potential exposure to the public or the environment and against the regulatory offsite dose limits for the facility.

b. The regulatory limits on offsite dose are:

1. $25 \mathrm{mrem} /$ year to the whole body of any member of the public.

2. $75 \mathrm{mrem} / \mathrm{year}$ to the thyroid of any member of the public.

3. $25 \mathrm{mrem} /$ year to any other organ of any member of the public. 
In addition to meeting these limits, effort shall be made to keep offsite radiation doses as low as is reasonably achievable.

c. The data will be reviewed for any indication that release of radionuclides to the environment or environmental radiation levels is increasing. Any indication of increases in these levels will be immediately reported, in writing, to the Director of Health Physics and investigated under the supervision of the Director of Health Physics. The Director of Health Physics will determine if any resampling or corrective actions will be taken.

3. Reporting of Environmental Monitoring Data.

a. The Health Physics Supervisor will submit, on a quarterly basis, all environmental monitoring data to the Director of Health Physics for review and signature. The data will be submitted on Form Numbers OP EM1-1, OP EM1-2, OP EM1-3, OP EM1-4, OP EM1-5, OP EM1-6, OP EM1-7, and OP EM1-8.

b. Any environmental monitoring data results that indicate that the offsite regulatory limits have been exceeded will be reported immediately by the Health Physics Supervisor or the Director of Health Physics to the facility's licensing agency.

c. The Director of Health Physics will prepare an Annual Environmental Monitoring Report using these data and specifically note any changing radiation level trends and any environmental radiation data that were investigated and the results of such investigations. The annual report data will also be reviewed against the facility's past Annual Environmental Monitoring Reports to ensure that releases of radionuclides to the environment or environmental radiation levels are not increasing.

d. The Annual Environmental Monitoring Report will be submitted by the Director of Health Physics to the facility's licensing agency by the end of the first quarter of the following calendar year.

e. The Director of Health Physics will, after preparing the annual report, compare the data in the report to projected critical pathway doses from the performance assessment of the facility to determine the adequacy of the performance assessment and to further evaluate the environmental monitoring data. This comparison and evaluation of environmental monitoring data with respect to the performance assessment will be in the form of a written report which will be submitted to the licensing agency by the end of the first quarter of the following calendar year. 


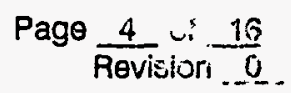

\subsection{RECORDS}

\subsection{REQUIRED FORMS}

Soil Sampling Data, Form Number OP EM1-1.

Sediment Sampling Data, Form Number OP EM1-2.

Vegetation Sampling Data, Form Number OP EM1-3.

Fauna Sampling Data, Form Number OP EM1-4.

Air Sampling Data, Form Number OP EM1-5.

Surface Water Sampling Data, Form Number OP EM1-6.

Groundwater Sampling Data, Form Number OP EM1-7.

Environmental TLD Data, Form Number OP EM1-8.

Annual Environmental Monitoring Report.

Annual Report Comparing Environmental Data to Performance Assessment Projections.

\subsection{COMPLETION AND APPROVAL REQUIREMENTS}

The environmental sampling data forms, Form Numbers OP EM1-1 through OP EM1-8, will be completed by health physics staff. The environmental sampling data forms will be reviewed, signed, and dated by the Health Physics Supervisor.

The Annual Environmental Monitoring Report and the Annual Report Comparing Environmental Data to Performance Assessment Projections will be prepared, reviewed, and signed by the Director of Health Physics.

\subsection{PROCESSING AND ARCHIVAL REQUIREMENTS}

1. Documents required or created in support of this procedure are quality assurance records. The environmental sampling data forms listed in Section 4.1 of this procedure will be included in the quality assurance records package.

2. The records shall be submitted to the Records Management Technician, who, as custodian, will ensure each document is complete, legible, and adequately identifiable. The quality assurance records resulting from this procedure shall be retained in accordance with Administrative Procedure AP by the records custodian.

\subsection{REFERENCES}

1. 10 CFR Part 61. 


\begin{tabular}{|c|c|c|c|c|c|}
\hline $\begin{array}{l}\text { Sampling } \\
\text { Location }\end{array}$ & $\begin{array}{c}\text { Date } \\
\text { Sampled }\end{array}$ & $\begin{array}{c}\text { Date } \\
\text { Analyzed }\end{array}$ & $\begin{array}{c}\text { Minimum } \\
\text { Detectable } \\
\text { Activity (MDA) } \\
\text { (pCi/g) }\end{array}$ & $\begin{array}{l}\text { Analysis } \\
\text { Results } \\
\text { (pCi/g) }\end{array}$ & $\begin{array}{c}\text { Counting } \\
\text { Error } \\
\text { (pCi/g) }\end{array}$ \\
\hline & & & . & & \\
\hline & & & & & \\
\hline & & & & & \\
\hline & & & & & \\
\hline & & & & & \\
\hline & & & & & \\
\hline & & & & - & \\
\hline & & & & & \\
\hline & & & & & \\
\hline & & & & & \\
\hline & & & & & \\
\hline & & & & & \\
\hline & & & & & \\
\hline & & & & & \\
\hline & & & & & \\
\hline & & & & & \\
\hline & & & & & \\
\hline
\end{tabular}

Signature:

Health Physics Supervisor

Date: 
SEDIMENT SAMPLING DATA

FORM NUMBER OP EM1-2

Year:

Analytical Laboratory:

\begin{tabular}{|c|c|c|c|c|c|}
\hline $\begin{array}{l}\text { Sampling } \\
\text { Location }\end{array}$ & $\begin{array}{c}\text { Date } \\
\text { Sampled }\end{array}$ & $\begin{array}{c}\text { Date } \\
\text { Analyzed }\end{array}$ & $\begin{array}{c}\text { Minimum } \\
\text { Detectable } \\
\text { Activity (MDA) } \\
\text { (pCi/g) }\end{array}$ & $\begin{array}{c}\text { Analysis } \\
\text { Results } \\
\text { (pCi/g) }\end{array}$ & $\begin{array}{l}\text { Counting } \\
\text { Error } \\
\text { (pCi/g) }\end{array}$ \\
\hline & & & & & \\
\hline & & & & & \\
\hline & & & & & \\
\hline & & & & & \\
\hline & & & & & \\
\hline & & & & & \\
\hline & & & & & \\
\hline & & & & & \\
\hline & & & & & \\
\hline & & & & & \\
\hline & & & & & \\
\hline & & & & & \\
\hline & & & & & \\
\hline & & & & & \\
\hline & & & & & \\
\hline & & & & & \\
\hline & & & & & \\
\hline
\end{tabular}

Signature:

Date:

Health Physics Supervisor 


\section{VEGETATION SAMPLING DATA FORM NUMBER OP EM1-3}

Year:

Analytical Laboratory:

\begin{tabular}{|c|c|c|c|c|c|}
\hline $\begin{array}{l}\text { Sampling } \\
\text { Location }\end{array}$ & $\begin{array}{c}\text { Date } \\
\text { Sampled }\end{array}$ & $\begin{array}{c}\text { Date } \\
\text { Analyzed }\end{array}$ & $\begin{array}{c}\text { Minimum } \\
\text { Detectable } \\
\text { Activity (MDA) } \\
\text { (pCl/g) }\end{array}$ & $\begin{array}{c}\text { Analysis } \\
\text { Results } \\
\text { (pCi/g) }\end{array}$ & $\begin{array}{c}\text { Counting } \\
\text { Error } \\
\text { (pCl/g) } \\
\end{array}$ \\
\hline & & & $\therefore$ & & \\
\hline & & & & & \\
\hline & & & & & \\
\hline & & & & & \\
\hline & & & & & \\
\hline & & & & & \\
\hline & & & & & \\
\hline & & & & & \\
\hline & & & & & \\
\hline & & & & & \\
\hline & & & & & \\
\hline & & & & & \\
\hline & & & & & \\
\hline & & & & & \\
\hline & & & & & \\
\hline & & & & & \\
\hline & & & & & \\
\hline
\end{tabular}

Signature:

Health Physics Supervisor

Date: 
FAUNA SAMPLING DATA

FORM NUMBER OP EM1-4

Year:

Analytical Laboratory:

\begin{tabular}{|c|c|c|c|c|c|}
\hline $\begin{array}{l}\text { Sampling } \\
\text { Location }\end{array}$ & $\begin{array}{c}\text { Date } \\
\text { Sampled }\end{array}$ & $\begin{array}{c}\text { Date } \\
\text { Analyzed }\end{array}$ & $\begin{array}{c}\text { Minimum } \\
\text { Detectable } \\
\text { Activity (MDA) } \\
\text { (pCi/g) }\end{array}$ & $\begin{array}{c}\text { Analysis } \\
\text { Results } \\
\text { (pCi/g) }\end{array}$ & $\begin{array}{l}\text { Counting } \\
\text { Error } \\
\text { (pCi/g) }\end{array}$ \\
\hline & & & & & \\
\hline & & & & & \\
\hline & & & & & \\
\hline & & & & & \\
\hline & & & & & \\
\hline & & & & & \\
\hline & & & & & \\
\hline & & & & & \\
\hline & & & & & \\
\hline & & & & & \\
\hline & & & & & \\
\hline & & & & & \\
\hline & & & & & \\
\hline & & & & & \\
\hline & & & & & \\
\hline & & & & & \\
\hline & & & & & \\
\hline
\end{tabular}

Signature:

Health Physics Supervisor

Date: 


\section{INSTRUCTIONS FOR SAMPLING DATA FORMS NUMBER OP EM1-1 THROUGH OP EM1-4}

1. Enter the calendar year of the data being compiled.

2. Enter the name and address of the analytical laboratory performing the sample analyses.

3. Enter the sampling location of each sample. NOTE: A separate form may be filled out for each sampling location if this makes review of the sample data easier.

4. Enter the date each sample was collected.

5. Enter the date each sample was analyzed.

6. Enter the minimum detectable activity for each type of analysis.

7. Enter the results of the sample analyses. Be sure to record the correct units, e.g., pCi/g.

8. Enter the counting error reported with the analysis results.

9. The Health Physics Supervisor, after reviewing the form, signs and dates the form. 


\section{AIR SAMPLNG DATA}

FORM NUMBER OP EM1-5

Year:

Analytical Laboratory:

\begin{tabular}{|c|c|c|c|c|c|c|}
\hline $\begin{array}{l}\text { Sampling } \\
\text { Location }\end{array}$ & $\begin{array}{c}\text { Start } \\
\text { Date and } \\
\text { Time }\end{array}$ & $\begin{array}{l}\text { End Date } \\
\text { and Time }\end{array}$ & $\begin{array}{c}\text { Date } \\
\text { Analyzed }\end{array}$ & $\begin{array}{c}\text { Minimum } \\
\text { Detectable } \\
\text { Activity } \\
\text { (MDA) } \\
\text { (pCi/l) }\end{array}$ & $\begin{array}{c}\text { Analysis } \\
\text { Results } \\
\text { (pCi/l) }\end{array}$ & $\begin{array}{l}\text { Counting } \\
\text { Error } \\
\text { (pCi/l) }\end{array}$ \\
\hline & & & & & & \\
\hline & & & & & & \\
\hline & & & & & & \\
\hline & & & & & & \\
\hline & & & & & & \\
\hline & & & & & & \\
\hline & & & & & & \\
\hline & & & & & & \\
\hline & & & & & & \\
\hline & & & & & & \\
\hline & & & & & & \\
\hline & & & & & & \\
\hline & & & & & & \\
\hline & & & & & & \\
\hline & & & & & & \\
\hline & & & & & & \\
\hline
\end{tabular}

Signature:

Date:

Health Physics Supervisor 


\section{INSTRUCTIONS FOR AIR SAMPLING DATA FORM NUMBER OP EM1-5}

1. Enter the calendar year of the data being compiled.

2. Enter the name and address of the analytical laboratory performing the sample analyses.

3. Enter the sampling location of the sampler. NOTE: A separate form may be filled out for each sampling location if this makes review of the sample data easier.

4. Enter the date and time the air sample was started.

5. Enter the date and time the air sample was stopped.

6. Enter the date the sample was analyzed.

7. Enter the minimum detectable activity for each type of analysis.

8. Enter the results of the sample analyses. Be sure to record the correct units, e.g., pCi/l.

9. Enter the counting error reported with the analysis results.

10. The Health Physics Supervisor, after reviewing the form, signs and dates the form. 


\section{SURFACE WATER SAMPLING DATA \\ FORM NUMBER OP EM1-6}

Year:

Analytical Laboratory:

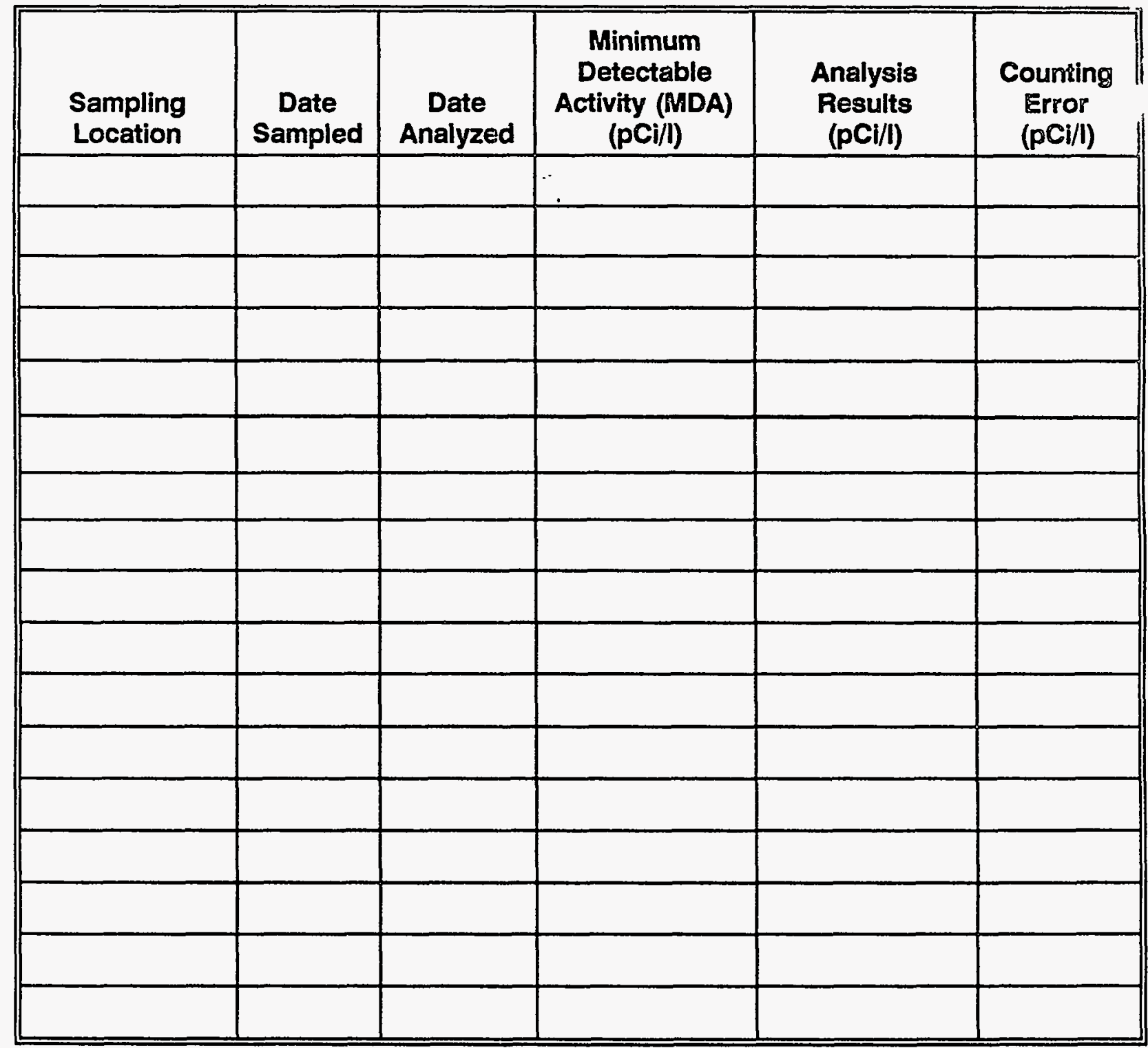

Signature:

Health Physics Supervisor

Date: 


\begin{tabular}{|c|c|c|c|c|c|}
\hline $\begin{array}{l}\text { Sampling } \\
\text { Location }\end{array}$ & $\begin{array}{c}\text { Date } \\
\text { Sampled }\end{array}$ & $\begin{array}{c}\text { Date } \\
\text { Analyzed }\end{array}$ & $\begin{array}{c}\text { Minimum } \\
\text { Detectable } \\
\text { Activity (MDA) } \\
\text { (pCi/l) }\end{array}$ & $\begin{array}{c}\text { Analysis } \\
\text { Results } \\
\text { (pCi/l) }\end{array}$ & $\begin{array}{c}\text { Counting } \\
\text { Error } \\
\text { (pCi/l) }\end{array}$ \\
\hline & & & & & \\
\hline & & & & & \\
\hline & & & & & \\
\hline & & & & & \\
\hline & & & & & \\
\hline & & & & & \\
\hline & & & & & \\
\hline & & & & & \\
\hline & & & & & \\
\hline & & & & & \\
\hline & & & & & \\
\hline & & & & & \\
\hline & & & & & \\
\hline & & & & & \\
\hline & & & & & \\
\hline & & & & & \\
\hline & & & & & \\
\hline
\end{tabular}

Signature:

Health Physics Supervisor

Date: 


$$
\text { Page } \frac{14}{\text { Revision of } \frac{16}{C}}
$$

\section{INSTRUCTIONS FOR SURFACE WATER AND GROUNDWATER SAMPLING DATA FORMS NUMBER OP EM1-6 AND OP EM1.7}

1. Enter the calendar year of the data being compiled.

2. Enter the name and address of the analytical laboratory performing the sample analyses.

3. Enter the sampling location of each sample. NOTE: A separate form may be filled 0 ': for each sampling location if this makes review of the sample data easier.

4. Enter the date each sample was collected.

5. Enter the date each sample was analyzed.

6. Enter the minimum detectable activity for each type of analysis.

7. Enter the results of the sample analyses. Be sure to record the correct units, e.g., pCi/l.

8. Enter the counting error reported with the analysis results.

9. The Health Physics Supervisor, after reviewing the form, signs and dates the form. 


\section{ENVIRONMENTAL TLD DATA \\ FORM NUMBER OP EM1-8}

Year:

Analytical Laboratory:

Minimum Detectable Dose (mrem):

\begin{tabular}{|c|c|c|c|c|c|}
\hline TLD Location & $\begin{array}{l}\text { Date and } \\
\text { Time Placed } \\
\text { in the Field }\end{array}$ & $\begin{array}{l}\text { Date and Time } \\
\text { Picked Up }\end{array}$ & $\begin{array}{c}\text { Date } \\
\text { Analyzed }\end{array}$ & $\begin{array}{c}\text { Analysis } \\
\text { Results } \\
\text { (mrem) }\end{array}$ & $\begin{array}{c}\text { Counting } \\
\text { Error } \\
\text { (mrem) }\end{array}$ \\
\hline & & & & & \\
\hline & & & & & \\
\hline & & & & & \\
\hline & & & & & \\
\hline & & & & & \\
\hline & & & & & \\
\hline & & & & & \\
\hline & & & & & \\
\hline & & & & & \\
\hline & & & & & \\
\hline & & & . & & \\
\hline & & & & & \\
\hline & & & & & \\
\hline & & & & & \\
\hline & & & & & \\
\hline & & & & & \\
\hline & & & & & \\
\hline
\end{tabular}

Signature:

$$
\text { Health Physics Supervisor }
$$

Date: 
Page $\frac{16}{\text { Revision of } \frac{16}{0}}$

\section{INSTRUCTIONS FOR ENVIRONMENTAL TLD DATA FORM NUMBER OP EM-8}

1. Enter the calendar year of the data being compiled.

2. Enter the name and address of the analytical laboratory providing and analyzing the TLDs.

3. Enter the minimum detectable dose for the TLDs.

4. Enter the location of each TLD. NOTE: A separate form may be filled out for each TLD location if this makes review of the data easier.

5. Enter the date and time each TLD was placed in the field.

6. Enter the date and time each TLD was picked up (replaced).

$7 \quad$ Enter the date each TLD was analyzed by the supplier.

8. Enter the results of the TLD analyses. Be sure to record the correct units, e.g., mrem.

9. Enter the counting error reported with the analysis results.

10. The Health Physics Supervisor, after reviewing the form, signs and dates the form. 


\title{
OPERATING PROCEDURE
}

\author{
VENDOR AUDITS
}

Date:

Revision No.: $\frac{0}{10}$

Supersedes:

Page 1 of 10

Approval:

Concurrence:

Title

Title

Date

\subsection{PURPOSE AND SCOPE}

This procedure describes how audits of vendors who provide safety-related equipment and supplies are conducted. The purpose of vendor audits is to ensure that the materials being procured are being manufactured according to the processes and specifications contained in the vendor's contract.

\subsection{EQUIPMENT AND MATERIALS}

\subsection{OPERATING EQUIPMENT}

Measuring and testing devices as required.

\subsection{SAFETY EQUIPMENT}

None.

\subsection{SPECIAL EQUIPMENT}

None.

\subsection{PROCEDURE}

\section{1 ' PREREQUISITES}

The Audit Team will consist of a Lead Auditor and any additional, qualified auditors required. 
Page $\frac{2}{\text { Risvision }}$ of $\frac{10}{n}$

\subsection{IRAINING}

Individuals who conduct vendor audits will meet the qualifications for Auditors and Lead Auditor described in Quality Assurance Procedure Number QA

\subsection{SPECIAL PRECAUTIONS}

None

\section{$3.4 \quad$ INSTRUCTIONS}

1. Preaudit Activities

a. The audit program is controlled by the Director of Health Physics who will also act as the Lead Auditor, or designate another individual to perform that function.

b. The audit will be scheduled and any other necessary arrangements will be made with the vendor before the audit. Audits will be scheduled in accordance with the Quality Assurance Plan.

c. Each audit will consist of an examination of selected aspects of products and services rendered, license conditions, operating activities, and the vendor quality assurance program. An Audit Checklist, Form Number OP 10-1, prepared in advance, will be used; space will be left on the checklist for the addition of new items whose importance becomes apparent during the audit. Audit checklists will be based upon applicable vendor's procedures and quality assurance plan, industry standards (e.g., ANSI, NBS), and specifications in the vendor's contract.

\section{Performance of the Audit}

a. An interview will be conducted with the appropriate vendor representatives (e.g., the vendor quality assurance manager) at the start of the audit.

b. Using the Audit Checklist, Form Number OP 10-1, conduct the audit of all the checklist items and others, as appropriate. This will include a review of records, observing operations, and review of corrective actions taken as a result of any previous audit.

c. Record the findings of the audit on the Audit Findings, Form Number OP 10-2. The findings will be objective, factual, and verifiable. Findings involving a specific procedure or process will identify the procedure or process.

d. Upon completion of the audit, the Lead Auditor will hold a post-audit interview with the appropriate vendor representatives. 
3. Post-audit Activities

a. The Lead Auditor will prepare an Audit Report and forward it to the Director of Health Physics.

b. The Director of Health Physics will review the Audit Report and forward the following to the vendor Quality Assurance Manager or appropriate representative:

1. A letter summarizing the findings of the audit.

2. Copies of the Audit Report and letter to the vendor, the Director of Operations, and the Deputy General Manager for Operations.

4. Audit Responses

a. The vendor will be requested to prepare a formal response to each of the unsatisfactory findings in the audit within 30 working days of receipt. The vendor will be requested to include in the response a description of any required corrective action and the date by which the corrective action is to be completed.

b. The Director of Health Physics will review the vendor's audit response for appropriateness. If the response is not satisfactory, additional information will be requested in writing.

c. If all the responses are satisfactory, the Director of Health Physics will issue a statement to the vendor closing the audit.

d. Copies of the vendor's response and the review by the Director of Health Physics of the response will be forwarded to the Director of Operations and the Deputy General Manager for Operations.

\subsection{RECORDS}

\subsection{REQUIRED FORMS}

Audit Checklist, Form Number OP 10-1.

Audit Findings, Form Number OP 10-2.

Audit Report.

\subsection{COMPLETION AND APPROVAL REQUIREMENTS}

The Audit Checklist and Audit Findings forms will be completed by the Lead Auditor. Where there were unsatisfactory findings, the completion of resolution of the findings will be verified by the QA Supervisor. The Audit Report will be prepared by the Lead Auditor and reviewed by the Director of Health Physics. 


$$
\text { Page } \frac{4}{\text { Revision of } \frac{10}{0}}
$$

\subsection{PROCESSING AND ARCHIVAL REQUIREMENTS}

1. Documents required or created in support of this procedure are quality assurance records. The Audit Checklist, Audit Findings, and Audit Report will be included in the quality assurance records package.

2. The records will be submitted to the Records Management Technician who, as custodian, will ensure each document is complete, legible, and adequately identifiable. The quality assurance records resulting from this procedure will be retained in accordance with Administrative Procedure AP custodian. by the records

\subsection{REFERENCES}

Disposal facility Quality Assurance Plan. 
Page 5 of 10 Revision 0

\section{FORM NUMBER OP 10-1}

AUDIT CHECKLIST

Vendor Audited:

Audit Team:

Lead Auditor:

Auditor:

Auditor:

Auditor:
Date of Audit:

Vendor's Contract Number: continuation pages.

Item to be Audited:

References:

Specifications:

Comments:

Hem to be Audited:

References:

Specifications:

Comments:

Hem to be Audited:

References:

Specifications:

Commente:

Prepared By:

Date: 


\section{FORM NUMBER OP 10-1}

AUDIT CHECKLIST

Continuation Page

Item to be Audited:

References:

Specifications:

Comments:

Item to be Audited:

References:

Specifications:

Comments:

ftem to be Audited:

References:

Specifications:

Comments:

ftem to be Audited:

References:

Specifications:

Comments:

Continuation Page Number:

Prepared By:

Lead Auditor

Date: 


\section{Page $\frac{7}{\text { Revision } \frac{10}{0}}$}

\section{INSTRUCTIONS FOR AUDIT CHECKLIST \\ FORM NUMBER OP 10-1}

The audit checklist will be completed and signed by the Lead Auditor.

1. Enter the name and address of the vendor audited.

2. Enter the date of the audit.

3. Enter the contract number (or numbers) that covers the item audited.

4. Enter the names of the members of the audit team.

5. If continuation pages are used, indicated how many such pages there are.

6. Enter the name of the item supplied by the vendor for which this audit applies. A separate box is needed for each major kind of item.

7. Enter any references in which quality specifications are provided.

8. Summarize quality-related specifications.

9. Enter comments on observations made during the audit.

10. Include as many continuation pages as are necessary. Number each continuation page, starting with number one.

11. The Lead Auditor will sign and date the form. 
Page 8 of 10 Revision 0

\section{AUDT FINDINGS}

FOPM NUMBER OP $10-2$

Note: Attach a copy of the Audit Plan, Form Number OP $10-1$.

Page Number

of _ Pages

Vendor Audited:

Date of Audit:

Vendor's Contract Number:

Audit Team:

Lead Auditor:

These findings include this page and

Auditor: continuation pages.

Auditor:

Auditor:

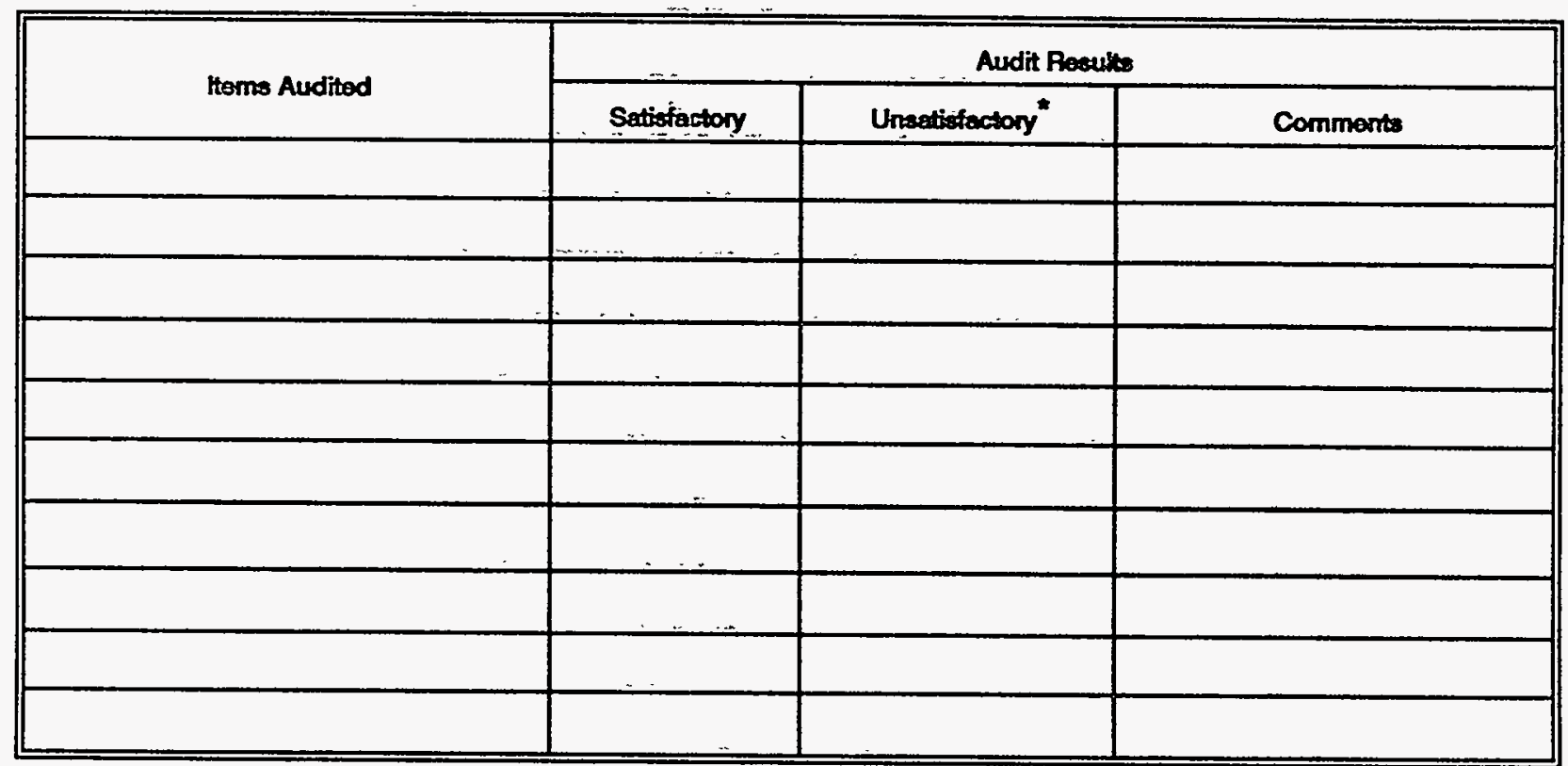

For each unsatisfactory item, a copy of the continuation page of this form must be attached. 


\section{AUDIT FINDINGS}

FORM NUMBER OP 10-2

Continuation Page

\section{Page Number \\ of \\ Pages}

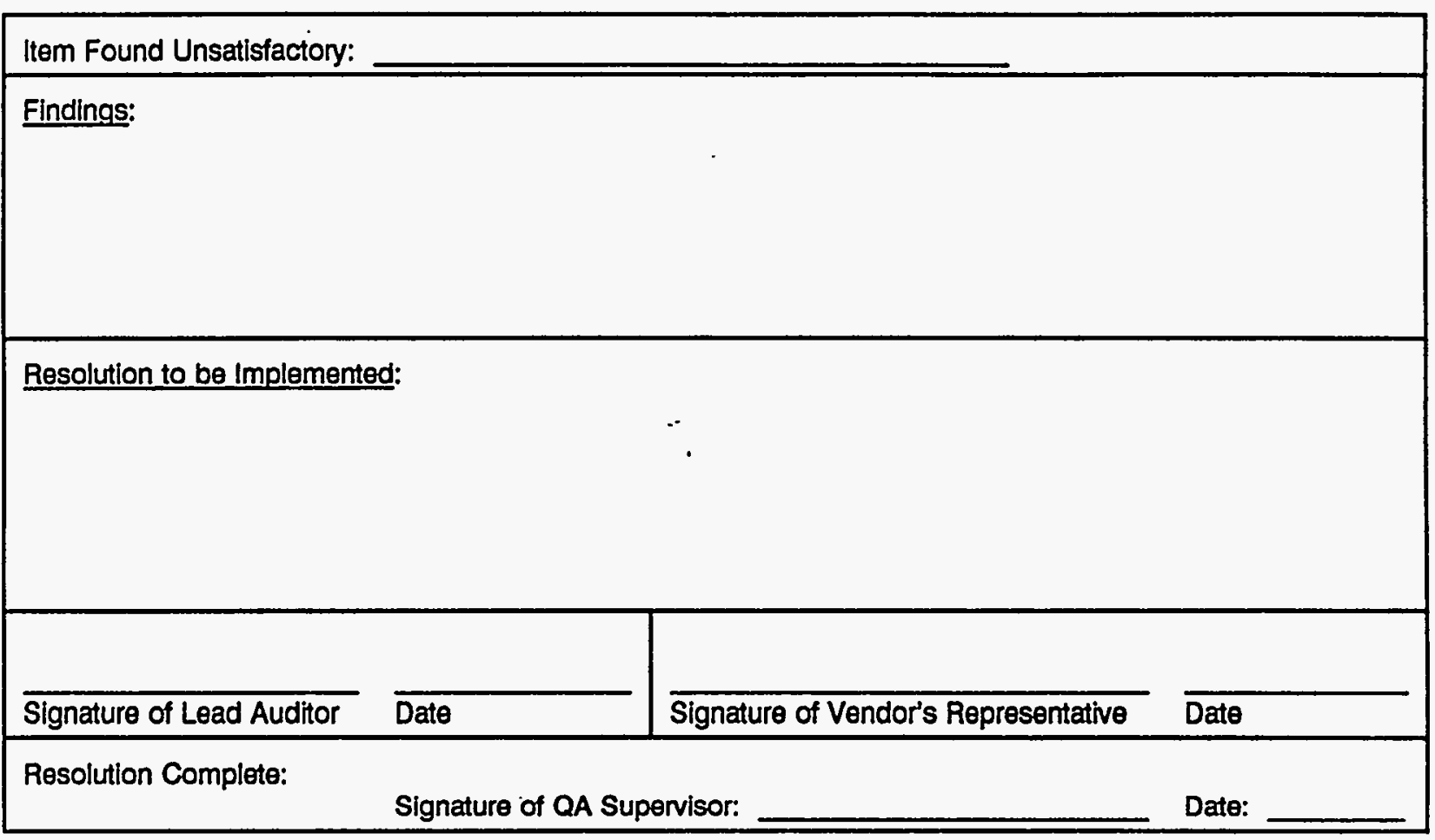

Item Found Unsatisfactory:

Findings:

Resolution to be Implemented:

\begin{tabular}{|ll|ll|}
\hline & & & \\
${$\cline { 1 - 1 }$} }$ & Date & Signature of Vendor's Representative & Date \\
\hline Resolution Complete: & Signature of QA Supervisor: & Date: \\
\hline
\end{tabular}




\section{INSTRUCTIONS FOR AUDIT FINDINGS \\ FORM NUMBER OP 10-2}

1. Enter the name and address of the vendor audited.

2. Enter the date of the audit.

3. Enter the contract number (or numbers) that covers the item audited.

4. Enter the names of the members of the audit team.

5. If continuation pages are used, indicated how many such pages there are.

6. List the items audited. The Lead Auditor will place his or her signature in the "Satisfactory" or "Unsatisiactory" column, as appropriate, and enter brief comments if desired.

7. For each item found to be unsatisfactory, details of the findings and the solution will be provided on a continuation page of the form.

8. In one of the two duplicate boxes on a continuation page of the form, enter the name of the item found unsatisfactory.

9. Enter the findings, detailing why the item was found to be unsatisfactory.

10. Describe the resolution of the unsatisfactory finding that has been agreed to by the vendor, including a deadine for implementing the resolutiori.

11. Each box on the continuation form that describes an unsatisfactory finding will be signed and dated by the Lead Auditor and a vendor's representative authorized to commit the vendor to the resolution described by the deadline indicated.

12. When the unsatisfactory item has been corrected (resolved), the QA Supervisor will sign and date the appropriate box on the continuation sheet to indicate the problem has been resolved.

13. Each continuation sheet used will be numbered, beginning with number one. The total number of continuation sheets will also be indicaled in the space near the upper right corner.

14. The Audit Findings, Form Number OP 10-2, will have attached a copy of the corresponding Audit Plan, Form Number OF 10-1. 